\title{
Report of the
}

Task Group on Operation of Department of Energy Tritium Facilities

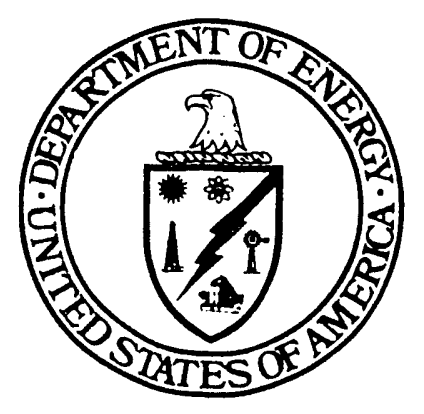

October 1991

U.S. Department of Energy Assistant Secretary for Environment, Safety, and Health Washington, DC 20585 


\section{TABLE OF CONTENTS}

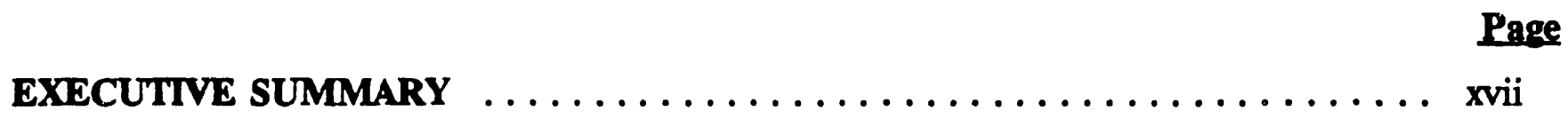

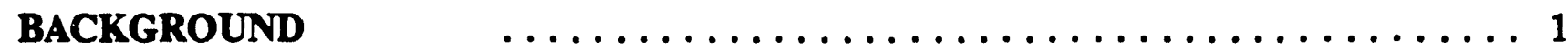

Environment, Safety, and Health Aspects of Tritium $\ldots \ldots \ldots \ldots \ldots \ldots 2$

Department of Energy Tritium Operations $\ldots \ldots \ldots \ldots \ldots \ldots \ldots \ldots$

Operating History from an Environment, Safety, and Health

Viewpoint $\ldots \ldots \ldots \ldots \ldots \ldots \ldots \ldots \ldots \ldots \ldots \ldots$

GENERIC ISSUES $\quad \ldots \ldots \ldots \ldots \ldots \ldots \ldots \ldots \ldots \ldots \ldots \ldots \ldots \ldots$

- Conduct of Operations $\ldots \ldots \ldots \ldots \ldots \ldots \ldots \ldots \ldots \ldots \ldots$

- Management of Operations and

Maintenance Functions ............... j

- Safe Shutdown of Tritium Facilities $\ldots \ldots \ldots \ldots \ldots \ldots \ldots 18$

- Management of the Facility Safety Envelope ........... . 19

- Maintenance of Qualified Tritium

Handling Personnel ................. 20

- Operating Philosophy and Requirements .............. 21

- DOE Tritium Management Strategy .............. 22

- Radiological Control Philosophy ................. 24

- Implementation of DOE Requirements ............. 25

- Management of Tritium Residues ............... 26

- Inconsistent Application of Requirements for

Measurement of Tritium Effluents ............ 28

- Interdependence of Tritium Facilities .............. 29

- Technical Communication among Facilities .......... 30 
- Implications for New Facility Design $\ldots \ldots \ldots \ldots \ldots \ldots \ldots \ldots 31$

- Incorporation of Confinement Technologies into

New Facilities ................... 31

- Operation/Management Requirements for

New Tritium Facilities ............... 32

\section{SAFETY MANAGEMENT ISSUES AT DEPARTMENT OF ENERGY TRITIUM}

FACILITIES

Lawrence Livermore National Laboratory

Background and Facility Descriptions $\ldots \ldots \ldots \ldots \ldots \ldots \ldots \ldots$

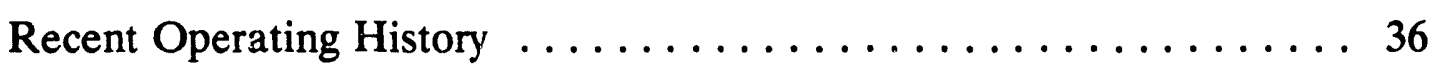

Technica! Review and Conclusions ............... 40

\section{Los Alamos National Laboratory}

Background and Facility Descriptions $\ldots \ldots \ldots \ldots \ldots \ldots \ldots 44$

Recent Operating History $\ldots \ldots \ldots \ldots \ldots \ldots \ldots \ldots \ldots . \ldots 49$

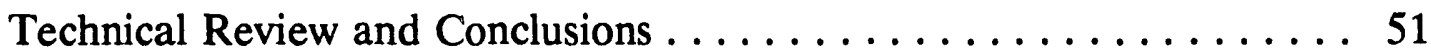

\section{Mound Plant}

Background and Facility Descriptions $\ldots \ldots \ldots \ldots \ldots \ldots \ldots 6$

Recent Operating History $\ldots \ldots \ldots \ldots \ldots \ldots \ldots \ldots \ldots \ldots$

Technical Review and Conclusions $\ldots \ldots \ldots \ldots \ldots \ldots \ldots \ldots$ 
Oak Ridge National Laboratory

Background and Facility Descriptions $\ldots \ldots \ldots \ldots \ldots \ldots \ldots$

Recent Operating History $\ldots \ldots \ldots \ldots \ldots \ldots \ldots \ldots \ldots \ldots \ldots$

Technical Review and Conclusions $\ldots \ldots \ldots \ldots \ldots \ldots \ldots \ldots$

\section{Pantex Plant}

Background and Facility Descriptions $\ldots \ldots \ldots \ldots \ldots \ldots \ldots . \ldots 8$

Recent Operating History $\ldots \ldots \ldots \ldots \ldots \ldots \ldots \ldots \ldots . \ldots 8$

Technical Review and Conclusions $\ldots \ldots \ldots \ldots \ldots \ldots \ldots \ldots 1$

\section{Pinellas Plant}

Background and Facility Descriptions $\ldots \ldots \ldots \ldots \ldots \ldots \ldots$

Recent Operating History $\ldots \ldots \ldots \ldots \ldots \ldots \ldots \ldots \ldots \ldots$

Technical Review and Conclusions. ............... 97

\section{Sandia National Laboratories, Livermore}

Background and Facility Descriptions $\ldots \ldots \ldots \ldots \ldots \ldots \ldots$

Recent Operating History $\ldots \ldots \ldots \ldots \ldots \ldots \ldots \ldots \ldots . \ldots 9$

Technical Review and Conclusions . . . . . . . . . . . . 101

\section{Savannah River Site H-Area}

Background and Facility Descriptions $\ldots \ldots \ldots \ldots \ldots \ldots \ldots$

Recent Operating History $\ldots \ldots \ldots \ldots \ldots \ldots \ldots \ldots \ldots \ldots \ldots$

Historical Releases and Observed Events $\ldots \ldots \ldots \ldots \ldots \ldots \ldots 110$

Technical Review and Conclusions ................. 112 
Savannah River Site Production Reactors

Background and Facility Descriptions $\ldots \ldots \ldots \ldots \ldots \ldots \ldots \ldots$

Recent Operating History $\ldots \ldots \ldots \ldots \ldots \ldots \ldots \ldots \ldots \ldots \ldots \ldots$

Technical Review and Conclusions $\ldots \ldots \ldots \ldots \ldots \ldots \ldots \ldots \ldots \ldots$

\begin{abstract}
APPENDIX A Secretarial Tasking Memorandum
APPENDIX B Background on Task Group, Charter, and

Conduct of its Evaluation
\end{abstract}

APPENDIX C Task/Working Group Members on Operation of DOE Tritium

Facilities

APPENDIX D Task Group Memoranda on Preliminary Findings

APPENDIX E Summary of Reported Events Resulting in Inadvertent Releases of

Tritium to the Environment (1986 to 1991)

APPENDIX F Bibliography 


\section{List of Figures}

Page

Figure 1

Figure 2

Figure 3

Figure 4

Figure 5

Figure 6

Figure 7

Figure 8

Figure 9

Figure 10

Figure 11

Figure 12

Figure B-1
Relationships among DOE Tritium Facilities ......... 5

Distribution of Routine Tritium Releases from

DOE Tritium Facilities from 1986 to 1991 - Cumulative . . . 7

Distribution of Tritium Releases by Site and Year

from 1986 to $1991 \ldots \ldots \ldots \ldots$. . . . . . . . . . . . . 8

Distribution of Occupational Doses due to Tritium at Nine Sites ....................... 10

Tritium Facility (Building 331) - Lawrence

Livermore National Laboratory . . . . . . . . . . . . . . . 37

Artist's Concept of the Weapons Engineering

Tritium Facility (Technical Area 16) - Los Alamos

National Laboratory .................... 45

Mound Plant ...................... 62

Tritium Operations - Mound Plant ............63

Trend in Effluent Releases - Mound Plant . . . . . . . . 67

Tritium Target Fabrication Facility

(Building 7025) - Oak Ridge National Laboratory . . . . . . . 79

H-Area Tritium Complex - Savannah River Site . . . . . 106

Tritium Releases from K-Reactor - Savannah River

Site $(1955$ to 1990$) \ldots \ldots \ldots \ldots$. . . . . . . . . . . 122

Task Group on Operation of DOE Tritium

Facilities - Implementation Schedule . . . . . . . . B-3 


\section{List of Tables}

Page

Table 1

Table 2

Table 3

Table 4

Table 5

Table 6

Table 7

Table 8

Table 9
Tritium Stack Emissions and Liquid Effluent Releases, Collective Occupational Doses, and the Average Tritium Inventory at Lawrence Livermore National Laboratory for Fiscal Years

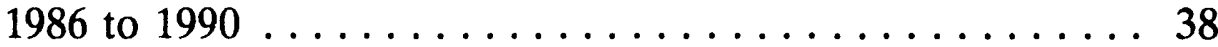

Distribution of Occupational Doses Due to Tritium at Lawrence Livermore National Laboratory for Calendar Years 1986 to 1990

Tritium Stack Emissions and Liquid Effluent Releases at Los Alamos National Laboratory for Fiscal Years 1988 to 1990

Distribution of Occupational Doses Due to Tritium at Los Alamos National Laboratory for Calendar Years 1986 to 1990

Tritium Stack Emissions Monitoring at Los Alamos National Laboratory $\ldots \ldots \ldots \ldots \ldots \ldots \ldots \ldots \ldots \ldots$ 59

Unintentional Transfers to the Effluent Removal System at Mound Plant . . . . . . . . . . . . . . . . . . . . . 69

Tritium Stack Emissions and Liquid Effluent Releases, Collective Doses to Personnel, and Average Inventory of Tritium at Mound Plant for Fiscal Years 1986 to 1990

Distribution of Occupational Doses Due to Tritium at Mound Plant for Calendar Years 1986 to 1990 . . . . . . . 70

Oak Ridge Tritium Shipment and Stack Release Statistics (Building 3026-C and Building 3033) 80 
Table 10

Table 11

Table 12

Table 13

Table 14

Table 15

Table 16

Table 17

Table 18

Table 19

Table 20
Oak Ridge Tritium Releases from Target Fabrication

Facility (Building 7025) . . . . . . . . . . . 82

Distribution of Occupational Doses Due to Tritium at

Oak Ridge National Laboratory for Calendar Years

1986 to $1990 \ldots \ldots \ldots \ldots$. . . . . . . . . . . . . . 82

Tritium Monitoring Systems at Oak Ridge National

Laboratory .....................8

Tritium Stack Emissions and Liquid Effluent Releases, Collective Occupational Doses, and Average Inventory of Tritium at Pantex Plant for Fiscal Years 1986 to 1990 . . . . 8

Distribution of Occupational Doses Due to Tritium at Pantex Plant for Calendar Years 1986 to 1990 . . . . . . 91

Tritium Stack Emissions and Liquid Effluent Releases, Collective Occupational Doses, and Average Tritium Inventcry at Pinellas Plant for Fiscal Years 1986 to $1990 \ldots \ldots \ldots \ldots \ldots$

Distribution of Occupational Doses Due to Tritium at Pinellas Plant for Calendar Years 1986 to 1990 . . . . . . 96

Tritium Stack Emissions and Liquid Effluent Releases, Collective Occupational Doses, and Average Inventory of Tritium at Sandia National Laboratories, Livermore, for Fiscal Years 1986 to 1990 . . . . . . . . . . . . . . 100

Distribution of Occupational Doses Due to Tritium at Sandia National Laboratories, Livermore, for Calendar Years 1986 to $1990 \ldots \ldots$. . . . . . . . . . . . . . . . . . . . 101

Tritium Stack Emissions and Liquid Effluent Releases, Collective Occupational Doses, and Average Tritium Inventory at Savannah River Site, H-Area for Fiscal Years 1986 to 1990 . . . . . . . . . . . . . . . . . . . . . . . . . 109

Distribution of Occupational Doses Due to Tritium at Savannah River Site, H-Area for Calendar Years 1986 to 1990 109 
Table 21

Table 22
Tritium Stack Emissions and Liquid Effluent Releases, Collective Occupational Doses, and Average Inventory of Tritium at Savannah River Production Reactors for Fiscal Years 1986 to 1990 . . . . . . . . . . . . . . . . . . . . 124

Distribution of Occupational Doses Due to Tritium at Savannah River Site Production Reactors for Calendar Years 1986 to $1990 \ldots \ldots \ldots \ldots \ldots \ldots \ldots$. . . . . . . . . 125 


\section{List of Abbreviations and Acronyms}

AEC

ALARA

ANSI

CX

DOD

DOE

DOT

DP

EDE

EH

EM

EPA

ER

ERS

ES\&H

ETC

ETS

GEND

HEPA

HPTL

HRF

IBF

ICF

ICPP

ICS

LANL

LCO
Atomic Energy Commission

as-low-as-reasonably-achievable

American National Standards Institute

Categorical Exclusion

U.S. Department of Defense

U.S. Department of Energy

U.S. Department of Transportation

Office of Defense Programs

Effective Dose Equivalent

Office of Environment, Safety and Health

Environmental Restoration and Waste Management Office

U.S. Environmental Protection Agency

Office of Energy Research

Effluent Removal System

Environment Safety \& Health

Emergency Tritium Cleanup

Effluent Treatment System

General Electric, Neutron Devices

high efficiency particulate air

High Pressure Tritium Laboratory

Hydrogen Research Facility

Ion Beam Facility

Inertial Confinement Fusion

Idaho Chemical Processing Plant

Instrumentation Control System

Los Alamos National Laboratories

Limiting Condition of Operation 
List of Acronyms and Abbreviations (continued)

LIMA

LLNL

MTF

NE

NEPA

NPR

NRC

NTS

ORNL

OSRs

PBFA

PPPL

PSOs

RCRA

RMA

RTF

SAN

SAR

SFMP

SNL, L

SRL

SROC

SRS

SW-R

TFF

TGCS
Light Isotope Monitoring Area

Lawrence Livermore National Laboratory

Materials Test Facility

Office of Nuclear Energy

National Environmental Policy Act

New Production Reactor

U.S. Nuclear Regulatory Commission

Nevada Test Site

Oak Ridge National Laboratory

Operations Safety Requirements

Pulse Beam Fusion Acceleration Program

Princeton Plasma Physics Laboratory

Program Secretarial Officials

Resource Conservation and Recovery Act

Radioactive Material Area

Replacement Tritium Facility

San Francisco Field Office

Safety Analysis Report

Surplus Facilities Management Program

Sandia National Laboratories, Livermore

Special Recovery Line

Savannah River Operations Contingency

Savannah River Site

Semi-Works-Research Complex

Target Fabrication Facility

Tritium Gas Confinement Subsystem 
List of Acronyms and Abbreviations (continued)

TGHS

TRL

TRS

TSF

TSTA

TWTS

UORs

VERS

WD

WETF

WSL
Tritium Gas Handling Subsystem

Tritium Research Laboratory

Tritium Recovery System

Tritium Salt Facility

Tritium Systems Test Assembly

Tritium Waste Treatment Subsystem

Unusual Occurrence Reports

Vacuum Effluent Recovery System

Waste Disposal Building

Weapons Engineering Tritium Facility

Weapon Subsystems Laboratory 


\section{EXECUTIVE SUMMARY}

On February 19, 1991, the Secretary of Energy directed the Assistant Secretary for Environment, Safety and Health (EH) to form an internal Department of Energy (DOE) Task Group to "...review tritium facility management practices and identify measures to improve operations." In this directive, the Secretary expressed his concerns over releases and ciser problems at the Department's tritium facilities and directed the Task Group to address "...mechanisms for sharing design and operational information and measures for reducing actual and potential releases."

The Task Group, which was formally established on March 15, 1991, was chaired by the Deputy Assistant Secretary for Safety and Quality Assurance, with membership from DOE line operating programs, the Office of Nuclear Safety and EH. Over a 3-month interval, from April through June 1991, the Task Group reviewed the event history for a 5-year period of the Department's tritium operaticns and conducted site visits to each of nine major DOE tritium facilities. The purpose of the site reviews was to identify, and assess firsthand, the safety management implications of curreut operating practices, as well as past tritium releases.

The DOE tritium complex consists of: (1) the three production reactors at the Savannah River Site (SRS), which are in commission, but whose operations are currently suspended awaiting safety upgrades; (2) the tritium target extraction facility at the Savannah River Site H-Area; (3) the weapons production facilities located at the Savannah River Site H-Area and the Mound, Pantex, and Pinellas Plants; and (4) the research facilities at the Los Alamos National Laboratory (LANL), the Sandia Nat'onal Laboratories, Livermore (SNL, L), the Lawrence Livermore National Laboratory (LLNL), and the Princeton Plasma Physics Laboratory (PPPL). The Mund Plant and the Savannah River Site H-Area reclaim tritium residues from other sites. Tritium-contaminated waste from DOE activities is buried as low-level waste, primarily at the Savannah River Site, Los Alamos National Laboratory, and the Nevada Test Site (NTS). Although not considered part of the active DOE tritium complex, Oak Ridge National Laboratory (ORNL), whose major tritium facilities are presently in a shutdown mode, was reviewed by the Task Group due to its remaining inveritory and release history.

The Task Group revie red tritium releases from DOE operations over the past 5 years, from 1986 to 1990 , inclusive. Most of the tritium is emitted as gas or vapor to the atmosphere during routine operations, with minor amounts released as liquid effluent. Approximately 90 percent of all routine tritium releases in DOE occur from three facility sources. These sources, which are located at the 
Savannah River Site, are: the H-Area target extraction facility, the H-Area reservoir operations, and the production reactors, each source releasing about 100,000 curies (10.4 grams ) per year under normal operations. The remaining DOE tritium facilities (primarily the national laboratories and the Mound, Pantex, and Pinellas Plants) are responsible for approximately 10 percent of the total release.

The Task Group found relatively strong tritium control programs at several sites, including the Mound Plant; Sandia National Laboratories, Livermore; and the Pantex Plant. Management initiatives have been underway at the Savannah River Site to strengthen conduct of operations for tritium handling, particularly in the H-Area process facilities. It was clear to the Task Group that, while operations were not necessarily optimal at all of these sites, facility management had learned from past releases and had taken concerted steps to reduce the potential for future ones. It was also concluded that the prospective operation of two new facilities -- the Weapons Engineering Tritium Facility (WETF) at Los Alamos National Laboratory and the Replacement Tritium Facility (RTF) at the Savannah River Site -- will serve to substantially reduce routine tritium releases from both sites.

While the Task Group found that, historically, tritium releases have not resulted in occupational or public dose limits being exceeded, inadequate steps have been taken to minimize such releases. Chronic tritium assimilation by workers at the 10 to 100 millirem annual dose level has occurred at some facilities where routine activities involve work environments with low levels of tritium contamination. Measurable levels of tritium have been detected above background levels in various environmental media offsite in the vicinity of DOE sites such as Lawrence Livermore National Laboratory and the Savannah River Site. Elevated tritium concentrations in rainwater have been correlated with routine releases from both sites. Trace levels of tritium have been detected in wine, offsite at Livermore, and in milk in the vicinity of Savannah River. These trace levels have been linked to site operations. However, the resultant annual dose to the public attributable to tritium uptake is orders of magnitude less than the permissible annual standard (i.e., 100 millirem per year, on average) and less than one tenthousandth of the radiation dose from natural, medical, and other man-made sources (approximately 350 millirem per year).

- 1 gram of pure tritium constitutes 9,619 curies of radioactivity, or 1 curie of tritium radioactivity is equivalent to about one ten thousandth of a gram of pure tritium. 
Accidental, as well as incidental (to routine operation), releases of tritium have occurred at nearly every DOE tritium facility. These range from a few microcuries (ten billionths of a gram, $10^{-10}$ gram) released over extended time periods to acute releases of several tens of thousands of curies (grams). Human error has been the primary cause of accidental tritium releases; system failures contributed to only a small fraction of these releases. Causes of accidental releases include: deficiencies in the conduct of operations, continued operation of aging facilities, inappropriate design of systems and experiments, and lack of knowledge and experience on the part of facility personnel. The adverse impact of both accidental and incidental releases has been unnecessary occupational exposures to the workers involved. Resulting dose equivalents have ranged from a few millirem to in excess of one rem per event, but none has exceeded DOE occupational exposure limits. The frequency and significance of tritium releases have not changed significantly over time; the reporting threshold for nonroutine releases, however, has become more stringent, leading to increased reporting under the recently issued DOE 5000.3A, "Occurrence Reporting and Processing of Operations Information."

Underlying the frequency and quantity of tritium releases and related incidents is the lack of a coherent, DOE-wide management approach to tritium operations. For environment, safety, and health programs, this is most evident in the widely divergent operating philosophies followed by the cognizant operating contractors. The lack of consistent DOE policies defining acceptable design requirements and operations for tritium facilities has contributed to past events. The absence of a uniform environment, safety, and health rationale has resulted in nonconservative confinement strategies and designs, personnel radiation exposures that are not aslow-as-reasonably-achievable (ALARA), and orders-of-magnitude differences in routine tritium emission levels among the various DOE tritium facilities. This concern is compounded by discrepancies found in personnel monitoring (i.e., bioassay), workplace contamination monitoring, and emission measurements, which may lead to under-reporting of releases.

The Task Group concluded that there are a number of underlying reasons for the observed divergence in operating practices. These include the influence of site history and individual contractor operating philosophies, prolonged contractor insularity, and lack of clearly defined design criteria and operational standards. Perhaps the most significant reason, however, is the widely held belief at DOE facilities that tritium, being less radiologically significant as compared with other radionuclides, needs to be controlled only from the dose or consequence standpoint. This is contrary to standard radiation protection philosophy, which calls for control of radioactive contamination at its source and for maintaining exposures as-low-as-reasonably-achievable, including duly considering the costbenefit of achievable reductions. 
The most effective reduction in the release of tritium from DOE facilities can be realized by: (1) reducing routine and accidental releases through increased use of improved engineered features, tritium confinement systems, and cleanup and recovery systems; (2) decontaminating and replacing aging facilities with facilities of more advanced design, as well as consolidating smaller tritium facilities; and (3) strengthening conduct of operations through implementation of improved procedures, training, and exposure-reduction goals.

The Task Group concluded that the lack of a coherent Department strategy or goal for tritium control and confinement has perpetuated an inconsistent approach to facility design and operations. While the prospective operation of new facilities, such WETF and RTF, will reduce tritium releases, it is not apparent that full advantage has been taken of advanced and innovative control technologies as well as more stringent operational practices. In this vein, attention also needs to be given to the applicability of advances made internationally, for example, in Canada and France, in the control of tritium releases and occupational exposures.

\section{Principal Findings}

The results of the Task Group's evaluations, including the generic and sitespecific issues discussed in the body of the report, are underscored by the principal findings set forth below.

1. Unplanned releases of tritium at DOE facilities occur with a frequency indicative of weak operational controls and inadequately engineered facility design, both of which were confirmed in reviews of past release events. While these shortcomings can be considered a subset of a broader DOEwide concern with the conduct of operations, management complacency, stemming from the perceived lesser radiological significance of tritium, compounds this problern.

2. Inadequate consideration has been given to controlling radiological releases at the source and maintaining exposures as-low-as-reasonably-achievable. Tolerance for allowing routine and frequent unplanned releases of tritium is strongly influenced by the fact that the resulting occupational and public radiation doses are considerably below the established DOE and Environmental Protection Agency (EPA) numerical limits. With few exceptions, available reductions in worker exposure and environmental releases have not been actively sought, although some reductions are clearly supportable from a cost-benefit standpoint and in keeping with Secretarial mandates for strengthening conduct of operations. In the past, management of waste and inventory at some DOE sites has not adequately considered the radiological significance of tritium-contaminated sources and residues. 
3. The Department's system to disseminate and implement requirements for the safe operation of tritium facilities is inadequate. In many instances, DOE and contractor line managers were found to lack a clear understanding of the DOE environment, safety and health requirements for which they have responsibility. This was particularly evident in the areas of conduct of operations and safety documentation. Therefore, contractor organizations often receive conflicting interpretations of DOE requirements from cognizant line programs. This situation is further exacerbated by contractor management, which has not pressed DOE for clear interpretation of environment, safety and health requirements.

4. Operational experience and technology developments are not being effectively shared throughout the Department's tritium complex. The Task Group found little interaction or technical exchange among the Department's tritium complex operations personnel, other than informal staff contact. Past attempts to cooperatively develop a code of accepted practice for tritium operations have not come to fruition. Instances were identified in which facility management has not been aware of pertinent operational experience and engineered safety system improvements at other DOE tritium facilities. A recent initiative to establish a focus group for tritium operations in Defense Programs should be capitalized upon and expanded to other program offices.

5. The Department has not articulated an effective, overall strategy and approach toward the design and operation of its tritium facilities. There is considerable variation, without clear rationale, from site to site and within facilities on a site, as to the following: (1) quantities of tritium permitted in routine releases; (2) personnel protection practices and overall conduct of operations; (3) control of tritium by multiple barriers and tritium capture and recovery technology; (4) management and recovery of residues; (5) accepted conditions for facility shutdown; and (6) availability and adequacy of tritium shipping containers. Clearly, any such overall strategy will need to apply graded requirements as a function of facility size (production versus laboratory), tritium inventory (curies versus gram quantities), and potential environmental release or personnel exposure pathways.

\section{Recommendations}

Based upon its evaluation of the DOE tritium complex, the significance of the generic and site-specific issues presented in the body of the report, and the principal findings expressed above, the Task Group offers the following recommendations: 
1. Program Secretarial Officials (PSOs) having program responsibility for tritium operations should jointly establish a tritium operations management function at DOE Headquarters for the purpose of developing and recommending to the Secretary an overall, Department-wide strategy and policy for design and operation of DOE's tritium facilities. This strategy should incorporate international, as well as DOE, experience and should be based on current radiological standards and control philosophy. It should address the generic and site specific conclusions provided in this report. An important facet of this initiative would be the furtherance of technical exchange at the contractor level through various subgroups, with emphasis on engineered systems and operating techniques to enhance the overall control and management of tritium.

2. Ongoing DOE facility reconfiguration alssessments should be expanded to evaluate the existing tritium complex (production, processing, and users) across PSO organizational lines to assure more effective management controls and efficient use of operational assets and to reduce reliance on aging facilities. A Departmental goal should be established to evaluate and, where justified, eliminate routine production and processing operations that do not have at least a secondary tritium confinement and capture system or equivalent control strategy. To compensate for facility design limitations, more effective personnel protection practices need to be addressed as a starting point for maintaining exposures consistent with ALARA goals. This should include an evaluation of tritium inventory either present in residues, being held in storage, or subject to disposal as hazardous waste, for any environment, safety and health implications.

3. Uniform standards and codes of accepted practice for tritium facility operations should be developed and applied by DOE line programs to guide these operations. The existing DOE requirements and guidelines for line implementation of ALARA programs should be reviewed and revised to better ensure that meaningful objectives are pursued for reduction of tritium releases. Criteria need to be established to define safe shutdown conditions for tritium operations. To enhance credibility, steps should be taken to initiate external standards development for tritium handling through a national or international consensus standards organization (e.g., the American National Standards Institute or the International Atomic Energy Agency).

4. Tritium handling personnel and supervisors should be uniformly trained and qualified in the accepted operational and environmental, safety, and health practices required for tritium operations, to be defined as noted above. The objective is to establish training programs at DOE facilities that combine the extensive tritium handling experience found within a declining 
tritium worker population with newly established programs to instill principles for strengthened conduct of operations. Increased attention also needs to be given to improved orientation of general employees who may be exposed to tritium contamination.

5. Line management should actively seek reductions in routine tritium releases, potential sources of nonroutine tritium releases, personnel exposure, and tritium residues at DOE tritium facilities. Operational experience data, including trends in environmental concentration levels and worker assimilations, should be collected, analyzed, and reported to the Secretary as part of the existing DOE Performance Indicator Program for progress against this goal. 


\section{BACKGROUND}

As a result of concerns about releases and other operational problems at Department of Energy (DOE) facilities that handle, process, and store tritium, the Secretary of Energy, through his memorandum of February 19, 1991 (provided in Appendix A), directed the Assistant Secretary for Environment, Safety and Health to form a Task Group on Operation of DOE Tritium Facilities (Tritium Task Group). The Secretary expressed the desire to "...take a closer look at the overall management of these facilities, including mechanisms for sharing design and operational information and measures for reducing actual and potential releases." The Task Group was directed "...to review tritium facility management practices and identify measures to improve operations."

The Task Group, which included representatives from the DOE line organizations that are responsible for operating tritium facilities, the Office of Nuclear Safety, and the Office of Environment, Safety and Health, conducted onsite evaluations of selected tritium facilities at the following sites: (1) Lawrence Livermore National Laboratory (LLNL); (2) Los Alamos National Laboratory (LANL); (3) Mound Plant; (4) Oak Ridge National Laboratory (ORNL); (5) Pantex Plant; (6) Pinellas Plant; (7) Sandia National Laboratories, Livermore (SNL, L); (8) the Savannah River Site H-Area Tritium Complex; and (9) the K-Reactor at the Savannah River Site (SRS). The purpose of these onsite visits was to evaluate safety management practices for tritium operations firsthand and evaluate the facility's release history in these terms.

Not all DOE facilities involved in producing, handling, or using tritium were visited -- only those that directly handle or store major quantities (greater than 1 gram) of tritium. Sites that release tritium as a byproduct of other operations, such as the Idaho Chemical Processing Plant, were not included in the Task Group's assessment, nor were facilities handling relatively small quantities of tritium, such as those using tritium for biological tracer activities. Background on the Task Group's charter, its organization and objectives, and the conduct of the evaluation is provided in Appendix B.

Tritium, the radioactive isotope of hylrogen, is of strategic importance to the Nuclear Weapons Program of the United States. In addition, tritium is used in the Nation's energy development program as well as in biological and medical research. The Department of Energy is responsible for the production and distribution of tritium in this country and for most of its use. A discussion follows on the unique chemical and radiological properties of tritium, tritium operations within DOE, and the history of these operations from an environment, safety, and health standpoint. 


\section{Environment, Safety, and Health Aspects of Tritium}

Tritium has a radiological half-life of 12.34 years, decaying to helium-3 $\left({ }^{3} \mathrm{He}\right)$ by emitting a low-energy beta particle. Because of this low energy, tritium beta particles cannot penetrate the outer, dead layer of human skin. In most situations, the radiological hazard associated with tritium is from deposition within the body. Elemental tritium gas (HT) ${ }^{1}$ and tritium oxide $(\mathrm{HTO})^{2}$ are the principal forms of tritium found at DOE facilities, although other forms may exist in the workplace and in the environment. To some extent, tritium gas adsorbs onto almost all materials, and will gradually desorb and degas to the atmosphere over time. Thus, there is always a potential for personnel contamination and exposure after a material has been exposed to tritium. Although the chemical energetics of the tritium gas interaction with water or oxygen favor the production of tritium oxide, these reaction rates are very small. The radiological hazard of tritium oxide is approximately 25,000 times that of elemental tritium gas, principally because of its ease of assimilation and its greater absorption in the body.

The health effects of tritium are dependent on the radiation dose that results from tritium exposure. Humans receive radiation dcses from tritium through four pathways, in the following order of significance: (1) inhalation, (2) skin absorption, (3) ingestion, and (4) external irradiation. Tritium oxide is rapidly absorbed and uniformly distributed throughout body fluids following intake. The average soft-tissue dose from tritium oxide exposure can be directly estimated by measuring the concentration of tritium in the urine. In contrast to tritium oxide, elemental tritium gas is not readily absorbed through the skin or when inhaled, and only very small portions (less than 1 percent) dissolve in body fluids. The average biological half-life for nonorganically bound tritium is 10 days, which closely follows the half-life for the turnover of body fluids. For this reason, a primary treatment for reducing tritium doses is to increase the turnover rate of body fluids by increasing fluid intake or using diuretics.

Normal operation of tritium facilities results in releases of tritium to the environment in three media: air, water, and solid waste. Upon airborne release from a facility, tritium rapidly disperses into the atmosphere. Due to the relatively noninteractive nature of elemental tritium gas, tritium concentrations are quickly and substantially diluted. However, removal of tritiated compounds from the atmosphere is more complex and takes place by transfer to surfaces or

1 Tritium gas is used throughout this document to represent HT, DT, and $T_{2}$.

2 Tritium oxide is used throughout this document to represent HTO, DTO, and $\mathrm{T}_{2} \mathrm{O}$. 
the ground or, to a much lesser degree, by radioactive decay. Rain-out of tritium, as the result of wet deposition, occurs at the rate of approximately 1 to 2 percent per day with normal humidity and at a considerably higher rate with actual precipitation. Oxidation of elemental tritium in free air takes place slowly, at a rate of less than 1 percent per day. Liquid effluents contaminated with tritium are categorized as aqueous or organic. Liquid waste streams may be released directly to the environment or treated such that the tritium contamination is adsorbed onto solids or appropriate media for subsequent burial. Tritiated solid waste streams include materials ranging from compactible waste to scrap equipment. Regardless of its origin, the predominant environmental pathway to the public is through drinking water and the food chain. While no standard exists for tritium in food stuff, the U. S. Environmental Protection Agency (EPA) drinking water standard for tritium is 0.02 microcuries per liter or 20 picocuries per milliliter.

As part of a routine occupational Radiation Protection Program, worker tritium exposures are monitored by routinely sampling urine for the presence of tritium oxide. These bioassay programs represent the most efficient way to determine the initial level of tritium present in a worker and allow for the use of control measures (e.g., increased fluid intake or diuretics) to minimize the committed dose as the result of the tritium uptake. Workers who routinely operate in a workplace environment where the potential for tritium exposure exists are normally required to submit urine samples on a routine basis and at a frequency dependent upon the anticipated worker dose. Workplace air monitoring for tritium is performed by instruments that detect and measure tritium concentrations in air, in liquid, and on surfaces. These instruments monitor tritium concentrations inside a facility, as well as tritium concentrations in the air and water that are released from the facility. Workplace concentrations of tritium are controlled to the Derived Air Concentrations limits of DOE 5480.11, "Radiation Protection for Occupational Workers." The Derived Air Concentrations for tritium oxide is 20 microcuries per cubic meter and for elemental tritilim is 500,000 microcuries per cubic meter, a factor of 25,000 higher.

Occasionally there are operations at a tritium facility for which there is a potential for significant exposure to airborne concentrations of tritium. Likewise, maintenance on tritium handling systems can expose workers to elevated concentrations of tritium. Air-sup lied plastic suits that completely enclose the body are widely used to protect workers in these situations. This approach provides protection against both inhalation and absorption of tritium through the skin. Respirators are not used for protection against occupational exposure to tritium, because they do not filter tritium from the air. 
Workplace contamination control for tritium consists of two key elements: (1) use of engineered features, such as gloveboxes, recovery systems, and doubly contained piping, to prevent or minimize tritium releases in the workplace; and (2) routine surveillances for airborne and surface tritium contamination using a variety of monitoring techniques including smears, outgas measurements, and area monitors.

\section{Department of Energy Tritium Operations}

Tritium is produced, processed, handled, and stored at several DOE facilities, primarily for use in the Nation's Nuclear Weapons Program. DOE also supplies tritium for basic research on fusion energy and provides a variety of isotopes, including tritium, to commercial clients. DOE bulk tritium is transported either in elemental gaseous form or solid form as a tritide, and must be shipped in certified packages approved either by the U.S. Nuclear Regulatory Commission (NRC) or DOE. Further, the certification must conform to requirements established by the U.S. Department of Transportation (DOT).

The Department of Energy's Savannah River Site serves as a primary production and distribution point for tritium to other DOE facilities. This tritium is used in the assembly of nuclear weapons from components supplied by the Savannah River Site and other DOE facilities. Tritium is produced at the Savannah River Site, where lithium targets are irradiated in the production reactors. The targets are then removed from the reactor, and the tritium is separated from the target and purified. Tritium is then loaded into reservoirs that are shipped to U. S. Department of Defense (DOD) destinations in support of the existing nuclear weapons stockpile and to the Pantex Plant for assembly into nuclear weapons. The Savannah River Site also provides tritium in gaseous form to: (1) the Pinellas Plant, for use in fabricating neutron generators; (2) the Mound Plant, for use in component production and the Fusion Research Program and for sale by DOE to commercial clients; and (3) the Los Alamos National Laboratory, Sandia National Laboratories, Livermore, and the Lawrence Livermore National Laboratory for use in conducting weapons and fusion-related research and basic research on tritium and tritium materials properties. Lawrence Livermore National Laboratory recently decided to significantly decrease the scope of research and development activities involving the use of tritium.

Figure 1 shows the relationship among the DOE sites involved in tritium operations. In addition to the major DOE facilities that handle tritium, the Nevada Test Site (NTS) handles components containing tritium and performs nuclear weapons tests of new and existing weapons to verify their performance. The Tokamak Fusion Test Reactor at the Princeton Plasma Physics Laboratory (PPPL) will use tritium in the next few years to achieve its primary 


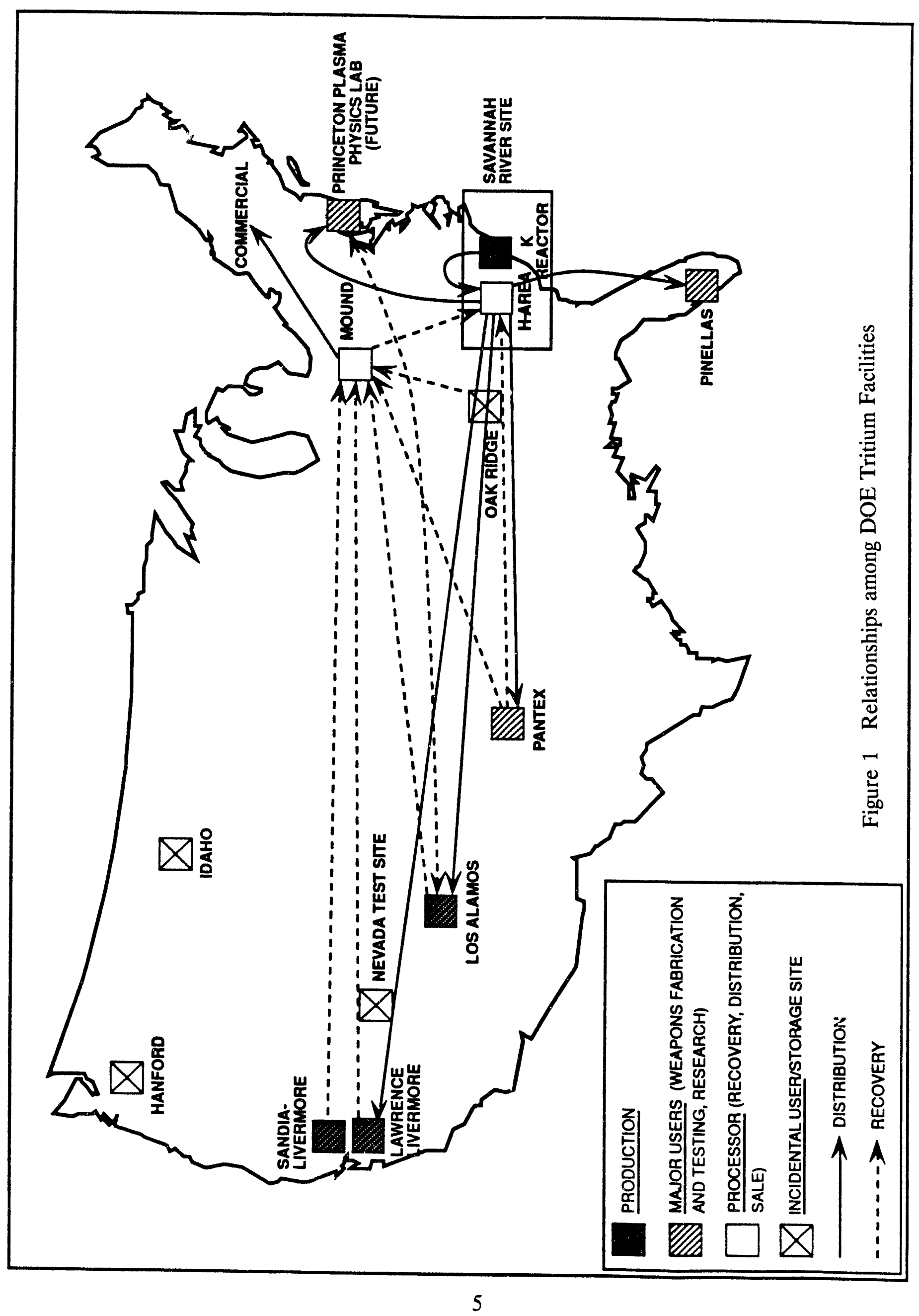


objective, the production of 15 to 30 megawatts of fusion power using deuteriumtritium fuel. Oak Ridge National Laboratory shut down its Radioluminescent Light Program, which was part of its Commercial Sales Program; the remainder of the Commercial Sales Program has been transferred to the Mound Plant. However, a significant amount of tritium remains in storage at the Oak Ridge National Laboratory.

Some new facilities are currently under construction. These facilities will have an improved ability to confine tritium and to increase efficiency of the Department's operations. The Weapons Engineering Tritium Facility, recently built at Los Alamos National Laboratory, is replacing the High Pressure Tritium Laboratory (HPTL); preoperational activities are now being completed. Also, a new tritium processing facility, the Replacement Tritium Facility, is under construction at the Savannah River Site H-Area. Scheduled for completion in 1992, this facility will load tritium for transport to, and use at, other DOE facilities and will unload reservoirs that are returned from the field.

A more detailed description of these operations is provided for each facility reviewed by the Task Group in the chapter of the report entitled "Safety Management Issues at Department of Energy Tritium Facilities."

\section{Operating History from an Environment, Safety, and Health Viewpoint}

Tritium releases and worker exposures occur as a result of: (1) normal offgassing of tritium from components that confine tritium gas or tritium oxide; (2) planned releases during processing operations or during system maintenance and testing; (3) discharges of effluent material when it is not cost-effective to confine or recover the tritium; and (4) accidental tritium releases.

At several DOE facilities, the routine and accidental releases of tritium that have occurred since 1986 have resulted in detectable levels of tritium in air onsite, and in water, produce, and animals at offsite locations. The distribution and yearly totals of these releases are shown in Figures 2 and 3, respectively. Substantial variations in routine tritium releases are attributable to variations in facility mission, and management's commitment to reducing tritium releases. Such variations can be traced to: (1) different tritium inventory and production levels; (2) different confinement systems; and (3) in some cases, the age of a facility and its equipment. Although these levels are measurable, they represent a small fraction of the DOE and Environmental Protection Agency concentration standards for tritium in air and water. In addition, estimates of annual maximum individual doses to the public from these releases have been, for the most part, 


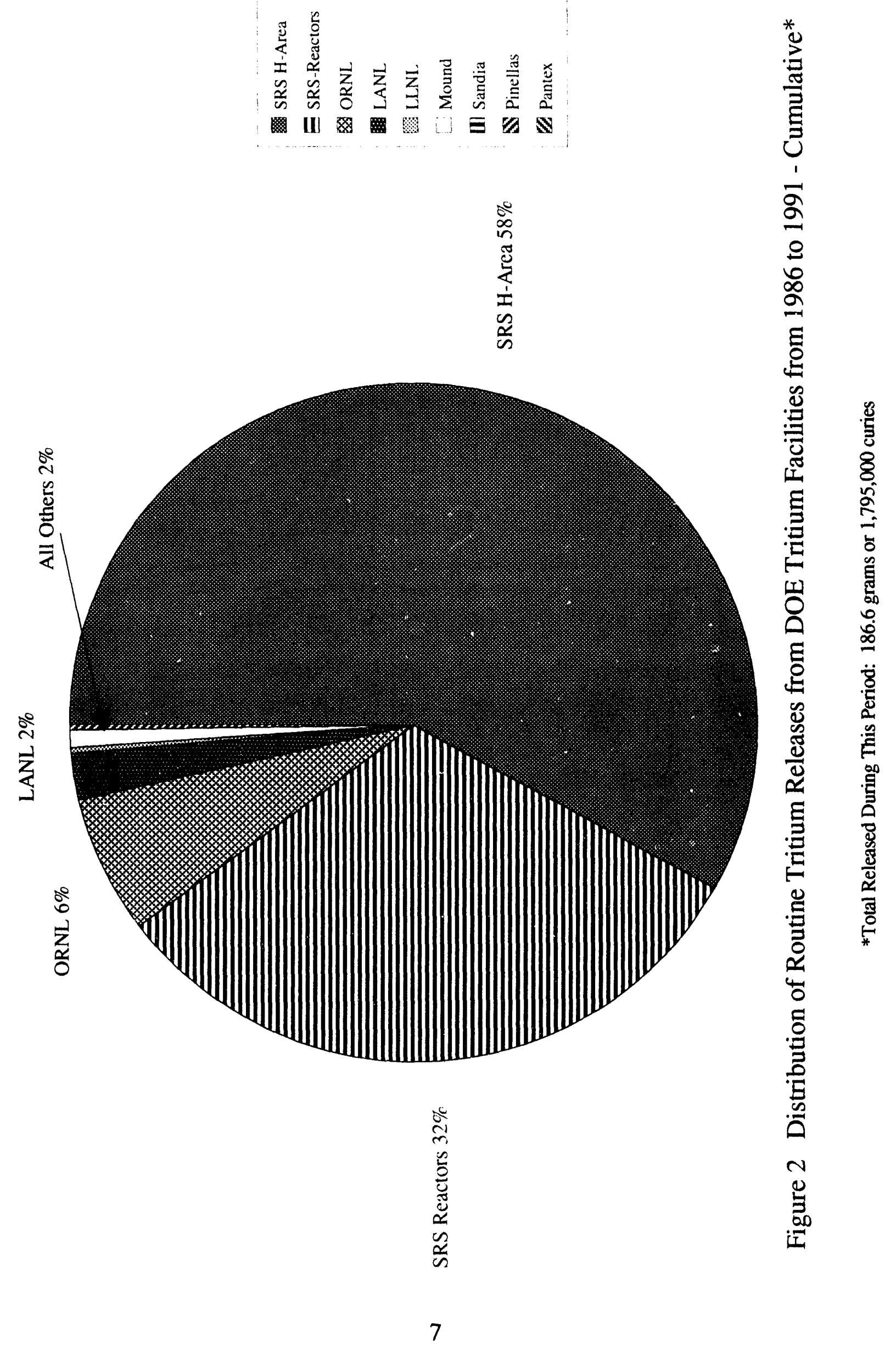




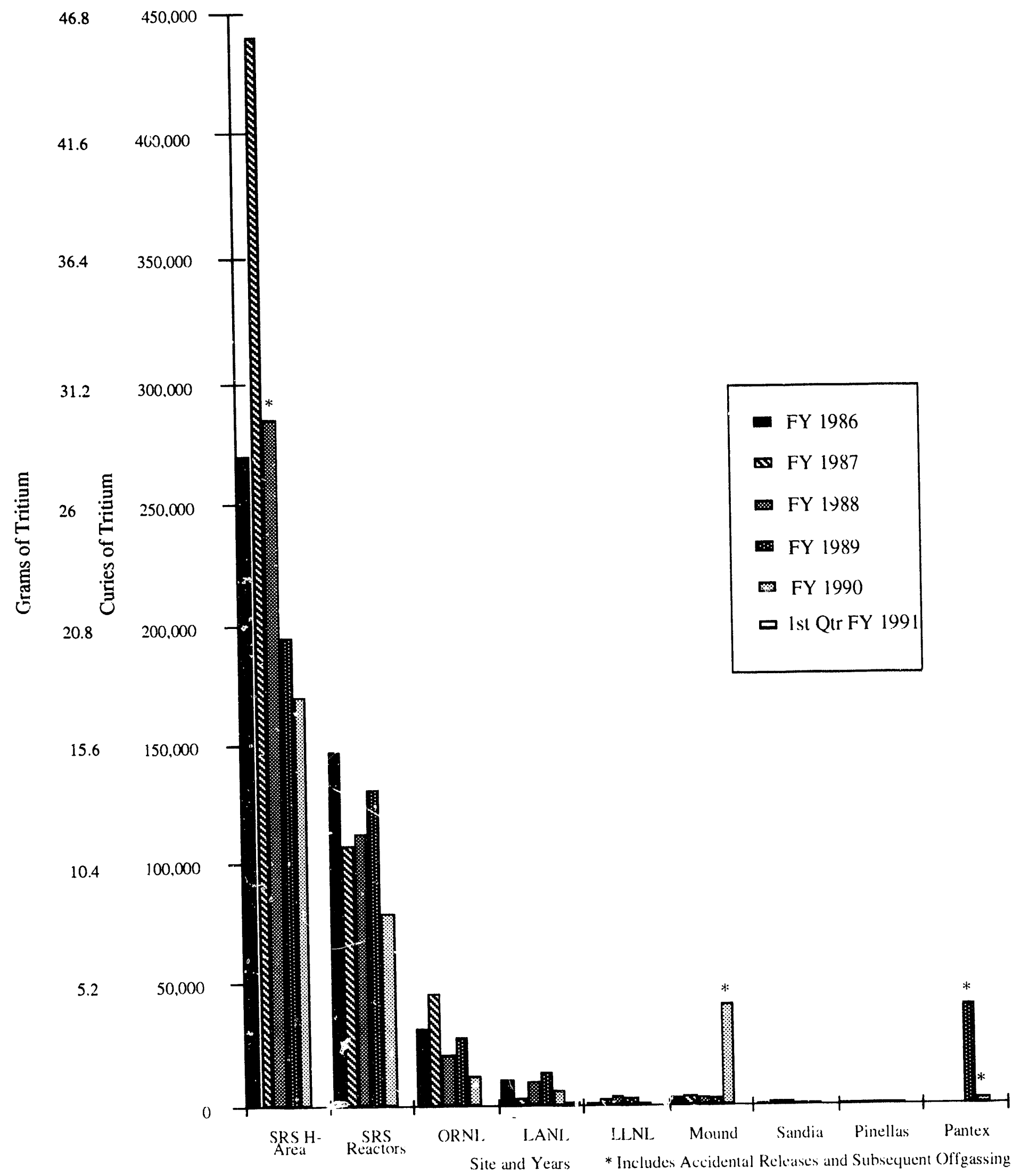

Figure 3 Distribution of Tritium Releases by Site and Year from 1986 to 1991 
much less than 1 millirem and no greater than 5 millirem. (Natural radiation background in the United States results in exposures of approximately 350 millirem.)

Worker exposures to tritium within the facilities that handle, process, or store tritium are generally a fraction of the allowable annual dose equivalent. For example, for those tritium workers monitored during the period 1986 through 1990, about 80 percent received dose equivalents of less than 10 millirem; about 19 percent of the workers received doses between 10 and 100 millirem; a small fraction of workers received doses between 100 and 500 millirem; and only a few workers per year received a dose exceeding 500 millirem. These dose distributions do, however, underscore the importance for management to ensure a rig $r$ of operation is maintained to minimize any potential exposure consistent withi the as-low-as-reasonably-achievable (ALARA) philosophy DOE has adopted. Occupational doses resulting from distribution of tritium exposure at each site are reported in Chapter 3; the distribution of occupational doses Department-wide is shown in Figure 4, as a summation over the 5-year period 1986 to 1990, inclusive.

In addition to routine releases and exposures, abnormal occurrences and accidents have resulted in worker exposure and the release of tritium gas and tritium oxide to the environment. Abnormal occurrences and accidents have resulted from equipment failures, failure to follow procedures, and inadequate personnel training. Most of these incidents have involved small quantities of tritium; however, some occurrences involved substantial quantities of tritium and significant worker exposures.

Currently, the largest routine atmospheric tritium releases occur at the H-Area tritium facilities of the Savannah River Site, where the largest tritium inventory resides. These facilities normally release several hundred-thousand curies per year (see Figures 2 and 3); however, the new Replacement Tritium Facility at Savannah River should significantly decrease H-Area routine annual tritium releases. The largest accidental release of tritium in the period from 1986 to 1991 occurred at the Savannah River Site H-Area facilities. On July 31, 1987, a worker made a line break in some tritium process equipment to perform maintenance, and removed the wrong transducer from a different, fully pressurized system, which resulted in a release of 172,000 curies of tritium through the plant stack.

The second largest source of routine tritium releases results from operations at the Savannah River Site production reactors. The primary coolant systems for the reactors are open to the atmosphere (the purification system is vented to the atmosphere), and evaporation from leaks and spills results in routine releases of tritium oxide vapor of approximately 100,000 curies per year (average for the 


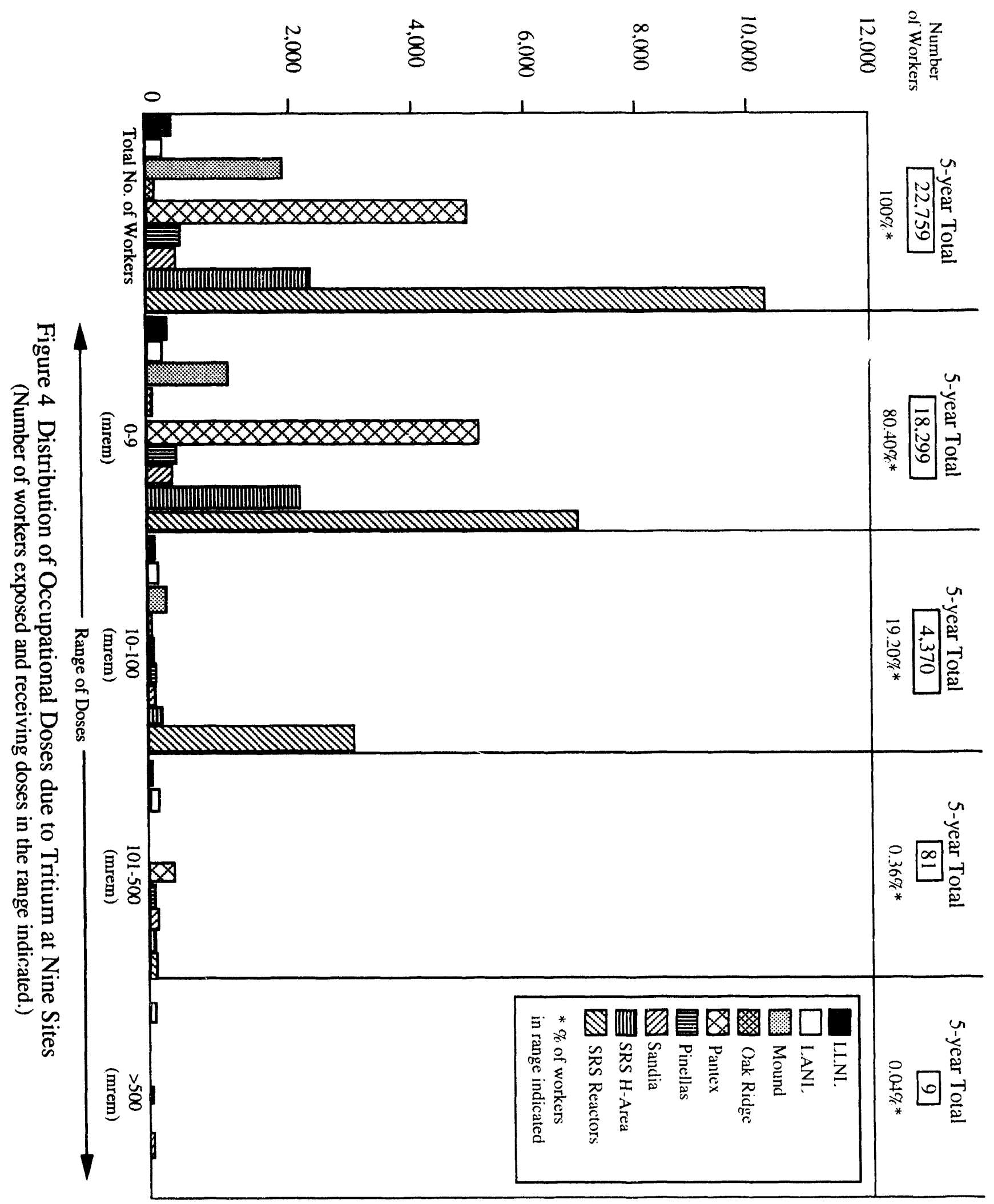


three production reactors). The reactors also routinely discharge liquids that contain tritium. The total released as liquid effluent is significantly smaller than the gaseous quantities released to the atmosphere.

The Mound Plant routinely handles the second largest inventory of tritium of all the DOE facilities. The plant has consistently maintained normal, annual releases of tritium between 3,000 and 4,000 curies per year over the last 5 years. Since 1986, the largest, single, unintentional release of tritium at Mound occurred on November 8, 1989, during the unloading of a pressurized container. Due to faulty fittings used for the unloading device, a gas transfer system component failed, and more than 10,000 curies of tritium were released into the walk-in fume hood and to the building stack.

The third largest inventory of tritium exists at the Los Alamos National Laboratory. Releases from this site have varied between 3,300 curies and 14,400 curies since 1986. Total release quantities at Los Alamos National Laboratory are dispersed among eight different facilities with varying missions. The largest, single release from Los Alamos National Laboratory occurred on February 22, 1988, when 5,700 curies were emitted into the atmosphere during a maintenance operation.

The primary tritium activities at the Oak Ridge National Laboratory have been the repackaging of tritium for commercial customers and the development and manufacture of radioluminescent light sources. In June 1990, Oak Ridge National Laboratory suspended tritium activities. Currently, the Laboratory is in the process of removing tritium inventories from the site. Annual releases of tritium during operations in the late 1980 s averaged 27,000 curies, with the repackaging program being the greatest source of release. Several accidental releases have occurred because of breakage of light sources. These releases amounted to less than 100 curies for each occurrence; therefore, they are small in comparison to the routine releases. Worker doses from the tritium operations have been low.

The Sandia National Laboratories, Livermore, and the Lawrence Livermore National Laboratory are located within one-half mile of each other. Sandia National Laboratories, Livermore, releases have varied between 800 and 1,800 curies per year. Annual releases of tritium at Lawrence Livermore National Laboratory have ranged between 1,300 and 4,000 curies for the past 4 years. In 1987, two events occurred at Sandia National Laboratories, Livermore, each of which resulted in a total release of approximately 1,100 curies of tritium. The events were similar, and involved loading a vessel with tritium and the subsequent temperature-conditioning of the loaded vessel. The first event resulted in a discharge of tritium to a glovebox, which was then exhausted to the stack. The second event resulted in a release of tritium into the room where the work was being conducted. There have been no events at Lawrence Livermore National 
Laboratory in the last 5 years that resulted in individual releases of tritium over 250 curies. However, in April 1991, a worker received a dose of 1.1 rem due to a release that occurred during the handling of a 1960s vintage container that was contaminated with tritium. The total release to the environment was 144 curies.

DOE's Pinellas Plant has contributed minimal tritium releases to the environment. The Plant's annual effluent is approximately 300 curies of tritium. There have been no significant unintentional releases or worker exposures at the Pinellas Plant.

At the Pantex Plant, routine operations are performed using only sealed tritium reservoirs; thus, a negligible quantity of tritium is released. The releases that do occur are caused by permeation of tritium from reservoirs and from the use of tritium gas for calibration of instruments. On May 19, 1989, during a disassembly operation, a release of more than 10,000 curies of tritium gas occurred. An electroexplosive valve inadvertently discharged, providing an open path from a tritium reservoir, and the tritium was released into the cell where the disassembly was being performed. Subsequently, most of the tritium was dischargeci through the ventilation system; however, some tritium was retained within the cell structure, which remains contaminated. One worker received a dose exceeding $1 \mathrm{rem}$. 


\section{GENERIC ISSUES}

The formation of the Tritium Task Group by the Secretary of Energy was in response to his concern over "releases and other problems at the Department's tritium facilities" and the need to "look at the overall management of these facilities." The Task Group's review of tritium facility operations, as well as incidents that occurred after the Group's formation, identified a number of issues at each facility. The Task Group found that the overall consequences to workers and the public of these and past release events were minimal, although individual workers have sustained doses in a few cases, in excess of $1 \mathrm{rem}$. However, the events did indicate deficiencies in the management and operation of the Department of Energy's (DOE's) tritium facilities, which, for the most part, can be remedied through improved conduct of operations, an ongoing Departmental priority. More importantly, this review revealed that past DOE efforts to disseminate and implement its policies and requirements for such operations have been deficient. Recognizing these difficulties, the Task Group developed specific recommendations to improve implementation of consistent operating philoscphy and requirements to ensure that new and planned facilities will substantially enhance performance over working facilities.

The Task Group evaluated the key activities of the tritium complex, including production, extraction, transportation, utilization, scrap and residue reclamation, and waste disposal. The Group found that most of the tritium releases from DOE facilities are to the atmosphere; approximately 90 percent of the total curie release occur as routine releases from facilities at the Savannah River Site (SRS). Less than 10 percent of the tritium released is the result of inadvertent or unintentional releases.

While the Task Group found that tritium releases have not historically resulted in occupational or public radiation dose limits being exceeded, adequate sıeps have not been taken to minimize such releases, whether routine or unintentional. Measurable levels of tritium have been detected offsite at Lawrence Livermore National Laboratory (LLNL) and at the Savannah River Site. While demonstrably below environmental limits, DOE's principle of maintaining radiation exposures as-low-as-reasonably-achievable (ALARA) requires that such impacts be mitigated w'here practical. This is likewise true for the workforce, where assimilations of tritium in maintenance operations at some sites are frequently tolerated because doses remain one to two orders of magnitude below the occupational limit. 
With this perspective in mind, the Task Group expanded its review beyond current operations and addressed the implications of existing management approaches to new facilities under construction or being considered. This was a limited review given the near-term startups of both the Savannah River Site Replacement Tritium Facility (RTF) and the Los Alamos National Laboratory (LANL) Weapons Engineering Tritium Facility (WETF), which obviate against major design reconsideration. However, the Task Group concluded that the lack of a coherent Departmental strategy or goals for tritium control could perpetuate design and operational philosophies in prospective facilities such as the New Production Reactor (NPR). This approach was viewed as cautionary, since a New Production Reactor technology option has yet to be decided, and specific design objectives have not been established.

Generic issues were derived from the site reviews discussed in the chapter entitled "Safety Management Issues at Department of Energy Tritium Facilities," and the event reviews included in Appendix D. Issues were deemed to be of generic significance if found at several DOE sites or if they held implications for overall DOE tritium operations. For clarity, the bases for the issues identified are abbreviated, with more explicit details and discussion provided in the individual site reports. These generic issues are presented as follows:

- Conduct of Operations

- $\quad$ Management of Operations and Maintenance Functions

- $\quad$ Safe Shutdown of Tritium Facilities

- $\quad$ Management of the Facility Safety Envelope

- $\quad$ Maintenance of Qualified Tritium Handling Personnel

- $\quad$ Operating Philosophy and Requirements

- $\quad$ DOE Tritium Management Strategy

- Radiological Control Philosophy

- Implementation of DOE Requirements

- Management of Tritium Residues

- Inconsistent Application of Requirements for Measurement of Tritium Effluents

- $\quad$ Interdependence of Tritium Facilities

- Technical Communication among Facilities

- Implications For New Facility Design

- Incorporation of Confinement Technology into New Facilities

- $\quad$ Operations/Management Requirements for New Tritium Facilities 
These issues are discussed in this chapter of the report, and are supported by general discussions of the Task Group's findings. Technical review conclusions resulting from the Task Group's facility-specific reviews are discussed in Chapter 3, "Safety Management Issues at Department of Energy Tritium Facilities."

\section{CONDUCT OF OPERATIONS}

Although a DOE conduct of operations policy has been developed (DOE 5480.19, "Conduct of Operations") and the Secretarial initiatives (e.g., Tiger Team Assessments) have begun to improve the formality and discipline of operations, DOE contractors responsible for tritium operations do not yet have a complete understanding of the need for, and implications of, a systematic approach to conduct of operations. This is particularly true as it pertains to minimizing tritium releases and eliminating unnecessary personnel radiation exposures.

Compared to the routine releases occurring at the Savannah River Site, accidental release of tritium to the environment is relatively small (less than 10 percent of the total curie release). In general, inadvertent or accidental releases are caused by human error. While some of the production facilities have developed stringent conduct of operations for routine production activities, the supporting facility operations and the tritium research and development operations would benefit measurably from improved conduct of operations. The Task Group performed a review of the inadvertent releases that have occurred over the last 5 years (listed in Appendix E). Because most of these releases were caused by human error, it was concluded that improved operations controls and the reduction in operator error rates could be expected to reduce the routine releases and the frequency of abnormal events. The major benefit of improved conduct of operations would be the reduction of unnecessary personnel exposure.

\section{Management of Operations and Maintenance Functions}

Lack of a systematic approach to management of operations and maintenance functions exists and is characterized by: (1) procedural deficiencies, particularty as applied to facility support activities; (2) training program deficiencies at most DOE facilities; (3) failure to investigate near miss situations; and (4) deficiencies in Radiation Protection Monitoring Programs across the complex and facility management's failure to fully integrate radiation protection management into their operations. 


\section{Procedural Systems}

The Task Group found that contractor procedure systems do not always ensure that facilities are operated within the design bases. Contractors do not fully address the impact of operations, maintenance, and other support activities, or off-normal conditions on facility safety or on the potential release of tritium to the environment. The Task Group noted procedural system deficiencies at all of the facilities reviewed. For example, a tritium leak occurred in March 1991 at the Los Alamos National Laboratory Tritium Systems Test Assembly. The leak was attributed to a procedural deficiency that failed to address the integrity of a secondary confinement seal. Procedures are not in place at DOE sites for many routine support operations, and many procedures that are in place lack sufficient detail to provide adequate direction to the operator. At the new Los Alamos National Laboratory Weapons Engineering Tritium Facility, the human factors element has not been properly considered in the person-computer interface.

Many facility managers rely upon matrixed support organizations to provide maintenance, calibration, training, and radiological protection services. In DOE tritium facilities, these managers do not have in-place management control systems to ensure that work performed by support organizations is reviewed and accomplished in compliance with operational requirements and procedures. In general, formalized maintenance procedures are lacking at many DOE tritium facilities, and the lack of adequate procedures has resulted in personnel omitting actions necessary for the proper operation of equipment important to safety. Procedural deficiencies were found for support systems, such as stack monitor maintenance and availability, emergency diesel generator maintenance, and bioassay submission.

\section{Training of Personnel}

Personnel training is an essential aspect of safe facility operation. Many DOE tritium facilities have not implemented classroom training or formalized on-the-job training programs that cover the necessary disciplines for operations, maintenance, health and safety, and emergency preparedness. Operator training is usually in the form of unstructured on-the-job-training experiences. In general, facilicy managers have failed to establish mechanisms to document procedures and processes for development of training materials and have failed to fully implement the necessary training programs. The Task Group found that training efforts at most tritium facilities are primarily in the planning stages or are just beginning to be implemented. The DOE-wide Conduct of Operations Training Programs being supported by DOE Headquarters would be helpful to accelerating understanding and acceptance at the DOE tritium facilities. 


\section{Investigation of Near Miss Situations}

As part of facility management's self-assessment responsibility, an effective corrective action system needs to be in place to identify problems, determine their cause, understand their implications, and correct deficient conditions. Presently, the program at most DOE tritium facilities applies solely to events that must be reported to consequence threshold requirements in DOE 5000.3A, "Occurrence Reporting and Processing of Operations Information." Thus, contractors do not typically include the investigation of near miss situations, which, if performed, might identify conditions that would reduce the probability of a similar situation becoming a precursor to a more serious event. It is apparent, however, that tritium releases that would have gone unreported to DOE and acted upon prior to DOE 5000.3A are now being systematically addressed.

\section{Radiation Protection Monitoring Programs}

Although most tritium facility managers understand the requirements for an effective Radiation Control Program, there have been deficiencies in integration of such programs into facility management and operations. This is not a new problem, and is being addressed through Secretarial initiatives to strengthen the accountability of line management.

For example, the Task Group noted at least two incidents in which worker tritium bioassay samples either were not taken or were not analyzed promptly following a significant exposure. At one facility, a nonroutine sample given by a worker who had received a dose that was later found to be several rem was not analyzed for approximately 2 weeks following the exposure. In a more recent incident at another facility, a nonroutine bioassay sample from a worker was not analyzed until the morning after an accidental tritium exposure of significance, delaying the initiation of dose-mitigating measures. It was instructive to the Task Group to observe that the tritium bioassay procedures imposed on Group members differed, sometimes significantly, at each of the nine sites visited.

Radiation worker training does not always ensure that all personnel who may be exposed to tritium understand its unique properties and know how to protect themselves from assimilation in the workplace. Unlike most other contamination sources, tritium, in its oxide form, is readily assimilated into the body; therefore, special precautions are necessary when working in areas where such potential exists. The Task Group found shortcomings in the scope and depth of both general employee training and radiation worker training.

The Task Group also found the lack of structured health physics reviews of routine work packages to define actions to minimize spills and releases, as well as comprehensive contamination control, at some sites. These include the use of 
temporary confinements, bagging of equipment, and installation of temporary local ventilation. Divergent approaches to the performance of smear samples, including no routine program at the Savannah River Site K-Reactor, were observed. Inconsistent use of protective clothing (gloves, anti-C's and airsuits) was found at most sites, which indicated a lack of understanding of basic tritium hazards and contamination control. Health physics briefings to maintenance and operations personnel on the specific concerns associated with a particular activity involving a tritium-contaminated worksite are not always provided.

\title{
Safe Shutdown of Tritium Facilities
}

\begin{abstract}
DOE tritium facilities do not have adequate, pre-established procedures to ensure that safe shutdown conditions will be achieved in an orderty manner in the event the facility is required to cease operation and remain out of operation for an indeterminant period of time.
\end{abstract}

The Task Group observed questionable safety conditions at several facilities in shutdown status. This was particularly evident at the Lawrence Livermore National Laboratory Tritium Facility, where operations were suspended immediately after an incident involving the release of tritium and a resulting tritium worker exposure. The immediate operational suspension resulted in materials and equipment left in a less than satisfactory condition. The facility manager prepared a list of actions necessary to obtain safe conditions after operations had ceased. This list included additional tritium operations. Since the actions required justification and approval by Laboratory management and DOE, this process took several weeks, during which time the unsatisfactory conditions persisted. Other DOE tritium facilities in questionable shutdown condition include the High Pressure Tritium Laboratory (HPTL) at Los Alamos National Laboratory and Building 3026-C at the Oak Ridge National Laboratory.

Currently, there is no requirement to maintain safe shutdown plans and procedures with specified minimum conditions to be met in the event facility operations are suspended. Such a shutdown plan, prepared in advance and carrying anprovals of the facility and contractor management, as well as the cognizant DOE authority, would establish the sequence of securing the facility in a logical manner, including: (1) which equipment should be shut down and which should not; (2) storage or disposition of materials to assure radiological safety and accountability; (3) removal of combustible or other hazardous material; (4) additional or changed (from normal) procedures and administrative controls; and (5) other important activities related to a safe shutdown condition. Execution of a well-conceived plan, updated on a regular basis to accommodate changes in mission and inventory, nature of materials, and facility conditions, would assure 
that facilities under these circumstances would be placed in a condition that minimizes personnel exposure and precludes inadvertent release of radioactive materials into the environment.

\section{Management of the Facility Safety Envelope}

There has been a lack of DOE and contractor definition, management, and application of the safety analysis process appropriate to the size and the nature of DOE tritium facilities. This deficiency has resulted in operations-related incidents and inadvertent environmental releases.

The term "safety envelope," as used by the Task Group, refers to the safe operating bounds for a facility as established through analysis in the Safety Analysis Reports (SARs); Operational Safety Requirements (OSRs), which are the conditions, safe boundaries, and bases thereof, and those management controls required to assure safe operation of a facility; and Limiting Conditions of Operation (LCO), which are the limitations of equipment, technical conditions, and characteristics of the facility necessary for continued safe operation. The Task Group found deficiencies in the identification of the systems and equipment that are important to safety and required to reduce tritium releases and minimize occupational exposure. The absence of pre-established control mechanisms to ensure that modifications to facilities or nonroutine activities do not violate the existing safety enveiope was also noted. The Group also found that detailed vulnerability analyses are not being performed for processes and systems that are important to the safety of the facility.

\section{Identification and Care of Equipment Important to Safety}

Although tritium facility personnel expressed general acceptance of their responsibility to safely operate and maintain their facilities, there was a lack of attention to identify systems and equipment important to the safety of the facility and required to reduce tritium releases and minimize occupational exposure. Such systems provide emergency power, ventilation, system pressure reduction, and effluent monitoring. This would also include support systems that are necessary to assure that safety systems can perform their functions.

At several facilities, operations, maintenance, and management personnel did not know which systems were important to the safety of their facilities and the protection of personnel. The Task Group found maintenance personnel have not been provided training on the importance of these systems to the safety of the facility. As a result of failure to identify such systems, tritium operations have, in several instances, been conducted without operational safety equipment. 


\section{Safety Reviews of Modifications and Nonroutine Operations}

The Task Group observed several projects in progress at various facilities to improve performance and reduce tritium releases. At the same time, it was observed that management controls varied widely. While the scope and goals of projects appeared to be well defined and had strong technical bases, the mechanisms required to evaluate the broader safety implications of the projects were not in place. Often, equipment modifications are not assessed to see if, and how, they might alter the facility's safety envelope or subordinate safety limits. For example, a minor modification to a system that was intended to be an improvement had the potential to render an emergency power generator inoperable. No reviev of this modification had been performed by operations or engineering.

It was also noted that most facilities do not perform formal safety reviews of nonroutine operations, such as downsizing and decommissioning of these tritium facilities. This was the case at Lawrence Livermore National Laboratory, and was also a contributing cause to recent tritium events at the Los Alamos National Laboratory.

\section{Vulnerability Analysis}

The Task Group found that the documents that control safe operations, such as operating instructions and emergency procedures, lack sufficient detail. The toplevel failure modes and effects analyses reported in the Safety Analysis Reports, as well as the hazards analyses required of many tritium facilities, are insufficient for use in developing safety documents. Detailed process vulnerability analyses have not been performed and documented. The operating instructions and emergency procedures that do exist are usually developed assuming that nothing will go wrong, and fail to identify potential problems; thus, operating controls are not sufficiently sensitive to the vulnerabilities within the process that could cause unintentional tritium releases.

\section{Maintenance of Qualified Tritium Handling Personnel}

There has been a continual decline in the number of experienced tritium handling personnel within the operating contractor organizations. In addition, inadequate documentation of operating and maintenance procedures makes training of new personnel difficult and incomplete. Improvements in conduct of operations necessitate maintaining a qualified staff. 
The Task Group observed that many tritium operations and processes have been conducted by small groups of individuals at the various facilities. These groups of individuals recently have been declining in size due to retirement and transfer to nontritium-related positions without replacement of this lost expertise. Thus, expertise and relevant knowledge regarding these facilities and their operations reside in a limited population. This is particularly true at Lawrence Livermore National Laboratory, Los Alamos National Laboratory, Oak Ridge National Laboratory, and Sandia National Laboratories, Livermore. At the larger tritium handling sites, such as the Mound Plant and the Savannah River Site, knowledge of critical tritium technology resides with a somewhat larger, but still a relatively small, population.

The Task Group found that loss of qualified personnel contributed to the accidental release of tritium, and an occupational exposure, at the Los Alamos National Laboratory in April 1991. The contractor had failed to recognize the significance of the loss of vital experience and knowledge resulting from a turnover in the staff of four over a 2- to 3-year period, and without detailed, written procedures, the facility staff lacked sufficient knowledge to safely carry out a maintenance activity.

\section{OPERATING PHILOSOPHY AND REQUIREMENTS}

The Task Group reviewed tritium releases for their management implications and the operating philosophy that guided controls and response to events. What was found was divergent sets of requirements that owed their basis more to the local contractor interpretation of adequacy than any fundamental DOE position or policy. The extent to which tritium was controlled was found to be a function of facility design, operating history at the site, and contractor aggressiveness in applying ALARA considerations to radiological releases. An earlier attempt to establish standard practices for tritium handling, in the form of a draft "Guide to Good Practices at DOE Facilities," failed because final agreement could not be reached among the contractors. Within the constraints posed by radiological limits, the Department's control of tritium releases is guided by ad hoc principles that have evolved within the Department's tritium complex. The lack of informational interchange among contractors DOE-wide, from contractor to contractor within the same facility, and between contractors and DOE has served to perpetuate an insularity that prevents effective use of lessons learned; comparison of environmental, safety, and health practices; and recognition of common issues, such as the environmental, safety, and health implications of stored tritium residues. 


\section{DOE Tritium Management Strategy}

The DCE line programs have not developed or implemented a uniform Department strategy for management of tritium facilities. There is wide variation in the operating plilosophies and practices being employed by DOE Field Offices and contractors in the operation of tritium facilities. This is manifested in the various confinement strategies, operation management standards, radiological control practices, and effluent monitoring approaches being used at the different sites. In many instances, this has led to unnecessary environmental releases and radiation exposure to operating personnel.

Wide variations in the levels of routine re eases of tritium have been permitted during the operation of the tritium facilities because the Department's line operating programs have not developed or impleriented an overall policy for consistent control and management of tritium. Without such a policy, DOE cannot ensure that all new and planned facility modification designs will minimize releases and maintain radiation exposures as-low-as-reasonably-achievable.

Tritium operations within the Department are directed through different program offices and Field Offices without courdination, centralized management control, or consistent approaches to facility design or operations. Thus, contractors have developed, with varying degrees of success, ad hoc tritium management programs for their facilities. Their programs are based on costs, contractor objectives and interpretation of the requirements, contractor initiative, DOE Field Office requirements and direction, program office needs, and public perceptions. Sitespecific variations can lead to legitimate differences in approach to tritium control. However, the lack of coordinated DOE strategy and the continued use of design and operating objectives developed under guidelines established years ago have resulted in DOE lagging behind current radiological control philosuphy and those developments in the international community that are directed towards minimizing tritium releases to the environment and occupational radiation exposures.

Because site boundary limits for tritium concentration have not been exceeded, and due to the lack a of compelling strategy to minimize releases and exposures, there has been little incentive within the Department to reduce substantial, routine releases of tritium from some facilities, such as those of Savannah River Site, that have large tritium inventories. Routine emissions from the Savannah River facilities constitute about 90 percent of the quantity of tritium released from all the DOE sites. 
Because of their design and age, each of the three production reactors at Savannah River Site routinely releases approximately 10,000 to 33,000 curies of tritium a year from evaporation of unconfined, tritiated, heavy-water moderator, regardless of their operating status. Spills of moderator are common, and together with the tritium from the unconfined moderator systems, workers are exposed to tritium oxide vapor and contaminated exposed surfaces. Systems to reduce tritium in reactor moderator have been in use in the international community for several years, notably in Canada and France. In the late 1970s, the Canadians elected to systematically reduce tritium concentrations generated in their heavy-water-moderated nuclear reactors to reduce occupational dose and concomitant environmen:al release from their nuclear stations (as well as to reduce maintenance downtime, thereby achieving monetary savings). DOE has not formally considered a similar systematic approach to tritium management in its existing operations or in the design of new facilities.

The implementation of such improvements at existing facilities may costeffectively reduce the releases of tritium from normal operations and as a result of incidents. However, the largest impact, in terms of curies of tritium released and cost/benefit, must be accomplished at new facilities currently being designed, constructed, or evaluated for incorporation into the tritium complex.

Significant routine releases are experienced from current extraction and reservoir operations at the Savannah River Site H-Area. Although tritium is pa.tially recovered by tritium capture systems now installed at some locations, the remaining emissions from such activities are released direcily to the stack and the environment. These releases may be significantly reduced by transfer of the reservoir operations to the Savannah River Site's Replacement Tritium Facility.

In addition to the ongoing design review process at the Replacement Tritium Facility as it approaches readiness for startup, operational needs should be addressed in the conduct of operations. In particular, review of procedures regarding the safety envelope during routine operations, off-normal conditions and shutdown procedural controls, and qualifications of personnel will be imperative to minimize the potential releases as this facility is brought into operation. For example, most releases from the existing extraction and reservoir operations at the Savannah River Site are caused by line breaks due to decoupling and maintenance activities in systems containing substantial quantities of tritium. These releases are subsequently vented to the stacks and into the environment. The Replacement Tritium Facility's secondary confinement and capture system will minimize such releases in the future. It is anticipated that the Replacement Tritium Facility startup will reduce tritium releases for reservoir operations to approximately 5,000 curies per year. 
An opportunity exists with the New Production Reactor to incorporate significant improvements specifically directed at reducing tritium releases. Regardless of the ultimate selection of technology, for example, high-temperature, gas-cooled, or light- or heavy-water moderated, for the planned New Production Reactor, it is appropriate to address key elements of an overall tritium control strategy and implementation of the ALARA philosophy early in New Production Reactor design and operation. The New Production Reactor and its supporting facilities, with a significantly improved tritium management strategy for control of releases and occupational exposure, will allow the aging production reactors to be decontaminated and decommissioned. When this is accomplished, DOE will eliminate longstanding routine releases of about 100,000 curies per year and routine occupational doses that have persisted at individual dose levels ranging up to 100 millirem per year for certain categories of workers at the Savannah River Site.

\title{
Radiological Control Philosophy
}

\begin{abstract}
At some DOE sites, tritium exposure is controlled more from a doseconsequence standpoint than from due consideration of controlling radiological releases at the source or maintaining exposures as low as reasonably achievable.
\end{abstract}

The Task Group found that, historically, tritium releases have not resulted in occupational or dose limits being exceeded; however, inadequate steps have been taken to minimize such releases, whether routine or unintentional. Routine atmospheric emissions of tritium oxide from the Savannah River Site averaged about 400,000 curies per year from the late 1970s until 1988, when production activities declined. Similar emissions at Oak Ridge National Laboratory and at the Lawrence Livermore National Laboratory averaged 20,000 curies and 5,000 curies per year, respectively, until tritium operations at Oak Ridge and at Building 331 at the Lawrence Livermore National Laboratory were suspended. At the Savannah River Site, tritium in liquid effluent is released to onsite streams by direct discharge from facilities and by migration from the low-level radioactive waste burial ground. A 1984 survey estimated that approximately 40,000 curies of tritium are present in the groundwater below the burial ground.

The Task Group found that line management has largely relied on major facility modifications or replacement facilities to achieve reductions in routine and unintentional tritium releases. Facilities such as Building 331 at the Lawrence Livermore National Laboratory and the High Pressure Tritium Laboratory at Technical Area 33 (TA-33) at the Los Alamos National Laboratory, both of which are aging facilities with single confinement design, continued to operate until recently, pending major modifications. While the Replacement Tritium Facility at the Savannah River Site will effect reductions in routine releases from the existing 
facilities in Building 234-H, substantial airborne emissions will continue from other Savannah River Site process facilities. Personnel protection practices, such as the use of protective clothing and equipment, can offer interim means to compensate for the lack of engineered barriers; however, they have not been used rigorously at most DOE sites. A systematic approach, by which needed facility upgrades can be justified and compensatory practices implemented while awaiting upgrades, has not been addressed at these DOE facilities. Such an approach would be consistent with maintaining radiation exposures as-low-as-reasonablyachievable, a prescribed Departmental policy that the Task Group found to be unrealized at most Department tritium facilities.

The implications of this prevailing radiological control philosophy are manifest in the longstanding levels of routine airborne emissions, the frequency of unintentional releases, and chronic worker exposures to tritium. Although environmental releases have not exceeded Environmental Protection Agency (EPA) standards, slightly elevated concentrations of tritium are routinely monitored in offsite rainwater, groundwater, and food products. From 1970 to 1990, Savannah River Site milk analysis data ranged from 0.3 to 1.1 picocuries per milliliter (The most recent background level in milk was 0.05 piocuries per milliliter). Tritium concentrations in wine from the 1982-vintage originating in the area surrounding Lawrence Livermore National Laboratory peaked at 0.62 picocuries per milliliter. Subsequently, the levels have declined to a 1988-vintage value of 0.27 picocuries per milliliter. Rainwater at the Savannah River Site measured an average of 0.6 picocurie per milliliter to 1.5 picocurie per milliliter for the period 1970 to 1988. In comparison, the Environmental Protection Agency drinking water standard is 20 picocuries per milliliter. While representing small fractions of permissible dose limits, these trace environmental tritium levels have been correlated with adjacent DOE operations, and should be subject to ALARA considerations.

\section{Implementation of DOE Requirements}

\section{The process whereby $D O E$ requirements flow through $D O E$ to the contractor organizations for implementation is fragmented and inefficient. Therefore, contractors often lack the information and understanding necessary to consistently and efficiently implement DOE directives.}

No single DOE organization interprets DOE Orders relative to tritium facility requirements or serves as a clearinghouse to disseminate best practices. The safety design objectives for tritium facilities, as outlined in DOE Orders, including DOE 6430.1A, "General Design Criteria," are currently interpreted by numerous levels of the DOE organizations when determining applicability and implementation. This practice has resulted in less-than-thorough safety 
evaluations of facilities and discrepancies in how design criteria are applied. For example, while DOE 6430.1A calls for redundant confinement for tritium operations, adherence to this criterion varies at the Replacement Tritium Facility and the Weapons Engineering Tritium Facility, the Department's newest facilities. This has also resulted in a lack of information required for conducting comprehensive design reviews and design basis analyses, identifying equipment important to safety, establishing Operational Safety Requirements, and performing the process-related analyses necessary to develop and implement controls that ensure safe operations. This deficiency is exemplified by the wide variance in the status of Safety Analysis Reports across the complex. Some facilities are operating without any Safety Analysis Report; others have Safety Analysis Reports that lack sufficient detail. Some facilities have been granted exemptions from DOE 5480.18A, "Accreditation of Performance-Based Training for Category AReactors and Nuclear Facilities," while other facilities with similar operations have not been granted the same exemptions. Thus, inconsistencies continue to be perpetrated within DOE regarding implementation of DOE requirements. Until the system whereby requirements are formulated, disseminated, and implemented is corrected, deficiencies will continue to exist with respect to incorporating changes in tritium facilities operations.

\section{Management of Tritium Residues}

\section{There has been an overall lack of attention to managing tritium residues throughout the DOE complex. This has resulted in materials being held that may contain recoverable quantities of tritium or that could be sources of tritium release to the environment.}

Tritium residues consist of material that may eventually be classified as waste tritium or scrap tritium, i.e., on molecular sieves, which may be worthwhile to recover. Three underlying causes were identified that discourage acceptable management of tritium residues. To effect a satisfactory residue management program, DOE must instill an appreciation of the value of tritium, develop a consistent disposition standard for evaluating residues for tritium recovery or burial as waste, and provide suitable shipping containers for moving tritium residues to DOE recovery sites.

\section{Value of Tritium}

Tritium is a resource whose replacement cost has significantly increased due to the shutdown of the production reactors and the projected cost of future production in the New Production Reactor. Therefore, this resource should be conservatively handled and recovered, where cost-effective. Although the dollar value of weapons-grade tritium is high and is expected to increase, there is a lack 
of appreciation and knowledge of the value of this material by those who manage tritium facilities and handle this radioisotope. In addition, DOE Program Secretarial Officials (PSOs) and contractor management are not emphasizing either the value of tritium or the need for its efficient use, recycling, and recovery.

The Task Group found that DOE line managers and contractor personnel managing tritium activities, or involved in its production, recycling, or recovery, were generally unaware of the increasing value of tritium. Among those who use it, tritium is most often viewed as a no-cost, government-provided material. The Task Group also found that the accepted norm for handling contained releases of tritium within process areas is to intentionally convert tritium to tritium oxide and treat it as waste, thereby forfeiting significant quantities of tritium-bearing material.

\section{Residue Recovery}

The Task Group did not attempt an exhaustive determination of the total quantity of tritium contained in residues throughout the DOE complex. However, it was evident that a substantial quantity of tritium residues exists, with very little emphasis placed upon its recovery or any potential environmental, safety, and health implications for its continued storage.

Residues containing significant quantities of tritium are not actively being evaluated for recovery and reuse. The Task Group observed the presence of tritium-bearing residues at several of the sites visited. In general, these materials are either being held with no immediate plans for disposition or, if plans exist, they are directed toward treating the materials as waste to be shipped for burial. At the Los Alamos National Laboratory, for example, more than 60 grams of tritium, as tritium oxide, are being held on molecular sieve materials that either have no planned disposition or are awaiting authorization to be shipped for burial as waste, and at the site's High Pressure Tritium Laboratory, approximately 140 grams of tritium residues are also being held with no immediate plans for disposition. At the Savannah River Site, a significant quantity of tritium gas is being held as part of the Reservoir Life Storage Program at the Materials Test Facility. Although the reservoirs containing this tritium were released from the program by the weapons design laboratories nearly 2 years ago, the tritium has not been recycled for reuse. Other process residues, such as gold traps that could contain substantial quantities of recoverable tritium, are being sent to mixed-waste storage without any recovery alternatives being evaluated. In addition, potentially recoverable quantities of tritium-bearing residues were observed at the Lawrence Livermore National Laboratory, Oak Ridge National Laboratory, and Sandia National Laboratories, Livermore. 
In addition to value concerns, tritium residues represent another potential source of release to the environment. Residue handling incidents in recent years have resulted in tritium releases and unnecessary exposures to personnel. These incidents involved operations with old tritium storage bottles and maintenance operations on systems containing tritium residues. Further, there is a potential for continued release of tritium to the environment from residues, as exemplified by the burial of gold traps at the Savannah River Site and the outgassing of tritium from contaminated facilities, equipment, and structures.

\section{Availability of Residue Shipping Containers}

The ability to recover tritium from residues is limited by the availability of approved shipping containers for their transport. The number of qualified shipping containers available to transport tritium residues, such as molecular sieve and other types of potentially recoverable materials, is inadequate. The only container approved for shipping tritium residues is the Lawrence Livermore National Laboratory Model UC-609, which was recertified for a 5-year period in November 1990 as meeting applicable Department of Transportation (DOT) and Nuclear Regulatory Commission (NRC) regulations. There are residues that have been stored for years that are currently confined in packages that are too large to be shipped in the UC-609. At the present time, due to a lack of policy requiring recovery of residues, there is no effort underway within DOE to design a larger container for shipping these residues. The timeframe to design, develop, qualify, and certify a new nuclear shipping package can be 2 to 3 years. Thus, the development and certification of shipping containers require immediate attention if DOE is to obtain near-term benefit of recovery and reuse of tritium that is now in various residue forms.

\section{Inconsistent Application of Requirements for Measurement of Tritium Effluents}

\section{Monitoring of tritium effluents for the purpose of personnel and public protection is inconsistent.}

Effluent monitoring of tritium sources is inconsistent within the DOE tritium complex. This leads to uncertainties in determining the actual amount and form of tritium released to the environment.

Different systems with varying sensitivities and capabilities are used to detect tritium gas and tritium oxide at effluent release points and stacks throughout the DOE complex. The Savannah River Site facilities provide for direct, real time determination of tritium gas and tritium oxide fractions, while most other facilities obtain this data only on a batch basis as infrequently as weekly. Because of the 
much more significant radiobiological effects of tritium oxide over tritium gas (by a factor of about 25,000), determination of the actual form is very important in establishing the radiation dose to the workers and the general public as a result of a release. If the form is unknown, the conservative approach is to assume that all of the tritium released is tritium oxide. When small amounts of tritium have been released, this conservatism has little consequence. However, when significant quantities of tritium are released, the assumption that the release is all in tritium oxide form, when in fact the release was perhaps all elemental, becomes overconservative, indicating a potentially significant consequence when such might not be the case. Such overconservatism has a further adverse effect if it engenders major facility modifications to mitigate releases without adequate cost-benefit analysis. This issue has not been uniformly addressed by the Department to date.

Some tritium facilities, for example, the tunnel portion of the Los Alamos Weapon Subsystems Laboratory, have no effluent monitoring systems on the stack. In this case, room monitors provide an indication of tritium presence, but they cannot quantify actual releases. In addition, custom monitoring systems in use do not comply with the design requirements of American National Standards Institute (ANSI) Standard N-323, "Radiation Protection Instrumentation and Calibrations."

\section{Interdependence of Tritium Facilities}

\section{The process of shutting down DOE tritium facilities does not always include an evaluation of the impact on other DOE tritium facilities, nor does it ensure that these facilities will be left in a safe configuration.}

Because there is a strong interdependence among the various DOE tritium facilities, those that are dependent upon a shutdown facility to provide services needed to maintain safe operation may be adversely impacted by the shutdown.

For example, when the Lawrence Livermore National Laboratory Tritium Facility was scaled down as part of the Laboratory's downsizing of operations, the Tritium Salt Facility at the Los Alamos National Laboratory was thought to be the only facility available to perform salt work in support of the Nevada Test Site. It was assumed that this facility could support the Test Site requirements; however, subsequent to the downsizing of the Livermore Tritium Facility, Los Alamos management decided to temporarily suspend operations of their Trit:um Salt Facility due to a tritium incident in April 1991. Thus, the Nevada Test Site requirements could not be met. Further, Los Alamos National Laboratory's Tritium Salt Facility could not perform certain operations that were required to 
support Nevada Test Site activities. In the process of shutting down both of these tritium facilities, support of the Test Site requirements by other facilities that may have the capability to perform salt work was not considered.

The Task Group found that neither DOE nor contractor facility and weapons design management fully understood, investigated, or determined the impact of recent decisions to downsize or shutdown tritium facility operations, and little consideration was given to the environmental, safety, and health implications for the complex as a whole.

Uncoordinated shutdown of tritium facilities has safety implications if the facility being shutdown is required to process tritium residues for recovery or disposal. In this case, those facilities that depend upon the facility that is to be shut down may be required to store these materials, even to build up a substantial quantity of residues, before some relief is available. This excess storage increases the potential for inadvertent releases of tritium.

\title{
Technical Communication among Facilities
}

\begin{abstract}
Important operational approaches, engineered systems for handling and confining tritium, and lessons learned have been developed at various DOE tritium facilities. However, these have not been consistently shared and applied across the DOE complex, nor has the development of new technologies for improved handling of tritium been emphasized.
\end{abstract}

Compartmentalization, particularly at the national laboratories, where competition for funds, sponsorship by different DOE line organizations, and the security requirements of tritium activities, has fostered insularity in the tritium community. There is no process within DOE to overcome this compartmentalization and encourage transfer of tritium engineering and operational technology to achieve improvements in the overall safety of operations complex-wide. Although informal exchanges occur among the various tritium facility sites, these exchanges have focused on specific technical or production issues; thus, they have not resulted in actual engineered safety system improvements being systematically incorporated into existing tritium facilities throughout the complex. The Task Group noted that there was an effort to incorporate more advanced, although not always state-of-the-art, confinement features from other DOE tritium facilities into both the Savannah River Site's new Replacement Tritium Facility and the Los Alamos National Laboratory's new Weapons Engineering Tritium Facility.

In April 1991, the concept of DOE facility focus groups for tritium, plutonium, and uranium contractors was proposed at the Defense Programs Management Meeting. As a result, focus groups have been created, which are to be directed toward achieving more consistency in goal setting, hazards analysis, risk 
assessment, operational initiatives, sharing of historical data bases, lessons learned from occurrences, and quality of vendor-supplied components. One key objective of the focus groups will be to foster the exchange of information and ideas, especially lessons learned and root cause determinations. These groups may provide a forum through which important tritium technology information can be shared and applied within the DOE tritium community.

\section{$* * *$ \\ IMPLICATIONS FOR NEW FACILITY DESIGN}

The DOE has the obligation to develop a consistent set of policies to govern its current tritium operations and to apply those policies to new facilities to reduce the release of tritium and mitigate impact on the health and safety of its workers, the generai public, and the environment. Specific guidance has not been developed and implemented to direct the design and construction of these facilities, and the policies on conduct of operations have not been stringently applied from the early design phases, so that available improvements may be realized.

\section{Incorporation of Confinement Technology into New Facilities}

\section{The latest tritium confinement technology and operational philosophies available at existing DOE facilities have not been thoroughly analyzed for possible application at new DOE tritium facilities.}

The Replacement Tritium Facility at the Savannah River Site and the Weapons Engineering Tritium Facility at the Los Alamos National Laboratory are two of DOE's newest tritium facilities that are nearing completion or operation. In reviewing the approaches to the design, operational philosophy, and confinement strategies to be applied at these facilities, the Task Group observed that little deliberate and rigorous examination of existing DOE tritium operations has been conducted to determine what operational features should be incorporated. Although there was cognizance of what other sites had employed in their confinement and operational philosophies; for example, the Tritium Systems Test Assembly at the Los Alamos National Laboratory and the Technical Building at Mound Plant both employ tertiary confinement systems; there was no evidence of a systematic examination of those existing philosophies to determine how and why they would or would not apply to these new facilities. The concept of tertiary confinement for incorporation into the Replacement Tritium Facility was rejected because of the added cost, yet there was no rigorous analysis performed to substantiate this decision. This overall approach to designing and developing operational philosophies for new DOE facilities lacks close scrutiny of existing DOE operations for lessons learned and use of successful technologies. 
Furthermore, it is typical of the way newer facilities have been developed and constructed in the past. The opportunity now exists, however, to incorporate the latest confinement and control strategies into new facilities during their design.

\section{Operations/Management Requirements for New Tritium Facilities}

\section{Strengthened policies for conduct of operations, protection, and training should be implemented at new tritium facilities to instill a strengthened operating philosophy.}

The startup of the Replacement Tritium Facility at the Savannah River Site and the Weapons Engineering Tritium Facility at Los Alamos National Laboratory provides an opportunity to instill a strengthened operating philosophy for tritium control from that found in the majority of DOE facilities. Better engineered confinement will not, by itself, mitigate against releases, many of which are due to poor practice or human error. Extensive training of workers in conduct of operations, radiological aspects, and tritium handling techniques must be followed up with attention to procedures implementation, safety documentation, and startup planning. Such steps will serve to increase awareness of the importance of maintaining tritium releases as-low-as-reasonably-achievable, which would be a starting point for fostering self-assessment and changes in existing operations at the site.

As a minimum, a Code of Good Practice for tritium operations must be completed and disseminated. Coupled with DOE 5480.19, this will establisil programmatic criteria where none exist and provide common goals and objectives for all DOE tritium operations. 


\section{SAFETY MANAGEMENT ISSUES AT DEPARTMENT OF ENERGY TRITIUM FACILITIES}

Prior to conducting onsite evaluations at the Department of Energy's (DOE's) tritium-handling facilities, the Task Group: (1) developed a list of the DOE facilities that handle, process, or store tritium; (2) collected and evaluated aata on tritium releases occurring at these facilities during the past 5 years; and (3) reviewed facility Tiger Team Assessment and Technical Safety Appraisal reports. The Task Group also reviewed relevant DOE Orders, Operational Safety Requirements (OSRs), and other documentation to judge the adequacy of existing standards and their implementation at DOE tritium-handling facilities. Not all DOE facilities involved in tritium activities were evaluated; only those that directly handle or store quantities greater than 1 gram of tritium. Facilities that release tritium as a byproduct of other operations, such as the Idaho Chemical Processing Plant (ICPP), were not included in the Task Group's endeavor.

The Task Group conducted onsite evaluations at the nine DOE sites listed below, using a bottom-up assessment that took into consideration existing facility practices, management awareness, and facility self-assessments.

- Lawrence Livermore National Laboratory

- Los Alamos National Laboratory

- Mound Plant

- Oak Ridge National Laboratory

- Pantex Plant

- Pinellas Plant

- Sandia National Laboratories, Livermore

- Savannah River Site, H-Area

- Savannah River Site, K-Reactor.

Several of the sites evaluated, notably Los Alamos National Laboratory (LANL), Mound Plant, Oak Ridge National Laboratory (ORNL), and the H-Area of the Savannah River Site (SRS), had more than one tritium facility. Of these, only the most noteworthy facilities (based upon tritium inventory, past or current utilization, and significant event history) were visited. 
This section provides a description of each tritium facility evaluated; a discussion of its recent operating history, including recent release information, occupational radiation exposures, typical tritium inventory, and a discussion of technical issues and related conclusions specific to the facility described. This material provides a foundation for the identification of generic issues and the development of the Group's principal findings and recommendations expressed in the Executive Summary. In addition, the Group evaluated certain tritium release events that occurred during its tenure. These events provided insight about facility conditions, management practices, and conduct of operations. Appendix D provides detailed summaries of these events in the form of memoranda to the cognizant Program Secretarial Officials (PSOs).

To validate observations and conclusions from the Task Group's site visits, tritium experts from many of the locations visited by the Task Group participated in a meeting at DOE Headquarters. As a result of this meeting, not only were Task Group observations validated, but input and perspectives from these experts were obtained. Input from these experts is reflected, where appropriate, in both the Generic Issues section of this report and in the following sections related to safety management issues at DOE tritium facilities. Specifically, these experts assisted in the identification of strategic issues and their implications for the DOE tritium community.

Appendix B provides more detail on the technical approach used by the Task Group to identify issues and develop recommendations. 


\section{Lawrence Livermore National Laboratony}

\section{Background and Facility Descriptions}

Lawrence Livermore National Laboratory (LLNL) is a major scientific research center operated by the University of California for the DOE. Established in 1952 for nuclear weapons research, today the Laboratory has some 7,600 employees and a physical plant consisting of 642 buildings with 4,900,000 square feet of working space.

Nuclear weapons work remains the cornerstone of Lawrence Livermure National Laboratory research, although this work has diversified on the basis of expertise gained from years of weapcns study. Current weapons research includes designing, developing, and testing weapons; assessing the reliability of weapons in the Nation's stockpile; and studying the feasibility of new weapons, including scenarios for their deployment. Two fusion energy research programs are being pursued, including Magnetic Fusion Energy, which uses a fusion reaction in superhot fuel (plasma) confined in a vacuum chamber by powerful, magnetic fields; and Laser Fusion, which uses a powerful laser to trigger a fusion reaction in the fuel.

The Lawrence Livermore National Laboratory Tritium Facility, Building 331, has operated since 1956 to provide research, development, and technical support for a variety of Lawrence Livermore National Laboratory programs, with the greatest emphasis on defense systems support under the management of the Chemistry and Materials Science Department. Work focuses on the use of hydrogen and its isotopes, nost notably tritium. In the recent past, the facility's typical tritium inventory was 200 to 235 grams. In the 1980 s, when the facility was designated a high hazard nuclear facility, it was authorized to maintain a tritium inventory of up to 300 grams.

A photograph of Building 331 is shown in Figure 5. The Radioactive Materials Area (RMA) was constructed in two increments, Increment I (south) in 1956, and Increment II (north) in 1962. Each increment has totally separate air supply and exhaust systems, including separate 30-meter stacks. Tritium handling has been carried out in both increments, with most Defense Programs work conducted in Increment II in recent years. Until recently, efforts in support of Defense Programs included:

- High-pressure gas fills

- $\operatorname{Li}(\mathrm{D}, \mathrm{T})$ syntnesis, forming, and packaging 
- Studies of $\mathrm{Li}(\mathrm{D}, \mathrm{T})$ swelling

- Historical monitoring of aged samples

- Beryllium hydride studies.

In September 1990, Laboratory management determined that continued support fo: the Lawrence Livermore National Laboratory Tritium Facility was not cost-effective. Management decided to reduce the tritium inventory and make the transition from a defense systems support facility to a research and development facility. Thus, the facility has been undergoing a downsizing effort, reducing tritium inventory from about 225 grams to under 5 grams. Upon reaching the 5-gram inventory goal, it was intended to divide the facility into two parts, the Hydrogen Research Facility (HRF) and the Light Isotope Monitoring Areas (LIMA).

The Hydrogen Research Facility was to be a research and development laboratory. In its final configuration, it was to occupy only the south increment of Building 331. These rooms were to house tritium work, the Physics Department Neutrino Experiment, the beryllium hydride work, and any new experiment that may become part of the Hydrogen Research Facility. The Hydrogen Research Facility was also to include Rooms 1210 and 1215 of the Vacuum Effluent Recovery System (VERS) Building for waste packaging and handling; the Building 331 office area; the mechanical and electronic shops in Room 127; and the yard outside Building 331, but inside the building fence. However, Laboratory management has indicated that it is highly unlikely that the Hydrogen Research Facility will be constructed.

All other parts of the north increment, Rooms 1200 and 1200A of the Vacuum Effluent Recovery System Building, and the storage yard outside of the superblock, will become the Light Isotope Monitoring Areas. The rooms in Light Isotope Monitoring Areas will be left in a decontaminated state for future use by others at Lawrence Livermore National Laboratory.

\section{Recent Operating History}

The Lawrence Livermore National Laboratory does not generally use systems that provide double or triple confinement to mitigate tritium losses to the atmosphere. Most of the experimental work has been carried out in fume hoods. Tritium salt work, however, is carried out in a glovebox with an inert gas atmosphere and a glovebox atmosphere cleanup system. The salt material is processed within a single confinement. A new glovebox system, which would have provided double 


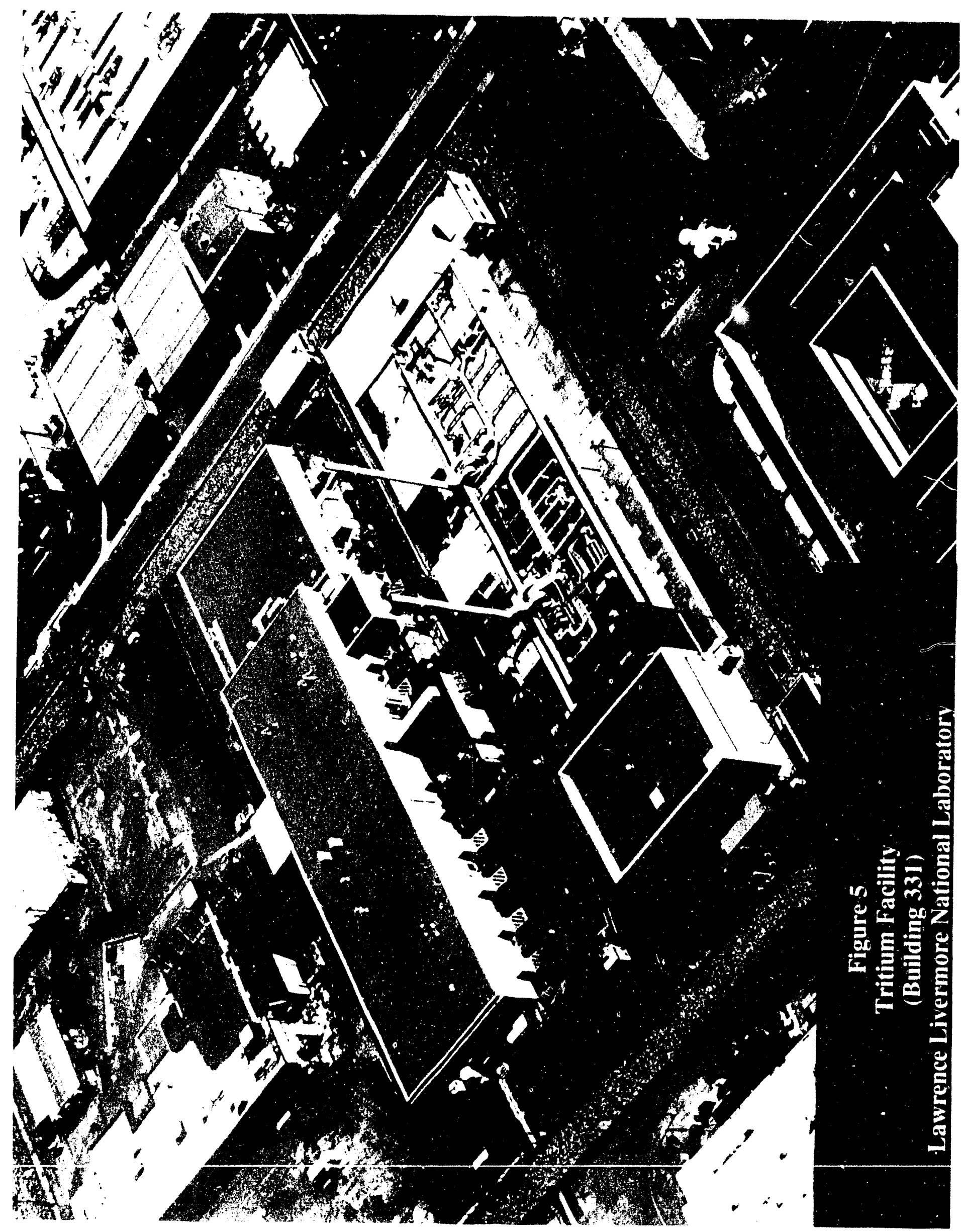


confinement and glovebox atmospheric cleanup, was to be installed. Installation was suspended, however, due to the decision to downsize and shift away from Defense Programs support. Data on tritium environmental emissions, occupational dose due to tritium, and average tritium inventory for the fiscal years 1986 to 1990, inclusive, are provided in Table 1.

The Lawrence Livermore staff uses a conservative philosophy to estimate offsite doses that result from nonroutine tritium releases. Preliminary offsite dose calculations for such releases are based on the assumption that all of the tritium released is in the oxide form, which has a significantly greater biological effect than the elemental form of tritium. However, offsite dose calculations for routine tritium emissions are based on the actual, measured amount of tritium gas and oxide that is released.

TABLE 1 Tritium Stack Emissions and Liquid Effluent Releases, Collective Occupational Doses, and the Average Tritium Inventory at Lawrence Livermore National Laboratory for Fiscal Years 1986 to 1990

\begin{tabular}{|c|c|c|c|c|c|}
\hline & FY 1986 & FY 1987 & FY 1988 & FY 1989 & FY 1990 \\
\hline $\begin{array}{l}\text { Stack and Liquid } \\
\text { Effluent Emissions (Ci) }\end{array}$ & 1,128 & 2,634 & 3,978 & 2,949 & 1,283 \\
\hline $\begin{array}{l}\text { Occupational Dose } \\
\text { (person-rem) }\end{array}$ & 0.281 & 0.974 & 1.34 & 0.824 & 0.468 \\
\hline $\begin{array}{l}\text { Average Tritium } \\
\text { Inventory (grams) }\end{array}$ & 218 & 218 & 218 & 218 & 218 \\
\hline
\end{tabular}

"Estimate of typical inventory in grams.

Table 2 shows the distribution of occupational doses resulting from tritium exposure for the calendar years 1986 to 1990 , inclusive. These doses have been stratified to show the number of individuals receiving doses within the indicated range. These exposures, while a fraction of the allowable annual dose for workers, indicate that as-low-as-as-reasonably-achievable (ALARA) considerations are important to minimizing unnecessary worker exposure. The distribution of doses is typical when compared with the across-the-complex averages for tritium workers.

The Lawrence Livermore National Laboratory conducts an environmental monitoring program to assess the presence of tritium in the environment that results from Laboratory operations. Comprehensive data collected for fiscal year 1989 indicate that measured offsite tritiun! concentrations in the atmosphere, water, vegetation, and foodstuffs were well below standards established by DOE 
and standards adopted by the State of California. For example, the highest concentration of tritium in air measured in the sampling program was $9.6 \times 10^{-11}$ microcuries per milliliter, which represents 0.1 percent of the DOE allowable concentration.

TABLE 2 Distribution of Occupational Doses Due to Tritium at Lawrence Livermore National Laboratory for Calendar Years 1986 to 1990

\begin{tabular}{|c|c|c|c|c|c|}
\hline \multirow[b]{2}{*}{ Year } & \multirow{2}{*}{$\begin{array}{c}\text { Total Number } \\
\text { of Workers } \\
\text { Monitored }\end{array}$} & \multicolumn{4}{|c|}{$\begin{array}{c}\text { Number of Workers Receiving Arnual Dose within } \\
\text { Indicated Range }\end{array}$} \\
\hline & & $\begin{array}{l}<10 \\
(\text { mrem) }\end{array}$ & $\begin{array}{l}10-100 \\
(\text { mrem) }\end{array}$ & $\begin{array}{l}101-500 \\
(\text { mrem })\end{array}$ & $\begin{array}{c}>500 \\
(\text { mrem })\end{array}$ \\
\hline 1986 & * & $*$ & $*$ & 0 & 0 \\
\hline 1987 & $51^{\mathrm{a}}$ & 39 & 8 & 4 & 0 \\
\hline 1988 & $96^{b}$ & 79 & 13 & 4 & 0 \\
\hline 1989 & $146^{\mathrm{c}}$ & 138 & 7 & 1 & 0 \\
\hline 1990 & $196^{\mathrm{c}}$ & 184 & 11 & 1 & 0 \\
\hline
\end{tabular}

* Data for 1986 are not readily available. The total collective dose for the facility in 1986 was 0.28 person-rem. The highest individual dose was 54 millirem.

The annual average concentration of tritium in sanitary sewer effluents was $3.5 \mathrm{x}$ $10^{-11}$ microcuries per milliliter, which is approximately 0.04 percent of the DOE annualized limit. Runoff from two rain storms sampled for tritium in 1989 showed higher than usual tritium levels at four of six monitoring locations, with the highest measured value as $57.4 \times 10^{-11}$ microcuries per milliliter. These measurements remain under investigation. Water samples from wells in the vicinity of the water treatment facility were found to be at normal background tritium levels, and well below drinking water limits. Samples of retail wines produced from grapes grown in the Livermore Valley were compared with samples from grapes grown in other locations in California and in Europe. In 1989, the mean Livermore Valley wine tritium content was greater than both the European and Californian mean tritium content. However, the measured levels had not increased over levels measured in prior years. The tritium concentrations in European wines, which were higher that those of Livermore in previous years, have decreased to approximately the same levels as livermore wines over the past 10 years. The net effect of tritium releases to the general population and to the individuals near the site can be considered inconsequential. 


\section{Technical Review and Conclusions}

Two issues were identified at the Lawrence Livermore National Laboratory that have the potential to affect tritium operations and releases. A discussion of the conclusions drawn by the Task Group regarding these issues follows.

\section{CONDUCT OF OPERATIONS}

Conclusion: Neither the DOE nor contractor management maintained proper control of the downsizing of the Lawrence Livermore National Laboratory Tritium Facility (Building B-331) while effecting an inventory reduction from about 225 grams of tritium to less than 5 grams. This failure to control tritium operations led directly to the accidental release of tritium on April 2, 1991, and the resultant radiation exposure of facility personnel.

A downsizing operation to reduce the inventory of tritium in Building 331 to less than 5 grams, consistent with a change in the Laboratory's mission to move away from weapons program support and toward research and development support, was begun in September 1990. The downsizing had the expected attendant advantage of decreasing budget costs due to the need for less stringent safety measures tied to a change in the hazard classification from a high rating to a lower one. Lawrence Livermore National Laboratory management control of safety in the downsizing process was found to be lacking, based upon interviews with facility personnel and a review of facility documents. Independent safety oversight for the facility was also compromised by expediting the facility downsizing effort. This concern was recognized by both facility management and DOE San Francisco Field Office (DOE/SAN) management.

Lawrence Livermore National Laboratory management failed to comply with several issues that the DOE San Francisco Field Office had identified as actions to be accomplished prior to downsizing. The failure of Lawrence Livermore National Laboratory management to accomplish these actions, and the failure of the San Francisco Field Office to require them led to the loss of control of the downsizing process. Because of a concern that the lack of planning and speed of the downsizing process might result in an incident, facility department management arranged for an independent review of the facility operations. However, facility management responses to the independent review group report (December 1990), which was critical of the circumstances, were superficial. 'This indicated a lack of recognition of the seriousness of the issues that had been identified by the reviewers. Laboratory management failed to require facility management to take ownership of the review and implement its recommendations. 
Lawrence Livermore National Laboratory management had not recognized the importance of performing a formal, timely hazards analysis as part of the downsizing process prior to proceeding with the effort. They had accepted what is now recognized as an incorrect premise that the nonroutine operations associated with the downsizing were within the normal operations parameters, or safety envelope. It appeared that the management had prematurely accepted a level of conduct of operations commensurate with an already downsized operation rather than for the higher levels still being conducted. This was evidenced by calibration dates having expired on portable tritium monitoring instruments, and some calibration stickers on some hoods not being signed. Also, the ventilation balancing had been neglected, and several rooms had no negative pressure relative to the hallway. The overall housekeeping in the facility indicated a lack of health and safety oversight. The presence of large numbers of tritiumcontaminated items in routine workplaces was not in keeping with responsible health and safety work policies and practices.

During the period of the Task Group reviews, an incident occurred, which is summarized to demonstrate the concern over Lawrence Livermore National Laboratory Tritium Facility conduct of operations and management's failure to control the downsizing process. On April 2, 1991, a tritium operator was in Building 331 preparing a 1968-vintage pressure vessel (that was labelled as containing tritium-contaminated helium) for pressure characterization of its contents. It was known that pre-1970 vintage pressure vessels had problems with radiation-damaged elastomer seals, and while most seals were replaced with metal, any pre-1970 vintage vessel was suspect (especially one with questionable pedigree withdrawn from long-term storage in the facility's vault). This was the last of 12 aged cylinders to be processed before shipment. Evaluation of such vessels was a part of the downsizing operation for Lawrence Livermore National Laboratory's Tritium Facility. Work was being performed in a tritium-approved fume hood. The procedure used for this operation did not provide adequate guidance for the operator, given the known hazards associated with the valves for the pre-1970 cylinders.

During the evaluation, the valve on the vessel was closed. When the operator loosened the plug located downstream from the valve, the contents of the vessel leaked through the faulty valve into the hood and room, and out the facility stack. (The room air is exhausted through the hood to the stack.) Both the portable tritium monitor next to the hood and the room monitor alarmed, alerting the operator to the release of tritium-contaminated helium. The operator attempted to stop the leak, but was unable to do so. He and the remainder of the facility staff evacuated the Radioactive Materials Area according to facility procedures. After the radiation level in the room began to drop, the operator and three other workers reentered the room to stop what was perceived to be a continuing release. Reentry was based on the assumption that there was no oxide associated 
with the release and due to an erroneous interpretation of the stack monitor strip chart. The vessel was bagged and moved to a tritium-approved maintenance glovebox to contain any further releases. It is important to note that this reentry action was apparently motivated by a strong desire to avoid any further environmental release and related publicity. Concern for worker safety was not adequately considered in the decision to reenter the room.

As a further indication of the concern over conduct of operations, it was observed that there has not been a formal, systematic approach to developing and using procedures at Lawrence Livermore National Laboratory. Tritium Facility (Building 331) procedures are deliberately flexible to allow for operator discretion; therefore, they foster an overly informal approach to conduct of operations. There is heavy reliance on operators to make important decisions related to performing tritium-related operations. The principle of procedural flexibility invoked by facility management does not provide for adequate review of important tritium handling activities that may result in a potentially hazardous situation.

\title{
FAILURE TO APPRECIATE POTENTIAL FOR EXISTENCE OF OXIDE FORM OF TRITIUM
}

\begin{abstract}
Conclusion: A mindset existed among the tritium facility personnel that the oxide form of tritium would not or could not be encountered during the inventory downsizing operations. This mindset had a direct impact on the conduct of operations and recovery during the event of April 2, 1991.
\end{abstract}

Because the facility utilized dry tritium gas for its operations, facility personnel mistakenly adopted the belief that the presence of tritium oxide within the facility was extremely unlikely. The gas only mindset of facility personnel, which was reflected in facility procedures, contributed significantly to the inadequate health and safety response (notably the reentry of personnel) to the event of April 2, 1991. In addition, after the release, the downward trend in the tritium level indicated by monitoring instruments was not that expected from tritium gas, but more indicative of the presence of the oxide form. The anomalous decline was noted by ine facility staff in their reentry consideration, but not correctly interpreted. The reentry was not coordinated with radiation protection professionals, and indicates a lack of discipline in the management of off-normal incidents. Further, the reentry was made without adequate consideration of the health and safety of facility personnel in an effort to mitigate an atmospheric release. The primary operator received a dose equivalent of $1.1 \mathrm{rem}$ from the initial release, and the dose equivalent to each of the other three exposed workers involved in the reentry was estimated to be 10 to 20 millirem, based on standard 
assumptions regarding tritium uptake and the results of bioassay samples.

Approximately 144 curies of tritium were released to the atmosphere through the exhaust stack. Tritium was not observed offsite, and the calculated site boundary dose was negligible. 


\section{Los Alamos National Laboratory}

\section{Background and Facility Descriptions}

Los Alamos National Laboratory is located in Los Alamos, New Mexico. The Laboratory is operated by the University of California, and receives its direction from the Los Alamos Field Office, which reports to the DOE Albuquerque Field Office. Since its inception in 1943, the Laboratory's primary mission has been nuclear weapons research and development. Today, the Laboratory employs approximately 7,500 people working in 32 technical areas. Laboratory programs include weapons development, magnetic and inertial fusion, nuclear fission, nuclear safeguards and security, and laser isotope separation. Basic research that supports the Office of Defense Programs includes activities in the areas of physics, chemistry, and engineering.

Tritium-related activities at the Los Alamos National Laboratory encompass nuclear weapons component evaluation and development, fusion fuel handling and processing development, and many other research and development programs for a variety of customers. These activities are conducted in eight facilities, six of which were visited by the Task Group.

Weapons Engineering Tritium Facility

The Weapons Engineering Tritium Facility (WETF) is located at Technical Area 16 (TA-16), adjacent to the weapons engineering complex. This facility was completed in 1991, and its design meets all of the safety standards required under DOE 5480.1B, "Environment Safety and Health Program for Department of Energy Operation." Figure 6 presents an artist's concept of the Weapons Engineering Tritium Facility. The services provided by the facility include: repackaging tritium into smaller quantities; repackaging tritium and other gases to higher pressures; removing helium; mixing tritium with other gases; and analyzing gaseous tritium. The Weapons Engineering Tritium Facility also conducts handling and repackaging of scrap tritium for recovery or disposal.

The following subsystems, which were designed to enhance the safety of Weapons Engineering Test Facility operations, include redundancies of critical components: (1) a Tritium Gas Handling Subsystem (TGHS), which is located in the process room; (2) a Tritium Gas Confinement Subsystem (TGCS), consisting of glovebox sections, that confines any tritium escaping from the Tritium Gas Handling Subsystem and minimizes exposure of operating personnel to tritium; (3) a Tritium Waste Treatment Subsystem (TWTS) that processes the Tritium Gas Confinement Subsystem exhaust to extract tritium for either recovery or disposal; 


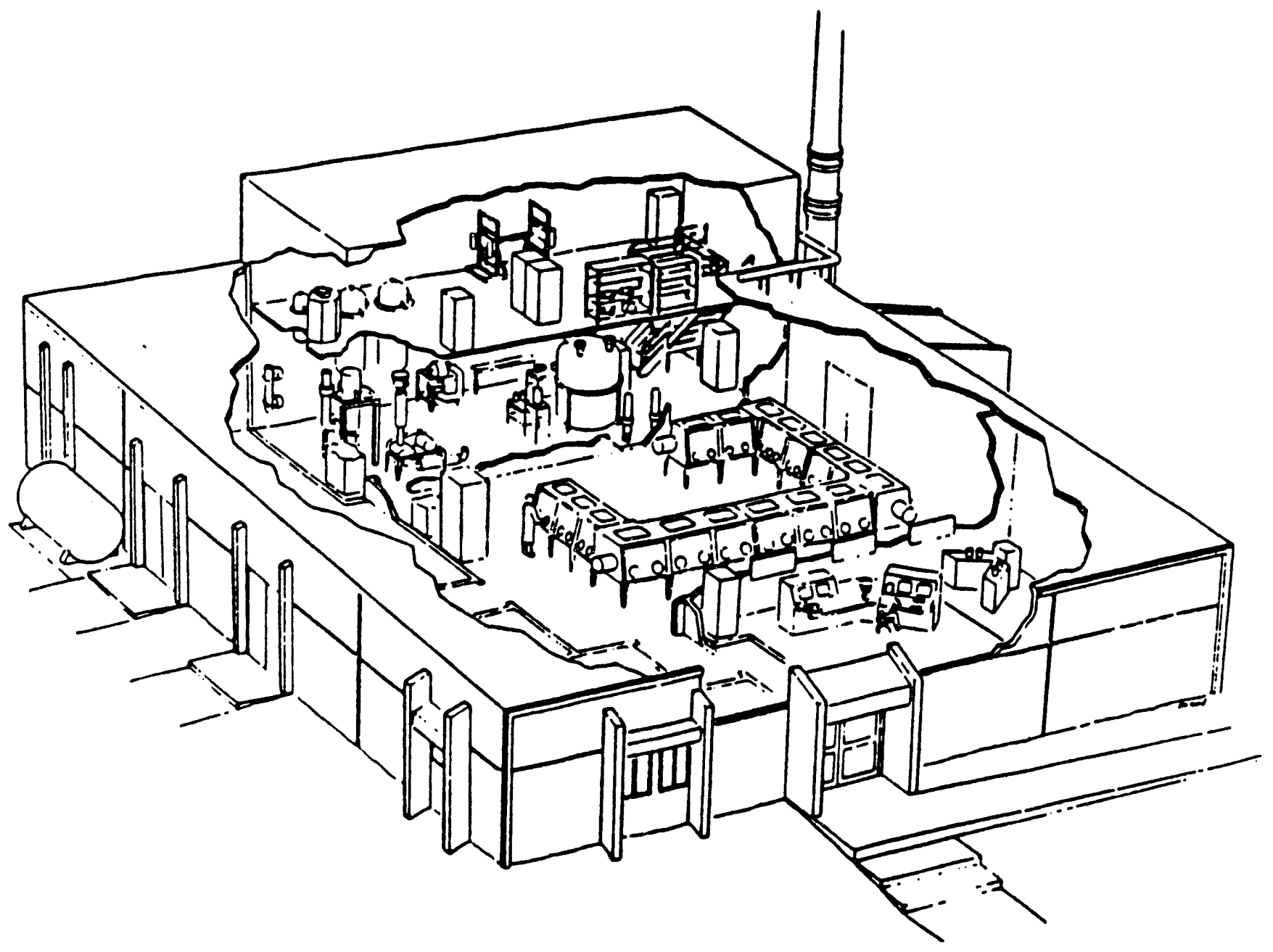

Figure 6 Artist's Concept of the Weapons Engineering Tritium Facility (Technical Area 16) - Los Alamos National Laboratory 
(4) an Emergency Tritium Cleanup (ETC) Subsystem that processes tritium releases to the process or recovery rooms that might result from an accident or Photo Weapon Engineering Tritium Facility (TA-16) other unintentional release; and (5) the Instrumentation and Control System (ICS) that provides the facility operator with real-time data, alarms, and control of process variables. The projected annual release from the Weapons Engineering Tritium Facility is less than 400 curies per year, with the maximum annual dose received by any individual of the public less than 0.1 millirem.

\section{Tritium Salt Facility}

The Tritium Salt Facility (TSF), Technical Area 21 (TA-21), was built in the early 1970s. Room 179 at Technical Area 21 consists of a large, dry glovebox system. This system is connected to a dry-train that maintains an inert atmosphere inside the glovebox. Both the glovebox and the dry-train are connected to an Effluent Treatment System (ETS), which is designed to remove tritium from glovebox effluents prior to their release to the environment. The glovebox is maintained at a slightly positive pressure, 0.5 inches of water, via two photohelic gauges that control the addition of fresh helium or removal of excess glovebox gas to the Effluent Treatment System. An oil bubbler is provided to protect the glovebox and dry-train from excessive pressures (plus or minus 5.6 inches of water) in the event the photohelic system fails. The bubbler leads directly to the stack. The glovebox is designed for handling highly reactive metal tritides, in particular, $\mathrm{Li}(\mathrm{D}, \mathrm{T})$ salt.

The Effluent Treatment System is an integral part of the Tritium Salt Facility. All components except the low-pressure receiver are redundant. Virtually every component of the Effluent Treatment System can be isolated by valves, and evacuated and back-filled with dry helium. All effluents produced by vacuum systems within the Tritium Salt Facility, as well as all purge gases used for regeneration of drying towers, are processed by the Effluent Treatment System prior to their release to the atmosphere. The Effluent Treatment System is designed to reduce tritium levels in the effluent stream to about 1 part per billion. The Effluent Treatment System does not continuously process gas, but operates intermittently, as needed. All stack gas is continuously monitored, and activity levels are recorded on a sîip chart recorder.

\section{Tritium Systems Test Assembly}

The Tritium Systems Test Assembly (TSTA), Technical Area (TA-21), is designed to model, in full scale, the deuterium-tritium fuel cycle of future fusion reactors. The Tritium Systems Test Assembly, built and completed in the early 1980s, consists of a number of systems arranged in a closed loop to simulate the reactor torus and its associated gas pumping, fuel processing, and reinjection systems. 
At the Tritium Systems Test Assembly Facility, all of the components of this process loop, as well as the interconnecting piping, are confined in gloveboxes or some other type of secondary confinement system.

Tritium releases into gloveboxes or secondary piping are removed by the Tritium Waste Treatment System. This system also removes tritium from vacuum pump effluents and purge gases used to clear out residue tritium from process lines and small experiments. Releases into the experimental cell or the two, small tritium laboratories can be processed by the Emergency Tritium Cleanup (ETC) system. The building acts as the third and final barrier to prevent tritium releases to the environment. Tritium is the predominant radioactive material handled at the Tritium Systems Test Assembly Facility. Other radioactive materials include small barium and cesium instrument check sources and depleted uranium. The Tritium Systems Test Assembly is a computer controlled and monitored system: alarms are sounded and recorded by the MDAC computer system, and automatic actions are initiated by the computer software to mitigate the effect of system failure or abnormal conditions.

\section{High Pressure Tritium Laboratory}

The High Pressure Tritium Laboratory Building (HPTL), Technical Area 33 (TA-33), was built in the early 1950s to provide weapons production support and to conduct some of the tritium-related research performed in support of the Nuclear Weapons Program. The laboratory has been replaced by the Weapons Engineering Tritium Facility, and preparations are being made to decommission and disassemble this facility. All tritium transfer operations are performed in a process room ventilated by single-pass air leading to a monitored stack. This room currently confines most of the tritium inventory. Smaller inventories of tritium are stored in approved containers inside other rooms. Tritium gas will be shipped to Technical Area 41 (TA-41) for storage and later use at the Weapons Engineering Tritium Facility. Impure gas will be shipped to the Savannah River Site for recovery. It is planned that the scrap tritiated water currently stored on molecular sieves will be repackaged in a means suitable for shipment to Mound for recovery and that tritiated waste water that is not economically recoverable will be disposed of when the calorimeter required for assay is available.

In the process room, tritium is confined by the gas-handling system, which consists of tubing, vacuum pumps, and valves. There are no gloveboxes, only exhaust hoods. The concrete walls provide secondary confinement. Tritium that passes through the vacuum pumps following a tritium transfer operation is oxidized to water and adsorbed on a molecular sieve. Air from the hoods and the room is exhausted through the building stack. 


\section{Target Fabrication Facility}

The Target Fabrication Facility (TFF), Technical Area 35 (TA-35), was built in 1982 to supply hardware for a number of programs, including the Inertial Confinement Fusion (ICF) Program (plus the Centurion Program), the Nuclear Weapons Program, the Pulsed Power and Pulse Beam Fusion Acceleration (PBFA) Program, the Advanced Concepts Program, and Special Projects for the Intelligence Agencies. The Target Fabrication Facility began operations in 1983. Originally, Target Fabrication Facility operations included machining, assembling, and inspecting tritium-filled parts. (The tritium gas-filled parts were filled elsewhere in the Laboratory to high pressure.) The limit for tritium inventories inside the Target Fabrication Facility is 2 grams (20,000 curies), vith only 1 gram of tritium to be capable of release at any one time. Prior to 1988, the tritiumfilled parts typically contained 130 milligrams of tritium. Since 1988, none of the traditional machining or assembling operations on tritium-filled parts has been performed in this facility; currently, there are less than 400 curies of tritium in inventory. This tritium is used for research on solid fusion fuel, and experimental activities associated with this research are conducted inside a tritium-approved hood. The experimental cell is instrumented for temperature and quadrupally confined.

A glovebox in Room D-17 is used for high-pressure filling operations of small quantities of tritium. The glovebox is connected to a complete cleanup system, the design, construction, and operation of which are similar to those in the Weapons Engineering Tritium Facility. The cleanup system has the capacity for the 2-gram tritium limit at the Target Fabrication Facility. To date, no tritium has been introduced into this glovebox or the cleanup system.

\section{Weapon Subsystems Laboratory}

The Weapon Subsystems Laboratory (WSL), Technical Area 41 (TA-41), is located in Buildings W-1 and W-4. Building W-4 is divided into an office area and an experimental wing behind the office wing. Building W-4, along with Building W-1, the tunnel (including the main vault), are called the "Ice House." Approximately 10 people work at the Ice House, which was built in 1951. In 1959, an annex to the experimental area was added to the building, which now houses the gas mass-spectrometry laboratory and the high-pressure gas test cells and control room. The activities within the Weapon Subsystems Laboratory are directed at weapons development and engineering studies.

Tritium operations at TA-41 are conducted inside California-type hoods in laboratories that are provided with single-pass air. Experiments are conducted in secondary containers within the hoods, and cleanup following experiments is conducted by expansion into evacuated volumes (typically, LP50 containers). 
These containers were formerly shipped to the High Pressure Tritium Laboratory for recovery or disposal; the Weapons Engineering Tritium Facility will provide this service in the future. Residual tritium from the experiments and massspectrometer operations is stacked.

\section{Recent Operating History}

Tritium stack emissions and liquid effluent releases from the Los Alamos National Laboratory are shown in Table 3. Those facilities with modern tritium confinement systems, such as the Tritium Systems Test Assembly, have relatively modest releases when compared to the older facilities such as the High Pressure Tritium Laboratory and the Weapon Subsystems Laboratory. The importance of these modern confinement systems is illustrated by two examples. On February 1, 1991, an operator in the Weapon Subsystems Laboratory accidentally opened a valve, and 2,900 curies of tritium were released to the stack. On May 6, 1990, an operator vented a leaking container, which resulted in the release of 1,960 curies to the stack at the same facility. If the Weapon Subsystems Laboratory facility, had secondary confinement (gloveboxes with atmospheric cleanup), these releases would most likely have been confined inside the facility, and the tritium would have been recovered, thereby preventing a release to the environment.

Occupational exposures from tritium at Los Alamos National Laboratory have historically been low. Table 4 shows the distribution of individuals receiving doses within indicated dose ranges. These exposures are a small fraction of the allowable annual dose for workers, and are typical when compared with the across-the-complex average for tritium workers. However, the number of workers with doses exceeding 100 millirem is higher than the DOE average for tritium workers.

Los Alamos uses a conservative philosophy in calculating offsite doses resulting from tritium releases. These calculations are based on the assumption that all tritium released is in the oxide form, unless data exist to prove otherwise. Onsite and offsite environmental monitoring array sample for tritium, and provide data on release quantities used to calcula 2 doses. 
TABLE 3 Tritium Stack Emissions and Liquid Effluent Releases at Los Alamos National Laboratory for Fiscal Years 1988 to 1990

\section{Facility}

Weapons Engineering Tritium

Facility (WETF) TA-16

Tritium Systems Test

Assembly (TSTA) TA-21

Tritium Salt Facility (TSF)

TA-21

High Pressure Tritium

Laboratory (HPTL)

TA-33

Weapon Subsystems Laboratory

(WSL) TA-41

Ion Beam Facility (IBF) TA-3

Target Fabrication Facility

(TFF; TA-35

Special Recovery Line

(SRL) TA-55

TOTAL RELEASES (Ci):

Not operational during period.

" Special cleanup/operation of another DOE facility accounted for most of this release.

1,777
FY 1988

0

42

118

$\$ 13$

422

7,960

854

1,730

$11,160^{* *}$

4,440

390

290

494

118

18

$<1$

314

265

166

18,672

13,964

6,393 
TABLE 4 Distribution of Occupational Doses Due to Tritium at Los Alamos National Laboratory for Calendar Years 1986 to 1990

\begin{tabular}{lccccc}
\hline & $\begin{array}{c}\text { Total Number } \\
\text { of Workers } \\
\text { Monitored }\end{array}$ & \multicolumn{5}{c}{$\begin{array}{c}\text { Number of Workers Receiving Annual Dose within } \\
\text { Indicated Range }\end{array}$} \\
\cline { 3 - 6 } Year & & $\begin{array}{c}<10 \\
(\mathrm{mrem})\end{array}$ & $\begin{array}{c}10-100 \\
(\mathrm{mrem})\end{array}$ & $\begin{array}{c}101-500 \\
(\mathrm{mrem})\end{array}$ & $\begin{array}{c}>500 \\
(\mathrm{mrem})\end{array}$ \\
\hline 1986 & 64 & 51 & 9 & 3 & 1 \\
1987 & 83 & 62 & 12 & 7 & 2 \\
1988 & 98 & 82 & 12 & 1 & 3 \\
1989 & 99 & 80 & 15 & 4 & 0 \\
1990 & 102 & 91 & 8 & 2 & $1^{*}$ \\
\hline
\end{tabular}

- Includes one 1,346-mrem accidental exposure

Technical Review and Conclusions

Four issues were identified at the Los Alamos National Laboratory that have the potential to affect tritium operations and releases. A discussion of the conclusions drawn by the Task Group regarding these issues follows.

\section{MANAGEMENT OF OPERATIONS}

Conchusion: Inadequate integration of tritum facilities management by DOE program offices and Los Alamos National Laboratory has contributed to deficiencies in their operation and to releases of tritum.

The Task Group identified no institutionalized approach or process for the conduct of tritium facility operations at the Los Alamos National Laboratory. Each associate director responsible for a particular tritium operation uses a different organization and management approach, and has generally dealt with problems and issues on an ad-hoc, case-by-case, reactive-versus-proactive basis. The Associate Director for Nuclear Weapons Technology, for example, recently established an Operational Surety Office to assist in fulfilling environmental, safety, and health objectives. This office supports the Director by providing 
environmental, safety and health compliance guidance, performing selfassessments, and achieving greater formality of operations. In contrast, the Associate Director for Chemistry and Materials relies upon an advisory committee comprised of Environmental, Safety, and Health (ES\&H) Division staff and other technical representatives. The scope of this committee is focused primarily on the identification of environmental, safety, and health issues, not on operating issues.

It is clear that Los Alamos National Laboratory management has recognized inconsistent ES\&H initiatives as a deficiency Laboratory-wide, not just as it affects tritium facilities. Several months ago, an ES\&H task group was established to develop recommendations for formalizing and institutionalizing ES\&H initiatives and for achieving greater consistency and uniformity in facility operations.

Results are not yet complete, but a review of the task group efforts indicates that a comprehensive approach is being taken that could have a significant, positive impact on the ability of Los Alamos National Laboratory to meet ES\&H objectives.

The Task Group found no evidence that a formal management process or integrated approach exists for reviewing, prioritizing, and making decisions regarding allocation of resources for facility maintenance, facility upgrades, and the preparation of safety documentation and operating procedures. Without a more systematic approach, it is possible that needed upgrades (e.g., for systems affecting safety) will not be given sufficient priority in the initial bottom-up, internal budgeting process or will not be raised to the attention of higher management. This occurred at the Target Fabrication Facility, where a reduction in maintenance funds resulted in the inability to maintain certain Laboratory spaces (tritium, beryllium, thallium areas) at the required level of cleanliness, and at the Tritium Salt Facility, where needed safety upgrades have not been accomplished.

Many examples of inconsistent facility design and operation were identified. These inconsistencies are the result, at least in part, of decentralized facility management, varying experience and background of cognizant personnel, and conflicting facility missions. Inconsistencies include different approaches relative to process design features, documentation, tritium monitoring systems, and emergency power. These inconsistencies are not detrimental in and of themselves, but they can lead to a more complicated and costly system of management and management overview.

Overall, utilization of tritium facilities has not been optimized. It is possible that consideration of future facility needs could result in fewer facilities and attendant cost reductions. This could be attained by eliminating multiple sets of safety documents and procedures, reducing the number of management teams, and reducing requirements for ES\&H Division support and maintenance. 
Los Alamos National Laboratory management is faced with the additional problem of aging facilities, such as the High Pressure Tritium Laboratory and the Weapon Subsystems Laborato.y, which, from the standpoint of design, cannot mitigate environmental releases. The High Pressure 'Tritium Laboratory is not currently in operation, but is a source of environmental release due to its aged equipment: a single pass exhaust system; an open floor drain that discharges outside the fenceline that surrounds the facility; and, an overall tritium inventory of approximately 140 grams, which is contained in equipment and on molecular sieves. It is apparent that, while it was still operating, the High Pressure Tritium Laboratory was not being given sufficient attention to assure that it was operating with necessary safety and environmental protection systems.

One root cause of the inadequate integration of management of these tritium facilities is that they operate under different DOE program offices. For example, the Weapon Subsystems Laboratory, High Pressure Tritium Laboratory, Target Fabrication Facility, Tritium Salt Facility, and Weapons Engineering Tritium Facility are the responsibility of the Office of Defense Programs; the Tritium Systems Test Assembly is operated in support of the Office of Energy Research (ER). These two program offices have different funding priorities and program objectives, which may be counterproductive to integrated management.

Conflicting programmatic demands and funding priorities within the same tritium facility have resulted in an unnecessary persolinel exposure incident and in the suspension of operations. Reallocation of funding to provide the needed upgrades to return the facility to operational status was based on programmatic demands rather than on a proactive management approach. Such an approach should be based on identifying and correcting deficiencies before they result in environmental releases or personnel exposure.

As expected, due to the wide range of ages, there is variation in the design of tritium facilities at the Laboratory. This has led to differences in the potential for tritium releases, as can be seen from the following examples.

- The Tritium Systems Test Assembly facility has an experimental room cleanup system that can be manually activated should there be a large tritium release into the room, but the Tritium Salt Facility does not. All room releases in the Tritium Salt Facility are collected by a fume hood that exhausts to the environment.

- The Weapons Engineering Tritium Facility is a modern facility using the latest technology for tritium confinement, while the Weapon Subsystems Laboratory uses fume hoods that exhaust directly to the stack. The High Pressure Tritium Laboratory, which is now shut down, uses exhaust hoods with even less worker protection than the fume hoods found in the 
Weapon Subsystems Laboratory. In both instances, these facility designs have contributed directly to increased tritium emissions at Los Alamos National Laboratory.

- Emergency power is provided for ventilation systems at the Tritium Systems Test Assembly and Weapons Engineering Tritium Facility, but not at the Tritium Salt Facility or the Weapon Subsystems Laboratory. A loss of power at these facilities results in loss of the ventilation system. This could lead to airborne tritium in the Laboratory spaces that would pose an exposure threat to workers in those buildings. In fact, a loss of power event occurred during the week of May 6, 1991. While this event did not result in worker exposure, it did point out generic implications for the Labolatory involving issues related to backup power, automatic restart, alarms, and notification procedures.

No lessons learned program is being applied across the various tritium facilities at Los Alamos National Laboratory, nor is useful information that could be used to reduce exposures and environmental releases being distributed. Evaluations of off-normal, nonreportable events are documented at the Tritium Systems Test Assembly, but are not distributed to other facilities. The managers at these facilities do not adequately communicate with each other concerning design, operation, and administrative problems, such as those associated with Safety Analysis Reports (SARs) and operating procedures. There is a need for management to review the potential for consolidation of tritium facilities and explore ways to improve operations with respect to safety and efficiency. It is incumbent upon both Los Alamos National Laboratory and DOE to work closely, so that appropriate alternatives can be selected to improve tritium operations and meet DOE requirements.

\title{
CONDUCT OF OPERATIONS
}

\begin{abstract}
Conclusion: Inadequate conduct of operations, as exemplified by turnover in experienced staff, lack of procedures, lack of a corrective action system, insufficient level of detail in the Safety Analysis Reports, and lack of a system to make determinations concerning unreviewed safety questions, has contributed to tritium release incidents.
\end{abstract}

The Task Group identified the turnover of experienced personnel, with the resultant loss of the knowledge base, as an issue at several DOE facilities, including the Los Alamos National Laboratory Tritium Salt Facility. For example, a key manager, who had intimate knowledge of, and had been responsible for, the design, construction, operation, and maintenance of the systems at the Tritium Salt Facility, transferred to the Tritium Systems Test Assembly. Other personnel 
involved with the Tritium Salt Facility operations have likewise been reassigned or have transferred to other operations. In addition, systems descriptions, design documentation, and operating and maintenance procedures are lacking or do not exist for many of the systems at the Tritium Salt Facility. The importance of assuring continuity of systems knowledge and procedures was illustrated by a recent incident at the Tritium Salt Facility. Because of the lack of knowledge and available documentation, Tritium Salt Facility personnel did not properly configure a system to replace a valve. As a result of this improper alignment, tritium was released to the room when the valve was removed, and the worker received an avoidable tritium dose.

A proactive mechanism for identifying and mitigating the potential for abnormal events has seldom been used in Los Alamos National Laboratory's tritium operations. Detailed process vulnerability analyses have not been performed and documented. The operating procedures assume that nothing will go wrong rather than considering what problems might occur. Hence, operating procedures do not address vulnerabilities within the process that could cause unintentional tritium releases. As a result, management frequently reacts to events as they occur rather than taking proactive precautions that prevent or mitigate such events.

Human errors have caused the majority of the accidental tritium releases at Los Alamos National Laboratory. The absence of sufficiently detailed operating instructions contributes to these errors. Detailed operating instructions are not generally available for most of Los Alamos National Laboratory's tritium processes. Operations usually depend on the experimenter's knowledge and familiarity with the process.

The quality of the procedures is also a concern. For example, a statement of caution is placed after the action statement to which it applies in procedure 01-WETF-87-023. Thus, the operator may have performed the step before being cautioned in the procedure against potential hazards related to the action. In addition, the labels on the instrumentation and control system are not consistent with the terminology used in the procedure.

As a part of management's self-assessment efforts, an effective corrective action system must be in place to determine, analyze, and correct the indicators, precursors, and causes of events. The Corrective Action Programs at Los Alamos National Laboratory concentrated on correcting specific, identified deficiencies rather than on identifying and classifying those events that might have significant implications. Causes of the observed deficiencies generally were not addressed. Some facilities had no programs outside of the reportable event process. Laboratory management has realized the need for such systems, but has not yet put them in place or developed a plan for doing so. 
Safety Analysis Reports for Los Alamos National Laboratory's tritium facilities have not been maintained and do not adequately define the basis for safe operations. The older tritium facilities at Los Alamos National Laboratory (i.e., the Tritium Salt Facility, the Weapon Subsystems Laboratory, and the High Pressure Tritium Laboratory) have operated without Safety Analysis Reports. In addition, the Safety Analysis Reports for the newer facilities (i.e., the Tritium Systems Test Assembly and the Target Fabrication Facility) lack sufficient detail to support the effective operational safety requirements. These reports do not define the items within the process that are important to safety. Therefore, they do not provide an adequate basis for anticipating or compensating for abnormal operating conditions. Plans are currently underway to develop Safety Analysis Reports for the older facilities. However, there is much confusion at the facilities concerning what constitutes an adequate Safety Analysis Report. The Los Alamos National Laboratory Health and Safety organization (HSE-3) is developing new Safety Analysis Report guidance and a comprehensive plan for supporting the Laboratory's Safety Analysis Report activities, but these have not yet been implemented at the facility level. Hence, the Safety Analysis Report at Los Alamos National Laboratory is generally not regarded as an integral part of facility operations (i.e., the Safety Analysis Report should be frequently reviewed and updated and should be available to facility personnel as a reference document).

The hazards classification of tritium facilities at Los Alamos National Laboratory has sometimes resulted in underclassification, and, therefore, inadequate safety assessments have been performed. Under DOE criteria, the Tritium Salt Facility was originally classified as a low hazard facility. This resulted in a safety assessment rather than a safety analysis being performed. Considering the level of hazards at this facility, and using more widely accepted criteria, it is arguable that the Tritium Salt Facility should have been classified as a moderate hazard facility and required to develop a facility Safety Analysis Report. Lack of consistent guidance in the area of hazards classification is the primary source of this deficiency.

The Laboratory is undertaking far-reaching documentation efforts. A chartered group is determining the hierarchy of documents, but has not yet taken steps to provide a standard method for developing, using, and controlling procedures. There are numerous examples of conduct of operations problems, some of which have contributed directly to release of tritium. The April 1991 tritium release at the Tritium Salt Facility is one such example. This event occurred during a maintenance activity that was performed by operating personnel who were not adequately trained. They did not tag out or properly isolate the system, and were not using approved, written work instructions for the job. There is a system in 
place for the use for Special Work Permits that includes a provision for detailed work instructions. This Special Work Permit, however, is generally applied only for outside maintenance workers, not for operating staff.

Currently, there is no well-defined process at Los Alamos National Laboratory to ensure that an unreviewed safety question determination is systematically made. These determinations are crucial in controlling the safety envelope, because they require that specific questions be answered that relate directly to the safety problems. Without a systematic approach for unreviewed safety question determinations, the impact on the safety envelope cannot be assessed.

\section{MANAGEMENT OF TRITIUM RESIDUES}

\section{Conclusion: There has been an overall lack of attention to managing tritium residues at Los Alamos National Laboratory.}

Tritium is a costly resource, the assigned value of which has significantly increased due to the shutdown of the production reactors at the Savannah River Site and the projected cost of production in the New Production Reactor (NPR). These factors necessitate that tritium be handled conservatively and releases minimized or recovered. However, management at Los Alamos National Laboratory has not stressed maximizing tritium utilization; minimizing the generation of tritium residues, such as scrap and waste; or minimizing the loss of material through environmental releases. Releases within gloveboxes are typically captured and converted to the oxide form and then treated as waste, rather than as nonrecoverable scrap. This is the case, for example, at the Tritium Systems Test Assembly. The operating philosophy at the Weapon Subsystems Laboratory and the High Pressure Tritium Laboratory is to stack tritium (i.e., release tritium to the stack) rather than attempt to confine it for potential reuse. Even though the newer tritium facilities at Tritium Systems Test Assembly and the Weapons Engineering Tritium Facility have tritium capture features, there is no emphasis on conservatively managing tritium and minimizing generation of the more hazardous oxide waste form.

Substantial quantities of tritium, in the oxide form, were found stored on molecular sieves at the Laboratory. This tritium has been, or will be, dispositioned as waste or scrap. A total of 60 grams of tritium in this residue form (18 grams at the Tritium Salt Facility, 7 grams at the Tritium Systems Test Assembly, and 35 grams at the High Pressure Tritium Laboratory) were observed, in addition to the unmeasured amounts of tritium in molecular sieves at the High Pressure Tritium Laboratory. These wastes represent potential sources of release to the environment. 
Los Alamos National Laboratory management has not completed its efforts to obtain tritium discard limit approvals for existing onsite wastes. Specifically, a formal request for approved discard limits has not been prepared and submitted to DOE, and an internal cost analysis has not been completed in support of this request. Meanwhile, some of the molecular sieve waste has been held for as long as 2 years without any authorization for its disposal.

Furthermore, a total of approximately 115 grams of tritium residues, which includes the 35 grams on molecular sieves discussed above, are being held at the High Pressure Tritium Laboratory. This facility has been shut down by Los Alamos National Laboratory management, and a plan for cleanup and decommissioning is being prepared. However, the material confined in the High Pressure Tritium Laboratory not only represents a significant potential release source to the environment, but is also a significant inventory of valuable material not being used.

The Los Alamos National Laboratory managers were not knowledgeable of the cost of tritium, and many viewed tritium as a government-furnished material at no cost. While there is no technology at Los Alamos National Laboratory to recover and reuse tritium, the capability to recover tritium from molecular sieves does exist at the Mound Plant. Use of this capability could result in recovery and reuse of this costly material.

\section{EFFLUENT MONITORING}

\section{Conclusion: Effluent monitoring of tritium sources is inconsistent at Los Alamos National Laboratory. This has led to uncertainties in the actual amount and form of tritium released.}

Tritium monitoring at effluent release points (i.e., stacks) is inconsistent among tritium handling facilities at Los Alamos National Laboratory. The installed equipment varies, depending on age of facility, philosophy of operation, and the source and expected form of tritium. Table 5 indicates the number of stacks at a particular facility and the monitoring system in place. Two types of ion chambers are used in the tritium monitoring systems at the Los Alamos National Laboratory: the older Kanne system, and the newer femto-TECH system. These systems are used to quantify the instantaneous release rate of tritium. However, they detect tritium in the elemental and oxide forms, but do not differentiate between them, and thus do not identify the amount in the oxide form. Oxide quantification is accomplished in a few facilities by using a bubbler system; whereby the oxide is collected in the liquid form and analyzed by liquid scintillation. Some Los Alamos National Laboratory tritium facilities, for example, the tunnel portion of the Technical Area 41 facility where tritium is 


\section{TABLE 5 Tritium Stack Emission Monitoring at Los Alamos National Laboratory}

\section{Tritium Facility}

TA-3 Bldg. 16

Van de Graaf

TA-3 Bldg. 16

Van de Graaf

TA-3 Bldg. 40

Instrument Calib.

Facility

TA-21 Bldg. 155

Tritium Systems Test

Assembly (TSTA)

TA-21 Rldg. 209

Tritium Salt Facility (TSF)

TA-33 Bldg. 86

High Pressure Tritium Laboratory (HPTL)

TA-35 Bldg. 213

Target Fabrication

Facility (TFF)

TA-16 Bldg. 205

Weapons Engineering

Trit um Facility

(WETF)

TA-41 Bldg. 4

Ice House

TA-41 Tunnel

TA-55 Bldg. PF-4

Plutonium Facility
Stack I.D.

FE-14

FE-16

FE-25

FE-5*

FE-1 to one Kanne (ion) Chamber, bubbler

FE-1 stack

FE-12

FE-6 to one

FE-11 stack

FE-1 two

FE-5 3 stacks

FE-1*

FE-17

FE-3

FE-16
Type of Monitoring System(s)

Kanne (ion) Chamber (no bubbler)

Kanne (ion) Chamber (no bubbler)

No monitor. Releases are all

known to be very small quantities

Kanne (ion) Chamber, bubbler

Kanne (ion) Chamber (no bubbler)

Kanne (ion) Chamber (no bubbler)

Kanne (ion) Chamber (no bubbler)

femto-TECH (ion) Chamber, bubbler

femto-TECH (ion) Chamber (no bubbler)

No Stack Monitoring

Kanne (ion) Chamber (no bubbler)

Limiting Conditions of Operation (LCOs) require only one of the two monitoring systems to be operational to perform tritium operations. Thus, the form of tritium released (elemental or oxide) may not always be known, even if the stack is equipped with a system that could differentiate between the two. 
stored, have no effluent monitoring systems on the stack. In these facilities, room monitors are used to provide an indication of a tritium release. Although these monitors provide an indication of tritium release, they cannot quantify a release. Therefore, there are uncertainties regarding the actual quantity and form of tritium release at Los Alamos National Laboratory.

Additionally, for those facilities using the Kanne instrumentation, each unit is custom-made for each facility with Laboratory-constructed electronics; therefore, components cannot be interchanged (American National Standards Institute (ANSI) qualification is not known). This may affect maintenance, and thus, availability. The Laboratory has recognized this problem and is making plans to install the femto-TECH instrumentation at all facilities. Additional femto-TECH units have been ordered, but installation will depend upon delivery and availability of staff to install, test, and calibrate the new equipment. In addition, the Los Alamos National Laboratory ES\&H staff is encouraging facility program directors to obtain bubblers for their monitoring systems. However, Los Alamos National Laboratory management has neither directed the program to obtain this equipment nor funded the purchase through overhead costs. 


\section{Mound Plant}

\section{Background and Facility Descriptions}

The Mound Plant, located in Miamisburg, Ohio, is operated by EG\&G Mound Applied Technologies. The Mound Plant provides production, development, and research support for DOE weapons and energy-related programs. When the plant began operations in May 1948, it was the first permanent Atomic Energy Commission (AEC) facility in the Nation. Today, the site employs more than 2,100 people and consists of more than 100 buildings with 1.31 million square feet of floor space. (See Figure 7.) The facility receives direction from the Dayton Field Office, which, in turn, reports to the Albuquerque Field Office. The Deputy Assistant Secretary for Military Applications has responsibility for the Albuquerque Field Office, and reports to the Assistant Secretary for Defense Programs.

Tritium activities at the Mound Plant encompass performance evaluations of gas transfer systems for nuclear weapons, production of tritium-bearing components for DOE, loading and shipping tritium for commercial customers, recovery and enrichment of tritium from tritium-bearing scrap materials, and solid storage process development. The Mound Plant receives tritium reservoirs for performance evaluations from the Department of Defense (DOD), via the Pantex Plant and the Savannah River Site. Production and tritium-handling facilities at the Mound Plant are used to unload tritium from these reservoirs and to load and ship tritium bearing components to DOE and to commercial clients. Tritium in excess of the amounts needed for operations at the Mound Plant and commercial sales is shipped to the Savannah River Site. The process development capabilities at Mound support the weapons design activities at Los Alamos National Laboratory and the Sandia National Laboratories, Livermore. The Mound Plant also provides tritium targets to DOE Laser Fusion Programs. Finally, the Mound Plant recovery and enrichment facilities are used to process scrap materials from its own operations and from operations at Lawrence Livermore National Laboratory, Sandia National Laboratories, Livermore, and Los Alamos National Laboratory. The recovered tritium is shipped to the Savannah River Site, and residual waste is packaged and shipped for burial. Figure 8 summarizes the relationship of activities between the Mound Plant and the other DOE facilities.

The following is a brief description of the most important facilities and buildings involved in tritium operations at the Mound Plant. 







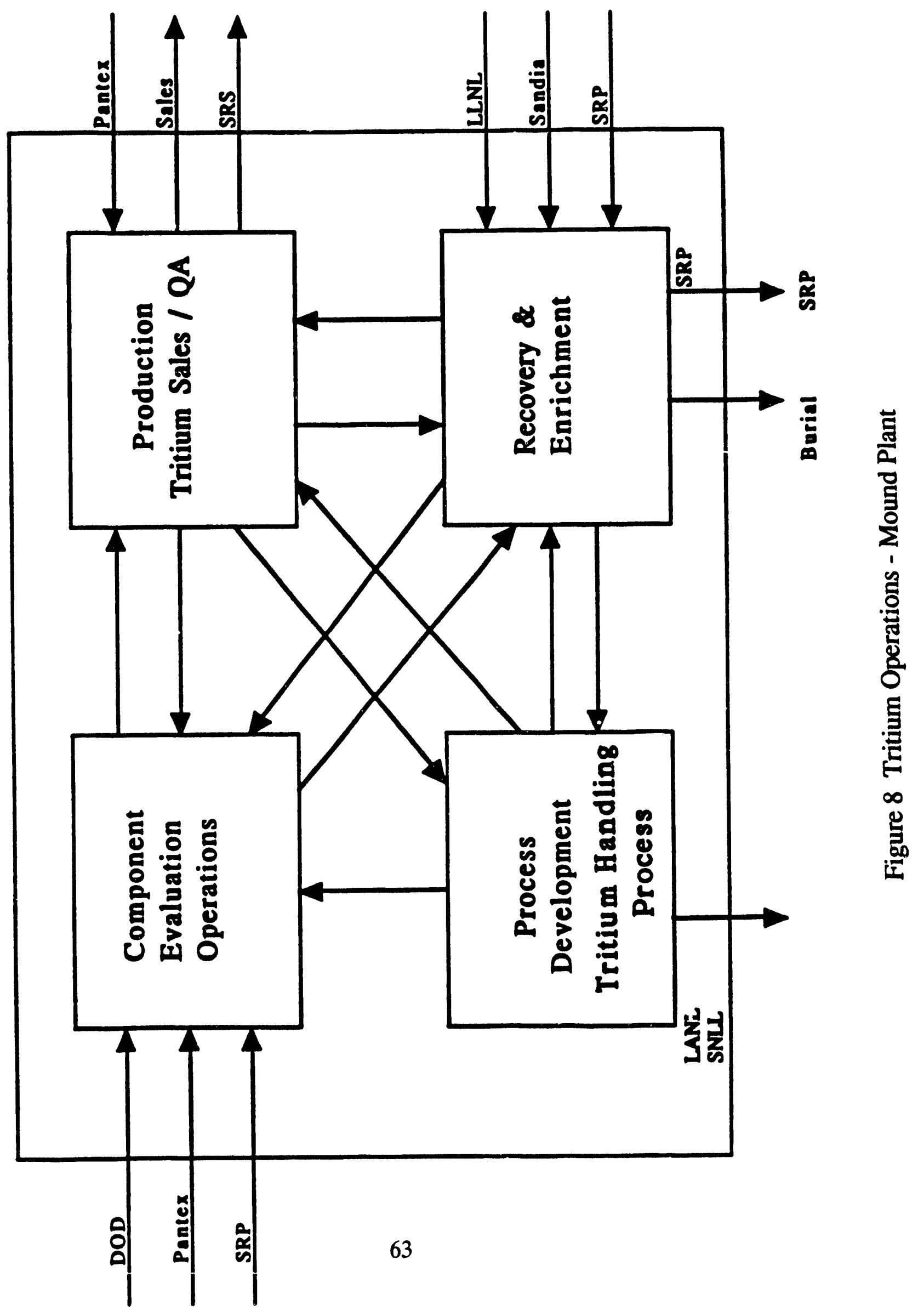




\section{Technical Building}

The Technical Building (T-Building) houses a number of tritium-related projects and facilities. The Technical Building was refurbished in the 1970s to include a Tritium Control Technology Project Laboratory. A number of research and development activities are conducted at this laboratory on advanced engineering systems and processes for capturing and enriching tritium waste streams.

In 1980, construction began on a state-of-the-art tritium component production facility (KYLE) designed to produce all reservoirs planned for new weapon systems. This facility now serves as one of the locations within the DOE complex for fabricating components that supply tritium to nuclear weapons. All of the tritium operations are conducted within glovebox confinement. Additional confinement of unloading operations is provided by metal bell jars located inside the gloveboxes. Operations that involve loading tritium parts are controlled by a sophisticated electronic data system. This production facility also uses a tertiary confinement system.

The Savannah River Operations Contingency (SROC) facility is also located in the Technical Building. This facility was designed and built as a backup for critical component loading operations, which are conducted at the Savannah River Site. Demonstration loadings of tritium gas have been completed in the glovebox located in the facility, including welding of prototype reservoirs.

Other activities conducted in the Technical Building include solid storage research and development, laser fusion support, tritium enrichment, and container fills for commercial customers. The enrichment facilities include a cryogenic distillation system and a gas phase thermal diffusion cascade. The Technical Building operators load hydride traps that contain up to 29,000 curies of tritium and gas cylinders containing less than 1,000 curies of tritium. The total annual sales are approximately 600,000 curies of tritium gas for shipment to commercial customers worldwide. These commercial programs, including tritium loading, sale.s, and distribution operations, were transferred to the Mound Plant by DCE in July 1990, and are supported by the Office of Nuclear Energy.

\section{Semi-Works-Research Complex}

The Semi-Works Buildirg is physically connected to the Research Building. These two buildings are referred to as the Semi-Works-Research (SW-R) Complex. The complex supports a variety of functions, including process development, component evaluation operations, and material analyses. Process development includes a variety of research and development activities in support of developing new processes for fabricating nuclear weapons components. 
Performance tests are conducted that are designed to evaluate the effects of mechanical shock, vibration, acceleration, and pressure and thermal transients. Approximately 30 different weapons system configurations are tested in the component evaluation operations facilities. During function tests, the test specimen is placed inside a sealed bell jar, which, in turn, is confined inside a glovebox. A laser unloading system is also integral to these test stations. The specimens are routinely considered operator-safe, in other words, safe to handle without unusual safety precautions as provided by weapons safety criteria.

An additional project within the Semi-Works-Research Complex is the unloading of tritium reservoirs from existing weapons. These operations use a laser to drill a hole in the reservoir, which is mounted in an apparatus that allows transfer of the tritium gas to a separate receiver. This operation is completed inside a multilayer metal bell jar and a glovebox. The tritium is then packaged or enriched for return to other programs at the Mound Plant or Savannah River Site.

\section{Waste Disposal Building}

The Waste Disposal Building (WD Building) is used for preparing the low-level liquid radioactive wastes generated during operations at the facility for shipment offsite. Tritium liquid wastes are transferred to the Waste Disposal Building via pipeline for solidification and packaging. The packages of low-level wastes are then monitored onsite prior to being shipped offsite for disposal.

\section{Recent Operating History}

EG\&G has continued the philosophy, developed in 1969 by its predecessor Monsanto Research Corporation, of minimizing both normal and abnormal releases of tritium to the environment. Effluent releases to the environment in 1990 were less than 1 percent of 1970 releases in terms of total curies. This reduction occurred even though the inventory of tritium has doubled in the same timeframe. Emphasis is placed on reducing the effluents through a combination of procedural and technological improvements. For example, tritium gas from such sources as gloveboxes, vacuum pumps, and some fume hoods, which had previously been released to the environment, is now routed through the Effiuent Removal System (ERS). In 1970, the Effluent Removal System capacity was increased, and maintenance practices were modified to collect airflow during maintenance activities for processing through the Effluent Removal System.

The Mound Plant's waterborne tritium emissions were reduced from more than 2,000 curies in 1969 to less than 300 curies in 1970. Further reductions during the 1970s anu early 1980s led to annual waterborne emissions of less than 10 curies. Likewise, the Mound Plant's tritium stack emissions were reduced from more 
than 300,000 curies in 1969 to less than 10,000 curies in 1974 . Since 1974, stack emissions have gradually been reduced to less than 5,000 curies per year, with one exception. In 1989, a single, designated Type A incident resulted in the release of approximately 38,000 curies of tritium; the total release for 1989 was 41,534 curies. The trend in tritium effluent releases and the relative tritium inventory are illustrated in Figure 9. Major upgrades to the Effluent Removal System in 1970 , as well as management emphasis on its proper use, were major factors influencing the reduction of emissions. The average annual stack emissions of less than 3,500 curies can be described as routine emissions. These emissions comprise about 500 curies from the Effluent Removal System effluent and between 2,500 and 3,000 curies from the Semi-Works-Research Complex.

The majority of tritium releases from the Semi-Works-Research Complex arise from the older facilities. Not all of the operations conducted within these facilities utilize glovebox confinement. Releases that occur outside of secondary confinement (e.g., slow offgassing from older, idle facilities, maintenance on equipment of older design) are vented to the stack and released to the environment. In comparison, the Technical Building, which is a newur facility and utilizes glovebox confinement along with a tertiary room confinement system, was the source of only 60 curies oif the tritium emissions in 1990. Some of the process development operations will be modernized (i.e., rebuilt to current standards) when they are moved from the Semi-Works-Research Complex to the Technical Building. This move, which is expected to improve their operation, is pending approval of National Environmental Policy Act (NEPA) documents.

The Effluent Removal System removes tritium in gas streams from a number of sources: glovebox purge systems, vacuum pump exhaust, analytical instruments, maintenance operations, and selective intermittent operations. The Effluent Removal System oxidizes tritium in gas streams to tritiated water and collects it for recovery of the tritium. Unconverted amounts of tritium (approximately 500 curies per year) are released to the stack. These are mostly in the form of tritiated methane and account for about 20 to 25 percent of the routine releases for the site. The Tritium Emissions Reduction Facility, scheduled to begin operation in 1992, is designed to further reduce routine emissions. The Tritium Emissions Reduction Facility will run in parallel with the Effluent Removal System, and will eventually replace the Effluent Removal System. The Reduction Facility will have greater capacity than the Effluent Removal System, will operate with a higher capture efficiency, and is expected to reduce emissions to less than 10 percent of those presently released through the Effluent Removal System, even 


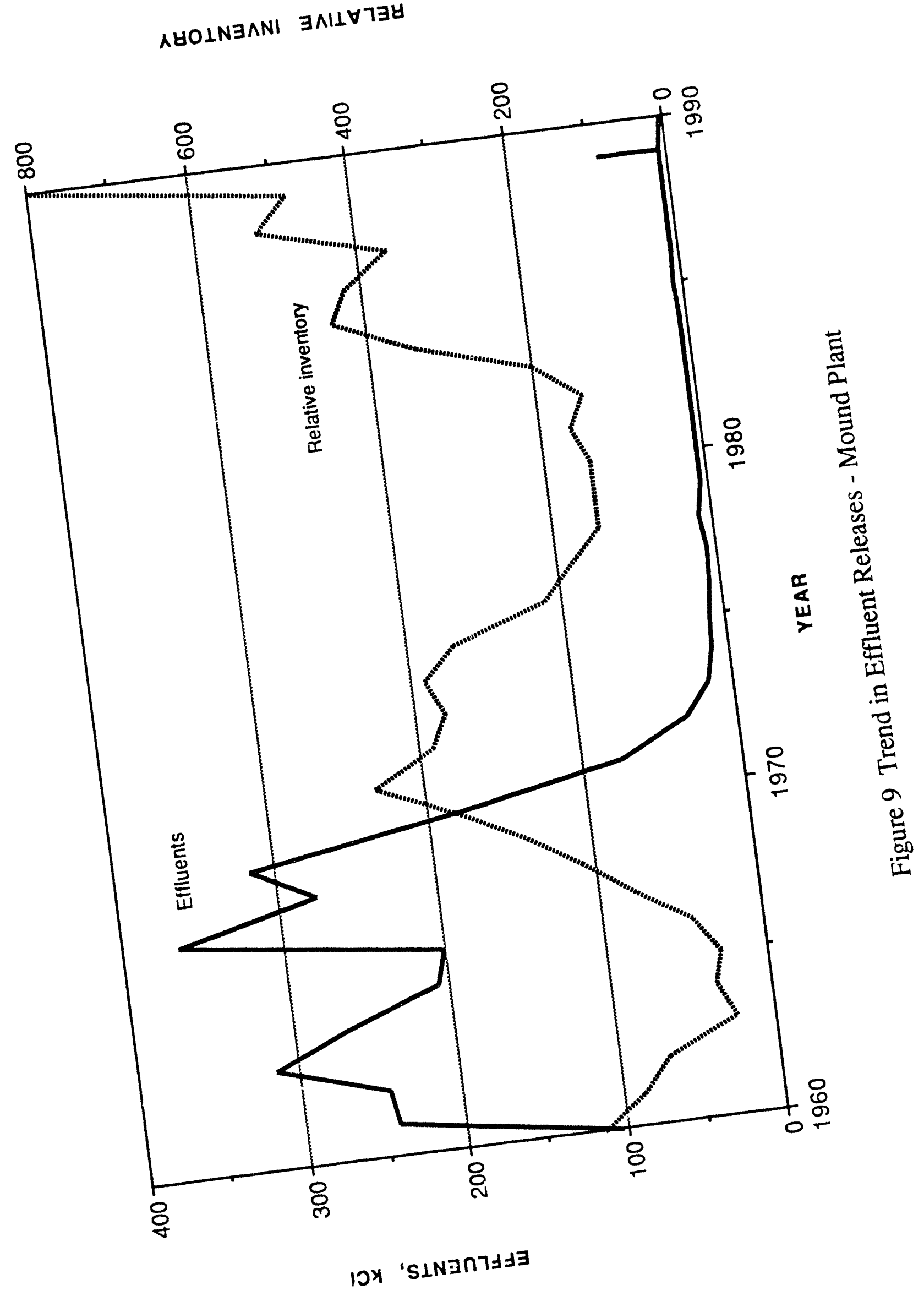


with increased operations and inventory. Unintentional releases of tritium to the Effluent Removal System greater than 0.1 gram have been reduced from eight in 1985 to one in 1990. (See Table 6.)

With the exception of the 1989 incident, there have been few significant environmental releases of tritium from the Mound Plant and few Unusual Occurrence Reports (UORs) related to tritium releases. A brief description of the 1989 incident and the corrective actions taken follows.

In November 1989, approximately 38,000 curies of tritium, including 68 curies in the oxide form, were released. A tritium container was being unloaded by a laser drilling operator when the primary confinement boundary failed, ejecting a fragment that broke the heavy quartz window on the bell jar secondary confinement. Tritium was released into a walk-in fume hood and up the building stack to the environment. The cause of the primary confinement failure was the substitution of an improper adapter in the unloading fixture that resulted in a buildup of pressure. This lead to catastrophic failure of the fixture and ejection of a fragment with sufficient energy to break the fused-quartz window. Related unloading operations were shut down until a Type A investigation was conducted and operational readiness reviews were completed. Although unloading and function testing operations resumed in February 1991, the use of walk-in fume hoods has been discontinued. All testing is now done in other bell jar-glovebox facilities.

With the low level of relearss and the limited number of incidents, occupational exposures from tritium at the Mound Plant are low. The average exposures for onsite employees were 4 millirem in both 1988 and 1989. Maximum exposures for onsite employees were 90 millirem in 1988 and 130 millirem in 1989. The maximum offsite exposure was 0.29 millirem in 1988 and 0.14 millirem in 1989 . The Mound Plant management has adopted a conservative philosophy for calculating offsite doses resulting from routine tritium releases and abnormal events. Calculations of offsite doses are based on the assumption that all tritium released is in the oxide form. The oxide form of tritium has significantly greater biological effects than the gaseous form. When data from the stack monitors and the environmental monitoring stations are available to determine the fractions of oxide and gaseous forms, the dose calculations for events are revised accordingly.

Tritium inventories are based upon a fiscal year timeframe. It is useful to compare tritium releases, collective occupational doses, and inventory to observe trends. This comparison is shown in Table 7. 
TABLE 6 Unintentional Transfers to the Effluent Removal System at Mound Plant

\begin{tabular}{cc}
\hline Year & Transfers $>0.1 \mathrm{~g}$ \\
\cline { 2 - 2 } 1985 & 8 \\
1986 & 6 \\
1987 & 5 \\
1988 & 3 \\
1989 & 3 \\
1990 & 1 \\
1991 & 0 (to date) \\
\hline
\end{tabular}

TABLE 7 Tritium Stack Emissions and Liquid Emuent Releases, Collective Doses to Personnel, and Average Inventory of Tritium at Mound Plant for Fiscal Years 1986 to 1990

\begin{tabular}{lccccc}
\hline & FY 1986 & FY 1987 & FY 1988 & FY 1989 & FY 1990 \\
$\begin{array}{lccccc}\text { Releases } \\
(\text { Ci) }\end{array}$ & 3,601 & 3,979 & 3,319 & 2,802 & 40,777 \\
$\begin{array}{l}\text { Doses } \\
\text { (serson-rem) }\end{array}$ & 3.0 & 2.0 & 1.3 & 1.9 & 1.0 \\
$\begin{array}{l}\text { Average Inventory } \\
\text { (no units) }\end{array}$ & 1.0 & 0.8 & 1.2 & 1.1 & 1.8 \\
\hline
\end{tabular}

- Tritium inventories in grams are classified. The inventories have been normalized to that of FY 1986.

Table 8 shows the distribution of occupational doses resulting from tritium exposure for the calendar years 1986 to 1990 , inclusive. These doses have been stratified to show the number of individuals receiving doses in the indicated range. These exposures are a small fraction of the allowable annual dose for workers. The distribution of doses is typical when compared with the across-the-complex averages for tritium workers. 
TABLE 8 Distribution of Occupational Doses Due to Tritium at Mound Plant for Calendar Years 1986 to 1990

\begin{tabular}{lccccc}
\hline & $\begin{array}{c}\text { Total Number } \\
\text { of Workers } \\
\text { Monitored }\end{array}$ & \multicolumn{5}{c}{$\begin{array}{c}\text { Number of Workers Receiving Annual Dose within } \\
\text { Indicated Range }\end{array}$} \\
\cline { 3 - 6 } Year & & $\begin{array}{c}<10 \\
(\mathrm{mrem})\end{array}$ & $\begin{array}{c}10-100 \\
(\mathrm{mrem})\end{array}$ & $\begin{array}{c}101-500 \\
(\mathrm{mrem})\end{array}$ & $\begin{array}{c}>500 \\
(\mathrm{mrem})\end{array}$ \\
\hline 1986 & 405 & 314 & 88 & 3 & 0 \\
1987 & 365 & 304 & 58 & 3 & 0 \\
1988 & 324 & 268 & 56 & 0 & 0 \\
1989 & 399 & 344 & 53 & 2 & 0 \\
1990 & 435 & 388 & 46 & 1 & 0 \\
\hline
\end{tabular}

\section{Technical Review and Conclusions}

Four issues were identified at the Mound Plant that have the potential to affect tritium operations and releases. A discussion of these issues and the conclusions drawn by the Task Group regarding these issues follows.

\section{CONDUCT OF OPERATIONS}

\section{Conclusion: Contractor formality of operations does not yet meet required performance levels.}

There has been an increase in the rigor with which operations are conducted at the Mound Plant, particularly in the component evaluation operations. However, there are still a number of plant operations for which controls are not sufficiently formalized.

Management diligence is critical in evaluating inadvertent transfers to the Effluent Removal System, since these transfers provide an important indicator of operating practices. At the Mound Plant, the inadvertent transfer of 1,000 curies of tritium to the Effluent Removal System requires an internal unusual event report. Only ne such transfer occurred in 1990 (approximately 8,000 curies of tritium were released to a glovebox as a result of a series of maintenance and operations errors). Inadvertent transfers of less than 1,000 curies may not be recorded or reported internally, and the cause of the internal release may not be determined. 
The reporting system allows for initiating a report whenever the occurrence is "an anomalous or unexpected event that might realistically lead to a more serious occurrence." However, this determination is left to the discretion of the operator who reports the event to the supervisor. In most cases of inadvertent tritium transfers, the operator is the person who was involved in the event. It should be noted that for many low-level events, the determination of cause was frequently left to the identifier of the event. No formal training in root cause analysis has been provided, and the causes documented for many events do not reflect sufficient analysis.

The contractor has a number of initiatives in progress that may contribute to improved formality of operations. These initiatives include development of a formal Conduct of Operations Program, implementation of a formal Training Program, and the recent implementation of a new policy and procedure on control of maintenaince and modifications. However. experience with the latter policy reflects the need for continued improvement.

\section{SAFETY ENVELOPE}

\section{Conclusion: The safety envelope for tritium facilities at the Mound Plant lacks clear definition and is not rigorously maintained}

The safety envelope for a facility is defined as the safe operating bounds as established by the Safety Analysis Reports, Operations Safety Requirements (OSRs), and Limiting Conditions of Operation (LCO).

The Semi-Works-Research Complex has had 13 major modifications since its completion in 1950. The building has operated since startup without an approved Safety Aralysis Report. The most recent Operations Safety Requirements for the Semi-Works-Research Complex were reviewed and approved in 1988. A draft Safety Analysis Report is currently in its final stages of preparation for the Semi-Works-Research Complex. Both this draft Safety Analysis Report and the Safety Analysis Report for the Technical Building are "Secret" documents, which limits their usefulness as ready references for operating, engineering, maintenance, and management personnel.

The Safety Analysis Report for the Technical Building (issued in 1983) includes a detailed description of the Effluent Removal System and the Emergency Surge Tank (EST). The Emergency Surge Tank provides backup capability for the Effluent Removal System for a period of time to allow orderly transition to a minimum safe configuration. The draft Safety Analysis Report for the SemiWorks-Research Complex does not include a similar description of the Effluent 
Removal System and Emergency Surge Tank, and does not discuss the emergency mode of operation of the Effluent Removal System. The Safety Analysis Reports do not define which systems are vital to safety and do not clearly discuss the safety functions of many of these systems. There is a separate initiative outside of the Safety Analysis Report development effort to define vital safety systems.

Operations Safety Requirements and associated Limiting Conditions of Operation are in effect for both the Semi-Works-Research Complex and the Technical Building. However, without a clear definition of the safety function of the various systems in the Safety Analysis Report and without clear Limiting Conditions of Operation statements and bases in the Operations Safety Requirements, it is difficult to implement the Limiting Conditions of Operation. The description of the Effluent Removal System in the Safety Analysis Reports is one example of where a clear description of the safety function is lacking. Neither the Effluent Removal System operators nor facility management could satisfactorily state the conditions under which the Effluent Removal System would be considered inoperable. Since it is generally believed that the Emergency Surge Tank is simply one component in a normal Effluent Removal System, failure of the Effluent Removal System in normal mode with the Emergency Surge Tank automatically coming online could result in a decision that the system was still operable. Therefore, a Limiting Conditions of Operation action statement to suspend tritium operations and place systems containing tritium in a minimum safe configuration would not be applied.

Emergency Surge Tank operation is based on having an evacuated tank of specified size that will provide a highly reliable method of ensuring tritium removal from glovebox purge streams and vacuum pumf, even in the event of loss of normal Effluent Removal System capability, including loss of power. The Emergency Surge Tank provides an adequate holdup volume for potential tritium releases to allow sufficient time to place tritium-handling operations in a minimum safe configuration. The most probable time for the occurrence of tritium releases is during transitions, such as hookups and valve manipulations, particularly when such transitions are made under stress, as might be the case when responding to a loss of Effluent Removal System. Any delay in declaring the Limiting Conditions of Operation allows the evacuated Emergency Surge Tank to begin filling and thereby reduces the available time for conducting the transition to minimum safe configuration. The lack of a clear definition of conditions that render the Effluent Removal System inoperable, and the potential for continued operation with only the Emergency Surge Tank to maintain system vacuum, decrease the available safety margin at any given time.

The Emergency Generator (EG-6) for the Semi-Works-Research Complex provides emergency power to selected systems. The Maintenance Organization has always had responsibility for maintenance and testing of emergency 
generators. Last year, the responsibility for the maintenance and testing of the engine portion of the system was switched from the mechanical operators to the heavy duty mechanics. The electricians are in charge of the generator portion of the system. None of these groups regard themselves as operators, and the traditional responsibilities normally assigned to operators of such equipment are not assigned to, or assumed by, any of them. Surveillance testing of the diesels consists primarily of a weekly no-load run (i.e., the generator does not assume any electrical load) for 15 minutes, coupled with inspections and checks of selected support systems through specific tests, such as observation of the battery voltage. Battery voltage is checked with the battery on "charge," which is not representative of true battery conditions. No additional visual surveillance of the diesel is conducted between weekly surveillances, and the Building Manager for the SemiWorks-Research Complex does not have keys to the Diesel Building, which is kept locked. Full-load testing has not been routinely performed, and testing of the ability of the diesel to start and assume its designated emergency loads within the timeframe described in the Safety Analysis Report is also not performed. A modification was performed on the diesel by adding an extended length of exhaust piping (approximately 100 to 150 feet with a backflow damper fabricated at the site) to help prevent exhaust fumes from entering an adjacent building. This modification, which is described as temporary, was performed without calculating the added backpressure on the diesel or accounting for requisite design change controls normally associated with modifications to safety systems.

\title{
WEAPON/SAFETY FACILITY INTERFACE
}

\author{
Conclusion: Handling and storage requirements of person-safe \\ tritum components are not always followed. These \\ requirements need to be clearty understood and practiced to \\ minimize potential for incidents.
}

Weapon design and development reports have analyzed safe handling of weapon comporents, including tritium reservoirs, during assembly, evaluation, and life-limited component exchanges. These components are produced to meet specifications for all environments they will encounter, including shock, vibration, and temperature ranges that exceed normal storage environments and routine handling by the military. The criteria for safe and reliable design include the following conditions: material and manufacturing processes are well characterized; proof pressure is 1.5 times the limit pressure; minimum burst pressure is 2 times the design pressure ( 2.5 times if failure is in a weld zone); maximum applied stress intensity is 0.4 times the threshold stress intensity (crack will grow from flaw); working stress is limited by creep strain for time-temperature conditions; permeation rates must meet leak requirements and strict process control, including development documentation, data acquisition, 
nondestructive testing, and sample certification. These characteristics are defined as the minimum design requirements, and certification is necessary to ensure pressure safety for components used in staffed areas, which are certified for person-rated service that allows them to be safely handled outside of confinement, for example, gloveboxes and sealed rooms.

During a walkthrough of the Semi-Works-Research Complex, five loaded components were observed on top of a low file cabinet. Three spherical components were resting on rolls of tape to prevent the spheres from rolling off the cabinet. One component was observed without a sleeve installed to protect any exposed stem. The Task Group was shown a secret document (Sandia National Laboratories, Livermore, RS 8446/206, dated January 30, 1990), which set out the technical basis for handling components after environmental testing. Other Mound Plant documents (MD-22066 and MD-10294) instruct that components must be visually inspected for damage and that there be no unprotected ;iems; padded cases must be used to transport up or down stairs; special care must be taken not to bump or drop components; and proper storage must be provided to prevent damage, degradation, or improper identification. Documents from the design laboratories for Mound Plant environmental testing require that throughout the assembly, disassembly, and testing operations, visual inspections shall be made for damage, deterioration, assembly anomalies, and foreign materials. The Laboratory documents also require periodic examination for damage, deterioration, loosening of parts, and other effects from environmentai exposure and that any significant abnormal results should be reported immediately. Although these components have been designed and constructed to be safe under normal handling conditions, management attention to these handling precautions is required to ensure that adequate margins of safety are maintained. The Task Group's observations indicate that inadequacies in this area may be a vulnerability that needs increased management vigilance.

\section{MANAGEMEN T OVERSIGHT/FOLLOWUP}

\section{Conclusion: DOE oversight und contractor self-assessment of environment, safety, and health issues remain inadequate at the Mound Plant's tritium facilities, although recent initiatives are beginning to take effect.}

Routine in-plant surveillance of ES\&H is a critical means by which management can monitrir the acceptability of conditions and practices in the workplace. Contractor self-assessment provides for internal reviews independent of line operating programs and gives management a means to verify that established ES\&H policies and practices are being carried out. At Mound Plant, self-assessment is performed through several mechanisms: the Triennial ES\&H 
Review conducted by EG\&G corporate offices, the Management Surveillance Program, the Performance Assurance Audit Program, and the Mound Plant Self-Assessment Program. With the exception of the Triennial ES\&H Review, these programs were initiated in 1989 and 1990 as a result of the Secretarial initiatives to strengthen ES\&H oversight in the DOE complex.

Overall, these internal review activities address a broad scope of ES\&H programs, although more from the perspective of compliance assessments than performancebased assessments. The one exception is the Management Awareness Program, which is part of the Management Surveillance Program. The Management Awareness Program encourages routine facility walkthroughs by management. However, the lack of a consistent agenda for these walkthroughs, the potential for gaps within a given manager's knowledge of ES\&H issues, and the lack of a mechanism to track items identified during the reviews may hamper the effectiveness of this program. Obviously, inroads in the prevailing safety culture at tritium facilities will take time, and these initiatives hold promise.

Management has not been aggressive in ensuring implementation of corrective actions based on self-assessments and past reviews. Self-assessment reports do not identify the status of corrective actions resulting from earlier self-assessments reports. In addition, corrective actions resulting from Performance Assurance audits are not being implemented within the specified intervals. In some cases, corrective actions are more than 5 months overdue. Finally, only a small portion of the corrective actions resulting from the Management Surveillance Program is formally tracked.

DOE oversight of EG\&G tritium operations is in its initial stages, with a new facility representative program being implemented in response to Secretary of Energy Notice, SEN-19-90, "Conduct of Operations." At present, the DOE Dayton Field Office has one facility representative providing routine coverage of the tritium facilities. However, the effectiveness of the Oversight Program is limited; findings are frequently repeated, the areas visited by the representatives are limited, and the scope of ES\&H issues addressed is also limited. Some of the limitations in the existing Facility Representative Program are directly linked to the significant work load imposed on the existing staff and the lack of personnel resources available for the overall program. There is a need at the Departmental level for definitive training and educational requirements for facility representatives. 


\section{Oak Ridge National Laboratory}

\section{Background and Facility Descriptions}

The Oak Ridge National Laboratory, located in eastern Tennessee, was founded in 1943. The Laboratory primarily supports the fission nuclear fuel cycle and development of magnetic fusion energy through scientific research and technology. In addition, Oak Ridge National Laboratory identifies and solves generic research problems in energy technologies, such as materials, separation techniques, chemical processes, and biotechnology, and is the major national source of stable and radioactive isotopes. The Laboratory occupies 10,270 acres and employs nearly 5,000 personnel. It is operated by Martin Marietta Energy Systems, Inc., and receives direction from the Oak Ridge Field Office, which maintains an onsite presence at the 'aboratory.

Tritium activities at Oak Ridge National Laboratory have focused on the repackaging of tritium for commercial customers, development and manufacture of radioluminescent light sources, fabrication of titanium tritide targets, and research into helium embrittlement of metals. Oak Ridge National Laboratory is in the process of shutting down its tritium facilities and removing the associated tritium inventory; very little tritium work is expected in the future at Oak Ridge National Laboratory, with the exception of small research facilities. Essentially, all tritium activities were suspended in June 1990, due to DOE's decision to terminate its Isotopes Sales Program activities, largely because of the aging facilities and the extensive effort associated with their maintenance and operation.

The Task Group sent a team composed of two working group staff members to review past activities at Oak Ridge National Laboratory for lessons learned and to review shutdown plans, methods, and scheduling. Tours of four facilities were made by the team. Interviews were conducted with Oak Ridge Field Office and Oak Ridge National Laboratory staff in addition to reviews of pertinent program and facility documents. A description of the facilities visited by the Task Group follows.

\section{Building 3026-C}

Building 3026-C is a two-story, wooden structure (22 feet high) located on Central Avenue to the west of the Isotope Circle facilities. Ancillary facilities consist of offices, low- and high-level radioactivity laboratories, and a counting room. A tritium facility at the northwest corner of Building 3026-C is constructed of reinforced concrete. The small laborc.tories, counting room, and cell banks are also of reinforced concrete. With the exception of these concrete structures, the partitions and ceilings throughout Building 3026-C are wooden. 
Originally, the building was used for about 5 years to develop meth Jds of isolating fission products. After World War II, effort shifted to processing radioisotopes for research and medical purposes, wherein the Commercial Isntope Program was started.

Tritium, in the form of radioluminescent light tubes, is stored in the concrete tritium laboratory room on the north side of the building, and in a hood in Room 7. A doorway on the south side of the concrete room is secured by a steel grate, which is kept locked for security reasons when the laboratory is not attended. The laboratory provides storage space for tritium light sources. Unassembled, tritium-filled tubes are also stored in a hood in Room 7.

\section{Building 3033}

The tritium and krypton production facility is housed in Building 3033, which is located in the central area of Isotope Circle, north of Central Avenue and west of 5th Avenue. This building contains two separate radioisotope processing systems for handling gaseous tritium and ${ }^{85} \mathrm{Kr}$.

The building is a steel frame structure covered with aluminum siding. The floor space is about 1,200 square feet with a total volume of about 20,000 cubic feet. The outer space of the building has been sealed by a cocooning process to make it as airtight as possible. Personnel and equipment entrances are gasketed and locked when the building is not occupied. The building is maintained at a nominal negative pressure of 0.3 inches of water gauge or more, relative to the outside atmosphere, and is locked when operators are not present.

Constructed in the late 1940 s, Building 3033 was used to process ${ }^{14} \mathrm{C}$, ${ }^{85} \mathrm{Kr}$, and tritium. Processing of ${ }^{14} \mathrm{C}$ was discontinued in 1975 . The loading of tritium shipping containers for sale to private industry has also been discontinued. Tritium was also handled in a hood inside the tritium room, which was located in the northeast corner of Building 3033. The hood was connected to the isotope area cell ventilation system and maintained at a nominal negative pressure of 0.5 inches of water gauge relative to the tritium room.

\section{Building 3100}

Building 3100 is a reinforced-concrete vault. The vault, which is locked, is alarm-equipped, and used to store a varicty of radioactive material containers. Currently, four LP50 containers (unapproved for shipping) with a total inventory of 337,795 curies of tritium are stored in this vault. Upon approvil of procedures and authorization from DOE and the Savannah River Field Office, these materials will be transferred to new, approved shipping containers and returned to the Savannah River Site. 


\section{Building 7025}

Building 7025 (shown in Figure 10) is located about 1.4 miles northeast of the central Oak Ridge National Laboratory Site. Although within the perimeter fence of the Oak Ridge National Laboratory 7000 area, it is isolated from other buildings. The structure is prefabricated and metal-sided with a total floor area of 590 square feet and a total free space volume of approximately 6,000 cubic feet.

The building was used for fabricating titanium tritide targets, for preparing metallurgical samples for helium embrittlement studies by diffusing tritium into the samples and allowing it to decay to helium, and for preparing thin films of $\mathrm{ThO}_{2} / \mathrm{UO}_{2}$ by vacuum evaporation. The tritium equipment is housed in a 26-footlong, stainless steel hood with a 2,000 cubic feet per minute exhaust fan. The tritium hood exhaust is not filtered because there are no solid radioactive species to be filtered. A forced-air exhaust system that runs continuously is located at the rear of the building. A forced-air input system for heating and cooling is located on the opposite side of the building. The two systems maintain a continuous, high-volume air flow through the building, preventing the buildup of any concentration of tritium gas in the occupied areas of the building in the event of any leakage or spill.

Building 7025, a surplus building belonging to the Tennessee Valley Authority, was converted in the late 1960 s to house a tritium target fabrication system. Through the early 1980s, the Lawrence Livermore National Laboratory funded the building's programs to produc' titaniuni tititide accelerator targets for the Rotating Target Neutron Source facilities at the Laboratory. Since that time, tritium targets have been prepared on a custom-order basis through the Isotope Distribution Office. The tritium system has also been used to prepare metallurgical samples for helium embrittlement studies related to fusion energy materials research.

\section{Recent Operating History}

Table 9 summarizes the tritium release measurements for the Building 3039 stack at Oak Ridge National Laboratory. This stack services both Building 3026-C and Building 3033, in which the radioluminescent light and the commercial tritium repackaging activities were conducted, respectively. Essentially, all of the measured releases can be attributed to the repackaging activities, with only a small fraction of the total associated with the Radioluminescent Light Program. The totals also include the accidental releases discussed later. 


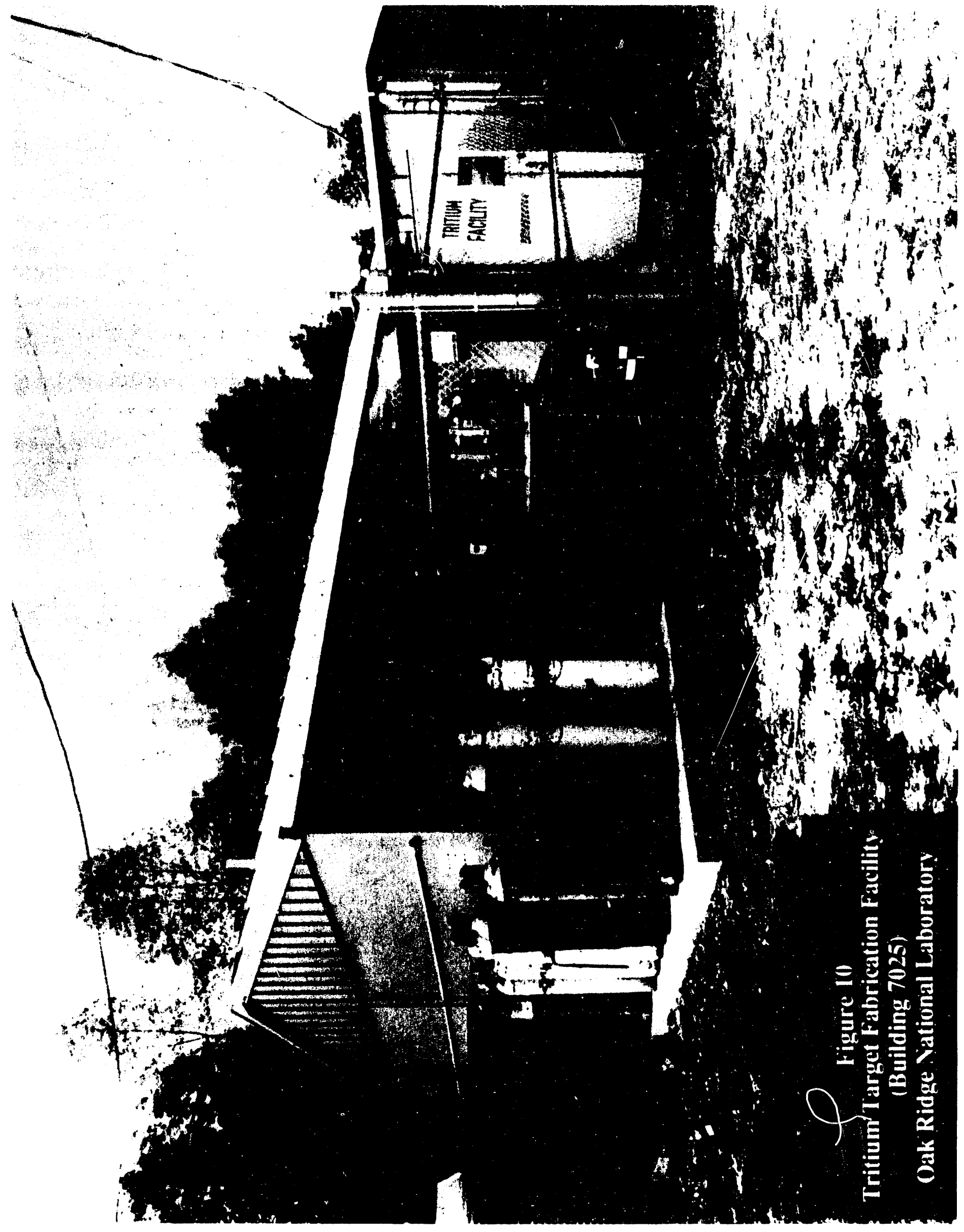


TABLE 9 Oak Ridge Tritium Shipment and Stack Releases Statistics (Building 3026-C and Building 3033)

\begin{tabular}{|c|c|c|c|c|c|}
\hline Year & $\begin{array}{c}\text { Annual } \\
\text { Release } \\
\text { 3039 Stack } \\
\text { (curies) }\end{array}$ & $\begin{array}{l}\text { Tritium } \\
\text { Shipped } \\
\text { (curies) }\end{array}$ & $\begin{array}{c}\text { Number of } \\
\text { Containers } \\
\text { Shipped }\end{array}$ & $\begin{array}{c}\text { Ratio } \\
\text { Annual } \\
\text { Release } \\
\text { to } \\
\text { Tritium } \\
\text { Shipped } \\
\text { (\%) }\end{array}$ & $\begin{array}{c}\text { Ratio } \\
\text { Annual } \\
\text { Release to } \\
\text { Number of } \\
\text { Containers }\end{array}$ \\
\hline 1986 & 30,690 & $1,663,516$ & 235 & 1.8 & 131 \\
\hline 1987 & 43,560 & $2,408,878$ & 237 & 1.8 & 184 \\
\hline 1988 & 20,664 & $1,954,884$ & 190 & 1.1 & 109 \\
\hline 1989 & 25,200 & 573,402 & NA & 4.4 & NA \\
\hline $1990^{\circ}$ & 11,900 & 553.997 & $\underline{\mathbf{N A}}$ & $\underline{2.1}$ & $\underline{\text { NA }}$ \\
\hline 5-Year Total: & 132,014 & $7,154,677$ & 662 & $1.8^{\circ *}$ & $143^{\circ \cdots}$ \\
\hline
\end{tabular}

$\begin{array}{lll}\text { NA } & = & \text { Not Available } \\ \ldots & = & \text { Tritium packaging activities ceased in June } 1990 \\ \ldots \quad & = & 1986-1990 \text { average } \\ & = & 1986-1988 \text { average }\end{array}$

Oak Ridge National Laboratory tritium facilities were operated using a singleconfinement philosophy within fume hoods or gloved enclosures. Thus, any releases from primary confinement systems or containers resulted in release of tritium to the environment.

The repackaging process involved removal of tritium from LP50 containers via uranium traps. The traps were heated to transfer the tritium to smaller gas containers or uranium trap containers that were shipped to customers. Annual tritium shipments were typically greater than 1 million curies. Table 9 indicates that the average annual release of tritium to the atmosphere was equivalent to 1.8 percent of the tritium shipped (1986 to 1990 , inclusive). When asked about this average, the Oak Ridge National Laboratory staff could not provide definitive evidence or explain the reasons for the large release quantities. Apparently, these releases were accepted and not investigated. The Oak Ridge National Laboratory staff theorized that the heating of the uranium traps caused tritium to diffuse through the trap walls. Other evidence, such as the use of unsupported 
assumptions to close the Laboratory's tritium material balance, suggests a degree of comp iasency regarding the control of tritium inventory and releases. In any event, an apparent 143-curie release, on average, had occurred for each container filled. (See Table 9.)

Table 10 reports the tritium released from the Building 7025 stack. This building was used for fabricating titanium tritide targets and for preparing metallurgical samples for helium embrittlement studies. The 2,800-curie release in 1989 was apparently caused by the heating of uranium traps as part of a tritium inventory assessment.

In general, the releases resulting from tritium operations at Oak Ridge National Laboratory are regarded by the Task Group as substantial in view of the activities conducted, and were due mainly to direct, unprocessed tritium discharges from the fume hoods and gloved enclosure exhausts. Because the releases did not exceed environmental standards, nor were any restrictive in-laboratory emission limitations in place, these releases did not engender concern on the part of the Laboratory staff and management. Thus, no actions were taken to identify the precise sources of the releases, and steps were not taken to reduce these releases.

Unusual Occurrence Reports (UORs) for 1983 to 1990 were reviewed. Less than 340 curies were released in three accidental events over the 8-year period. Corrective actions appear to have been adequate, and the frequency of events has been low. Tritium activities generally involved the same three to four individuals over the past 8 years, so experience in running operations was concentrated within a small group. The two events in 1983 involved breakage of radioluminescent lamp light tubes resulting in a release of about 140 curies. Better procedures were developed, and equipment was modified. No further accidental releases were reported until 1989, when a third accidental release occurred. This release occurred when a technician, not normally associated with the tritium activities, was assigned cleanup duties. Unaware of the conditions in the room, the technician attempted to move a radioluminescent light fixture without knowing its base was loose. Two light tubes were broken, releasing less than 140 curies.

Table 11 shows the distribution of occupational doses resulting from tritium exposure for calendar years 1986 to 1990 , inclusive. These doses have been stratified to show the number of individuals receiving doses in the indicated range. The exposures are a small fraction of the allowable annual dose for workers, and the distribution of doses are typical when compared with the across-the-complex averages for tritium workers. 
TABLE 10 Oak Ridge Tritium Releases from Target Fabrication Facility (Building 7025)

\begin{tabular}{cc}
\hline Year & Annual Release (curies) \\
1986 & 310 \\
1987 & 440 \\
1988 & 336 \\
1989 & 2,800 \\
1990 & $\underline{480}$ \\
TOTAL Releases (curies): & $\mathbf{4 3 6 6}$ \\
\hline
\end{tabular}

IABLE 11 Distribution of Occupational Doses Due to Tritium at Oak Ridge National Laboratory for Calendar Years 1986 to 1990

\begin{tabular}{lccccc}
\hline & $\begin{array}{l}\text { Total Number } \\
\text { of Workers } \\
\text { Monitored }\end{array}$ & \multicolumn{5}{c}{$\begin{array}{c}\text { Number of Workers Receiving Annual Dose within } \\
\text { Indicated Range }\end{array}$} \\
\cline { 3 - 6 } Year & & $\begin{array}{c}<10 \\
(\mathrm{mrem})\end{array}$ & $\begin{array}{c}10-100 \\
(\mathrm{mrem})\end{array}$ & $\begin{array}{c}101-500 \\
(\mathrm{mrem})\end{array}$ & $\begin{array}{c}>500 \\
(\mathrm{mrem})\end{array}$ \\
\hline 1986 & 7 & 4 & 3 & 0 & 0 \\
1987 & 9 & 8 & 1 & 0 & 0 \\
1988 & 11 & 6 & 5 & 0 & 0 \\
1989 & 14 & 11 & 3 & 0 & 0 \\
1990 & 16 & 15 & 1 & 0 & 0 \\
\hline
\end{tabular}

Table 12 summarizes tritium monitoring at the tritium facilities and around the Oak Ridge National Laboratory Site. Room monitoring appears adequate, except that the $\mathbf{3 1 0 0}$ vault has no room air monitors. (Note that the four cylinders of tritium gas stored in the vault are contained in $2 \mathrm{R}$ overpacks that are Department of Transportation approved, these overpacks provide additional assurance that leakage during storage does not occur.) 
TABLE 12 Tritium Monitoring Systems at Oak Ridge National Laboratory

\begin{tabular}{|c|c|c|}
\hline Tritium Facility & Monitor Purpose & Monitor Type \\
\hline ORNL Site & $\begin{array}{l}\text { Environmental } \\
\text { (air) }\end{array}$ & $\begin{array}{l}\text { Two silica-gel tritium sample collectors } \\
\text { along Bethel Valley Road. One west } \\
(\# 3) \text { and one east (\#8) of Laboratory. }\end{array}$ \\
\hline \multirow[t]{2}{*}{ Building 3026-C } & Room Air & $\begin{array}{l}\text { Triton Model } 111 \text { portable ion } \\
\text { chambers. }\end{array}$ \\
\hline & Stack Effluent & See Building 3039 stack. \\
\hline \multirow[t]{3}{*}{ Building 3033} & Room Air & $\begin{array}{l}\text { Two Triton 955B ion chambers; one } \\
\text { internal and one external to Tritium } \\
\text { Process Room. }\end{array}$ \\
\hline & $\begin{array}{l}\text { Pre-Stack } \\
\text { Monitor }\end{array}$ & Overhoff Betatec 100 ion chamber. \\
\hline & Stack Effluent & See Building 3039 stack. \\
\hline $\begin{array}{l}\text { Building } 3039 \\
\text { (stack) }\end{array}$ & Stack Effluent & $\begin{array}{l}\text { - Berthold Model LB110 ion } \\
\text { chamber. } \\
\text { A catalytic converter followed by } \\
\text { a silica-gel desiccant to collect } \\
\text { total tritium (both HTO and HT). } \\
\text { Paper filter, activated charcoal, } \\
\text { and other units to measure } \\
\text { nontritium isotopes. }\end{array}$ \\
\hline $\begin{array}{l}\text { Building } 3100 \\
\text { (vault) }\end{array}$ & Room Air & $\begin{array}{l}\text { No immediate detection; only surface } \\
\text { swipes taken. }\end{array}$ \\
\hline \multirow[t]{2}{*}{ Building 7025} & Room Air & $\begin{array}{l}\text { Triton Model } 111 \text { portable ion } \\
\text { chamber. }\end{array}$ \\
\hline & Stack Effluent & Same instrumentation as 3039 stack. \\
\hline
\end{tabular}

External room monitor readouts to warn personnel before entering a room are not generally available, except outside the Tritium Processing Room in Building 3033. Stack effluent monitors measure only the total tritium and do not differentiate between tritium oxide and tritium gas. Environmental monitoring for tritium is done at only two stations on the reservation, indicating a rather marginal Tritium Monitoring Program for the Oak Ridge National Laboratory Site. 
All tritium activities were suspended at Oak Ridge National Laboratory as of June 1990. This suspension of activities was a result of DOE management's decision to terminate operations associated with the Isotopes Sales Program. This was due, in large part, to aging facilities and the high costs associated with their maintenance and operation. It is anticipated that all tritium will be removed from Oak Ridge National Laboratory facilities by the end of fiscal year 1992.

As part of the planned inventory transfer, tritium-containing, radioluminescent light tubes are to be shipped to the Mound Plant for recovery. The proposed approach for this transfer was documented in a letter from Doyle R. Brown, DOE Oak Ridge Field Office, to W. R. Wilkes, Mound Plant; Subject: Tritium Lights Tubes Transfer to EG\&G Mound, February 6, 1991. The Mound Plant has not formally responded to this correspondence. Telephone conversations with The Mound Plant management and program personnel indicated that an agreement on the recovery of tritium from these light sources has been achieved in principle, but specific details have yet to be worked out. The Mound Plant was recently asked by management of DOE's Office of Environmental Restoration and Waste Management (EM) to prepare a proposal for the recovery of tritium from light tubes. It is not clear if this proposal is to apply only to Oak Ridge National Laboratory light tubes or not. According to Mound Plant management, the recovered tritium from Oak Ridge National Laboratory light sources belongs to DOE Defense Programs; thus, Environmental Restoration and Waste Management is taking action to recover these sources. At this point, the recovery of tritium from Oak Ridge National Laboratory light tubes is an open issue with respect to funding and responsibility for the recovered tritium.

The DOE Oak Ridge Field Office is communicating with the Office of Nuclear Energy (NE), Environmental Restoration and Waste Management, and the Mound Plant to achieve agreement on the subject. The DOE Office of Nuclear Energy and the Oak Ridge Field Office are committed to removing the stored tritium within a reasonable time period. The schedule for completing tritium removal has been accelerated from fiscal year 1994 to the end of fiscal year 1992. This will provide sufficient time for planning the safe removal of the material and, at the same time, minimize the potential for accidental release of stored tritium gas and the continued release from offgassing containers and contaminated equipment.

\section{Technical Review and Conclusions}

Three issues were identified at the Oak Ridge National Laboratory that affected past as well as present and future releases of tritium. A discussion of the conclusions drawn by the Task Group regarding these issues follows. 


\section{SINGLE CONFINEMENT}

\section{Conclusion: The operational philosophy for handling tritium has been focused on single confinement, which has contributed to releases from the Oak Ridge Naticnal Laboratory Site.}

The operations at Oak Ridge National Laboratory do not provide for secondary confinement of tritium. In Buildings 3026-C, 3033, and 7025, tritium-handling equipment has been located in fume hoods that vent directly to the stacks. Historically, these operations supported the DOE Isotope Sales Program, the Radioluminescent Light Program, and the Rotating Target Neutron Source Program. The transfer of tritium inventory and shutdown of these facilities, planned for fiscal year 1993 and fiscal year 1994, will be conducted using the same single-confinement approach. Uranium traps, a source of tritium release in Building 7025 in the past, have been removed from that facility. Yet residual surface contamination on the remaining equipment in the processing fume hood continues to release tritium gas to the environment. Similarly, light tubes leaking tritium (through diffusion) in a fume hood located in Building 3026-C, are being exhausted through the Building 3039 stack and filters, and are monitored on a daily basis. In addition, the packaging of existing bulk tritium in Building 3033, anticipated as part of the transfer of tritium inventory, will be performed in the tritium laboratory and in the fume hood that vents directly to the Building 3039 stack. Historically, releases have occurred in these process systems as a result of the bulk tritium and light fabrication activities. A substantial portion of these releases could have been prevented if the equipment had been secondarily confined and the released tritium captured.

\section{ASSURANCE OF SAFE OPERATIONS DURING SHUTDOWN}

\section{Conclusion: The existing Oak Ridge National Laboratory Isotopes Facilities Shutdown Program plan and draft management plan do not define the approaches to be used to ensure that shutdown of facilities will be conducted in a safe manner.}

The "ORNL Isotopes Facilities Shutdown Program Plan," ORNL/TM-11689, October 1990, is a detailed project and cost document using a work breakdown structure for all of the Oak Ridge National Laboratory isotopes facilities, which include tritium-handling facilities in Buildings 3026-C, 3033, and 7025. The work breakdown structure is a complete description of the activities and the cost and schedule associated with the overall Shutdown Program, although some portions of the schedule have slipped due to a delay in approval by DOE Headquarters of a Categorical Exclusion (CX) for the transfer of isotopes. (The CX was approved on July 15, 1991.) 
In addition, a draft "Management Plan, Oak Ridge National Laboratory Isotspe Facilities Shutdown Program" document has been prepared that defines overall program objectives, organizational responsibilities, and control systems to be applied. Both of these documents are thorough and clearly defined. However, neither document defines an overall approach for conducting shutdown operations. An overall approach is being defined, but has not yet tecin completed. This approach covers: (1) how overall safety is to be integraced into the shutdown operations; (2) how strengthened Conduct of Operations in accordance with DOE 5480.19 will be applied to these operations; (3) how tritium monitoring requirements of personnel, facilities, and the environment are to be met; (4) how nonroutine operations (for example, the handling and packaging of leaking bare light tubes) will be reviewed; and (5) how safety reviews will be conducted prior to operation.

In addition, ORNL/TM-11689 refers to an existing maintenance and surveillance plan that defines the requirements for maintaining these facilities in a safe standby condition until shutdown operations begin. However, this plan is only now being developed. Thus, aside from existing procedures, the isotopes facilities currently have no formal measures to ensure they are maintained in a safe manner while awaiting shutdown.

\title{
ADEQUACY OF FUNDING
}

\author{
Conclusion: Program funding support for the Oak Ridge National \\ Laboratory Isotopes Facilities Shutdown Program Plan appears to be \\ adequate. However, funding support during the active phase of the \\ Isotope Program was not always sufficient to provide the necessary \\ equipment to property process and account for tritium.
}

On December 11, 1989, DOE Headquarters directed the DOE Oak Ridge Field Office to prepare its isotopes production and distribution facilities, including the tritium-handling facilities, for safe shutdowns. The shutdown, which includes the transfer of inventory, is intended to place the isotopes facilities at Oak Ridge National Laboratory in a radiologically and industrially safe condition for routine maintenance and surveillance prior to eventual decommissioning. By these actions, these facilities are intended to meet the requirements for surplus facilities acceptance specified in the DOE Environmental Restoration Program Surplus Facilities Management Program Plan. The funding requirements for these actions have been identified in ORNL/TM-11689. Funding for the overall program is shared by DOE Nuclear Energy and Environmental Restoration and Waste Management from fiscal year 1990 to fiscal year 1994, inclusive. In general, these funding levels appear to be adequate, and are supported by the respective DOE program offices. 
Funding during the prior operational phase of the Oak Ridge National Laboratory Isotopes Program was marginal and did not include funds for facility and equipment upgrades. Important measurement equipment, such as a mass spectrometer and calorimeter for assaying tritium in product shipments, was requested by the Isotopes Program, but not approved by DOE Headquarters. The absence of this equipment led to several shipper-receiver discrepancies as to the actual quantity of tritium transferred. These deficiencies were the subject of several investigative reports that included the "Investigation Committee Report on Tritium Inventory Discrepancy in Oak Ridge National Laboratory Tritium Sales Program," July 20, 1989; "Initial Report from the Committee for Internal Invertigation of the Discrepancy in a Tritium Shipment to Moravek Biochemicals Corporation," October 18, 1989; and a DOE Nuclear Energy report, "Review of Discrepancies in Shipper-Receiver Measurements for Tritium Shipments Under the Isotope Production and Distribution Program," September 28, 1989. The lack of timely funding to provide appropriate measurement equipment appeared to have contributed to these discrepancies. In addition, the overall measurement of tritium inventory was not adequate. This led to an inventory write off of 1.83 grams (17,626 curies) of tritium, as documented in an Unusual Occurrence Report UOR-MMES-90-673X10-90-122, September 28, 1990. 


\section{Pantex Plant}

\section{Background and Facility Descriptions}

The Pantex Plant, located near Amarillo, Texas, has been operated by Mason \& Hanger - Silas Mason Co., Inc., since October 1, 1956. The principal nuclear operations performed at Pantex are the assembly of nuclear weapons from components (including tritium reservoirs) received from other DOE plants; disassembly of obsolete nuclear weapons for retirement; maintenance, modification, and repair of nuclear weapons; and nonexplosive testing of nuclear weapons components. The Pantex Plant also fabricates high-explosive chemical components used in nuclear weapons.

Assembly and disassembly operations that involve handling tritium reservoirs are conducted in cells or bays designed primarily to minimize the potential for the release of fissionable materials to the environment in the event of a handling accident. The bays are also designed to prevent propagation of explosions between cells. Neither the cells nor the bays are designed to capture tritium that is accidentally released during assembly or disassembly operations. The cells and bays are maintained at positive pressure and are continuously vented to the atmosphere directly or through covered corridors or ramps. Under emergency conditions, cells and bays are vented to the atmosphere only through highefficiency particulate air (HEPA) filters.

Tritium reservoirs are received at the Pantex Plant from the Savannah River Site. The reservoirs are sealed at the Pantex Plant, and require no further processing before being assembled into weapons. Tritium reservoirs removed from retirement units are also sealed. Because normal operations at the Pantex Plant deal only with sealed tritium reservoirs, release of tritium gas during normal operating conditions is highly unlikely. The only situations that can lead to tritium release are accidental actuation of the explosive valve that connects the reservoir to the weapon, reservoir leakage, or mechanical failure during handling. Tritium reservoirs removed from weapons are returned either to the Mound Plant or the Savannah River Site for stockpile evaluation tests, recovery of tritium, or long-term storage.

\section{Recent Operating History}

The Pantex Plant does not produce a continuous gaseous tritium effluent. Known quantities of tritium are used for the calibration of tritium monitors. The Pantex Plant releases approximately 0.1 curie of tritium to the environment on an annual basis. 
It is useful to compare tritium releases, collective occupational doses due to tritium, and average inventory of tritium to observe trends. This information for fiscal years 1986 to 1990 , inclusive, is presented in Table 13.

TABLE 13 Tritium Stack Emissions and Liquid Effluent Relea ses, Collective Occupational Doses, and Average Inventory of Tritium at Pantex Plant for Fiscal Years 1986 to 1990

\begin{tabular}{lccccc}
\hline & FY 1986 & FY 1987 & FY 1988 & FY 1989 & FY 1990 \\
Releases (curies) & 0.130 & 0.096 & 0.121 & 40,000 & 2,550 \\
Doses (person-rem) & 0.056 & 0.054 & 0.008 & 1.820 & 0.002 \\
$\begin{array}{l}\text { Average Inventory } \\
\text { (grams) }\end{array}$ & NA & NA & 3,931 & 4,506 & 4,937 \\
\hline
\end{tabular}

Only one unintentional tritium release has occurred at the Pantex Plant in its 40year operating history. The incident occurred on May 17, 1989, during a normal weapons disassembly and retirement operation. An electroexplosive-actuated valve operated accidentally, resulting in discharge of tritium from the gas reservoir. Approximately 40,000 curies of tritium gas were released into the disassembly cell, and ultimately to the environment. The incident resulted when the disassembly technician, who did not realize the valve had malfunctioned, loosened a gland nut on the reservoir. The equipment contaminated by this event continues to offgas tritium, which accounted for the majority of the 2,550 curie release in fiscal year 1990.

When the tritium was released into the cell, portable and fixed tritium monitors alarmed and all workers immediately exited from the cell. Of the five workers in the area at the time of the incident, four received negligible exposures; the fifth worker received approximately $1.18 \mathrm{rem}$ of whole body dose.

As a result of this incident, three investigation teams were assigned to examine various aspects of the event. The first team evaluated the cause of the accident, assessed the nature and extent of the tritium release, personnel exposures, and Plant contamination, and determined the adequacy of the Plant's emergency response at the time of the incident. A second team evaluated the design characteristics of all electroexplosive devices in the weapons stockpile and assessed weapons handling procedures at the Pantex Plant. The third group reviewed tritium operations at the Pantex Plant and the associated airborne effluent monitoring, filtering, and confinement systems. 
The purpose of the third team's review was to identify options for improving the safety of tritium operations and to determine associated costs and implementation schedules. The review focused on what actions could be taken at the Pantex Plant to eliminate or mitigate the consequences and effects of tritium release on assembly and disassembly workers, other Pantex Plant employees, the general public, and the environment.

The Task Group performed a review of the adequacy of tritium release-related corrective actions, proposed as a result of the three separate inver,tigations, and the current status of their implementation. As a result of the $f^{\prime}$ t team's investigation and recommendations, changes were made in the Pantex Plant disassembly operations procedures. The $c$ serators now monitor for tritium prior to and during the tritium reservoir removal, and all operations involving tritium reservoir installation or removal are now conducted while wearing self-contained breathing apparatus. Additionally, improvements were made in operator radiological training and in Plant operating and emergency procedures, and the health physics staff was increased.

The second investigation team recommended modifications to the design characteristics of electroexplosive devices in the weapons stockpile and revisions to the Pantex Plant weapons handling procedures. The DOE weapons laboratories are currently reviewing these recommended modifications. Recommended revisions to the Pantex Plant weapons handling procedures have been implemented.

The third investigation team identified four improvernent options in equipment and facilities, and five improvement options in environmental monitoring and protection. The site contractor has since concluded that the four equipment and facilities improvements are not warranted, based upon actions taken to correct the immediate cause of the incident and upon a simple cost-benefit analysis. The onsite DOE staff has yet to decide whether or not to accept this contractor recommendation. DOE's final decision on the viability of facility modifications will be based, in part, on the results of a probabilistic risk assessment currently being conducted on tritium operations at the Pantex Plant.

Both the site contractor and DOE accepted all five of the recommendations for improvement in environmental monitoring and protection. Two of the recommendations have been implemented; actions on the other three are in progress.

The Task Group found the recommendations and subsequent implementation actions resulting from the three investigations to be effective tritium release control measures. 
Table 14 shows the distribution of occupational doses resulting from tritium exposure for the calendar years 1986 to 1990 , inclusive. These doses have been stratified to show the number of individuals receiving doses in the indicated range. These exposures are a small fraction of the allowable annual dose for workers. The distribution of doses indicate lower than average exposures when compared with the across-the-complex averages for tritium workers.

TABLE 14 Distribution of Occupational Doses Due to Tritium at Pantex Plant for Calendar Years 1986 to 1990

\begin{tabular}{lccccc}
\hline & $\begin{array}{c}\text { Total Number } \\
\text { of Workers } \\
\text { Monitored }\end{array}$ & \multicolumn{5}{c}{$\begin{array}{c}\text { Number of Workers Receiving Annual Dose within } \\
\text { Indicated Range }\end{array}$} \\
\cline { 3 - 6 } Year & & $\begin{array}{c}<10 \\
(\mathrm{mrem})\end{array}$ & $\begin{array}{c}10-100 \\
(\mathrm{mrem})\end{array}$ & $\begin{array}{c}101-500 \\
(\mathrm{mrem})\end{array}$ & $\begin{array}{c}>500 \\
(\mathrm{mrem})\end{array}$ \\
\hline 1986 & 1015 & 1015 & 0 & 0 & 0 \\
1987 & 517 & 517 & 0 & 0 & 0 \\
1988 & 499 & 499 & 0 & 0 & 0 \\
1989 & 674 & 653 & 20 & 0 & 1 \\
1990 & 2340 & 2340 & 0 & 0 & 0 \\
\hline
\end{tabular}

Technical Review and Conclusions

Two issues were identified at the Pantex Plant that have the potential to affect tritium operations and release. A discussion of the conclusions drawn by the Task Group regarding these issues follows.

\section{SAR CONSIDERATION OF INCIDENTS/ACCIDENTS INVOLVING TRITIUM}

Conclusion: The existing Safety Analysis Reports and thase under development do not inchude explicit consideration of operational events that involve releases of tritum due to handling accidents with resenvois.

The existing Pantex Plant Safety Analysis Reports do not include explicit consideration of operational events that involve releases of tritium due to handling accidents with reservoirs. The Pantex Plant is currently preparing new Safety Analysis Reports for moderate- and low-hazard facilities onsite, as well as a 
sitewide Safety Analysis Report. These Safety Analysis Reports will include consideration of normal operations and accidents involving tritium.

In conjunction with Sandia National Laboratories, Livermore, the Pantex Plant has estimated the probability of spontaneous failure of a reservoir. The probability of a reservoir failure during handling is judged to be between one and two orders of magnitude greater than the probability of spontaneous failure. The Pantex Plant's consideration of the potential for reservoir failures during handling is different than consideration given to the potential for such failures at other DOE sites. At other sites, the reservoirs are considered to essentially invulnerable to rupture and be able to withstand all reasonable events during routine handling, based on evaluations and design standards. The Pantex Plant has determined that reservoir failures during handling have marginal consequences and are extremely unlikely, and a basis for this determination has been documented. Other DOE sites should consider and document reservoir vulnerabilities in their safety documentation.

\title{
CONDUCT OF OPERATIONS
}

\begin{abstract}
Conchusion: No formal procedures exist at the Pantex Plant requiring documented verification of the operability of equipment identified in the Limiting Conditions for Operation. Thus, operations in a cell or bay may continue even though the LCOs are not met.
\end{abstract}

Operations that involve the handling of components that contain tritium are completed in accordance with rigorous operations and inspection procedures developed for each weapon program. The operations and inspection procedures identify all activities that must be completed by the operations personnel during the assembly, disassembly, or retirement operations. However, the operations and inspection procedures do not include any requirements to ensure that surveillance has been completed or that the equipment in the cell or bay, which is required to be operable for safety, is in fact operable.

In Building 12-44, Cell 6, the tritium monitor serves a safety function by indicating when evacuation is required due to release of tritium. The monitor is periodically verified to be operable by radiation protection technicians. However, the Area Supervisor is not required to ensure that the monitor is operable before initiating operations that could result in tritium release. In addition, an interlock is provided so that the cell ventilation system is shut down if radiation is detected. Area mechanics perform surveillance activities to ensure that this interlock is functional. However, the Area Supervisor is not required to ensure that this surveillance is current, and, therefore, it cannot be assumed that the interlock is operable before operations are started. 
A lack of formality also affects how interlocks on doors in the cell area are verified to be operable. The Area Supervisor for Cell 6 in Building 12-4 is responsible for ensuring that these interlocks are functional, but no requirement states how frequently operability must be demonstrated or documented.

Inconsistencies exist in where to find certification requirements regarding the operability of components required to mitigate accidents. For example, in Building 12-44, the requirement to ensure that door interlocks are operable is included in a Building Procedure (7-5044), while the requirement to verify operability of the tritium monitors and the ventilation system interlocks is not. 


\section{Pinellas Plant}

\section{Background and Facility Descriptions}

The Pinellas Plant, located near St. Petersburg, Florida, is operated for DOE by General Electric, Neutron Devices (GEND). Approximately 715,000 square feet in size, the plant is located on 96.9 acres in central Pinellas County, the most populated county in Florida, with 2,850 residents per square mile. The nearest residential area is approximately 0.25 mile from the site boundary.

The Pinellas Plant was built in 1956 to manufacture neutron generators, which are principal components in nuclear weapons. The Plant mission has expanded to include manufacturing and testing of other special components for nuclear weapons applications. Tritium is used in the Plant's manufacturing and engineering iaboratory testing facilities, which generate waste process gases that contain small amounts of tritium contamination. Most tritium operations are conducted in Area 108. Pure tritium gas $\left(\mathrm{T}_{2}\right)$ is received from the Savannah River Site in standard LP50 containers and transferred to uranium (U) beds containing depleted uranium. Overall, tritium usage at the Pineallas Plant is considered to be low. The current tritium inventory at the Pinellas Plant is about 15 grams.

Area 108 is the primary tritium handling area at the Pinellas Plant. Numerous production and engineering development activities are conducted in Area 108, including production loading of tritium into neutron tubes and neutron tube parts. In this process, $T_{2}$ is transferred from a U-bed onto the assemblies, where it is captured by a previously deposited thin, metal film through the hydrating process. The total $T_{2}$ retained by a single production neutron tube is less than 100 millicuries. Other activities include calorimetric analysis of U-beds for tritium content, mass spectrometer analysis of gas samples, engineering development loading of $\mathrm{T}_{2}$ olıto neutron tube parts, and processing of U-beds that contain tritium prior to disposal. Most tritium at the facility is stored and used in Area 108. In other areas of the Plant, tritiated components (mostly neutron tubes) are handled for the purpose of analysis and testing. Preparation of samples and mass spectrometer analysis for $T_{2}$ content is performed in Area 157/158.

The Tritium Recovery System (TRS) converts residual $T_{2}$ to tritiated water for disposal using a high-temperature converter that oxidizes the tritium gas and captures the resulting water on molecular sieve columns. The primary source of $T_{2}$ entering the Tritium Recovery System is from mechanical pumps and sorb pumps in tritium processing systems, which are hard-piped to the Tritium Recovery System. 
Except for the limited flow of approximately 2 standard cubic feet per hour through the Tritium Recovery System, most tritium operations are conducted using a single confinement barrier, with personnel protection provided by local exhaust trunks over work areas, fume hoods, or locally constructed ventilated cabinets that exhaust directly to monitored stacks.

\section{Recent Operating History}

Since 1983, the annual amount of tritium released to the environment from the Pinellas Plant has decreased. In 1990, the facility released 100 curies. Tritium releases to the environment are predominantly in trace amounts, and result from normal facility activities such as equipment calibration and testing and component fabrication. Inadvertent releases have been few, always in trace amounts, and usually result from the opening of contaminated equipment for maintenance or repair. Tritium gas and tritium oxide are discharged into the laboratory and main exhaust stacks of Building 100, the Building 200 exhaust stack, and the Building 800 exhaust stack. Gas samples are taken at all four exhaust stacks for the measurement of both the gas and oxide forms of tritium. In addition, the Building 100 stacks and the Building 800 stack are monitored. The Building 200 stack is not monitored. Six onsite and five offsite sampling stations monitor the atmospheric levels of tritium gas and tritium oxide resulting from these stack emissions. Exhausts from most processing and laboratory equipment that use tritium in Building 100 are connected to the Tritium Recovery System. The exhaust effluent from the Tritium Recovery System (from which 95 to 99-plus percent of the tritium has been removed) is directed into the Building 100 main stack. The initial use of the Tritium Recovery System in 1989 resulted in a prompt reduction of tritium releases of approximately one-half. Of the 100 curies of tritium released in 1990, 1 curie came from the exhaust effluent of the Tritium Recovery System, while the remaining 99 curies came from unprocessed building ventilation exhaust.

It is useful to compare tritium releases, collective occupational exposure, and tritium inventory to observe trends. This is presented in Table 15. For the Pinellas Plant, it is noted that, while the average inventory remains relatively stable over the last 5 years, both the emissions and collective doses trend significantly downward.

Occupational exposures to tritium at the Pinellas Plant are relatively low when compared with the across-the-complex average for tritium workers. The average dose attributed to tritium in 1990 was 1.04 millirem per tritium worker. The total collective exposure attributed to tritium in 1990 was 184.4 person-millirem. Table 16 shows the distribution of occupational doses resulting from tritium 
exposure for the calendar years 1986 to 1990 , inclusive. These doses have been stratified to show the number of individuals receiving doses in the indicated range.

TABLE 15 Tritium Stack Emissions and Liquid Emuent Releases, Collective Occupational Doses, and Average Tritium Inventory at Pinellas Plant for Fiscal Years 1986 to 1990

\begin{tabular}{lccccc}
\hline & FY 1986 & FY 1987 & FY 1988 & FY 1989 & FY 1990 \\
\cline { 2 - 3 } $\begin{array}{l}\text { Stack and Liquid } \\
\begin{array}{l}\text { Effluent Emissions } \\
\text { (curies) }\end{array}\end{array}$ & 198.5 & 181.0 & 296.2 & 116.7 & 124.5 \\
$\begin{array}{l}\text { Occupational Dose } \\
\text { (person-rem) }\end{array}$ & 0.697 & 0.777 & 0.466 & 0.564 & 0.335 \\
$\begin{array}{l}\text { Average Tritium } \\
\text { Inventory (grams) }\end{array}$ & 22 & 20 & 19 & 19 & 22 \\
\hline
\end{tabular}

TABLE 16 Distribution of Occupational Doses Due to Tritium at Pinellas Plant for Calendar Years 1986 to 1990

\begin{tabular}{lccccc}
\hline & $\begin{array}{c}\text { Total Number } \\
\text { of Workers } \\
\text { Monitored }\end{array}$ & \multicolumn{5}{c}{$\begin{array}{c}\text { Number of Workers Receiving Annual Dose within } \\
\text { Indicated Range }\end{array}$} \\
\cline { 3 - 6 } Year & & $\begin{array}{c}10-100 \\
(\mathrm{mrem})\end{array}$ & $\begin{array}{c}101-500 \\
(\mathrm{mrem})\end{array}$ & $\begin{array}{c}>500 \\
(\mathrm{mrem})\end{array}$ \\
\hline 1986 & 194 & 173 & $21(86)^{\circ}$ & 0 & 0 \\
1987 & 139 & 130 & 8 & $1(105)$ & 0 \\
1988 & 129 & 115 & 13 & $1(130)$ & 0 \\
1989 & 201 & 189 & $12(97)$ & 0 & 0 \\
1990 & 177 & 171 & $6(31)$ & 0 & 0 \\
\hline
\end{tabular}

- Highest individual dose in millirem 


\section{Technical Review and Conclusions}

Three technical issues were identified at the Pinellas Plant that have the potential to affect tritium operations and releases. A discussion of these concerns and the conclusions drawn by the Task Group regarding these concerns follows.

\section{MAINTENANCE PRACTICES}

\section{Conclusion: Current maintenance practices create the potential for unalarmed tritium releases to the environment.}

Tritium monitoring equipment maintenance is performed without the use of an integrated conduct of operations approach, including approved procedures. Uncontrolled maintenance actions contributed to an incident on May 21, 1991, in which a maintenance technician removed the main tritium monitor from service to facilitate maintenance on another piece of equipment without notifying the cognizant operations personnel or receiving their approval. The technician, then, failed to return the tritium monitor to service after completing his work.

The lack of operations-approved maintenance procedures also contributed to the May 23, 1991, incident in which a technician failed to return a tritium room monitor to service after a design modification. The removal of equipment from service without the knowledge of cognizant operations personnel and the lack of operations-approved maintenance procedures resulted in the main stack monitor being out of service while the remaining process monitors were removed from service, one at a time, for modification. During this period, the potential existed for an unalarmed tritium release to the environment.

\section{OPERATING EXPERIENCE REVIEW}

\section{Conclusion: Current efforts to review operating incidents to determine} cause and take corrective action are not totally effective.

At the Pinellas Plant, the review of operating incidents concentrates on correction of the symptoms identified, rather than on identifying causes of the incidents. In revi uwing the May 21 and May 23, 1991, incidents, the Task Group noted that facility management failed to identify the potential for an unalarmed release. Further, facility management failed to recognize that the incident report of May 23, 1991, directly contradicted the May 21, 1991, incident report. Additionally, the Task Group noted that recommended corrective actions for 
these incidents addressed maintenance activities only on equipment involved in the incidents rather than addressing the important issue of operations control of equipment status and operations approvals of maintenance activities.

\section{SAFETY ENVELOPE}

\section{Conclusion: Without Safety Analysis Reports, Operational Safety Requirements, and Limiting Conditions for Operation, the Pinellas Plant is not able to develop and implement a systematic approach to tritium handling safety.}

Facility operators were not aware of specific prerequisites for safe tritium handling operations, nor were specific steps or actions required to verify equipment operability before tritium operations commenced. For example, two of the facilities emergency diesel generators provide a tritium handling safety function in that they provide backup power to the stack ventilation fans and stack tritium monitors, as well as backup power to some of the tritium process monitors. Neither the utilities personnel nor Plant personnel were readily aware of the loads carried by each emergency generator. The emergency generator that supplies backsp power for the main stack exhaust fans and the main stack tritium monitors recently failed its full load test. Lacking a definition of the generator's safety function, operations personnel were not alerted to the potential impact on tritium operations. Without clearly defined safety requirements, it is not possible for operators or supervisors to make informed and technically sound decisions about operating conditions and practices associated with tritium operations. 
Sandia National Laboratories, Livermore

\section{Background and Facility Descriptions}

The Sandia National Laboratories, Livermore (SNL, L), located in Livermore, California, is operated for the DOE by the Sandia Corporation, a subsidiary of AT\&T Technologies, Inc. Sandia's Liverm ore Laboratory provides research and development support to DOE nuclear weapons and energy-related programs. An additional Laboratory task is to continually assess the nation's weapons stockpile to ensure that it provides a reliable deterrent. Established in 1956, the Laboratory employs about 1,100 people and occupies 57 buildings with approximately 500,000 square feet of floor space. Sandia National Laboratories, Livermore, receives direction and oversight from the Albuquerque Field Office. The Deputy Assistant Secretary for Military Applications has responsibility for the Albuquerque Field Office, and reports to the Assistant Secretary for Defense Programs.

The Tritium Research Laboratory (TRL) is the facility in which Sandia National Laboratories, Livermore, conducts tritium research activities. In Building 968 of the Tritium Research Laboratory, tritium compounds and gas mixtures are handled for a variety of research and development activities. Personnel safety and environmental protection are provided by using sealed gloveboxes connected to a central tritium decontamination system. The Tritium Research Laboratory is a single-story structure ( 80 feet by 200 feet), with a detached equipment room, and is supported by three other facilities: an administrative office, Building 967; an assembly/storage area, Building 969; and a hazardous waste handling facility, Building 961.

\section{Recent Operating History}

Stack releases and typical inventories of tritium at the Tritium Research Laboratory for fiscal years 1986 to 1990, inclusive, are shown in Table 17.

The Tritium Research Laboratory uses a multiple tritium confinement system. All work involving more than 0.1 gram of tritium is conducted in gloveboxes, where atmospheres are circulated through a tritium recovery system. Work involving a small amount of tritium (less than 0.1 gram), such as metallographic samples, tensile samples, and some maintenance activities, is carried out in ventilation hoods, which have been proven effective in the control of tritium releases. 
TABLE 17 Tritium Stack Emissions and Liquid Emuent Releases, Collective Occupational Doses, and Average Inventory of Tritium at Sandia National Laboratories, Livermore, for Fiscal Years 1986 to 1990

\begin{tabular}{lccccc}
\hline & FY 1986 & FY 1987 & FY 1988 & FY 1989 & FY 1990 \\
Releases (curies) & 760 & 1828 & 1590 & 834 & 295 \\
Doses (person-rem) & 1.33 & 0.58 & 1.65 & 0.92 & 1.06 \\
$\begin{array}{l}\text { Average Inventory } \\
\text { (grams) }\end{array}$ & 173 & 125 & 102 & 143 & 122 \\
\hline
\end{tabular}

Uncontained releases at the Laboratory have been the result of corroded storage containers and improper operations outside of the gloveboxes, as the following examples illustrate.

- A 200 -curie release occurred on January 10,1986 , due to the leaking of tritiumcontaminated water from a corroded storage container.

- A 1,100-curie release occurred on August 18, 1987, when an employee disassembled a vessel outside a glovebox in violation of operating procedures.

- A small release of tritium (estimated to be 9 curies) from reopening a waste container occurred during the period of April 1 to May, 16, 1991 in Building 961, where the reopened container was being held.

Occupational exposures to tritium at Sandia National Laboratories, Livermore, are a small fraction of the allowable annual dose to workers. Table 18 shows the distribution of occupational doses resulting from tritium exposure for the calendar years 1986 to 1990, inclusive. These doses have been stratified to show the number of individuals receiving doses in the indicated range. When compared with the across-the-complex averages for tritium workers, Sandia National Laboratory, Livermore, shows higher than average numbers of individuals receiving doses greater than 100 millirem per year. 
TABLE 18 Distribution of Occupational Doses Due to Tritium at Sandia National Laboratories, Livermore, for Calendar Years 1986 to 1990

\begin{tabular}{lccccc}
\hline & $\begin{array}{c}\text { Total Number } \\
\text { of Workers } \\
\text { Monitored }\end{array}$ & \multicolumn{5}{c}{$\begin{array}{c}\text { Number of Workers Receiving Annual Dose within } \\
\text { Indicated Range }\end{array}$} \\
\cline { 3 - 6 } Year & & $\begin{array}{c}<10 \\
(\mathrm{mrem})\end{array}$ & $\begin{array}{c}10-100 \\
(\text { mrem })\end{array}$ & $\begin{array}{c}101-500 \\
(\text { mrem })\end{array}$ & $\begin{array}{c}>500 \\
(\text { (nirem) }\end{array}$ \\
\hline 1986 & 131 & 105 & 17 & 8 & 1 \\
1987 & 99 & 87 & 10 & 2 & 0 \\
1988 & 98 & 89 & 7 & 2 & 0 \\
1989 & 120 & 103 & 8 & 9 & 0 \\
1990 & 139 & 125 & 11 & 3 & 0 \\
\hline
\end{tabular}

\section{Technical Review and Conclusions}

Four issues were identified at the Sandia National Laboratories, Livermore, that have the potential to affect tritium operations and releases. A discussion of the conclusions drawn by the Task Group regarding these issues follows.

\section{PROJECT CONTROL OF FACILITY MODIFICATION}

Conchusion: Control mechanisms are not established to ensure that facility modifications do not deviate from the facility safety envelope.

The Task Group observed that several projects were underway to improve performance and reduce tritium releases. In several cases, system improvements and replacements had been underway for some time. At the same time, it was observed that control mechanisms to guide the projects varied widely and that, in many cases, personnel turnover had affected the course of these projects. Design change control and safety analysis reviews, have not been in place to minimize the effect of personnel turnover or to lend continuity to the extended nature of the projects. In some cases, the scope and goals of a project were well defined and had strong technical bases; however, the mechanisms required to question the broader implications of the project were not in place. 
At the Tritium Research Laboratory, for example, the vacuum effluent recovery system is being replaced. As part of this system replacement, which has been underway for several years, the new system is being located in a sealed metal room that provides for secondary confinement in the seismic bracing buttresses outside of the facility. The new system will affect the safety analysis performed in support of the current Safety Analysis Report, yet the impact of the seismic interaction of the new system confinement on the existing seismic buttress system is not known by Sandia National Laboratories, Livermore.

To ensure that such an unknown is explored and resolved before implementation of a new system, procedures must be in place to establish the sequence and substance of project control, design, and safety reviews as they relate to facility modifications. Execution of a well-conceived plan, updated on a regular basis to accommodate changes in project requirements and schedule, would ensure that facility modification would not adversely affect facility safety.

Frequently, minor modifications are not assessed to determine if, or how, they might alter the safety envelope of a facility. In some cases, a process of formal communication, approval, and documentation of the modification has not been followed. For example, a modification was made to the emergency power diesel generator to correct a deficiency in the speed controller switch on the generator control panel. It had been noted that the controller switch on the front of the panel heated up during operation and that it was overly sensitive. The modification consisted of the addition of a terminal board and a cutout switch inside the generator control panel, which would disable the speed control switch. At the same time, a switch was added to allow the hookup and selection of a remote alternate diesel. This change was made by the electrical maintenance technician, based on informal discussion and approval by engineering. Facility management was neither involved in, nor informed of, the system change. Formal design control measures, including design review and drawing changes, were not used. No indication exists on the outside of the panel that a disabling switch is in place.

\section{EVENT ANALYSIS}

\section{Conclusion: The Sandia National Laboratories, Livermore, Tritium Research Laboratory program for abnormal event reporting, analysis of cause, and corrective action lacks formality when events fall below the $D O E$ reporting criteria.}

As part of line management's self-assessment efforts, an effective and formal corrective action system must be in place to identify, determine cause, and correct deficient conditions. Presently, the formal program at the Sandia Tritium Research Laboratory applies solely to events that must be reported in accordance 
with DOE 5000.3A for occurrence reporting. A Tritium Research Laboratory form does exist for reporting an abnormal condition during a daily operations readiness check to describe the condition, immediate actions taken, and any additional actions required, as well as to document the completion of actions. However, although actions may be taken and reported, the form itself is generally not completed. Even when the form is used, it is not retained once corrective action is accomplished. Thus, it is not available to management to assess conditions in the facility, evaluate trends, or verify that corrective actions were appropriate or effective.

\section{CONDUCT OF OPERATIONS}

\section{Conclusion: The operational conirol of utility equipment considered part of the safety envelope is inadequate. Personnel training on such equipment is also inadequate.}

Tritium Research Laboratory utility equipment/systems, such as the emergency diesel, the ventilation systems, and emergency lighting, are operated by the maintenance organization. The extent of operations is primarily limited to testing and maintenance, without the traditional responsibilities for facility safety normally assigned to operators of such equipment. The Task Group's onsite visit revealed that diesel maintenance personnel were not aware of the specific requirements associated with the Operational Safety Requirements and Limiting Conditions for Operation, nor had they been trained to know what conditions would render the diesels inoperabie per Limiting Conditions for Operation definitions. Without such knowledge, an electrical maintenance technician modified the diesel generator control circuitry without applying rigorous design or operations control measures.

In October 1990, a series of power outages was reported to DOE in Occurrence Report SNLL-90-F1-001. Concentrating on the power outages themselves, the report concluded that the emergency power system (backup generator) "came on, maintaining the integrity of the safety systems for the facility." Discussions with maintenance personnel during a followup site visit indicated that, during one of the power outages, operator action was required to allow the generator to pick up the load. This failure of the diesel generator to respond as designed was neither recognized nor reported in the Occurrence Report. Likewise, there was no investigation to determine the cause of the generator response failure (i.e., disabling the auto-load-assuming function of the generator).

In May 1991, a power outage again required the diesel generator to respond, which it did satisfactorily. Following restoration of normal power, an operator unsuccessfully attempted to manually transfer loads from the diesel to normal 
power. This failure was caused $b_{y}$ 'transfer circuit timers prohibiting such a manual transfer if performed too soon. There are no written procedures for manually shutting down the diesel, and the operator who attempted the transfer was not sufficiently familiar with the circuitry to recognize the limits on manual transfer.

\section{STACK MONITORING LIMITING CONDITIONS FOR OPERATION}

\section{Conclusion: The Limiting Conditions for Openation for tritum effluent monitoring allow potential releases to occur without real-time or integrated monitoring.}

Tritium monitors on the process systems (i.e., Gas Purification System, Vacuum Effluent Recovery System, and Replacement Vacuum Effluent Recovery System) are not required to be operable during process system operation at the Tritium Research Laboratory. The Limiting Conditions for Operation for the stack tritium monitors, which are downstream of all tritium sources, allow normal operations to continue if either the ionization monitor (real-time) or bubbler (integrating sampler) is inoperable. Thus, there is the potential for a release of tritium to the environment without management being aware of the release. 


\section{Savannah River Site H-Area}

\section{Background and Facility Descriptions}

The Savannah River Site, a nearly circular site of 300 square miles, is located in parts of Aiken, Barnwell, and Allendale Counties of South Carolina. It is bounded by the Savannah River on the south, and is about 25 miles southeast of Augusta, Georgia. The site is operated by Westinghouse Savannah River Company. Today the site employs approximately 24,000 people in major operating areas and in many other areas of administrative and technical support.

The Savannah River Site was constructed in the early 1950s, and is a key installation for the production and research of nuclear weapons materials, primarily plutonium and tritium, for the national defense. Plant operations include fuel and target fabrication, nuclear reactor operations, chemical separations, waste management, and research and development. Tritium facilities are located near the center of the site in the H-Area. (See Figure 11.) These facilities include Buildings 232-H, 233-H, 234-H, 236-H, 237-H, and 238- H, which were visited by the Task Group. The Site receives direction from DOE's Savannah River Field Office, which reports to the Assistant Secretary of Defense Programs. A description of the tritium handling facilities follows.

None of the operating tritium facilities at the Savannah River Site has secondary confinemient systems such as those found at the Mound Plant or the Tritium Systems Test Assembly at the Los Alamos National Laboratory. The Replacement Tritium Facility (RTF), Building 233-H, will have sealed, leak-tight gloveboxes with nitrogen atmosphere recirculation and cleanup. However, this facility is still under construction, and will not be completed until at least 1992.

\section{2-H Tritium Extraction and Furification Facilities}

Building 232-H began operation in 1958 as a replacement for the 232-F facility, originally constructeu in 1954. (Building 232-F was then abandoned.) Building 232-H is a T-shaped, one-story, reinforced-concrete building. One high bay is clad with cement asbestos board.

The mission of the $232-\mathrm{H}$ facility is the extraction of virgin tritium from irradiated lithium-aluminum reactor targets and the purification and enrichment of both virgin and recycled tritium for use in Building 234-H. The building also contains facilities for loading and unloading LP50 containers and regeneration facilities for 





zeolite beds (Z-beds). The gas extraction process recovers tritium from irradiated target elements that have been removed, cooled, and chemically cleaned. Tritium and other isotopes of hydrogen are separated from other gases by diffusion through the wall of a hot palladium/silver tube in a process known as primary separation. The nonhydrogen gases are discharged to the atmosphere. The diffused mixture of hydrogen isotopes is further processed in cryogenic distillation columns to provide the required concentration of tritium and deuterium.

Water in the system is adsorbed on Z-beds at many locations. After use, the zeolite bed is moved to the Z-bed recovery system, where the water is desorbed from the zeolite and decomposed, releasing the hydrogen isotopes. Nearly all of the protium (the most common, nonradioisotope of the element hydrogen) is efficiently separated from tritium by cryogenic distillation and discarded to the atmosphere. Decayed, tritium-lean mixtures of tritium and deuterium, which are returned from the stockpile, are isotopically enriched in the 232- $\mathrm{H}$ cryogenic distillation columns to provide acceptable concentrations of the isotopes. All waste gases are processed by the byproduct gas stripper system before they are discharged to the atmosphere, thus reducing tritium losses.

A KYLE function test facility and a thermal cycling and absorption process for virgin tritium purification are being installed in Building 232- $\mathrm{H}$.

\section{4/236-H Tritium Loading Facility/Burst Test Facility}

Building 234- $\mathrm{H}$ is a single-story structure of corrugated cement asbestos board, supported by a steel frame, with an insulated steel roof deck and built-up roofing. Building 236- $\mathrm{H}$ is of similar construction. The 234- $\mathrm{H}$ facility is the site of reservoir receiving, unloading, loading, finishing, and shipping operations. There are separate processes for tritium and inert reservoirs. Major tritium processing operations include reservoir unloading, recycle purification (palladium diffusion), reservoir loading, and reservoir finishing. The $236-\mathrm{H}$ facility processes helium-3 recovery and has reservoir burst test capabilities. Buildings 234- $\mathrm{H}$ and $236-\mathrm{H}$ share common ventilation facilities. In 1990, a KYLE reservoir preparation facility was installed in $234-\mathrm{H}$.

\section{8/237-H Reclamation Facility/Warehouse}

Buildings 238/237- $\mathrm{H}$ are single-story structures similar to Building 234-H. The Reclamation Facility refurbishes returned tritium reservoirs to allow reuse. Primarily machine-shop-type operations are conducted in gloveboxes to contain any residual tritium contamination from the reservoirs. An adjacent warehouse $(237-\mathrm{H})$ is partially utilized for empty reservoir storage. There are no tritium inventories in these buildings other than residuals diffused into the tritium reservoirs. 


\section{3-H Replacement Tritium Facility}

The Replacement Tritium Facility, Building 233-H, is a one-story, reinforcedconcrete, seismically qualified structure that is presently under construction. The building is located completely underground except for the entryways, diesel generators structure, and an auxiliary support building. When operational in fisca! year 1992, the Replacement Tritium Facility will replace the tritium reservoir loading and unloading processes currently operating in Building 234- $\mathrm{H}$. The Replacement Tritium Facility design incorporates hydride technology for the storage and pumping of hydrogen isotopes. Secondary confinement is attained by nitrogen-filled inerted gloveboxes. The glovebox atmosphere can be precessed to recover tritium losses from the process systems.

\section{The Materials Test Facility}

The Materials Test Facility (MTF) laboratories in Buildings 232-H and 234-H include KYLE reservoir functionality testing, life storage of loaded reservoirs, metallography of metal samples, and failure analysis of reservoirs. Measurements of tritium and deuterium pressure isotherms of different metal hydride beds are also made, along with examination of small reservoir materials samples, by scanning electron microscopy and an Auger scanning microprobe.

\section{Recent Operating History}

Tritium releases from the Savannah River Site H-Area tritium facilities, together with : ollective occupational dose due to tritium and average annual inventories are shown in Table 19 for fiscal years 1986 to 1990, inclusive.

Reported occupational exposure from tritium at the Savannah River Site H-Area tritium facilities is average when compared with the across-the-complex average for tritium workers. Since 1987, there has been no tritium assimilation to any individual that has led to a dose of more than 100 millirem. This is due primarily to the use of fume hoods with glove ports for all tritium work, improved protective clothing, plus increased management control of operations and maintenance procedures. Table 20 shows the distribution of occupational doses resulting from tritium exposure for the calendar years 1986 to 1990, inclusive. These doses have been stratified to show the number of individuals receiving doses in the indicated range. 
TABLE 19 Tritium Stack Emissions and Liquid Emuent Releases, Collective Occupational Doses, and the Average Tritium Inventory at Savannah River Site H-Area for Fiscal Years 1986 to 1990

\begin{tabular}{lrrrrr}
\hline & FY 1986 & FY 1987 & FY 1988 & FY 1989 & FY 1990 \\
$\begin{array}{l}\text { Stack and Liquid } \\
\text { Effluent Emissions } \\
\text { (curies) }\end{array}$ & 260,000 & 445,000 & 277,000 & 193,000 & 170,000 \\
$\begin{array}{l}\text { Occupational Dose } \\
\text { (person-rem) }\end{array}$ & 6.39 & 8.50 & 6.36 & 3.92 & 2.14 \\
$\begin{array}{l}\text { Average Tritium } \\
\text { Inventory (no units) }\end{array}$ & 1.00 & 0.78 & 0.77 & 0.95 & 1.03 \\
\hline
\end{tabular}

- Tritium inventories are classified. The inventories are normalized to FY 1986.

TABLE 20 Distribution of Occupational Doses Due to Tritium at Savannah River Site, H-Area for Calendar Years 1986 to 1990

\begin{tabular}{lccccc}
\hline & $\begin{array}{c}\text { Total Number } \\
\text { of Workers } \\
\text { Monitored }\end{array}$ & \multicolumn{5}{c}{$\begin{array}{c}\text { Number of Workers Receiving Annual Dose within } \\
\text { Indicated Range }\end{array}$} \\
\cline { 3 - 6 } Year & & $\begin{array}{c}\text { <10 } \\
(\mathrm{mrem})\end{array}$ & $\begin{array}{c}10-100 \\
(\mathrm{mrem})\end{array}$ & $\begin{array}{c}101-500 \\
(\mathrm{mrem})\end{array}$ & $\begin{array}{c}>500 \\
(\mathrm{mrem})\end{array}$ \\
\hline 1986 & 328 & 281 & 47 & 0 & 0 \\
1987 & 413 & 323 & 88 & 2 & 0 \\
1988 & 484 & 435 & 49 & 0 & 0 \\
1989 & 610 & 584 & 26 & 0 & 0 \\
1990 & 534 & 487 & 47 & 0 & 0 \\
\hline
\end{tabular}


The Savannah River Site uses a multiple system of stack gas measurements to determine the offsite doses resulting from tritium releases. Calculation of offsite doses is based on: (1) ion chamber readings of a continuously sampled portion the stack effluent, (2) tritium readings of a portion of the stack effluent after it passes through a dryer, and (3) a system called a "stack monitor integrator," which uses a computer model to calculate stack releases.

Typical tritium inventories at the Savannah River H-Area facilities are classified, because it is a weapons production facility. However, the inventory is very large compared to that of any of the other tritium faciiities.

\section{Historical Releases and Observed Events}

Since the facilities began operation in 1954, the highest annual releases occurred during the early years of operation. Releases of tritium from reactors, separations, and laboratory operations go to the atmosphere, site streams, and groundwaır. Decreases in tritium releases have been attributed to process control improvements designed to minimize the impact of Savannah River Site operations on the environment and public.

Historically, the greatest amount of atmospheric tritium releases has been attributed to the $\mathrm{H}$-Area tritium facilities. From a maximum of 2.3 million curies released in 1957, these releases declined until the late 1970s. Since then, releases remained at approximately 400,000 curies per year until 1988, when production of tritium declined. H-Area tritium facility releases in 1990 were less than 200,000 curies, contributing a potential of 0.14 millirem effective dose equivalent (EDE). In the past 10 years, 20 to 40 percent of the annual site releases have been from the $\mathrm{H}$-Area tritium facilities. These releases will be substantially reduced when the Replacement Tritium Facility becomes operational. Maximum airborne releases from the Savannah River Site reactors are typically less than 100,000 curies per year for each reactor; whereas average releases are approximately 50,000 curies per year. Commercial nuclear power facilities normally release several hundred to a few thousand curies of airborne tritium per year.

Tritium is released to Savannah River Site streams by direct liquid effluent discharge from facilities and by migration from seepage basins. There has been a decline in direct discharges, beginning in the mid-1970s due to in-process control improvements and less seepage basin use. However, in 1988, about 72 percent of the tritium in streams came from migration and 28 percent by direct discharge. While discharges of tritium from other Savannah River Site facilities are decreasing, liquid discharges from separations facilities increased to over 10,000 curies per year in the mid- to late-1980s. This increase is due in part to phasing out use of the Savannah River Site F- and H-Area seepage basins. In 1988, the 
Separations Area Effluent Treatment Facility was placed in operation to receive water that was formerly discharged to seepage basins as required under the Resource Conservation and Recovery Act (RCRA). Although this facility reduces the amount of other radionuclides in liquid discharges, it is unable to remove tritium from such discharges. In 1990, the Effluent Treatment Facility released 1,200 curies of tritium, resulting in an estimated potential dose of less than 0.012 millirem effective dose equivalent to offsite drinking water users at Port Wentworth and Beaufort-Jasper, downstream, on the Savannah River.

Several million curies of tritium have been placed in the Savannah River Site burial ground in packaged solid materials since Savannah River Site operations be zan. In 1984, it was estimated that approximately 40,000 curies of tritium were present in the groundwater below the burial ground. Although monitoring wells at this location indicate tritium contamination, there is no indication that tritium from the burial ground has reached the public, with the exception of seepage through outcrops to Savannah River Site streams. It is estimated that this would be $7 \times 10^{-3}$ piocuries per milliliter by the time it reaches the Savannah River in the year 2085 .

Measured airborne tritium concentrations between 1970 and 1990 demonstrate a correlation with releases from Savannah River Site operations. The data show a decrease in air concentrations at the Site perimeter from 1989 to $1990\left(3.7 \times 10^{-5}\right.$ to $3.2 \times 10^{-5}$ picocuries per milliliter), while the average concentration at control locations during recent years was $9 \times 10^{-6}$ picocuries per milliliter. Milk analysis data for dairies in the Savannah River Site vicinity show a correlation with tritium release data for Savannah River Site operations. From 1970 to 1990, milk analysis data ranged from 0.3 to 1.1 picocuries per milliliter, corresponding to a potential dose of 0.004 to 0.016 millirem effective dose equivalent. Average tritium concentrations for milk samples collected from control locations in 1989 and 1990 were 0.06 and 0.05 picocuries per milliliter, respectively. It should be noted that the average 1990 milk data have exhibited a 46 percent decrease since 1988. Concentrations of tritium measured in rainwater for the period from 1970 to 1988 ranged from 0.06 to 1.5 picocuries per milliliter; the values for 1989 and 1990 were 1.3 and 1.2 picocuries per milliliter. The average values for control rainwater samples for 1989 and 1990 were 0.09 picocuries per milliliter and 0.06 picocuries per milliliter, respectively. This demonstrates a measurable influence from Savannah River Site airborne emissions.

There is a decreasing trend in the concentration of tritium observed in indicator Savannah River water samples taken from 1958 to 1990 . The data for this period ranged from 1.7 to 15 picocuries per milliliter, with the highest values occurring during the early 1960s. Average concentration values for control surface and drinking water samples taken in 1989 and 1990 were 0.3 picocuries per milliliter and 0.2 picocuries per milliliter. As expected, the concentration ranges of tritium 
in drinking water from 1970 to 1988 was similar to downstream Savannah River water samples. The average concentration values for drinking water in 1989 and 1990 were 2.3 and 1.4 picocuries per milliliter, which correspond to a dose of 0.12 and 0.06 millirem effective dose equivalent.

\title{
Technical Review and Conclusions
}

Eight issues were identified at the Savannah River H-Area that have the potential to affect tritium operations and releases. A discussion of the conclusions drawn by the Task Group regarding these issues follows.

\section{CONTINUED ROUTINE TRITIUM RELEASES FROM SAVANNAH RIVER SITE H-AREA TRITIUM FACILITIES}

\begin{abstract}
Conclusion: Although timely startup of the Replacement Tritium Facility will reduce tritium releases from $\boldsymbol{H}$-Area, facility age, future extraction operations, and other facility operations will continue to contribute to the significan. release of tritium to the environment.
\end{abstract}

As shown in Table 19, releases from H-Area tritium facilities have been reduced over the past 5 fiscal years. These reductions have resulted from the use of improved operations and maintenance procedures, equipment replacement and improvement, and, in the last 2 years, from reduced tritium extraction operations. The timely startup of the Replacement Tritium Facility will further reduce the potential for tritium releases from the tritium loading and unloading operations that are currently contained in Building 234-H. However, residual tritium releases from the outgassing of the remaining processes, equipment, ventilation ducting, and other associated items located in this building will continue. In addition, extraction and related operations in Building $232-\mathrm{H}$ and reservoir refurbishment operations in Buildings $237-\mathrm{H}$ and $238-\mathrm{H}$ will continue to release substantial amounts of tritium. A significant reduction in tritium releases from these buildings will be achievable only through further replacement or modification of existing facilities.

\section{MANAGEMENT OF TRITIUM RESIDUES}

Conclusion: Some reservoirs in storage as part of the Life Storage Program at the Materials Test Facility are being held even though the weapons design laboratories have authorized the release of those reservoirs for the recovery of their contents. One particular reservoir, in a sealed secondary container, has been leaking into the secondary vessel over the past 2 years. 
Reservoirs are being held at the Materials Test Facility as part of the Life Storage Program. For the most part, these are reservoirs that the weapons design laboratories have designated for retention and periodic inspection. The contents of these reservoirs represent a significant quantity of tritium. Some of these storage units are singly contained; most are doubly contained in sealed, outer vessels; all are currently being kept in hoods that vent directly to a stack. Thus, in the event that any of these units leak (singly-contained units or secondary containers), tritium would be discharged to the environment.

The weapons design laboratories have identified approximately 40 storage units that can be removed from storage for tritium recovery. Of these 40 units, 25 are sealed in secondary vessels, while 15 have no such protection. One reservoir, sealed in a secondary container, has been leaking for the past 2 years, as evidenced by a measurable pressure rise within the secondary vessel. This condition has necessitated bleeding off the excess tritium pressure to a capture system on a regular basis. This leaking reservoir, along with the others released by the weapons design laboratories, has been available for recovery for approximately 2 years. The reservoirs have not been processed, because processing them is not a priority. In addition, there are no resources for fabricating the necessary fixtures and modifying the recycle station for transfer of the tritium gas from these units. Many of these units have aged, which poses an increasing risk of leakage and the release of their contents into the atmosphere.

\section{TRITIUM MATERIALS DISPOSITION AS WASTE OR RESIDUES}

\section{Conclusion: An evaluation of waste material containing tritium should be performed and criteria established for the new engineered disposal area.}

The Task Group examined information about materials that become spent residues or waste that could subsequently be released for storage or disposal. Members of the Task Group looked at various residues or wastes resulting from processes and studied treatment and disposal methods for their impact on groundwater or the atmosphere.

Many materials that flow through the tritium facilities create waste streams of various types. A waste characterization survey was conducted in June 1990 as a first step in a Savannah River sitewide process toward cataloging waste streams and implementing waste acceptance criteria and a waste certification plan.

"Tritium Facilities Waste Characterization," OPS-TTG-900105, describes in detail the various types of waste and the treatment and disposal methods. Approximate annual generation rates are also listed in this document. 
One type of waste generated at the Savannah River Site is spent melts in crucibles. Because of the level of radiation from the crucibles (approximately 5 to 10 roentgen per hour due to ${ }^{65} \mathrm{Zn}$ ), they are not monitored for tritium before being placed in the low-ievel solid waste disposal facility trenches (concrete vaults beginning in 1992). A study using single slugs extracted in 1958 determined that the average value of tritium per gram of residue was equivalent to approximately 200 curies to 500 curies per spent melt. In 1961, Savannah River Site laborat'sries developed techniques and equipment to determine residual tritium in plantextracted billets. Analyses of random core samples drilled from the irradiated alloy showed that average tritium per gram of residue was more appropriately about 100 curies. Due to high levels of radiation and the low tritium content, extraction of tritium appears to be unjustified.

Another set of residues consists of uranium beds (U-beds), zeolite beds (Z-beds), and magnesium beds (Mg-beds) used in the Z-bed recovery. Residual tritium in all three beds totals approximately 500 curies. All three types of beds are packaged and placed into B-25 boxes for disposal in the low-level solid waste disposal facility. There is currently no means to regenerate the U-beds; they are used until there is breakthrough or gas channeling. The Z-beds are regenerated or recovered and not routinely placed in disposal. The Mg-beds are disposed routinely. No revisions to this practice appears to be warranted.

Gold traps contain mixed waste of tritium with contaminated mercury. Currently, gold traps are stored in a mixed-waste storage building (Building 643-29G), which is located at the edge of the low-level solid waste disposal facility (inside the security fence). The traps are stored in the mixed-waste storage building, because mercury is an RCRA, Land Disposal Restricted waste, and there is no Environmental Protection Agency (EPA) approved treatment or disposal method for this waste stream. Therefore, the traps will be held in storage for some time. Since 1985, only five traps have been shipped for storage. The traps are welded into stainless steel containers and put into 55-gallon drums. Two of the five traps are in Department of Transportation 17C drums; one drum has been overpacked in an 85-gallon drum. The drums are then placed inside concrete culverts. The two traps that are in the Department of Transportation-17C drums contain 76,960 curies of residual tritium. The mixed-waste storage building is monitored weekly by Health Protection Department personnel with a Scintrex portable monitor for tritium. To date, no releases have been detected from the drums or culverts. Before 1985, the traps were not regulated as mixed waste, but as low-level waste and were disposed of in the old mixed-waste disposal facility, which is currently undergoing a RCRA closure.

The last category of waste evaluated was nonreclaimable reservoirs. These reservoirs are placed in cans, then in B-12/25 boxes, and finally in a classified low-level waste disposal facility. The curie content is estimated. Related 
procedures do not explain estimating or verifying curie content; thus, offgassing may be an issue. The new Savannah River Site waste acceptance criteria state that low-level waste shall not contain offgassing tritium. Further, the new waste acceptance criteria state that verification is to be conducted with a tritium monitor before the waste is packaged in a waste container to verify that no offgassing tritium above background levels is present. However, there is a need to let a package sit for some period of days after bagging the waste to determine if there is offgassing. Currently, the reservoirs in the B-12 boxes are placed in the ground, where the tritium has time to decay even if it does reach the groundwater. In a vault, there will be workers moving boxes around until the vault is full and buried with an earthen cover. As a result, when the new low-level waste disposal vaults are completed and this material is in the vaults, the offgassing may become more of an issue during the time ( 1 to 2 years) the vaults are being filled.

The new criterion for annual tritium waste disposal is being lowered from 400,000 curies to 100,000 curies. New ways to reduce the amount of tritiumcontaminated materials or the amount of tritium on $\mathrm{v}$ in the materials will need to be addressed.

Westinghouse Savannah River Company recently formed a Tritium Materials Issues Task Group composed of representatives from the Tritium Department and Savannah River Laboratory. The Task Group identified the definition of a methodology to determine or define residual tritium in obsolete equipment and waste as an issue to be addressed. The Task Group does not include a representative from the Waste Management Department, who could assist them in defining characterization, packaging, treatment, and disposal methodologies for the various wastes discussed here.

Tritium is a primary contributing contaminant to the groundwater from the low-level solid waste disposal facility. However, based on complex flows of groundwater, travel time, and other variables, it is estimated that the peak flux of tritium from this facility would be approximately $7 \times 10^{-3}$ picocuries per milliliter by the time it reached the Savannah River in the year 2085. The Environmental Protection Agency Drinking Water Standard for tritium is 20 picocuries per milliliter. The new concrete disposal facility will mitigate future releases.

PROCEDURE DETAIL

Conclusion: The criteria and actions required for the change out of purification beds and traps are not documented and included in the procedures. In addition, independent verification of valve alignments is not required by procedure. 
In Building 232-H, U-beds and Z-beds are used both in the gas extraction and primary separations steps: $\mathrm{Mg}$-beds are used in the $\mathrm{Z}$-bed recovery process, Z-beds are used in the reservoir unloading process, and both Z-beds and gold traps are used in the loading process. During discussions of the sources and disposition of tritium "residues" (i.e., waste, scrap) with Westinghouse Savannah River Corporation personnel, it was noted that, generally, the lifetime of the beds and traps was tied to required operations and process parameters, primarily through the knowledge and experience of the operating personnel, and that no documented limits or criteria exist for bed and trap performance.

It was also noted during the Task Group visit to Savannah River Site that there was an incic at in which a rupture disk failed during transfer of tritium from one system to another. The cause of the incident was the improper alignment of valving in the lines transferring the gas. Although, valve alignment is considered for specific activities, such as line breaks, and lock, try, and tag activities, the Savannah River Site tritium facility has neither established nor implemented an overail valve alignment verification policy.

\section{SECONDARY CONFINEMENT}

\section{Conclusion: The current fume hood system used at the Savannah River Site facilities offers excellent protection to the operator, but in most cases vents normal operating losses, offgassing, and accidental releases to the environment.}

Most tritium operations at the Savannah River Site take place in fume hoods with glove ports. Only small metal samples and metallurgical polishing of samples in the laboratory is done in fume hoods. These hoods are kept at a slightly negative pressure with respect to the rooms by the once-through ventilation systems. All maintenance work requiring a line break is covered by a special work permit, a job review, and special radiation monitoring coverage. The use of these enclosures, the management attention given to tritium releases, and more structured procedures have resulted in a very low worker radiation exposure over the last 5 years. Only Building $234-\mathrm{H}$ has a dump and diversion system that actuates if tritium is detected in the ventilation system. Approximately 90 seconds of stack flow can be accumulated, which appears sufficient to retain a large portion of an accidental release. Stack gases from the dump and diversion system can be recycled for tritium recovery, thus preventing large tritium losses. However, the system is not effective for recovery of normal operating releases, and is only about 80 to 90 percent effective in capturing a large accidental release. It would not be considered adequate as the secondary confinement in a modern facility. The tritium operations involving gas handling will be phased out of the Building 234-H after the Replacement Tritium Facility has been placed in service. 
The glovebox system in the Replacement Tritium Facility has an inert gas atmosphere and recirculation system, which is designed to remove tritium and oxygen from the gloveboxes.

\title{
SAFETY ANALYSIS
}

\section{Conclusion: The Safety Analysis Reports for the existing Savannah River Site tritium facilities do not completely define the technical bases for safe operations.}

The Savannah River Site tritium facilities Safety Analysis Reports lack sufficient detail to support the development of operational safety requirements. The Safety Analysis Reports do not define the items within the process that are important to safety. Therefore, they do not provide an adequate basis for anticipating and compensating for all potential abnormal operating conditions. Current H-Area Safety Analysis Report guidance provides a framework for developing an adequate Safety Analysis Report, and plans are currently underway to revise the Safety Analysis Report for the older tritium facilities. In addition, the Safety Analysis Report has not been regarded as an integral part of current facility operations, wherein facility personnel use it as an important reference document that they frequently review and update. The Safety Analysis Report for the new Replacement Tritium Facility is significantly improved over the those of the older facilities.

\section{TRITIUM CONTROL PHILOSOPHY}

\author{
Conclusion: The startup of the Replccement Tritium Facility at \\ Savannah River Site H-Area should significantly reduce tritium \\ releases for operations currently being conducted in Building 234-H. \\ However, routine tritium releases from the other $H$-Area buildings will \\ continue for the foreseeable future.
}

The Replacement Tritium Facility incorporates the use of secondary confinement and more extensive tritium recovery capability than that which exists in Building 234-H. It is estimated that the routine releases from the Replacement Tritium Facility will be approximately 5,000 curies per year. However, fugitive releases will continue to be released from discontinued operations in Building 234-H until such time that the tritium contamination is removed from the equipment. At this time, estimates of these continued releases have not been determined. 
Extraction operations in Building 232-H have been curtailed in recent years due to the relative unavailability of targets. As a result, the routine tritium releases have been reduced from previous levels. However, resumption of full extraction operations will result in the increase of tritium releases from the building.

Significant reduction of tritium releases from this building will require wholesale modification of building systems or complete replacement of the facility. At this time, preliminary work is underway to define a replacement extraction facility. A formal request for funding to design and construct such a facility is not expected until fiscal year 1994, and completion of this work will not be likely until after the year 2000.

Building 238- $\mathrm{H}$, the reclamation facility, refurbishes returned tritium reservoirs for reuse. The refurbishment requires machining operations that produce metal chips. These chips, along with the reservoirs themselves, outgas tritium to the environment through the single-pass ventilation system. Although the design of this facility minimizes personnel radiation exposure from tritium, the release of tritium to the environment is greater than 1,000 curies per year. There are no plans to reduce these releases in the future. Without reduction, these tritium releases will become a larger portion of the total facility tritium release.

\section{SAFE CONTROL OF OPERATIONS}

\section{Conclusion: Periodic process hazands reviews are required for Savannah River Site processes. These reviews consider the current process configuration, past operating experience, and result in recommendations for potential process upgradies and procedure improvements.}

The Task Group has expressed a generic issue concerning the lack of processrelated vulnerability analyses for tritium processes. Such analyses are of importance in the evaluation of process safety and in the development of controls that assure safe operations. However, in the case of the Savannah River Site, such analyses are being performed. Every 5 to 7 years each Savannah River Site process is required to undergo a process hazards review. Engineers are trained in the hazard review methodologies that appear in the "Savannah River Site Process Safety Management Manual," WSRC-IM-90-135. The process hazards reviews for the Cryogenic Distillation Process and the 232-H Tritium Extraction Process were evaluated, and one of the analysts that conducted process hazards reviews was interviewed. Typically, when a process is scheduled for reanalysis, a different review team is used, and a different review method is tried. Methods described in the manual include: (1) What-if/Checklist; (2) Hazards Operability Study; (3) Failure Modes and Effects Analysis; and (4) Fault Tree/Event Tree Analysis. The overall effectiveness of the Process Safety Program appears substantial. It 
was verified that valuable safety recommendations came out of these reviews. It was not verified if all recommendations resulting from the analysis were instituted. In addition, it appears that more can be done in incorporating the results of process hazard reviews into operator procedures and training. However, on the whole, the process hazard reviews appear to be effective in considering the processes' current configuration and past operating experience, and they result in recommendations for potential process upgrades and procedural improvements. 
Savannah River Site - Production Reactors

\section{Background and Facility Descriptions}

Five nuclear reactors are located at the Savannah River Site (SRS) to produce tritium and plutonium required for nuclear weapons. The R-Reactor was shut down in 1964 following detection of cracking in nozzles of the reactor tank. The C-Reactor ceased operations in 1986 due to intergranular stress corrosion cracking detected in the reactor tank. In August of 1988, an event occurred at the P-Reactor that indicated potential deficiencies in the contractor's ability to safely operate the reactors. At that time, both the K-and L-Reactors were in an extended outage, and the contractor agreed to suspend operation at all three reactors pending improvements in safety management systems. Due to the current mission needs for the weapons complex, DOE has directed that the P-Reactor be shut down, the K-Reactor be restarted to support production requirements, and the L-Reactor be maintained as a backup to the K-Reactor.

The K- and L-Reactor designs are very similar. A description of the K-Reactor design generally illustrates the design of both reactors. The reactor core, which consists of fuel assemblies, target assemblies, safety rods, and control rods, is confined within the reactor tank. The core is moderated and cooled by heavy water (deuterium) containing significant amounts of tritium due to the reaction of the deuterium atoms with neutrons. The current concentration of tritium in the K-Reactor moderator (or coolant) is approximately 9,000 microcuries per milliliter.

Spent fuel, irradiated targets, and used control rods are discharged from the reactor tank and stored underwater in the disassembly basin. This basin contains light water, which is contaminated with tritium and is cooled through heat exchangers that transfer heat to the cooling water system. The quality and clarity of water in the disassembly basin are maintained by a settling tank, filters, and deionizers that minimize the potential for corrosion of components stored in the disassembly basin.

The portions of the building containing the reactor tank, the process water system, the purification system, the supplementary safety system, and other potential sources of radioactive releases are maintained at negative pressure with respect to the external environment. The exhaust air is normally routed through demisters, high-efficiency particulate air filters, and charcoal filters to remove particulate material and elemental iodine before discharge to the atmosphere through a 60meter-high stack. If the exhaust fans are unavailable, the discharge air can be routed directly to the stack. Discharges through the stack are monitored for radioactivity from gases such as xenon, krypton, argon, and iodine, and specifically 
for the quantities of tritium released. The disassembly basin area is provided with a separate ventilation system that does not discharge to the stack. Irradiated components are discharged to the vertical tube storage portion of the disassembly basin, and tritium is purged from the vertical tube storage through deionizers and sent to the percolation field, which is a holdup basin to minimize discharge of tritiated liquid effluents. The quantity of tritium released during purging operations is not directly measured, but is estimated based on a calculation of the product of measured specific activity and flow.

\section{Recent Operating History}

The Savannah River Site reactors release tritium oxide vapor and liquid to the environment during normal operations. Figure 12 shows the measured tritium releases from the K-Reactor between 1955 and 1990. Approximately 99 percent of the tritium oxide vapor released to the atmosphere was discharged through the 60 -meter stack on the reactor building. The quantity of tritium released through the stack is calculated based on measurements of tritium activity in the stack exhaust. The remaining 1 percent of the tritium release was through evaporation from the disassembly basins, where fuel and targets are stored. This quantity of tritium release is estimated based on periodic grab samples of air from the disassembly basin area, and has been about 1 percent of the total release.

Liquid releases from the reactor are due to purges of liquids from the disassembly basin and minor leakage of moderator from the process water system to the cooling water. The liquid releases from the cooling water are discharged to the Pen Branch, a stream onsite. The liquid releases due to disassembly basin purge are currently discharged to a confinement basin. The quantities of tritium discharged as liquid are calculated based on periodic grab samples taken from the discharged effluents.

In addition to releases during normal operations, events have occurred that have resulted in unintentional releases of moderator and associated releases of tritium through the stack. Virtually all of these releases are associated with spills or overflows of moderator, some of which evaporates and is released through the stack. In most cases, the total tritium released by these events is relatively small, and the quantity released by individual spills is not calculated. However, the aggregate effect of these events has a significant effect on the total quantity of tritium released through the stack. 
curies

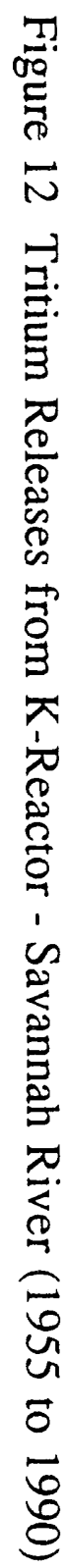

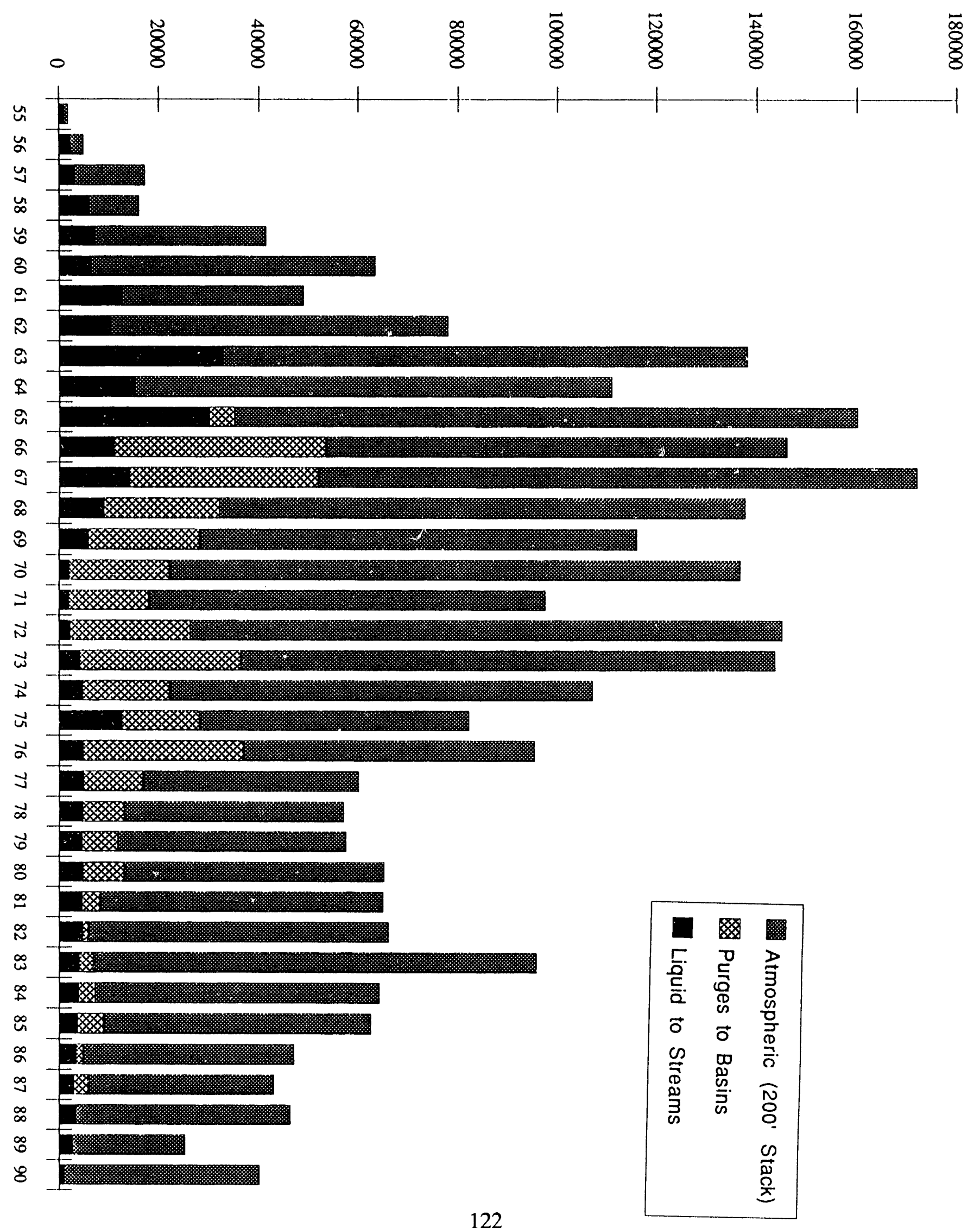


The criteria for recording unintentional airborne releases of tritium have been revised. Any spill greater than a quart of moderator requires preparation of an off-normal occurrence report. At present, Westinghouse Savannah River Company is reporting events involving spillage of even smaller quantities of tritium, such that virtually any unintentional loss of moderator is reported. This does not include what are considered to be normal operational losses of moderator, such as leakage from flanged connections, or minor drips from items requiring corrective actions.

The reported number of events involving spills of moderator increased during the 3-months review interval, attributable to the increased testing associated with preparations for resumption of operations at the K-Reactor. This testing has resulted in an increase in the total number of operations involving movement of moderator. The DOE Savannah River Special Projects Office noted this increase in the total number of spills and releases and requested Westinghouse Savannah River Company to identify planned corrective actions to decrease the total number of incidents in a letter frum F. MícCoy to P.D. Rice, dated April 24, 1991.

Table 21 provides tritium releases, collective occupational dose and tritium inventory for fiscal years 1986 to 1990, inclusive, while Table 22 shows the distribution of occupational doses resulting from tritium exposure for the calendar years 1986 to 1990 , inclusive. These doses have been stratified to show the number of individuals receiving doses in the indicated range. While these exposures are a small fraction of the allowable annual worker dose, it should be noted that they are higher when compared to the other tritium facilities with nearly one-third of the reactor work force being regularly exposed to low tritium levels resulting in annual exposures in the 10 millirem to 100 millirem range. This may be due to the amount of tritium oxide that is routinely present.

\section{Technical Review and Conclusions}

Nine technical issues were identified at the Savannah River Site production reactors. Although the Task Group's review focused on activities at the $\mathrm{K}$-Reactor, the issues identified by the Task Group may be equally applicable to the L-Reactor. 
TABLE 21 Tritium Stack Emissions and Liquid Emuent Releases, Collective Occupational Doses, and Average Inventory of Tritium at Savannah River Production Reactors" for Fiscal Years 1986 to 1990

\begin{tabular}{|c|c|c|c|c|c|}
\hline Category & FY 1986 & FY 1987 & FY 1988 & FY 1989 & FY 1990 \\
\hline $\begin{array}{l}\text { Releases } \\
\text { (Total of all stack, } \\
\text { stream and basin } \\
\text { releases; expressed in } \\
\text { curies) }\end{array}$ & 146,700 & 106,900 & 112,000 & 131,200 & 78,900 \\
\hline $\begin{array}{l}\text { Doses } \\
\text { (Total of all personnel } \\
\text { exposures due to tritium; } \\
\text { expressed in person-rem) }\end{array}$ & 25.2 & 27.3 & 19.8 & 15.4 & 20.3 \\
\hline $\begin{array}{l}\text { Average Inventory } \\
\text { (Estimates of tritium } \\
\text { contaminant in Heavy } \\
\text { Water Moderator; } \\
\text { expressed in grams. } \\
\text { These estimates do NOT } \\
\text { include tritium product } \\
\text { contained in target } \\
\text { assemblies.) }\end{array}$ & 540 & 550 & 530 & 490 & 470 \\
\hline
\end{tabular}

Includes K-, L-, P- and C- Production Reactors 
TABLE 22 Distribution of Occupational Doses Due to Tritium at Savannah River Site, Production Reactors for Calendar Years 1986 to 1990

\begin{tabular}{lccccc}
\hline & $\begin{array}{c}\text { Total Number } \\
\text { of Workers } \\
\text { Monitored }\end{array}$ & \multicolumn{5}{c}{$\begin{array}{c}\text { Number of Workers Receiving Annual Dose within } \\
\text { Indicated Range }\end{array}$} \\
\cline { 3 - 6 } Year & & $\begin{array}{c}<10 \\
(\mathrm{mrem})\end{array}$ & $\begin{array}{c}10-100 \\
(\mathrm{mrem})\end{array}$ & $\begin{array}{c}101-500 \\
(\mathrm{mrem})\end{array}$ & $\begin{array}{c}>500 \\
(\mathrm{mrem})\end{array}$ \\
\hline 1986 & 1865 & 1102 & 756 & 7 & 0 \\
1987 & 1600 & 850 & 746 & 4 & 0 \\
1988 & 1865 & 1242 & 618 & 5 & 0 \\
1989 & 2399 & 1843 & 556 & 0 & 0 \\
1990 & 3218 & 2334 & 883 & 1 & 0 \\
\hline
\end{tabular}

\section{MAINTENANCE AND STARTUP TEST PRACTICES}

Conclusion: Inadequate attention has been given to actions that could prevent the inadvertent release of tritium during maintenance and startup test activities. Although program enhancements for maintenance are being planned, continued Westinghouse Savannah River Company management attention is required to successfully complete and implement these improvements.

Historical practices for maintenance work have not included adequate emphasis on actions or planning to minimize the potential for spills of liquids containing tritium. Health Physics personnel review maintenance work packages to determine whether or not radiation work permits are required and assist in radiation work permit preparation. The emphasis of these reviews has been to ensure that adequate radiation and contamination protective measures were specified for workers. Although these measures have been effective in controlling dose and worker assimilations of tritium, no structured review has been made that defines actions to minimize and mitigate spills and releases, such as erection of confinement tents, bagging of work areas, and installation of temporary, local ventilation. Health Physics personnel evaluations could result in specification of confinement techniques. In addition, in some cases where various confinement strategies have been used, the requirements for their use were not specified either in the work request package or on the radiation work permit. Also, in at least two instances, the radiation work permits specified no requirement for Health Physics to conduct a pre-job briefing for maintenance work involving line breaks for systems containing tritium. 
The K-Reactor's Startup Program is a phased approach, developed to ensure that the plant's systems are ready to operate safely and that the systems and components meet required functional performance criteria. This Program has included tests on a number of systems containing moderator, including the Supplementary Safety System, the Process Water System, and the Purification System. Although this testing has involved a wide range of changes in operating conditions and numerous movements of moderator after extended shutdown of systems, little consideration was given during plans for the tests to containing spills or minimizing the potential for spills. Specific cautions as to steps that could prevent spills were not included in the startup test procedures, and, initially, confinement strategies were not used in areas that might be subject to spills. Partially as a result of this lack of planning, a series of minor spills and events occurred over the initial weeks of the Startup Test Program. Fifteen minor releases occurred as a result of testing the Supplementary Safety System, although most of these were well below the threshold of requiring preparation of an offnormal occurrence report. Westinghouse Savannah River Company reports any moderator release greater than 1 quart to DOE.

Recently, Westinghouse Savannah River Company has focused considerable management attention on actions that may inadvertently result in release of moderator. The work control procedure is being revised to specify the circumstances under which Health Physics is required to complete an ALARA review using a checklist as part of the process for planning all modifications inside the K-Reactor exclusion area. Health Physics is developing a separate procedure that will be used to document the ALARA reviews.

Draft versions of the checklist for the ALARA review take specific account of confinement strategies, placement of leakage collection materials, and adequacy of preparations for evolutions. In addition, Startup Test Program management has implemented an informal lessons-learned program to share information about events that occur during startup testing. Two people have been assigned to informally review plans for startup test activities, determine if there is a potential for an unintentional release of tritium, and specify appropriate mitigative measures. These actions should help heighten worker sensitivity about taking all necessary precautions to minimize releases of moderator.

\section{PREVENTIVE MAINTENANCE}

Conclusion: Westinghouse Savannah River Company has not adequately addressed implementation of a preventive maintenance program to reduce the probability of release of fluids containing tritum due to equipment degradation and failure. 
Westinghouse Savannah River Company conducted a maintenance self-assessment in 1989 to identify ways to improve the maintenance programs for the K-Reactor. In response, a Maintenance Improvement Program was prepared and formally issued in April 1990. One of the initiatives idertified was preparation of a formal procedure to implement a preventive maintenance program.

Limited progress has been made to establish an integrated program to enhance the Preventive Maintenance Program. However, discussions with Westinghouse Savannah River Company personnel indicate that the focus of this program will be to improve plant reliability and safety. No specific preventive maintenance activities have been cited that would be aimed at reducing the potential for equipment failures that lead to inadvertent releases of tritium. Given the age of the plant and the susceptibility of the design to releases of moderator from a variety of sources, the Preventive Maintenance Program, when it is initiated, should specifically include those tasks that can contribute to reducing the potential for unintentional releases of tritium.

\section{CONDUCT OF OPERATIONS}

\section{Conclusion: Failure to follow procedural requirements regarding the calculation of tritium concentrations in moderator has resulted in the use of incorrect values of moderator concentrations.}

The equations used to calculate moderator loss rate and tritium release values make use of a moderator tritium concentration. The tritium concentration is determined by a procedural step that requires that the results of the first three tritium samples be averaged each w sek. The Task Group noted that the current value used for moderator tritium activity had not been calculated for some time, at least not in the recent memory of control room operators. A review of operating logs indicated that tritium concentrations were infrequently changed and were often based upon copying the value from an uncontrolled, informal, handwritten note. The control room operations personnel never questioned the bases or the validity of the currently used tritium concentration value. The Task Group was unable to determine the bases for the value in use, and, subsequently, calculated the value. The Task Group found that the resultant tritium concentration was higher than the tritium concentration value currently in use. The use of a lower tritium value, therefore, resulted in a lower indicator of moderator effluent loss. 


\section{RADIATION WORKER TRAINING}

\section{Conclusion: Radiation worker training for reactor area personnel does not ensure that all pensonnel who may be exposed to tritium undestand its unique properties and know how to protect themselves from assimilation of tritium.}

One objective of training for radiation workers is to ensure that they understand the basic hazards related to work in a radiation environment, and can then take appropriate measures to minimize their exposure. Unlike most other contamination sources, tritium, in its oxide form (the predominate form of tritium released at the Savannah River Site reactors), is readily assimilated into the body and, therefore, special precautions are necessary when working in areas where the potential exists for exposure to tritium oxide. General new employee training only touches on tritium exposure and does not provide the kind or depth of knowledge required to properly react to tritium releases. The next level of training, reactor area radiation worker training, concentrates on how to properly read, understand, and use radiation work permits and how to don and remove anticontamination clothing. Neither course presents the assimilation properties of tritium oxide or fully explains the proper reaction to tritium releases. For instance, no training is given on what immediate actions are necessary to minimize uptake if anticontamination clothing or bare skin is wetted with process water (heavy water with up to 12 curies per liter of tritium in the oxide form).

Workers are given additional training if they are required to wear plastic suits (plastic, air-supplied suits, often referred to as bubble suits) as a part of their job requirements. This training provides information on the assimilation paths for tritium. However, the training does not include explicit discussion of exposuremitigation techniques, such as frequent changes of gloves when working with tritium or immediate removal of tritium oxide-wetted contamination clothing.

Not all workers who enter areas where they may be exposed to tritium oxide receive the additional plastic suit training, and not all personnel understand the basic hazards of working with tritium oxide and the steps they can take to minimize their exposure. Routine training does not explain the difficulty in detecting tritium contamination, and the fact that a whole body frisk is not useful in determining if tritium contamination is present.

\section{OPERATING EXPERIENCE REVIEW}

Conclusion: Management has not implemented an effective program to analyze operational events and ensure that corrective actions are completed to minimize the potential for recurrence. 
Operational events that result in uncontrolled releases of moderator occur on a relatively frequent basis at the K-Reactor. For example, Westinghouse Savannah River Company identified a total of 43 events that resulted in loss of moderator from October 1990 to the end of April 1991. These events varied in significance from observations of drip leakage to spills of 160 gallons.

Events judged to be significant are critiqued, corrective actions are identified, and assigned to personnel for completion. The results of such critiques are distributed to other Site reactors for informational purposes. The Task Group noted that corrective actions have not always been implemented in a manner timely enough to prevent recurrence of events. For example, changes in procedures and practices were expected to minimize the potential for hoses and tubing connections to separate and become sources of moderator leaks containing tritium. Yet, subsequent spills have occurred due to failure to adequately secure hoses and tubing.

Accountability for implementation of the corrective actions assigned during critiques is weak. Corrective actions are entered into the Master Tracking System at each site. However, at present, there is no capability for generating sorts of all open corrective action items in the system. Thus, management has no effective mechanism to verify closure of these items. A sample of five corrective action items, all of which were past their due dates for closure, were reviewed to examine the corrective action closure process. The Task Group found that none of the individuals who had been assigned responsibility for these items was aware that the responsibility had been assigned or knew the closure due date.

The Task Group attended a critique of a P-Reactor moderator spill in which 0.7 pound of moderator was lost. The spill occurred when a partially full segment of hose or pipe (called a jumper) connecting the deionizer to the drain was disconnected following draining operations. There is no mechanism to verify that the jumper is empty following a draining operatio:i, and similar events have occurred numerous times at the site reactors. Although this is a recognized, recurring problem, steps have not been initiated to implement design modifications or corrective actions to prevent future spills. As a result of the critique, a commitment was made to prepare a request for engineering assistance to correct this problem.

Within the K-Area, ineffective evaluation takes the place of critique-generated corrective actions. Individuals are not formally assigned to review corrective actions for applicability, and there is no mechanism to track due dates of evaluations or status of actions. Westinghouse Savannah River Company management has just approved an organizational modification, which will provide additional resources to review operating experience information. 
The critique process is highly dependent on the individuals who participate in it. Participants receive no formal training on how to diagnose root and contributing causes of the problems they identify. Definitions of corrective actions to eradicate the underlying causes of problems vary widely.

\section{STACK EFFLUENT MONITORING}

\section{Conclusion: Weaknesses associated with determination of tritium concentration in the stack and the air flow through the stack result in uncertainties in the quantification of tritium released from the $K$-Reactor.}

The determination of the amount of tritium ieleased from K-Reactor is based on measurement of tritium concentration in the stack and the air flow through the stack. Both of these parameters contain sources of error that, at present, have not been quantified. In addition, there are tritium releases from systems located outside the reactor building, such as spills of reactor coolant. Releases from these systems are not monitored.

There are two types of stack monitors: Berthold Stack Monitors and Stack Tritium Monitors. Currently, the methods for checking the accuracy of these monitors to measure tritium release do not account for all sources of error in the tritium monitoring system.

For the Berthold Stack Monitors, the sampling line extends from the 1-inchdiameter, perforated pipe in the stack to the monitor. Incorporated into this sampling line are manifolds, water traps, heaters, and vacuum pumps. The response of this instrument is evaluated by injecting a known quantity of tritium gas directly into the monitor. However, the effects of the sampling line and its associated components on the tritium concentration measurement of the monitor are not evaluated.

Periodic calibrations of the electronic components are not performed for either the Berthold Stack Monitors or the Stack Tritium Monitors. Instead, proper operation of the electronic components is assumed if the instruments correctly respond to a source check and the value of the bias voltage is within required tolerances. Because it is not practical to perform the source check for more than one point on one scale, the electronic calibration is important to verify that the instrument is responding in a known and predictable manner over its full range.

The response of both of these instruments depends on the flow of air from the stack to the detectors. An unannunciated failure of the vacuum pumps, which maintain flow to the monitors or other off-normal conditions in the sampling line, 
could introduce errors in tritium monitor measurements. Action has been proposed to install a remote indicator status for the vacuum pumps.

The measurement of the air flow introduces an additional source of error in the calculation of tritium release. At present, because the detectors for monitoring air flow in the ventilation exhaust have not been authorized for use at K-Reactor, air flow is determined by engineering calculations that establish values for air flow for a given configuration of the ventilation system (e.g., number of fans operating, dampers open). Differences between the calculated air flow and the true air flow create another source of error in the determination of the tritium release.

The uncertainties associated with the calculation of tritium loss could be important. However, the significance of these sources of eiror cannot be determined until their effect on the calculation of the tritium concentration has been evaluated. The uncertainties associated with the sampling line (loss of tritium and unannunciated decrease in air flow) could introduce a negative bias into the calculation of the tritium concentration. The other uncertainties discussed can vary in both the positive and negative direction. Accordingly, the effect of these uncertainties on the determination of the tritium releases is not likely to produce a consistent bias in the determination of the tritium releases.

The value of the tritium concentration used to calculate tritium releases from the K-Reactor at the Savannah River Site is the most probable value, not the most conservative value. Because those sources of error that have : een quantified provide estimates of the statistical variation of the tritium concentration, as opposed to providing an indication of a bias, the current method of calculating tritium emissions probably will not result in significant error when averaged over time. However, if a factor has been overlooked that results in a negative bias, the tritium concentration could be significantly underestimated.

\section{RADIOLOGICAL PROTECTION}

\section{Conclusion: A dowswwand trend in recorded tritium assimilations has contributed to complacency regarding releases and an approach that is not consistent with the Department's ALARA policy.}

The average radiation doses to personnel working at the K-Reactor have been maintained at relatively low levels for the past several years. The contribution of tritium to the total dose has also been consistently low. Management and site personnel consistently cite those successes as evidence that the Radiological Controls Program is effective in controlling exposure. 
Great emphasis is placed on the fact that there have been no assimilations of tritium that have required reporting to DOE; however, the threshold above which reporting is required is a committed, effective dose equivalent of 100 millirem. Assimilations of smaller quantities of tritium resulting in measurable doses to workers have occurred. Rather than focusing on not exceeding the threshold, the emphasis should be on eliminating events that lead to measurable assimilations.

Another area in which the Radiological Controls Program could be improved is the reporting of internal doses. The small magnitude of the individual doses recorded at the Savannah River Site could contribute to an incorrect assessment of the effectiveness of the Radiological Controls Program. At the Savannah River Site, the lowest recorded committed effective dose resulting from an uptake of tritium is 5 millirem. This results from the practice of recording doses in multiples of 5 millirem. Thus, if a dose is determined to be greater than or equal to 2.5 millirem, it is recorded as 5 millirem and, if a dose is determined to be less than 2.5 millirem, it is recorded as 0 millirem. Because doses determined from measured bioassay data are accurate at levels less than 1 millirem, the Savannah River Site is capable of reporting doses at levels less than 5 millirem. The practice of rounding doses may result in misinterpretation of internal depositions of tritium because: (1) the n!mber of individuals with measurable tritium doses will be underestimated due to rounding doses below 2.5 millirem to zero; and (2) depending on the distribution of the magnitudes of the doses in the range between 0 to 5 milirem, a significant portion of total dose to the K-Reactor workers may not be recorded.

\section{CONTAMINATION MONITORING}

\section{Conclusion: Surface tritium contamination at K-Reactor is not routinely monitored; thus, the radiological conditions of the workplace are not fully characterized.}

Tritium contamination at K-Reactor derives from many sources. A primary source is the presence of tritium in the heavy water moderator, currently at 9.6 curies per liter. Any spills or leaks of moderator within or around K-Reactor result in releases of tritium oxide. Spills are usually recontained, which recovers the bulk of the tritium activity. However, tritium oxide vapor is usually released to the air in the vicinity of the spill, and residual tritium contamination is present on surfaces. The residual tritium contamination eventually evaporates, leaving low levels of contamination. However, tritium contamination at K-Reactor is not routinely monitored by smear testing. Thus, the K-Reactor Health Protection staff does not have enough information to fully document the radiological conditions of the workplace. 
In the absence of adequate information on tritium contamination levels, the staff assumes that the beta-gamma contamination from mixed fission and corrosion products is an adequate indicator of tritium contamination. One recent calculation of the ratio between tritium and mixed fission and corrosion product activity in the moderator in the liquid phase is $3 \times 10^{8}$. This large ratio between tritium and beta-gamma emitters could lead to significant oversight. The Health Physics inspectors routinely survey for beta-gamma contamination, but if their instruments read background (typically 100 to 200 counts per minute), they declare a surface free of contamination. However, significant amounts of tritium contamination could be present and go undetected due to the very low energy of radiation emitted by tritium contamination.

There was no clear indication that operations staff understood that tritium surface contamination could be present. The prevailing assumption seemed to be that tritium was present only in the form of tritium oxide vapor, which was rapidly being exhausted from the area. Such a conception endangers contamination control, and, indeed, several examples of poor contamination control were observed (such as not changing contaminated gloves, touching clean surfaces with contaminated gloves, and touching the skin with potentially contaminated gloves).

Another example of poor contamination control practices was observed as about 20 barrels of low-level waste (from minus 40-foot sumps) were pumped into a tanker. The manifest for the shipment indicated that contamination levels were only one count per minute per milliliter alpha, and less than one count per minute per milliliter beta-gamma; there was no result for tritium concentration. These results did not adequately characterize the liquid waste, since concentrations expressed in counts per minute per milliliter are not quantitative if the counting efficiency is not known and no tritium result is provided. Consequently, the technicians were misled into believing the liquid waste was free of contamination. Although they were dressed in full protective clothing, they did not change their gloves and handled all the equipment as though it were free of contamination. If contamination had been present (tritium contamination probably was present), they would have spread contamination to the exterior surfaces of the barrels, to the auxiliary equipment, to the manifests, to the Health Physics inspector, and to the areas outside the contamination control area. 
APPENDIX A

SECRETARIAL TASKING MEMORANDUM 


\section{The Secretary of Energy}

Washington, DC 20585

February 19, 1991

MEMORANDUM FOR PAUL L. ZIEMER

ASSISTANT SECRETARY

ENVIRONMENT. SAFETY AND HEALTH

SUBJECT:

FORMATION OF TASK GROUP--OPERATION OF

DOE TRITIUM FACILITIES

I am concerned about releases and other problems at the Department's tritium facilities. Therefore, I would like you to take a closer look at the overall management of these facilities, including mechanisms for sharing design and operational information and measures for reducing actual and potential releases.

This memorandum directs you to take the lead in forming a task group to review tritium facility management practices and ldentify measures to improve operations. report should be prepared outlining the task group's Eindings, including your recommendations for addressing these concerns. Please provide me with a status report by March 15, 1991, os the group's progress.

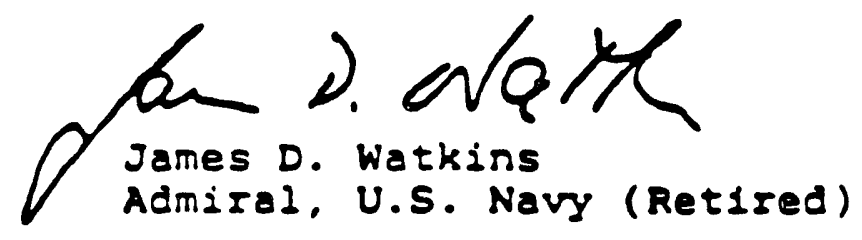




\section{APPENDIX B}

BACKGROUND ON TASK GROUP, CHARTER, AND CONDUCT OF ITS EVALUATION 


\section{APPENDIX B}

\section{BACKGROUND ON TASK GROUP, CHARTER, AND CONDUCT OF ITS EVALUATION}

\section{Background on Tritium Task Group}

As a result of concerns about releases and other operational problems at Department of Energy (DOE) facilities that handle, process, and store tritium, the Secretary of Energy, by his memorandum of February 19, 1991, directed the Assistant Secretary for Environment, Safety and Health to form a Task Group on Operation of DOE Tritium Facilities (Tritium Task Group). In the memorandum (provided as Appendix A), the Secretary expressed the desire to "...take a closer look at the overall management of these facilities, including mechanisms for sharing design and operational information and measures for reducing actual and potential releases." The Task Group was directed "...to review tritium facility management practices and identify measures to improve operations."

\section{Organization}

The Deputy Assistant Secretary for Safety and Quality Assurance (EH-30) served as chairman of the Group under the overall direction of the Assistant Secretary for Environment, Safety and Health. The Task Group was formally established on March 15, 1991, when its membership, protocol, and work schedule were provided to the Secretary. The Task Group included representatives from the DOE line organizations who are responsible for operating tritium facilities and a representative from the Office of Nuclear Safety. A working group was also formed. This group included members from DOE's Office of Environment, Safety and Health and Office of Defense Programs, as well as independent consultants. The members of the Task Group and the supporting working group are listed in Appendix C.

\section{Objectives}

In accordance with its Charter, the objectives of the Task Group were to:

(1) examine tritium operations and releases in terms of environment, safety and health performance and experience; (2) review oversight and self-assessment activities; (3) identify relevant standards and operational requirements; 
(4) conduct field evaluations of the operation and management of tritium facilities, including significant tritium events occurring during the tenure of the Task Group; and (5) develop recommendations to improve operations and minimize tritium releases.

\section{General Technical Approach}

The implementation schedule followed by the Task Group (Figure B-1) illustrates the sequence in which the assessment was approached. The Task Group began its assessment by identifying the facilities that handle, process, or store tritium. The Group then reviewed the operational history and performance profile of these facilities. In addition, onsite evaluations of selected facilities were performed to examine management and operation practices on a first-hand basis. The facilities evaluated were: Lawrence Livermore National Laboratory (LLNL), Los Alamos National Laboratory (LANL), Mound Plant (Mound), Oak Ridge National Laboratory (ORNL), Pantex Plant (Pantex), Pinellas Plant (Pinellas), Sandia National Laboratory, Livermore (SNL,L), Savannah River Site (SRS) H-Area Tritium Complex and Reactor Complex.

Not all DOE facilities involved in tritium were visited, only those that directly handle or store major quantities (greater than 1 gram) of tritium. Sites that release tritium as a byproduct of other operations, such as the Idaho Chemical Processing Plant, were not included in the Task Group's endeavor, nor were facilities handling relatively small quantities of tritium, such as those using tritium for biological tracing activities.

Onsite evaluations were conducted at the Lawrence Livermore National Laboratory and the Los Alamos National Laboratory to follow up on releases or related events that occurred at these sites during the Group's tenure. The Task Group's preliminary findings regarding these events were transmitted by memoranda to the cognizant Program Secretarial Offices. Copies of these memoranda are provided in Appendix D.

Subsequent to the completion of onsite evaluations, the Task Group conducted senior review team sessions involving selected, well-qualified members of the Department's tritium community and other senior technical program management with an overall appreciation of the Department's management approach. The senior review team examined the materials developed during the onsite evaluation efforts and identified strategic issues and their implications. These issues and implications helped the Task Group focus on the critical aspects of the Department's tritium operations. 


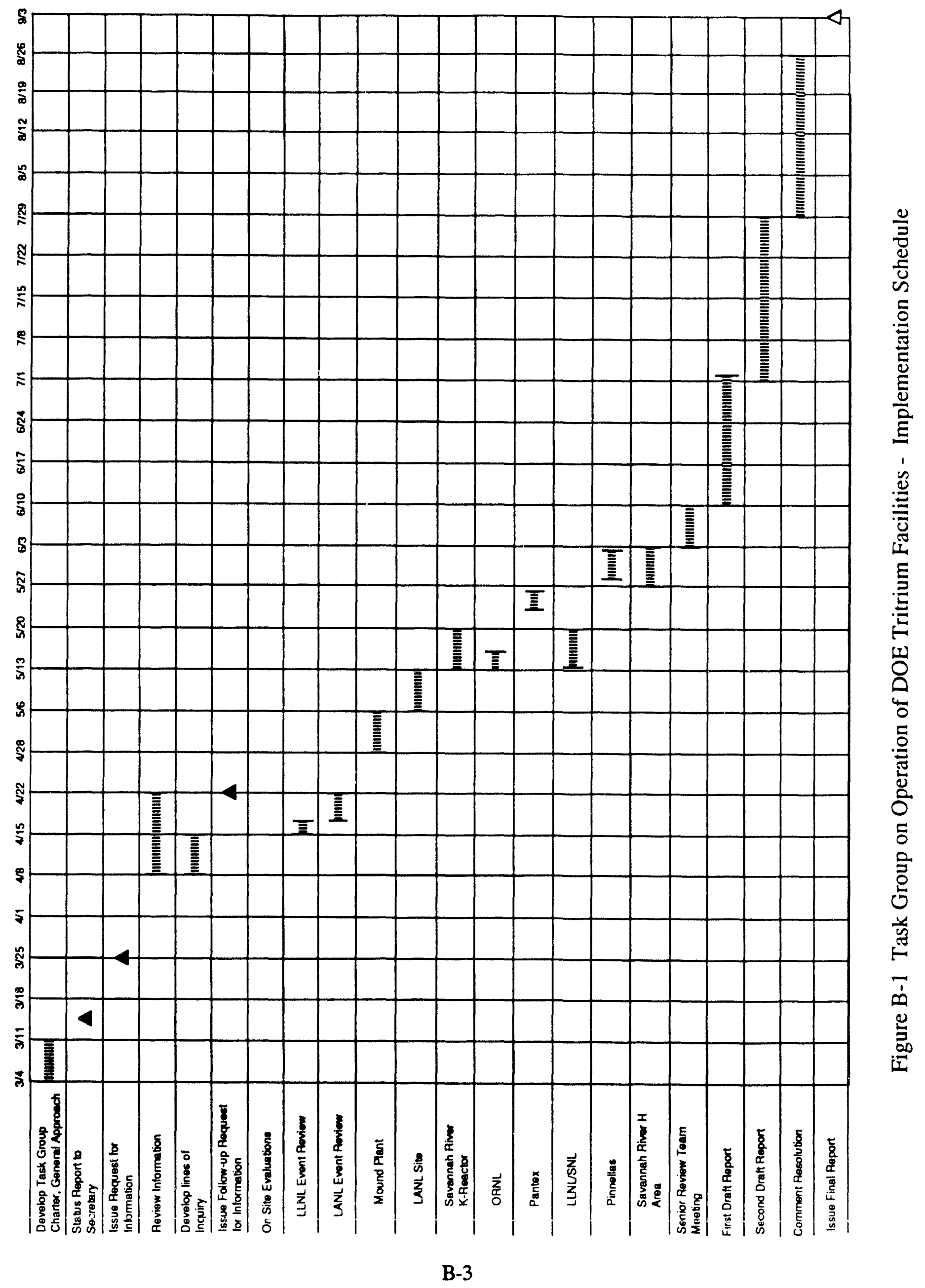




\section{Strategies for Meeting Objectives}

Examination of Tritium Operations and Releases. The Task Group developed a list of facilities that handle, process, or store tritium. This list was prepared through consultation with the cognizant program offices and was used to establish the total scope of the Task Group's efforts.

The Task Group reviewed information about tritium releases over the last 5 years. Events to study were selected from DOE databases and in consultation with the program offices. Documents reviewed included: Unusual Occurrence Reports (UORs), event critiques, and reports that described corrective actions taken. The Group discussed the events with appropriate DOE and contractor personnel to ensure that key implications regarding the events were identified.

Review of Oversight and Self-Assessment Activities. The Task Group reviewed Tiger Team Assessment (TTA) and Technical Safety Appraisal (TSA) reports to determine the most significant tritium-handling facilities. This review ensured that any deficiencies previously identified by the Department were considered by the Task Group.

Identification of Relevant Standards. The Task Group sought to identify standards, guidelines, and operational requirements applicable to the tritium facilities. The Group reviewed DOE Orders, Operational Safety Requirements, and other relevant documents. This effort provided a basis for judging the adequacy of existing standards and the effectiveness of their implementation at individual facilities.

Onsite Evaluations. The Task Group conducted onsite assessments at selected tritium facilities to examine management and operations. This effort included examination of facilities that have historically experienced problems with tritium releases, as well as facilities where tritium has only rarely been released. The group developed a basis for identifying good practices, as well as deficiencies in facility design, programs, and equipment.

During the course of these evaluations, the Task Group used a "bottom-up" assessment of existing management practices, i.e., used a sample of operational practices to evaluate ES\&H philosophy and performance. The Group determined if these practices conformed to applicable standards, guidelines, and requirements; identified problems with existing practices; and assessed management awareness of deficiencies, including self-assessment capabilities and activities. The Task Group considered the full spectrum of factors that contributed to tritium releases (routine, as well as accidental), including management practices, operating procedures, operator training, equipment and system design, maintenance, and quality verification activities. 
The Group also examined operational feedback programs to determine if the DOE tritium community is effectively applying lessons learned at other facilities. The Task Group: (1) reviewed the means for disseminating event information (within the facility, throughout the relevant site, and throughout the DOE tritium complex); (2) evaluated the actual event review; and (3) analyzed management attention to corrective actions taken. In addition, the Task Group examined timeliness of reviews and determinations of applicability of events to other facilities.

A list of prioritized recommendations on how to minimize tritium releases was developed by the Task Group. This list is provided in the Executive Summary. 
APPENDIX C

TASK/WORKING GROUP MEMBERS ON OPERATION OF DOE TRITIUM FACILITIES 


\section{APPENDIX C}

\section{TASK/WORKING GROUP MEMBERS ON OPERATION OF DOE TRITIUM FACILITIES}

\section{TASK GROUP MEMBERS}

Joseph E. Fitzgerald, Jr.

Oliver D.T. Lynch, Jr.

David E. Bailey

William W. Weaver

Gene R. Nardella

Ralph A. Hagan

Andrew Wallo III

H. Kay Whitfield

Robert W. Barber
Deputy Assistant Secretary for Safety and Quality Assurance, Office of Environment, Safety and Health (EH-30), Task Group Chairman

Director, Office of Performance Assessment, Office of Environment, Safety and Health (EH-32), Deputy Chairman

Director, Office of Facilities, Fuel Cycle and Test Programs, Office of Nuclear Energy (NE-471)

Functional Manager for Systems Engineering, Performance Assessment Division, Office of Nuclear Safety (NS-10)

Engineer, Office of Fusion Energy, Office of Energy Research (ER-53)

Mound/Savannah River Site Action Team Leader for the Deputy Assistant Secretary, Office of Defense Programs (DP-224)

Director, Air, Water and Radiation Division, Office of Environment, Safety and Health (EH-232)

Environmental Specialist, Office of Waste Operations, Office of Environmental Restoration and Waste Management (EM-321)

\section{WORKING GROUP MEMBERS}

Director, Office of Risk Analysis and Technology, Office of Environment, Safety and Health (EH-33), Team Leader 
Michael Hillman

Kenneth G. Murphy

Darrell A. Huff

Joel L. Rabovsky

Raymond Cooperstein

Robert Evans

Dan M. Stover

Bernard R. Kokenge

Douglas P. Serpa

Jerome B. Martin

Margaret H. Surdivant

Don L. Hobrock
Dire ctor, Resident Programs Division, Office of Environment, Safety and Health (EH-30.2), Team Leader

Acting Director, Safety Technology Division, Office of Environment, Safety and Health (EH-332), Operations

Nuclear Engineer, Safety Technology Division, Office of Environment, Safety and Health (EH-332), Operations

Health Physicist, Office of Health Physics/Industrial Hygiene Programs, Office of Environment, Safety and Health (EH-41), Health Physics

Physical Scientist, Program Planning Division, Office of Defense Programs (DP-132), Tritium Operations

Consultant to the Office of Environment, Safety and Health, Operations

Consultant to the Office of Environment, Safety and Health, Operations

Consultant to the Office of Environment, Safety and Health, Tritium Operations

Consultant to the Office of Environment, Safety and Health, Tritium Operations

Consultant to the Office of Environment, Safety and Health, Health Physics

Consultant to the Office of Nuclear Safety, Engineering

Consultant to the Office of Environment, Safety and Health, Tritium Operations 


\section{APPENDIX D}

TASK GROUP MEMORANDA ON PRELIMINARY FINDINGS 


\section{APPENDIX D \\ TASK GROUP MEMORANDA ON PRELIMINARY FINDINGS}

Onsite evaluations were conducted at the Lawrence Livermore National Laboratory (LLNL) and the Los Alamos National Laboratory (LANL) to follow up on selected accidental releases and related events (including an off-normal occurrence) that occurred at these sites during the early portion of the Task Group's tenure. The following four memoranda transmitted the results of these evaluations to the cognizant Program Secretarial Offices, and provide summaries of the events and their root causes as determined by the Task Group. These memoranda provide useful insight regarding the facility conditions, management practices, and conduct of operations existing at these facilities at the time of the events. This information was considered in the development of the Generic Issues, as well as the principal findings expressed in the Executive Summary. One event, a 144-curie release, occurred at the Tritium Facility at the Lawrence Livermore National Laboratory on April 2, 1991. Three events occurred at the Los Alamos National Laboratory: a less-than 5-curie release at the Tritium Salt Facility on April 11, 1991; a 0.4-curie release at the Tritium System Test Assembly on March 28, 1991; and a loss of power to ventilation system, a potential-release-only event, at the Weapons Subsystem Laboratory' on April 30 through May 1, 1991. 
DAtE: May 6, 1991

MEPLY TO

ATTN OF: EH-33

suaECT: Preliminary Findings of Tritium Task Group -. LLNL Building 331, Event of April 2, 1991

To:

Richard A. Claytor

Assistant Secretary for

Defense Programs, DP-1

The Secretary of Energy directed that a Tritfum Task Group be formed by a memorandum to the Assistant Secretary for Environment, Safety and Health (EH-1) on February 19, 1991. The purpose of the Task Group is to examine the overall management of the Department's tritium facllities and recommend ES\&H. related improvements. The Task Group was established and a schedule of activities was issued on March 15, 1991. In addition, it was decided that the Task Group would review any tritium-related events which occurred during the Group's tenure to avail itself of any lessons learned that may be pertinent to DOE tritium operations. Accordingly, a site visit was conducted at the Lawrence Livermore National Laboratory (LLNL) the week of April 15, 1991, to review the circumstances surrounding the April 2, 1991, tritium release at LLNL's Tritium Facility, Building 331. The review was conducted during the period April 15-16, 1991, and preliminary findings regarding the event were discussed with Don Pearman, Manager, San Francisco Operations Office (SAN); Ed Keheley, Manager, DOE Livermore Site Office; Duane Sewe 11, Deputy Director, LLNL; and DP-20 staff. The Task Group members conducting the LLNL review are listed in Attachment 1 , with LLNL staff contacted listed in Attachment 2.

The Task Group was briefed by SAN staff and the cognizant facility management concerning facility functions, the incident, the management organization, and its response to the event. A detailed tour of the facility was then made, the involved personnel and their management interviewed, the related facility procedures, Safety Analys is Reports (SARs), or other documents reviewed, and the extent of oversight of the operation by DOE reviewed. It was stressed that in view of ongoing investigations of this event by SAN and the contractor, the Task Group would only cite preliminary findings that would be more formaily addressed in the larger context of its report to the Secretary.

The event occurred when a tritium operator was preparing a 1968-vintage pressure vessel (that was assumed to have the potential to contain tritium) for pressure characterization of its contents. Evaluation of such vessels is part of the downsizing of LLNL's Tritium Facility. Hork was being performed in a iritium-approved work hood. 
The valve on the vessel was closed. When the operator attempted to remove the plug located downstream from the valve, the contents of the vessel leaked through the valve into the work hood and laboratory room and out the facility stack (room air exhausts through the stack). The portable tritium monitor next to the hood and the room monitor alerted the operator to the release of tritium. The operator attempted to stop the leak, but was unable to do so. Both he and the remainder of the facility staff evacuated the Radioactive Materials Area (RMA) according to facility procedures. After the radiation level in the room began to drop, the operator and three other workers reentered the room under the basic assumption that there was no oxide associated with the release, and moved the vessel to a tritium-approved maintenance glovebox to contain any further releases. It is important to note that this reentry action was apparently motivated by a strong desire to avoid any further environmental release and related publicity.

The appropriate LLNL and SAN management was notified, as well as national, State, and county agencies. The estimated radiation dose was 1.2 to 1.5 rem for the main operator. The dose to each of the other three workers was estimated at 10-20 mrem, based on standard assumptions regarding tritium uptake and the results of bioassay samples. Approximately $144 \mathrm{Ci}$ of tritium was released to the atmosphere through the exhaust stack.

Downsizing was underway on the B-331 Building tritium inventory to effect a reduction from about $225 \mathrm{grams}$ of tritium to less than 5 grams. The downsizing is consistent with a change of mission for the facility from weapons program support to one of R\&D support, while at the same time, decreasing budgetary costs attendant with a change in hazard classification from a high to a lower rating.

The likely direct cause of this event was the failure of the cylinder valve. The valve gasket seal was made from an elastomer and had hardened and cracked. This is a common failure mode for this component due to radiation damage from tritium; this resulted in modification of such gaskets to metal composition subsequent to about 1970. This was the last of 12 aged cylinders to be processed before shipment. A very brief procedure was in place for this operation, but no consideration was given to this type of hazard, although it was recognized that pre-1970 cylinders were considered unreliable.

A more fundamental cause of this event was seen by the Task Group as being the failure of management and the operators in the Building 331 to recognize the potential hazard of opening tritium pressure cylinders in a hood (rather than alovebox) and to recognize that tritiated water vapor, as well as tritium gas, could be avallable from such a source. There was no way the operator could have prevented the leak once the seal was broken, and there was no way to predict whether a cylinder might have a faulty vaive. Reentry of personnel to remove the leaking cylinder violated basic emergency response practice and weighed occupational dose against environmental consequences. This was considered by the Group to be a questionable management decision. 
Preliminary viewpoints of the Task Group on the management implications of the event are as follows:

- The LLNL Tritium Facility Review Comittee, established in response to the incident, is provided with a charter which only addresses technical issues and symptoms and not the management issues that were major contributors to the incident. The criteria for normalizing tritium operations does not address the overall operation of the facility (beyond the process of tritium handling) which may be more likely to create problems in the future.

- The "gas only" mindset of facllity management, which was reflected in facility procedures, contributed significantly to the inadequate health and safety response (notably the reentry of personnel) to the event. In addition, the behavior of the tritium level decline indicated by monitoring instruments was not that expected from tritium gas, but more indicative of the presence of the oxide form. The anomalous decline was noted by the facility staff in their reentry consideration, but not correctly interpreted. The reentry was not coordinated with professional radiation monitors or medical staff and indicates a lack of formality and discipline in the management of off-normal incidents. This brings into question the ability of the Laboratory to respond to and manage a larger incident or emergency. The reentry was made without adequate consideration of the health and safety of facllity personnel in an effort to mitigate an atmospheric release.

- The concept of independent safety oversight for the facility is compromised by the obvious demands from programmatic interests in expediting the facility downsizing effort. This problem was recognized by facility and DOE/SAN management.

- LLNL management control of safety in the downsizing process is lacking. Based on interviews with facility personnel and review of facility documents, it appears that Laboratory management had taken a hands-off attitude in this respect.

- The responses to an LLNL independent review group report (December 1990) have been superficial and indicate a lack of recognition of the seriousness of the issues identified by the independent reviewers. One of the original reasons stated for the review was a concern that downsizing and the speed of the downsizing process might result in an incident. LLNL management has falied to require facility management to take ownership of the review and implement its recommendations.

- Facility procedures are deliberately flexible to allow for operator discretion; ani therefore, foster an overly informal approach to conduct of operations. 
- The overall housekeeping in the facility indicates a lack of health and safety oversight by all concerned (facllity, department, and hazards control). The presence of large numbers of tritium contaminated items in routine work places is not in keeping with responsible health and safety work policies and practices.

- Portable tritium instruments used during the incident had outdated calibration stickers. Further, hood face velocity testing and adjustments, as required by Laboratory policy, have not been made on a timely basis as indicated by calibration stickers. These items should be recognized as indicating a lack of health and safety discipline throughout the facility.

- The Laboratory does not have the management systems fully in place to provide the self-assessment that should have identified the systematic problems that led to this incident. Likewise, DOE oversight in the facility was considered inadequate; although steps are underway to establish a DOE facility representative program.

- 'LLNL has not recognized the importance of performing hazards analysis, as part of the downsizing effort prior to proceeding on this effort. They had accepted what is now seen as an incorrect premise that the off-normal operations were within the normal operational parameters. The "can do" attitude is commendable, but it must be disciplined to ensure safety.

- The LLNL tritium facility operates with a single barrier philosophy with respect to tritium containment. Yet, facility management had failed to implement compensatory steps to mitigate tritium releases while awaiting upgraded confinement through the now eliminated SCOTS program and when dealing with nonroutine activities as part of its downsizing activities.

- The shutdown facility is not considered to be in a safe condition as there are several LP-50 containers holding approximately 11 grams of tritium that are not properly secured in their secondary containers. In addition, there are salt containers not securely contained on their transportation device and tritium pressure is increasing within several palladium containers for which action must be taken to prevent tritium migration from the primary into the secondary container.

- There is a heavy reliance on operators to make important decisions related to performing tritium-related operations. The "Principle of Procedural Flexibility" invoked by facllity management does not provide for review of important tritium handiing activities.

Should you have any questions regarding these preliminary viewpoints, please contact me at 353-5532. I encourage you to share these initial observations on this event with other DP tritium operations to encourage a broader exchange of operating experiences. 
On behalf of the Task Group, I would like to express my apprectation for the assistance extended by SAN and LLNL to us during our review. The openness and candor of SAN and LLNL management and staff have facilitated what we believe will be a constructive and timely assessment of DOE's tritium operations for the Secretary.

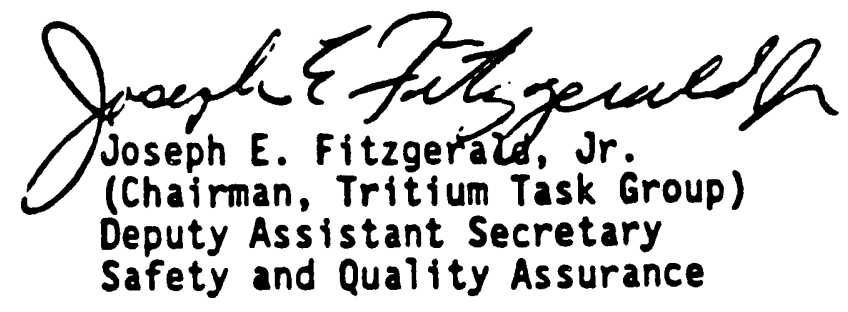

2 Attachments

cc w/att:

John Tuck, S-3

P. Ziemer, EH-1

S. Biush, NS-1

L. Smith, S-3

B. Hyder, S-3

J. Barr, DP-20

D. Pearman, SAN

E. Keheley, SAN 
Members of Tritium Task/Working Group

LLNL Visit - April 15-16, 1991
J. Fitzgeraid
0. Lynch
D. Bailey
R. Cooperstein
$R$. Duncan
R. Hagan
B. Kokenge
D. Serpa
D. Stover

\author{
EH-30 (Chairman, Team Leader) \\ EH-33 (Deputy Chairman) \\ NE -47 \\ DP -132 \\ NP -42 \\ DP-22 \\ Consultant (EH-33) \\ Consultant (EH-33) \\ Consultant (EH-33)
}


ATTACHMENT 2

Site Personnel Interviewed

LLNL Visit - April 15-16, 1991

\author{
Rebecca Failor \\ Rex Beach \\ David Taylor \\ Jon Maienschein \\ Robert Carter \\ Jeff Richardson \\ Clark Souers
}

D-8 


\title{
-memorandum
}

DATE: May 6, 1991

AEPLY TO

ATTN OF:

EH-33

suavect: Preliminary Findings of Tritium Task Group -. LANL, Tritium Sal.t Facility (TSF) Event of April 11, 1991

To:

\author{
Richard A. Claytor \\ Assistant Secretary for \\ Defense Prograns, DP-1
}

The Secretary of Energy directed that a Tritium Task Group be formed by a memorandum to the Assistant Secretary for Environment, Safety and Heaith (EH-1) on February 19, 1991. The purpose of the Task Group is to examine the overail management of the Department's tritium facilities and recommend ES\&Hrelated improvements. The Task Group was established and a schedule of activitios was issued on March 15, 1991. In addition, it was decided that the Task Group would review any tritium-related events which occurred during the Group's tenure to avail itself of any lessons learned that may be pertinent to DOE tritium operations. Accordingly, a site visit was conducted at Los Alamos National Laboratory (LANL) the week of April 15, 1991, to review the circumstances surrounding the tritium releases at the TSF and the Tritium Systems Test Assembly (TSTA). This memorandum is concerned only with the TSF. The LANL review was conducted during the period April 17-19, 1991, and preliminary findings for the TSF incident were discussed with Bruce Twining, Manager, DOE Albuquerque Operations Office (AL); Jerry Bellows, Manager, DOE LOS Alamos Area Office; Sigfried Hecker, Director, LANL; and Jim Jackson, Deputy Director, LANL. The Task Group members conducting the LANL review are listed in Attachment 1 , with LANL staff contacted listed in Attachment 2.

The Task Group was briefed by the cognizant facility management concerning facility functions, the incident, the management organization, and its response to the event. A detailed tour of the facility was made, the personnel in the event and their management interviewed, the related facility procedures, Safety Analys is Reports (SARs) or other documents reviewed, and the extent of oversight of the operation by DOE reviewed. It was stressed that in view of ongoing investigations of the event by $A L$ and the contractor, the Task Group would only cite preliminary findings that would be more formally addressed in the larger context of its report to the Secretary.

The tritium release at the TSF occurred during the attempted replacement of a valve stem and bellows assembly in the TSF glovebox atmosphere (nitrogen) circulating and cleanup system. An experienced faclitity operator, a radiation monitor, and an operator trainee were involved in the incident. A release of vapor from the bellows valve assembly occurred as the experienced operator, under close surveillance of the radiation monitor and observed by the trainee, removed three bolts, and started to remove the fourth, of a four slot head 
unit retaining the assembly. Immediately upon detection of a leak, the radiation monitor asked the trainee to leave. The operator quickly reinstalled the bolts in the valve assembly, and then both the operator and monitor left the room.

Outside the room the operator was found to have tritium contamination on the sleeve of his lab coat. He was ordered by the radiation monitor to remove $h$ is lab coat and take a shower. Repeated washings removed the contamination. The room al arm, set at $100 \mathrm{micro} \mathrm{Ci} / \mathrm{m}^{3}$, did not sound, al though the monitor was very close to that level. As a result of the event, the experienced operator received a whole body dose of about $24 \mathrm{mrem}$; the radiation monitor received approximately 1 mrem; and the trainee operator received approximately 4 mrem. About 3-4 Ci of tritium was released up the stack into the atmosphere.

Although the valve repair procedure was generally understood by the experienced operator and the radiation monitor, there was no written procedure, nor was a special work perimit prepared. It was noted that the experienced operator had only performed this specific task twice in the previous 10 years. The leak incident was apparently caused by failure of the operator to properly align the system. As a result, the valve to the high pressure receiver (10 psig at the time) and adjacent piping was open. Quick action by the operator prevented a more serious incident. Subsequent response by the LANL radiation protection personnel and operator was both prudent and appropriate.

A likely root cause of this incident was the operator's failure to properly align the system before attempting to perform maintenance on the bellows valve. This failure resulted in one receiver not being isolated from the defective valve. The consequence is considered by some LANL personnel to be rather minor, the maximum personnel dose being about $24 \mathrm{mrem}$, and the release to the atmosphere being less than $5 \mathrm{Ci}$. However, there was the potential that as much as $100 \mathrm{Ci}$ of tritiated water, which was estimated to be in the receiver at the time, sould have been released by the incident, should the operator have been unable to reassemble the vaive in a timely manner.

Preliminary viewpoints of the Task Group are as follows:

- The resporise to the April 11, 1991, event by health and safety personnel was prudent and appropriate, in allowing the replacement of the valve assembly to mitigate further leakage. The evacuation of the room and action to decontaminate the operator were likewise accomplished in an appropriate and prudent manner.

- The facility's staff exhibited insufficient knowledge to perform work on the auxiliary system without detailed written procedures. This is a failure by the contractor to recognize the loss of vital experience and knowledge caused by recent personnel turnover of 50 percent in the staff of four over the last $2-3$ years. No action has been taken to mitigate these 
losses by recognizing the need for formal procedures, documented systems descriptions, and formal training needed to ensure safe facility operation by the less experienced personnel.

- The TSF has been funded on a program basis for several years resulting in the emphasis on the process components, rather than the overall facility. Thus, TSF operations are not all formalized; system descriptions are not developed for most support systems.

- Knowledge by management personnel is not always commensurate with their level of responsibility. The TSF manager has a number of programatic responsibilities beyond the activities of the TSF that are technical in nature, diluting his effort to manage the TSF.

- DOE (LAAO, AL, and the Program Office) does not have adequate site presence to be aware of facility or operator inadequacies that lead to such events. Likewise, LANL does not have an organization or program to identify facility or operator inadequacies.

- Although the LANL radiation protection personnel show continuing presence at the facility, other safety disciplines, such as specialists in quality assurance, operations, maintenance, auxiliary systems, and technical support safety personnel, are not involved at this level.

- LANL and DOE event investigation groups exhibited difficulty in understanding the cause and implications of the actual event; specifically, that the entire pressurized accumulation of tritiated water vapor in the high pressure receiver had been opened to the room.

- In reviewing the investigation report of the TA-41 incident of last year and the review for the two incidents investigated by this Task Group, it appears that the LANL investigation process is not adequately focused. The LANL approach is more directed at symptom fixing, not root problem solving.

- The operations at the TSF are not conducted in a sufficiently formal manner; e.g., a lock and tag system has not been implemented, procedures are lacking for most operations, and those procedures that do exist have no requirement that they be "walked-down."

- Abnormal event reporting is poorly managed. There is essentially no followup and application of lessons learned within the TSF/TSTA and across the LANL site.

Should you have any questions regarding these preliminary viewpoints, please contact me at 353-5532. I encourage you to share these initial observations on this event with other DP tritium operations to encourage a broader exchange of operating experiences. 
On behalf of the Task Group, I would like to express my appreciation for the assistance extended by LANL to us during our review. The openness and candor of LANL management and staff have facllitated what we believe will be a constructive and timely assessment of DOE's tritium operations for the Secretary.

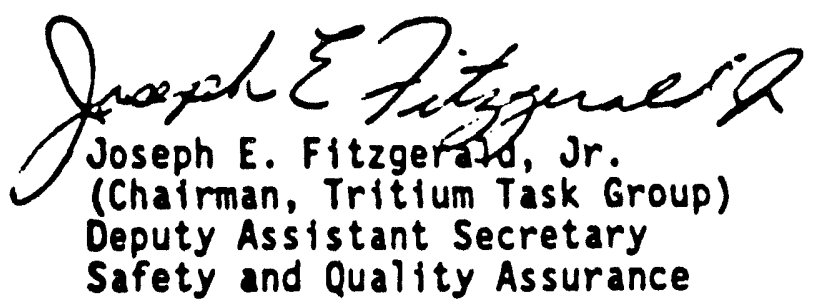

\section{Attachments}

cc w/att:

John Tuck, S-3

P. Ziemer, EH-1

S. Blush, NS-l

B. Twining, $A$ !

J. Bellows, LAAO

J. Barr, DP-20

L. Smith, S-3

B. Hyder, S-3 


\section{ATTACHMENT 1}

\section{Members of Tritium Task Grolip Event Team}

LANL Visit - April 17-19, 1991
0 . Lynch
R. Cooperstein
$R$. Duncan
R. Hagan
G. Nardella
B. Kokenge
D. Serpa
D. Stover
M. Sturdivant

EH-33 (Deputy Chairman, Team Leader)

$D P-132$

NP -42

DP-22

ER-1

Consultant (EH-33)

Consultant (EH-33)

Consultant (EH-33)

Consultant (NS-1)

D-13 


\section{ATTACHMENT?}

Site Personnel Interviewed

LANL Visit - Aprif 17-19, 1991
J. L. Anderson
J. Phoenix
R. V. Carlson
A. Valentine
J. D. Purson
J. Bellows 


\section{nemorandum}

DATE: May 6, 1991

REPLYTO

ATTN OF:

EH-33

subuect: Preliminary Findings of Tritium Task Group -. LANL Tritium Systems Test Assembly (TSTA) Event of March 28, 1991

TO: James F. Decker

Acting Director

Office of Energy Research, ER-1

The Secretary of Energy directed that a Task Group be formed by a memorandum to the Assistant Secretary for Environment, Safety and Health (EH-1) on February 19, 1991. The purpose of the Task Group is to examine the overall management of the Department's tritium facilities and recommend ES\&H-related improvements. The Task Group was established, and a schedule of activities was issued on March 15, 1991. In addition, it was decided that the Task Group would review any tritium-related events which occurred during the Group's tenure to avail itself of any lessons learned that may be pertinent to DOE's tritium operations. Accordingly, a site visit was conducted at the Los Alamos National Laboratory (LANL) the week of April 15, 199i, to review the circumstances surrounding the recent tritium releases at the ISTA and the Tritium Salt Facility (TSF). This memorandum is concerned only with the TSTA. The review was conducted during the period April 17-19, 1991. Preliminary findings for the LANL TSTA incident were discussed with Bruce Twining, Manager, DOE Albuquerque Operations Office (AL); Jerry Bellows, Manager, DOE Los Alamos Area Office; Sigfried Hecker, Director, LANL; and Jim Jackson, Deputy Director, LANL. The Task Group members conducting the LANL review are listed in Attachment 1 , with LANL staff contacted listed in Attachment 2.

The Task Group was briefed by the cognizant facility management concerning facility function, the incident, the management organization, and its response to the event. A detailed tour of the facility was ther. made, the personnel involved in the incident and the ir management interyiewed, the related facility procedures, Safety Analys is Reports (SRis) or other documents reviewed. It was stressed that in view of ongoing isyestigations of this event by SAN and the contractor, the Task Group woulj only cite preliminary findings that would be more formaliy addressed in the larger context of its report to the Secretary.

The tritium release event at TSTA occurred when an operator was filling an experimelital cylinder with tritium gas inside the receiving glovebox. He closed the cylinder valve, evacuated the connecting lines, closed the fill line valves, disconnected the flll line from the cylinder valve fitting, and was attaching a plug to the fitting when the glovebox alarm sounded, soon followed by the low-level room alarm. The operator quickly installed the plug and when it was tight, left the room. The cylinder isolation valve had leaked 
tritium into the box. The experimental cylinder had two valves, a needle valve next to the cylinder for flow control and an isolat,ion valve next in series to the outlet fitting. The isolation valve leaked. The needle valve did not seal and is not intended to do so. The isolation valve had been previously used and had not been tested since its last use. The exact cause of the isolation valve fallure is not known at this time because the valve had not been disassembled (due to ceased operations) and was still in place on the partially filled experimental cylinder at the time of our review.

Although this was an inert gas glovebox with a once-through nitrogen atmosphere and tritium recovery system, about $0.4 \mathrm{Ci}$ of tritium was released into the room and out the stack into the atmosphere. This was caused by a faulty connection between the transportation container (also called PC in the procedures) and the glovebox port. The transportation container had no "0" ring seal and was improperly attached to the glovebox port with " $C$ " $c l a m p s$. Although the receiving glovebox is designed to prevent tritium leakage into the working space in the room, it failed to do this because the PC was improperly attached. The transportation container "O" ring had apparently dropped off at the mass spectrometer fume hood in the TSF and remained there. Thus, the transportation container was attached to the glovebox by "C" clamps without an " 0 " ring seal. This condition had been in existence for 5 to 6 weeks while a total of $7473 \mathrm{Ci}$ of tritium had been handled in the glovebox. The glovebox was at positive pressure to the room, against DOE recommendations that gloveboxes in tritium facilities be kept at negative pressure.

The incident was initiated by the isolation valve leak on the experimental cylinder assembly. This may have been caused by employing a used valve without requalifying it by testing before it was installed on the cylinder. Used valves must always be tested before reuse, particularly where radioactive gases are involved. There could have been foreign material in the valve seat, such as material from the tungsten filler rod that had been placed in the tube between the valves to reduce the available gas volume between the valves. The operator did not receive any known radiation exposure above the background level at the glovebox.

There were two obvious causes of this event. One was the isolation valve leak, and the second was the improper connection of and the missing seal from the transportation container. The consequence was rather minor with the operator not receiving any additional radiation exposure over background. The release to the room and the atmosphere was only about $0.4 \mathrm{Ci}$. However, there was a potential of a much greater release because in 19 previous runs, a total of $7473 \mathrm{Ci}$ of tritium had been handled through the unsealed glovebox. The tritium in the cylinder assembly in this event was the largest amount handled in any of the 20 runs. 
Preliminary findings by the Task Group are as follows:

- The response to the March 28, 1991, incident by the operator and Health and Safety personnel was prudent and appropriate relative to the incident, resulting in minimum radiation exposure and a reasonable incident evaluation.

- The facility management has focused attention on the experimental systems to the detriment of the support systems. No procedures exist regarding some of the support system activities, such as valve testing.

- The incident at TSTA reflects an approach to continue work while in the process of fixing problems. The design and construction of the new load in-load out (LILO) glovebox has been underway for some time. There have been design problems that have been identified by Quality Assurance, facility personnel, and others. While the recognition of these problems is important, thorough design review at the front-end of the project is a key to avoiding problems of this type. Discipline and precise planning are also necessary to address and resolve problems on a concerted basis, rather than attempt to complete too many tasks simultaneously.

- The facility management failed to recognize potential operational and quality assurance problems associated with nonexperimental activities, such as handling the shipping containers.

- There are no procedures requiring safety testing of experimental tritium assemblies, such as the cylinder and valves, before their assembly.

- The review and approval process for procedures lack rigor and depth, resulting in the omission of important safety-related instructions. There is no requirement that procedures be "walked down" by the reviewers as part of the approvil process.

- DOE (LAAO, AL, Program Office) site presence is not sufficient to provide early identification of the operator or equipment inadequacies that lead to events. However, TSTA staff meets weekly to discuss the activities planned for the coming week.

- LANL does not possess an organization or program which can identify operator or equipment inadequacies that can lead to events.

- Abnormal event reporting is poorly managed. There is essentially no followup and application of iessons learned within the TSTA and across the LANL site. Incidents are not fully examined by facility management; e.g., the missing " 0 " ring later found in the TSF.

- Responses to incidents by DOE and the contractor are motivated by the seriousness of the consequence and not by recognition of potential implications; if insignificant amounts of tritium are involved, there is little interest to thoroughly examine, understand, and share information regarding the event's implications. 
Should you have any questions regarding these preliminary viewpoints, please contact me at 353-5532. I encourage you to share these initial observations on this event with other ER tritium operations to encourage a broader exchange of operating experiences.

On behalf of the Task Group, I would like to express my appreciation for the assistance extended by LANL to us during our review. The openness and candor of LANL management and staff have facllitated what we believe will be a constructive and timely assessment of DOE's tritium operations for the Secretary.

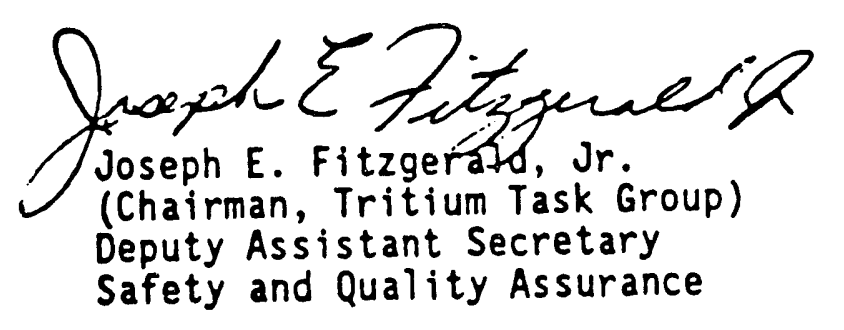

2 Attachments

cc w/att:

John Tuck, S-3

P. Ziemer, EH-1

S. Blush, NS-1

B. Twining, AL

J. Bellows, LAAO

J. Barr, DP-20

L. Smith, S-3

B. Hyder, S-3

D-18 


\section{ATTACHMENT 1}

Members of Tritium Task/Working Group

LANL Visit - Apri1 17-19, 1991

0. Lynch

R. Cooperstein

$R$. Duncan

R. Hagan

B. Kokenge

G. Nardella

D. Serpa

D. Stover

M. Sturdivant
EH-33 (Deputy Chairman, Team Leader)

$D P-132$

NP- 42

DP-22

Consultant (EH-33)

ER-1

Consultant (EH-33)

Consultant (EH-33)

Consultant (NS-1)

D-19 


\section{ATTACHMENT 2}

Site Personnel Interviewed

LANL Visit - April 17-19, 1991

J. Anderson

R. Y. Carlson

M. A. King

D. Hannderdinger
J. Phoenix

A. Valentine

J. Bellows 


\section{memorandum}

uare: May 30, 1991

AEPLY TO EH - 33

ATTN OF:

subect: (LANL) Loss of Stack Exhaust at the Weapons Subsystem Laboratory (WSL/Ice House) and Storage Vault (TA-41)

TO: Richard A. Claytor

Assistant Secretary

for Defense Programs, DP-1

By his memorandum of February 19, 1991, the Secretary of Energy directed the Assistant Secretary for Environment, Safety and Health (EH-1) to form a Task Group to examine the overall management of the Department's tritium facilities and recommend ES\&H-related improvements. The Task Group on Operation of Department of Energy (DOE) Tritium Facilities was established, and a schedule of activities was issued on March 15, 1991. In addition, it was decided that the Task Group would review any tritium-related events which occurred during the Group's tenure, in order to avail itself of any lessons learned that may be pertinent to DOE's tritium operations. Accordingly, during the Task Group's scheduled visit to LANL during the week of May 6, 1991 , a review was conducted of the off-normal occurrence at TA-41, a nuclear facility operated by the Weapons Subsystem Group (WX-5).

At TA-41, the WX-5 Group operates the Weapons Subsystem Laboratory, locally entitled "The Ice House" (TA-41-4) and a Storage Vault (TA-41-1). The activities performed at TA-4l include tritium storage and testing, fabrication and testing of NTS boost and gas transfer systems, and processing and testing of special nuclear material (SNM) containing components. The Ice House is equipped to conduct gas pressure testing to 45,000 psia, leak testing, light element mass spectrometry, SNM verification, and precise volume measurements on volumes up to six liters, as well as hydrogen and deuterium gas experiments.

Preliminary findings for the TA-41 off-normal occurrence were discussed with Jerry Bellows, Manager, DOE Los Alamos Area Oifice (LAAO), and George Hill, LANL WX-5 Division Director. The Task Group members conducting the LANL review are listed in Attachment 1, with LANL staff contacted isted in Attachment 2.

The Task Group was briefed by the cognizant facility management concerning facility function, the incident, the management organization, and its response to the event. A detalled tour of the facility was then made. Management personnel were interviewed and the related facility procedures, operational safety requirements (OSRs), and other documents were reviewed. It was stressed that, in view of ongoing event review by LAAO and the contractor, the Task Group would only cite preliminary findings that would be more forma iy addressed in the larger context of its report to the Secretary. 
An unmonitored 10 -hour loss of facility ventilation through the stack exhaust in TA-41 resulted from an electrical power outage beginning at approximately 10:40 a.m. on April 30, 1991. Electrical power to the building was lost for 2 hours. Building management was not informed of the outage. The stack monitor and exhaust fan were not operational during the outage. Room air monitors switched from $A C$ to battery backup. Restoration of power did not restart the exhaust fan. When power was restored, room air monitors switched back to $A C$. An air monitor alarmed. According to building personnel, switching from and to $A C$ power can initiate an alarm that can be mistaken to be detection of tritium at concentrations above 40 microcuries per cubic meter.

At $7 \mathrm{a.m}$. on May 1, ti,e following morning, two employees entered the bullding, failing to notice that the exhaust fans were not working. One of the employees noted that a tritium air monitor alarm was sounding, but took no action. At 7:40 a.m. the Assistant Building Manager noticed the exhaust fans were not running, notified personnel in the building, and notified Engineering. The exhaust fans were restarted by Engineering at 8:30 a.m.

When the stack exhaust was restored, tritium monitors on the stack indicated no release. However, during the 10 hours in which the stack exhaust fans were off, there was potential for an unventilated tritium release within a controlled work area (Rooms 250 and 252).

A preliminary estimate of the potential tritium release within the controlled area indicates the maximum credible release to be less than 200 microcuries of tritium oxide. This represents less than 5 percent of the Derived Air Concentration (DAC) for tritium oxide. Any material released would have been estimated at less than 15 percent tritium oxide. Preliminary screening bioassays of all six potentially exposed employees indicated no tritium exposure. Complete bioassay results are pending.

The consequences of the abnormal occurrence in TA-41 proved to be minor, essentially because no release of tritium and no personnel exposure occurred. However, the implications of the occurrence are more significant and present issues of more generic concern to LANL. TA-41 is an aging facility which lacks a defense-in-depth approach toward reduction of tritium releases and relies wholly on the ventilation system for personnel protection. The faclitity has neither appropriate engineered safety features nor an adequate level of formality in its conduct of operations.

Preliminary findings of the Task Group are as follows:

Administrative controls for conduct of operations were inadequate.

- TA-41 managements had inadequate control of the safety of the facility.

- No emergency plan was instituted.

- TA-41 management was not notified of the power outage.

- The call list for outage notification was shallow (one person deep) 
- LANL Engineering failed to take compensatory action when the notification system failed.

- Safety documentation does not adequately address personnel safety.

- Operational Safety Requirements (OSR) for the exhaust stack ventilation are in effect only "during normal operations." Fallure to have ventilation and monitoring system requirements for off-shift and shutdown modes puts personnel entering the faclitity at risk if these systems have failed during this time.

- Standard operating procedures required no evacuation of personnel under the conditions indicated.

- Procedures and training are not in place to assure personnel safety.

- The employee took no action in response to the tritium air monitor alarm.

- The OSR surveillance requirement for the exhaust stack ventilation system states that "Normal condition is apparent because of fan noise and the noise created by air flow into the chemical fume hoods in building $\mathrm{WH}^{\mathrm{N}}$.

At 7 a.m. May 1, two employees, on reporting to work at the facility, failed to notice that the exhaust fan was not operating.

- Engineered Safety features were inadequate:

- No remote readout of operations in TA-41.

- Exhaust fan was not on an uninterrufcible power system.

- Exhaust fan was not on the laboratory-wide alarm supply.

- Exhaust fan had no backup power.

- Exhaust fan required manual startup after a power outage.

- Stack monitor was not on an uninterruptible power supply.

- No backup stack monitor.

- No remote indication of stack operation.

LANL management has undertaken an azgressive effort to review the off-normal occurrence for potential consequences and generic implications, and has committed to compensatory safety design upgrades.

TA-4l management had already undertaken major program changes (safety analysis report, quality assurance, procedures, training) to introduce formality into the operation. However, the age of the facility and the longevity of 
operations continue to raise questions about how much justification is required for operating aging facilities. There are tentative plans to replace the Ice House with a new Weapons Subsystems Laboratory in Fy 1994. However, the WX-5 Group's experience with the Weapons Engineering Tes: Facility (WETF) makes them skeptical of schedules. They also know from experience with the High Pressure Tritium Laboratory in TA-33 that when a facllity is being phased out and the replacement schedule slips, the facility is forced to stretch out its capability for production. Facilities, such as these, can be caught in a cycle of "slip and stretch." In this cycle, safety as well as schedule often sips. Based on firm schedules, decisions must be made on aging facilities to establish long-range modification plans to upgrade these facilities with continuing utility and a phaseout plan to decomission the facilities which are to be replaced. The focus of both plans should be the safety of workers and the public.

Should you have any questions regarding these preliminary viewpoints, please contact me at 353-5532. I encourage you to share these initial observations on this event with other tritium operations to encourage a broader exchange of operating experiences.

On behalf of the Task Croup, I would like to express my appreciation for the assistance extended by LANL to us during our review. The openness and candor of LANL management and staff have facilitated what we believe will be a constructive and timely assessment of DOE's tritium operations for the Secretary.

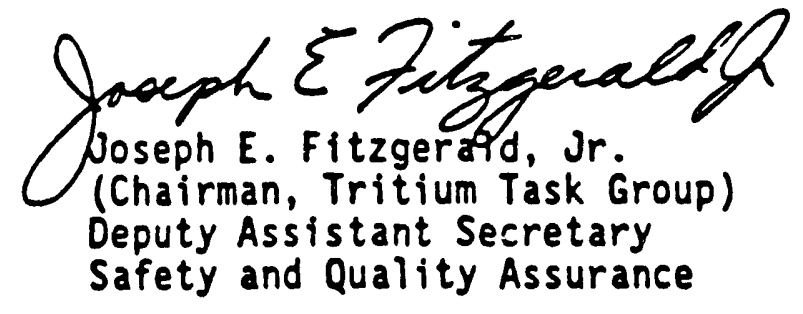

\section{Attachments}

cc w/att:

J. Tuck, S-3

P. Ziemer, EH-I

5. Blush, NS-1

B. Twining, AL

J. Bellows, LAAO

J. Maher, ER-8

B. Hyder, S-1 


\section{ATTACHMENT 1}

Members of Tritium Task Group Event Team

Los Alamos National Laboratory Visit

of

May 6-10, 1991

0. Lynch

D. Bailey

R. Duncan

R. Hagan

K. Murphy

D. Huff

B. Kokenge

D. Serpa

D. Stover

M. Sturdivant
EH-33 (Deputy Chairman, Team Leader)

NE-47 Task Group Member

NP-42, Task Group Member

DP-22, Task Group Member

EH-33, Horking Group Member

EH-33, Working Group Member

Consultant (EH-33)

Consultant (EH-33)

Consultant (EH-33)

Consultant (NS-1) 


\section{ATTACHMENT 2}

Los Alamos National Laboratory Personnel

Interviewed in Relation to Loss of Power Event
G. Hill
E. M. Hanson
A. Paas
B. Banks
R. Hurdie

WX-5 Division Director

WX-5 Group Leader

WX-5 Deputy Group Leader

Former WX-5 Group Leader

Compliance and Quality Assurance 


\section{APPENDIX E}

SUMMARY OF EVENTS RESULTING

IN INADVERTENT RELEASES

OF TRITIUM TO THE ENVIRONMENT

(1986 - 1991) 


\section{APPENDIX E}

\section{SUMMARY OF REPORTED EVENTS RESULTING IN INADVERTENT RELEASES OF TRITIUM TO THE ENVIRONMENT (1986-1991)"}

\section{Savannah River Tritium Facilities}

May 20, 1986

3,155-curie release of tritium from a leak across the seat of an automatic valve.

May 29, 1986

5,950-curie release of tritium during maintenance operation on process piping.

June 4, 1987

692-curie release of tritium due to operator valving error.

July 4, 1987

2,212-curie release of tritium from a reservoir leak into a process hood.

July 31,1987

172,400-curie release of tritium during maintenance work associated with removal of a faulty transducer.

September 16, 1987 1,372-curie release of tritium as a result of a construction worker flexing high-pressure piping during installation of new transducers.

October 15, 1987

1,109-curie release of tritium while leak-checking loading manifolds.

October 19, $1987 \quad 3,469$-curie release of tritium due to a leak across the valve seat in an argon system.

March 1, 1988

19,980-curie release of tritium from a reservoir fill-tube failure on a recycle station.

June 8, 1988

4,400-curie release of tritium during repair of a valve.

June 23, 1988

789-curie release of tritium when an automatic valve leaked.

August 8, 1988

530-curie release of tritium when an operator opened the wrong valve.

As reported in Occurrence Reports submitted to DOE Headquarters. 
September 12, 1988 723-curie release of tritium during maintenance change-out of a zeolite bed.

October 6, $1988 \quad 7,162$-curie release of tritium during the transfer of tritium gas between two tanks.

December 7, 1988 3,560-curie release of tritium from burn-through of a reservoir fill stem.

March 10, 1989 - 1,300-curie release of tritium leaked into the stack from the

March 14, 1989

vacuum pump of a mass spectrometer.

March 30, $1989 \quad 11,000$-curie release of tritium from a bellows leak in a Nur: $\mathcal{O}$ valve.

April 19, 1989 440-curie release of tritium during maintenance operation on a low-pressure valve.

May 29, 1989

408-curie release of tritium when a tritium-contaminated argon flush was sent to the stack while preparing for a line break.

June 30, $1989 \quad 400$-curie release of tritium from a bell jar while checking the status of a reservoir.

May 30,1990 - 1,200-curie release of tritium from a leak in a process pipe

May 31, 1990 weld in the recovery system.

June 26, 1990 367-curie release of tritium from a loading hood.

\section{Savannah River Production Reactors}

October 1, 1988 - 15-curie release of tritium to Par Pond from the P-Area

October 14, 1988 process sewer.

November 17, 1988 112-curie release of tritium to Pen Branch Creek from the $\mathrm{K}$-Area process sewer.

December 16, 1988 0.1-curie release of tritium to Par Pond from the P-Area process sewer. 
December 30, 1988 - 70-curie release of tritium to Pen Branch Creek from the January 1, $1989 \quad$ K-Area process sewer.

December 14, 1989 437-gallon moderator spill containing tritium due to a damaged valve.

January 31, 1990

20-gallon heavy water moderator spill containing 2,000 curies of tritium at the K-Reactor.

December 12, 1990 3-curie release of tritium due to loss of the moderator at the K-Reactor.

January 26, $1991 \quad 75$-gallon spill of the K-Reactor moderator containing tritium due to sight-glass failure. Liquid flowed into a dyked area.

Approximately 75 curies of tritium released to the atmosphere; approximately 23 curies of tritium were released to the soil outside the dyked area.

February 17, $1991 \quad$ 54-gallon spill (approximate) of moderator due to sight-glass failure to the same dyked area as the January 26, 1991, event. Releases to the environment were estimated at approximately 40 curies of tritium to the atmosphere and 74 curies of tritium to the soil outside of the dyked area.

\section{Mound Plant}

September 10, 1987 135-curie release of tritium gas when gas covering a shipping container was discharged instead of being routed to a separate facility for oxidation.

September 29, $1987 \quad 86$-curie release of tritium when gas was accidentally transferred from oxidation facilities to the Effluent Recoveıy System.

September 1, 1988 300-curie release of elemental tritium when the Effluent Removal System inadvertently released.

November 8, 1989 More than 10,000-curie release of tritium during unloading operations due to failure of the unloading system, which in turn led to failure of the confinement systems. 
December 15, 1989 54-curie release of tritium when tritiated water leaked from a mechanical fitting during removal of a tritium system line.

\section{Los Alamos National Laboratory}

February 20, 1986 12-curie release of tritium from a reused cryosorption trap at TA-41.

July 24,1986

1500-curie release of tritium gas when the hand valve on a container holding tritium was inadvertently opened at TA-33.

October 30, $1986 \quad 500$-curie release of elemental tritium when the packing in a system high-pressure valve leaked during a transfer operation at TA-33.

November 18, 1986 52-curie release of elemental tritium when a defective LP50 container was unpacked at TA-33.

November 10, 1987 44-curie release of tritium when overpressurizing a mercury manometer while introducing a tritium sample into a mass spectrometer at TA-41.

February 22, 1988 5,700-curie release of tritium from TA-33 when an O-Ring failed during pressure cycling in an adhesive joining operation.

May 17, 1990

1,960 -curie release of tritium from a hood in TA- 41 during venting operations.

February 1, 1991 2,900-curie release of tritium from TA-41 when an operator inadvertently opened a valve.

March 28, 1991

0.4-curie release (approximate) of tritium gas during transfer of gas to a sample cylinder at TA-210.

April 11, 1991

A small quantity of tritium gas was released at Building 209 when a maintenance worker began disassembling a bellows-type valve with one side of the valve uncier pressure. 


\section{Sandia National Lajuratory, Livermore}

January 10, $1985 \quad 40$-milliliter release (approximate) of tritium-contaminated water (containing approximately 200 curies) during regeneration/water recovery operations.

February 13, 1987 1,100-curie release (approximate) during loading of a vessel with tritium gas and temperature-conditioning of the loaded vessel.

August 18, $1987 \quad 1,100$-curie release into a room during vessel loading and conditioning.

October 6, 1988 124-curie release (approximate) of tritium gas during a dryer regeneration cycle.

February 6, 1989 1-curie release of tritium due to failure of a chilled water line that released 850 gallons of water through a tritium working area.

\section{Lawrence Livermore National Laboratory}

December 15, 1986 125-curie release of tritium following a pump failure that led to a temperature rise in a cyrogenic vessel.

April 14, 1987

198-curie release of tritium due to equipment failure and operator error.

January 19, 1988 145-curie release of tritium of unknown origin or due to stack monitor malfunction.

January 25, 1988 138-curie release of tritium of unknown origin or due to stack monitor malfunction.

May 15, 1988

653-curie release of tritium due to unexpected presence of tritium in gases being vented.

August 1, 1988

120-curie release of tritium of unknown origin or due to stack monitor malfunction.

February 28, 1989 112-curie release of tritium of unknown origin or due to stack monitor malfunction. 
August 22, 1989

October 31, 1989

April 2, 1991

\section{Pantex Plant}

May 19, 1989

\section{Pinellas Plant}

May 25, 1986

January 6, 1989

Nevada Test Site

May 19, 1989 329-curie release of tritium during improper pressure relief of a sample container.

112-curie release of tritium from Palladium bed thought to contain only deuterium and hydrogen.

144-curie release (approximate) of tritium during preparations for pressure characterization of a tritium reservoir.

More than 10,000-curie release of tritium during disassembly of a weapon component.

1.45-curie release of gaseous tritium during routine maintenance of a vacuum pump.

1.1-cubic-centimeter release of tritiated water containing about 1 curie of tritium during maintenance on a vacuum pump.

50-curie release (approximate) of tritium from a weapon assembly operation tritium leak at Area 27, Buildings 5310 and 5321.

\section{Oak Ridge National Laboratory}

April 28, 1989

90-curie release of tritium when movement of a radioluminescent light source fixture caused two light tubes to fall to the floor and break. 
APPENDIX F

\section{BIBLIOGRAPHY}




\section{APPENDIX F}

\section{BIBLIOGRAPHY}

\section{General Documents}

EG\&G Mound Applied Technologies. Guide to Good Practices at DOE Tritium Facilities, MLM-3610 (draft). October 15, 1989.

Los Alamos National Laboratory. Guidance for the Preparation of Safety Analysis Reports, Volume I: Format and Content, Volume II: Performing Safety Analyses. LA-11661-MS, UC-610. Issued June 1990.

U.S. Department of Energy. Summary of the Annual Environmental Monitoring Reports Submitted to the U.S. Department of Energy, January through December 1986. Office of Environment, Safety and Health. October 1988.

U.S. Department of Fnergy. Environment, Safety and Health Needs of the U.S. Department of Energy, Volume 2: Site Summaries. DOE/EH-0079. December 1988.

U.S. Department of Energy. Summary of the Annual Environmental Monitoring Reports Submitted to the U.S. Department of Energy, January through December 1987. Office of Environment, Safety and Health. August 1989.

U.S. Department of Energy. A Summary of the Annual Site Environmental Reports Submitted to the U.S. Department of Energy, January through December 1988. Office of Environment, Safety and Health. August 1990.

U.S. Department of Energy. DOE Tritium Surface Contamination Limits Committee. Recommended Tritium Surface Contamination Release Limits (draft). Attached to March 26, 1991, Letter from John R. Johnson to Ollie Lynch. March 1991.

U.S. Department of Energy. SPMS Unusual Occurrence Report (Computer Report). March 1, 1991.

U.S. Department of Energy. Request for Information Regarding "Man-Safe" Criteria. Memorandum from J.M. Barr to R. Hagan (with attachment). June 20, 1991. 
U.S. Department of Energy. Report on Compliance with National Emission Standards for Hazardous Air Pollutants, 1989 Radionuclides Emissions from Major Department of Energy Facilities. (n.d.)

U.S. Nuclear Regulatory Commission. Radioactive Materials Released from Nuclear Plants, Annual Report. J. Tichler, K. Norden, and J. Congemi. NUREG/CR-2907, Vol. 8. October 1989.

\section{Argonne National Laboratory Documents}

U.S. Department of Energy. Argonne Area Office. Response to Request for Information from Task Group of Operation of Department of Energy (DOE) Tritium Facilities (draft). Memorandum from A.L. Taboas to Oliver D.T. Lynch (with attachment). April 9, 1991.

U.S. Department of Energy. Argonne Area Office. Response to Request for Information from Task Group of Operation of Department of Energy (DOE) Tritium Facilities. Memorandum from A. L. Taboas to Oliver D.T. Lynch (with attachments). April 22, 1991.

\section{Lawrence Berkeley Laboratory Documents}

Lawrence Berkeley Laboratory. Annual Environmental Monitoring Report of the Lawrence Berkeley Laboratory - 1989. LBL-27170 1990/UC-407. August 1990.

Lawrence Berkeley Laboratory. Operational Safety Procedures for Users of Lawrence Berkeley Laboratory National Tritium Labeling Facility, Bldg. 75. Revised January 1991.

Lawrence Berkeley Laboratory. Paper on Reduction of Tritium Emissions from the NTLF (Bldg. 75). (n.d.)

Lawrence Berkeley Laboratory. Paper on Monitoring of Tritium Emissions from the NTLF (Bldg. 75). (n.d.)

Lawrence Berkeley Laboratory. Table on Tritium Purchases \& Disposal Shipments: 1973-Present. (n.d.)

Science Applications International Corporation. Environmental Compliance Assessment for the Lawrence Berkeley Laboratory (draft). January 1991. 
U.S. Department of Energy. Tiger Team Assessment of Lawrence Berkeley Laboratory (draft). Office of Environment, Safety and Health. DOE/EH-0164.

January/February 1991.

U.S. Department of Energy. San Francisco Operations Office, Request for Information Response to Questionnaire, Tritium Operations Task Group. Facsimile from Tony Sorenson to Oliver Lynch (with attachments). April 23, 1991.

U.S. Department of Energy. San Francisco Operations Office. LBL Tritium Facility Information. Memorandum from Sheryl J. Boutte to Oliver D.T. Lynch (with attachments). April 26, 1991.

\section{Lawrence Livermore National Laboratory Documents}

Lawrence Livermore National Laboratory. Unusual Occurrence Report for the December 19, 1986, Tritium Release (with attachments). Bldg. 331 86-3. December 23, 1986.

Lawrence Livermore National Laboratory. Unusual Occurrence Report for the April 16, 1987, Tritium Release (with attachments). Bldg. 331 87-3. May 6, 1987.

Lawrence Livermore National Laboratory. Notes of Meeting to Discuss Two $250 \mathrm{Ci}$ Releases in 3 Days and Unusual Occurrence Reports for the May 16 \& 18, 1988, Tritium Releases. Bldg. 331 88-1 and Bldg. 331 88-2. May 18, 1988.

Lawrence Livermore National Laboratory. Fácility Safety Procedure 331. Tritium Facility Bldg. 331. July 1989.

Lawrence Livermore National Laboratory. Operating Instructions for the Ostlund HTO/HT Sampler. July 14, 1989.

Lawrence Livermore National Laboratory. Final Unusual Occurience Report LLNL-8923-B-331 for the August 25, 1989, Tritium Release. Letter from T.R. Crites to James

T. Davis (with attachments). October 24, 1989.

Lawrence Livermore National Laboratory. Tritium Facility (Bldg. 331) Training Plan. March 1990.

Lawrence Livermore National Laboratory. Building 331 Safety Analysis Report, 331

SAR. UCRL-AR-106001. October 1, 1990.

Lawrence Livermore National Laboratory. Tritium Facility Downsizing Overview Report. December 14, 1990. 
Lawrence Livermore National Laboratory. Response to Downsizing Overview Committee Recommendations. Letter from R. Failor. January 22, 1991.

Lawrence Livermore National Laboratory. Downscoping the Tritium Facility at LLNL. Letter from George H. Miller to RADM J. Michael Barr (with attachment). February 8, 1991.

Lawrence Livermore National Laboratory. Procedure for Determination of Tritium Content and Pressure and Removal of Same from Gas Bottles and Hydride Traps. March 5, 1991.

Lawrence Livermore National Laboratory. Schedule for Completion and Status of DOE/SAN Downsizing Issues for Bldg. 331, Lawrence Livermore Laboratory. March 8, 1991.

Lawrence Livermore National Laboratory. Schedule for Completion and Status of DOE/SAN Safety Appraisal Recommendations, LLNL Tritium Facility (Bldg. 331), Lawrence Livermore Laboratory. March 8, 1991.

Lawrence Livermore National Laboratory. Schedule for Completion and Status of DOE Technical Safety Appraisal Recommendations, LLNL Tritium Facility (Bldg. 331), Lawrence Livermore Laboratory. March 8, 1991.

Lawrence Livermore National Laboratory. Procedure Policy. Internal Memorandum from R. Failor to B331 Residents and Workers (with attachment). March 29, 1991.

Lawrence Livermore National Laboratory. Cost/Benefit Analysis of Completing VERS and SCOTS. Letter from Jeffery H. Richardson to Kenneth Zahora (with attachment). March 29, 1991.

Lawrence Livermore National Laboratory. LLNL Tritium Facility Downsizing Plan. April 1991.

Lawrence Livermore National Laboratory. Occurrence Report for the April 2, 1991, Tritium Release. LLNL-91-024. April 3, 1991.

Lawrence Livermore National Laboratory. Incident Analysis Team Appointment for the April 2, 1991, Tritium Release at LLNL's Tritium Facility. Memorandum from J. H. Richardson to S. A. Steward. April 5, 1991.

Lawrence Livermore National Laboratory. Tritium Facility Review Committee. Internal Memorandum from D.C. Sewell to A.J. Toy. April 10, 1991. 
Lawrence Livermore National Laboratory. Approved Actions for Continued ES\&H Protection in Bldg. 331. Internal Memorandum from A.J. Toy to D.C. Sewell. April 15, 1991.

Lawrence Livermore National Laboratory. Fact Sheet on the April 2, 1991, Tritium Release at LLNL's Tritium Facility. April 3, 1991.

Lawrence Livermore National Laboratory. Environmental Report for 1989. UCRL50027-89. 1990.

Lawrence Livermore National Laboratory. 1988-1989 Chemistry \& Materials Science Department Annual Report. UCRL-53943-89. May 28, 1991.

Lawrence Livermore National Laboratory. Chemistry \& Materials Science Chemistry Department Self-Assessment Plan (draft). (n.d.)

U.S. Department of Energy. Office of Environment, Safety and Health. Technical Safety Appraisal of the Tritium Facility, Lawrence Livermore National Laboratory. DOE/EH-0052. October 1987.

U.S. Department of Energy. San Francisco Operations Office. Safety Appraisal of Bldg. 331 at LLNL. July 17, 1989.

U.S. Department of Energy. San Francisco Operations Office. Tritium Facility Downscoping Issues. Letter from W.E. Keheley to George Miller. January 7, 1991.

U.S. Department of Energy. Office of Defense Programs. Downscoping the Tritium Facility at Lawrence Livermore National Laboratory. Memorandum from J.M. Barr to the Associate Director for Nuclear Design, LLNL. March 14, 1991.

U.S. Department of Energy. San Francisco Operations Office. Transmittal of Information Requested for the Task Group on Operation of the Department of Energy (DOE) Tritium Facilities. Memorandum from W.W. Warner to Oliver D.T. Lynch (with attachments). April 8, 1991. 


\section{Los Alamos National Laboratory Documents}

Los Alamos National Laboratory. Tritium Systems Test Assembly Specification, Secondary Containment for Intersystem DT Piping. TTA-SP-117-1, Revision 1. April 4, 1981.

Los Alamos National Laboratory. Safety Analysis Report for the Tritium Systems Test Assembly Facility (TA-21). 1982.

Los Alamos National Laboratory. Tritium Systems Test Assembly Test Plan, Test Plan for Tests of SEC. TTA-TP-117-1, Revision 0. February 7, 1984.

Los Alamos National Laboratory. Tritium Systems Test Assembly Specification, Glovebox Atmosphere-Control System. TTA-SP-117-3, Revision 2. April 23, 1984.

Los Alamos National Laboratory. Safety Analysis Report for the Target Fabrication Facility (TFF). July 1984.

Los Alamos National Laboratory. Tritium Systems Test Assembly Test Plan, Plan for Testing Secondary Glovebox Pressure Controllers. TTA-TP-117-2, Revision 0. October 29, 1984.

Los Alamos National Laboratory. Tritium Systems Test Assembly Test Plan, Plan for Testing High-Sensitivity Check Valve as an Alternate to Pressure Relief Bubblers. TTA-TP-117-3, Revision 0. June 28, 1985.

Los Alamos National Laboratory. Tritium Systems Test Assembly Test Plan, Plan for Periodic Testing of Glovebox Relief Devices. TTA-TP-117-4, Revision 0. August 30, 1985.

Los Alamos National Laboratory. TSTA TTA-TP-117-4 Test Plan Results. Memoranda from Don Coffin to Distribution. December 31, 1985, and March 18, 1986.

Los Alamos National Laboratory. Safety Assessment for the Tritium Salt Facility, TA21-209 (draft). June 1986, Revised February 1987.

Los Alamos National Laboratory. Tritium Systems Test Assembly Procedure, Filling of Sample Container at LIO with Tritium. TTA-OP-125-02, Revision 0. April 1987.

Los Alamos National Laboratory. Weapons Engineering Tritium Facility Standard Operating Procedure: Instrumentation an Control Subsystem. SOP No. 33.8, Revision 0. October 3, 1987. 
Los Alamos National I_aboratory. Weapons Engineering Tritirm Facility Standard Operating Procedure: Tritium Gas Containment Subsystem. SOP No. 38.5, Revision 0. October 14, 1987.

Los Alamos National Laboratory. Weapons Engineering Tritium Facility Standard Operating Procedure: Tritium Waste Treatment Subsystem. SOP No. 29.5, Revision 0. October 15, 1987.

Los Alamos National Laboratory. Operational Safety Requirements for TSTA. June 1988.

Los Alamos National Laboratory. Health, Safety, and Environment Division. Facility Appraisal of the Tritium System Test Assembly's Health, Safety, and Environmental Protection Program. June 30, 1983.

Los Alamos National Laboratory. Operational Safety Requirements for the Tritium Salt Facility. Seprember 1988.

Los Alamos National Laboratory. Weapons Engineering Tritium Facility Standard Operating Procedure: Tritium Gas Handling Subsystem. SOP No. 37.5, Revision 0. October 26, 1988.

Los Alamos National Laboratory. Operational Quality Assurance/Control Plan for the Weapons Engineering Tritium Facility (WETF) TA-16-205. WETF-88-046. November 23, 1988.

Los Alamos National Laboratory. Organizational Appraisal of MST Division's ES\&H Program Including Nuclear Facility Appraisals of CMR Building, TSTA, and TSF. January 1989.

Los Alamos National Laboratory. Safety Analysis Report for the Weapons Engineering Tritium Facility. June 27, 1989.

Los Alamos National Laboratory. MST-3/TSTA Safety Manual. July 1989.

Los Alamos National Laboratory. Health, Safety and Environment Division. Facility Appraisal of the Tritium System Test Assembly's Health, Safety and Environmental Protection Program. July 31, 1989.

Los Alamos National Laboratory. Health, Safety, and Environment Division. Facility Appraisal of the Tritium Salt Facility's Health, Safety, and Environmental Protection Program. 89-TSF/FAC. July 31, 1989. 
Los Alamos National Laboratory. 'Tritium Systems Test Assembly System Design Description, 25.0 Load-In/Load-Out System (LIO). TTA-SDD-125, Revision 7. October 23, 1989.

Los Alamos National Laboratory. Paper on The Tritium Systems Test Assembly at Los Alamos National Laboratory. John R. Bartlit. Submitted on October 2, 1989. Accepted on November 2, 1989.

Los Alamos National Laboratory. Tritium Systems Test Assembly System Preventative Maintenance Procedure, Checkout and Calibration of Glovebox Pressure Controller. TTA-PMP-117-1, Revision 17. December 18, 1989.

Los Alamos National Laboratory. Tritium Systems Test Assembly System Operating Procedure, Nuclide High Resolution Mass Spectrometer. TTA-OP-124, Revision 0. April 6, 1990.

Los Alamos National Laboratory. Proposed Tritium Measurement Plan for Mol Sieves. Internal Memorandum from A.O. Paas to Bruce H. Erkkila. May 7, 1990.

Los Alamos National Laboratory. Target Fabrication Facility Operational Safety Requirements (draft). June 1990.

Los Alamos National Laboratory. Establishment of an Investigation Committee for Tritium Exposure at TA-41. Memorandum from Ronald G. Stafford to Investigation Committee Members (J. Anderson, B. Reinert, L. Hoffman, and J. Williams). June 7, 1990.

Los Alamos National Laboratory. High Pressure Studies of Tritiated Metals. MH-DPT01, Revision 0. June 18, 1990.

Los Alamos National Laboratory. Tritium Systems Test Assembly Procedure, Procedure for Glovebox Window Removal. TTA-OP-117-01, Revision 0. June 19, 1990.

Los Alamos National Láboratory. Tritium Systems Test Assembly Specification, Electrical and Mechanical Interfaces for Gloveboxes. TTA-SP-117-2, Revision 2. June 20, 1990.

Los Alamos National Laboratory. Discard Limit Increase Request. Letter from A.O. Paas to Joel A. Baca. June 27, 1990

Los Alamos National Laboratory. Tritium Systems Test Assembly Test Plan, Reliability Test of Low-Range Differential-Pressure Switches. TTA-TP-117-5, Revision 0. July 19, 1990. 
Los Alamos National Laboratory. Tritium Systems Test Assembly System Design Description, Secondary Containment (SEC). TTA-SDD-117, Revision 6. August 1, 1990.

Los Alamos National Laboratory. Tritium Discard Status. Internal Memorandum from A.O. Paas to D.H.W. Carstens. August 7, 1990.

Los Alamos National Laboratory. Report from the Investigation Committee for the Tritium Exposure, Group WX-5, TA-41, that Occurred in May of 1990. Letter from Allen J. Tiedman to Harry T. Season, Jr. (with attachments). August 29, 1990.

Los Alamos National Laboratory. Tritium Systems Test Assembly Test Plan, Calibration of Line Volumes in New LIO System. TTA-TP-125-01, Revision 0. August 30, 1990.

Los Alamos National Laboratory. Test Results: Test Plan TTA-TP-125-01. Memorandum from Don Coffin and Mary King to Distribution. September 25, 1990.

Los Alamos National Laboratory. Tritium Systems Test Assembly Specification, Purging System for LIO Tritium Tank Hatches. TTA-SP-117-4, Revision 0. October 4, 1990.

Los Alamos National Laboratory. Safety Analysis Report for the Tritium Systems Test Assembly. Noveinber 9, 1990.

Los Alamos National Laboratory. Plutonium 238 Encapsulated Sources for Calorimetry Calibration. TSF-SOP-06, Revised). November 13, 1990.

Los Alamos National Laboratory. Environmental Surveillance at Los Alamos During 1989. LA-12000-ENV. December 1990.

Los Alamos National Laboratory. Weapons Engineering Tritium Facility Operating Procedure: Field Change Notice/As-Built Drawings. 90-113, Revision 0.

December 2, 1990.

Los Alamos National Laboratory. Materials Science and Technology 1990 Review. LALP-91-009. January 1991.

Los Alamos National Laboratory. HE-3 Growth Measurements in Molecular Sieve Containing Vessels. Internal Memorandum from H.R. Maltrud to B.H. Erkkila. January 29, 1991.

Los Alamos National Laboratory. Weapons Engineering Tritium Facility Operating Procedures: WETF Non-Conformance Report (WNCR). WETF 90-004 and 90-005, Revision 0. February 10, 1991. 
Los Alamos National Laboratory. Weapons Engineering Tritium Facility Operating Procedures: Component/Equipment Control. WETF 90-103, Revision 0.

February 10, 1991.

Los Alamos National Laboratory. Weapons Engineering Tritium Facility Operating Procedures: WETF Improvement/Difficulty Report (WIDR). WETF 90-111, Revision 0. February 10, 1991.

Los Alamos National Laboratory. Weapons Engineering Tritium Facility Operating Procedures/Instructions: Maintenance. WETF 90-112, Revision 0. February 10, 1991.

Los Alamos National Laboratory. Operational Safety Requirements for the Weapons Engineering Tritium Facility. WETF 87-012. February 22, 1991.

Los Alamos National Laboratory. Weapons Engineering Tritium Facility Operating Instructions: WETF Glovebox Antechamber. WETF 91-013, Revision 0. February 28, 1991.

Los Alamos National Laboratory. Weapons Engineering Tritium Facility Operating Instructions: WETF LP-50 Use. WETF 91-024, Revision 0. March 5, 1991.

Los Alamos National Laboratory. Management of ES\&H Formality of Operations. Internal Memorandum from James F. Jackson to Senior Management Group. March 6, 1991.

Los Alamos National Laboratory. Weapon Subsystems Group (WX-5) ALARA Program. WX-5-GP-91-002-U (draft). March 19, 1991.

Los Alamos National Laboratory. Tritium Systems Test Assembly Operating Procedure, Load-In/Load-Out (LIO) System. TTA-OP-125, Revision 4. April 1, 1991.

Los Alamos National Laboratory. Review of Operating Procedure Modifications for Tritium Operations at TSTA. Internal Memorandum from Donald J. Sandstrom to Theresa Cull and Robert Romero, April 4, 1991.

Los Alamos National Laboratory. Tritium Systems Test Assembly Standard Operations Procedure, Pumping Gas from a Product Container (PC) at the Load-In/Load-Out (LIO) Glovebox to a Sample Container at LIO Using the Transfer Pump \#1 (TP1). TTA-OP-125, Revision 1. April 4, 1991.

Los Alamos National Laboratory. Tritium Systems Test Assembly Standard Operations Procedure, Secondary Containment. TTA-SOP-117, Revision 6. April 5, 1991. 
Los Alamos National Laboratory. Review of Tritium Operations at TSTA. Internal Memorandum from Donald J. Sandstrom to J. Bellows. April 8, 1991.

Los Alamos National Laboratory. Tritium Systems Test Assembly Operating Procedure, Load-In/Load-Out (LIO) Tritium PC Procedure. TTA-OP-125-01, Revision 4. April 8, 1991.

Los Alamos National Laboratory. Information on the Tritium Systems Test Assembly (TSTA) at the Los Alamos National Laboratory Prepared for the DOE Tritium Operations Task Group. Memorandum to Oliver Lynch (with attachments). April 9, 1991.

Los Alamos National Laboratory. Standard Operating Procedure for the Tritium Salt Facility, TA-21 Bldg. 209 (draft). TSF-SOP-11, Revision 10. April 10, 1991.

Los Alamos National Laboratory. Tritium Systems Test Assembly Test Plan, Testing of VAC Differential Pressure Gauge/Controller. TTA-TP-117-6, Revisior 0. April 11, 1991.

Los Alamos National Laboratory. Standard Operating Procedure for the Tritium Salt Facility Welding Operations. TSF-SOP-01, Revision 3. April 17, 1991.

Los Alamos National Laboratory. Weapons Subsystems Group (WX-5) Safe Operations Program. WX-5-GP-91-009-U (draft). April 24, 1991.

Los Alamos National Laboratory. Tritium Facility Information Requested for LANL Tritium Facilities at TA-3, TA-35, and TA-41. Letter from Allen Valentine to Oliver Lynch, Jr. (with attachments). April 25, 1991.

Los Alamos National Laboratory. Operational Changes at TSTA. Letter from James L. Anderson to Robert Price (DOE). April 28, 1991.

Los Alamos National Laboratory. HE-3 Growth Measurements in Molecular Sieve Containing Vessels. Internal Memorandum from A.O. Paas to B.H. Erkkila, April 29, 1991.

Los Alamos National Laboratory. LANL External Tritium Advisory Committee (ETAC) Charter (draft). May 1991.

Los Alamos National Laboratory. Office of the Director ES\&H and Quality Policy Document (draft). April/May 1991.

Los Alamos National Laboratory. Lockout/Tagout Procedure. LANL Standard Practice Procedure No. 500 (draft). May 1, 1991. 
Los Alamos National Laboratory. Information Concerning LANL's Tritium Salt Facility. Facsimile from Allen Valentine to Kenneth Murphy (with attachments). May 1, 1991.

Los Alamos National Laboratory. Weapon Subsystems Group (WX-5) Quality Management Program. WX-5-GP-91-001-U (draft). May 2, 1991.

Los Alamos National Laboratory. Standing Committee on Operation of Tritium Facilities. Internal Memorandum from J.L. Anderson and R.L. Nolen to E.M. Wewerka and J.H. Birely. May 2, 1991.

Los Alamos National Laboratory. Document Control Procedure for the Tritium Salt Facility, TA-21 Bldg. 209 (draft). May 3, 1991.

Los Alamos National Laboratory. Tritiurn Effort in WX Division (Specifically WX-5). Internal Memorandum from S.V. Sundberg to R.E. Stapleton. May 7, 1991.

Los Alamos National Laboratory. Tritium Technical Exchange Forum for Los Alamos National Laboratory (LANL) Tritium Facility Operations. Internal Memorandum from R.L. Nolen to J.H. Birely. May 8, 1991.

Los Alamos National Laboratory. TFF SOP for Beta Layering Experiments (draft). May 9, 1991.

Los Alamos National Laboratory. Tips for the Fabrication of Temporary Tritium Experiments. LA-UR-88-845. (n.d.)

U.S. Department of Energy. Office of Environment, Safety and Health. Technical Safety Appraisal of the Tritium Systems Test Assembly, Los Alamos National Laboratory. DOE/EH-0074. April 1989.

U.S. Department of Energy. Albuquerque Operations Office, Dayton Area Office. Mound Processing of Tritiated Water Waste. Memorandum from James A. Morley to H.T. Season, Jr. (with attachments). August 1989.

U.S. Department of Energy. Albuquerque Operations Office, Dayton Area Office. Mound Materials Management Plan for tritiated Water. Memorandum from Dewain V. Eckman to L.A. Paz (with attachments). March 14, 1990.

U.S. Department of Energy. Office of Energy Research. Update on Off-Normal Occurrence at the Tritium Systems Test Assembly (TSTA), Los Alamos National Laboratory (LANL), March 28, 1991. Memorandum from James F. Decker to the Secretary of Energy. Facsimile dated April 15, 1991. 
U.S. Department of Energy. Albuquerque Operations Office. Request to Transfer Deuterium and Request for an Increase of the Discard Limits. Memorandum from Raymond S. George to A.O. Paas. July 25, 1990.

U.S. Department of Energy. Los Alamos Area Office. Assessment Report. SCIE-DAL002-91. March 4, 1991.

U.S. Department of Energy. Office of Nuclear Safety. Startup Assessment of the Weapons Engineering Tritium Facility at LANL. Memorandum from Steven M. Blush to Victor Stello. March 29, 1991.

U.S. Department of Energy. WETF Response to ONS Dose Calculations. Note from Don George to Jerry Bellows. April 3, 1991.

U.S. Department of Energy. Los Alamos Area Office. Review of Tritium Release Incident on 3/28/91 by DOE/Albuquerque. Informal Summary of Incident Review from Jerry L. Bellows. Transmitted via Telecopier. April 5, 1991.

U.S. Department of Energy. Los Alamos Area Office. Environment, Safety and Health Responsibilities within the Albuquerque Operations Office. April 15, 1991.

\section{Mound Plant Documents}

EG\&G Mound Applied Technologies. Operational Safety Requirements (OSR) for SW'R Tritium Complex. Technical Manual MD-10298. November 1988.

EG\&G Mound Applied Technologies. Operational Safety Requirements (OSR) for TBuilding. Technical Manual MD-10290, Issue 2. January 9, 1989.

EG\&G Mu'ind Applied Technologies. Unusual Occurrence Report Regarding May 18, 1989, Trituin Release. MD-89-7. June 2, 1989.

EG\&G Mound Applied Technologies. Building Manager Program. EG\&G Policy Procedure Number 1009. August 17, 1989.

EG\&G Mound Applied Technologies. EG\&G Self-Assessment Report for Period from October 1, 1989, to March 3, 1990.

EG\&G Mound Applied Technologies. Unusual Occurrence Report Regarding April 5, 1990, Tritium Release. 90-4. April 9, 1990.

EG\&G Mound Applied Technologies. Environmental Monitoring at Mound: 1989 Report. D.G. Carfagno and B.M. Farmer. MLM-3634. May 1990. 
EG\&G Mound Applied Technologies. Unusual Occurrence Report Regarding December 15, 1989, Tritium Release. 89-14. June 15, 1990.

EG\&G Mound Applied Technologies. Unusual Occurrence Report Regarding May 25, 1990, Tritium Contamination on Incoming Shipment in Excess of DOT Shipping Specifications. 90-13. June 27, 1990.

EG\&G Mound Applied Technologies. Management Awareness Program Assessment Report. Letter from R.C. D'Amico to D.V. Eckman (DAO-DOE). July 5, 1990.

EG\&G Mound Applied Technologies. Mound Plant Unloading Operations, Restart Preparations and Assessment. August 27, 1990.

EG\&G Mound Applied Technologies. Unusual Occurrence Report Regarding February 19-21, 1990, Failure to Report Tritium in Urine Above $10 \mathrm{uCi} / \mathrm{L}$ Notification Limit. 90-3. Seprember 13, 1990.

EG\&G Mound Applied Technologies. EG\&G Self-Assessment Report for Period from April 1, 1990, to September 30, 1990.

EG\&G Mound Applied Technologies. Performance Assurance Department Quality Audit Schedule, Fiscal Year 1991. October 22, 1990.

EG\&G Mound Applied Technologies. Management Awareness Status Report. Letter from R.A. Benson to M.A. Reker (DAO-DOE). November 20, 1990.

EG\&G Mound Applied Technologies. Tritium Environmental and Safety Overview Committee. Margin of Safety Review, SW/R Building. November 27, 1990.

EG\&G Mound Applied Technologies. Tritium Environmental and Safety Overview Committee. Margin of Safety Review, T-Building. November 29, 1990.

EG\&G Mound Applied Technologies. Environment, Safety and Health Self-Assessment Program. Letter from P. Ayres to M.A. Reker (DAO-DOE). December 3, 1990.

EG\&G Mound Applied Technologies. Summary of Accidental Tritium Releases, 19631990. December 20, 1990.

EG\&G Mound Applied Technologies. Control of Maintenance and Modifications for Mound's Nuclear Facilities. EG\&G Policy Procedure Number 1015. December 21, 1990.

EG\&G Mound Applied Technologies. Monitoring Limiting Conditions of Operation in Nuclear Facilities. EG\&G Policy Procedure Number 1016. January 23, 1991. 
EG\&G Mound Applied Technologies. Implementation Plans for DOE 5480.19. Letter from M.P. Shade to J.A. Morley (DAO-DOE). January 29, 1991.

EG\&G Mound Applied Technologies. Unusual Occurrence Report Regarding May 14, 1990, Activation of the Emergency Containment System. 90-15. January 29, 1991.

EG\&G Mound Applied Technologies. Mound Audit Charter. EG\&G Policy Procedure Number 1006. February 28, 1991.

EG\&G Mound Applied Technologies. Revised Corrective Action Plans for Tritium Unloading Operations in SW Building, Rooms 208 and 219. Letter from Harold F. Anderson to James A. Morley (with attachment). March 4, 1991.

EG\&G Mound Applied Technologies. EG\&G Mound Implementation Plan for DOE 5480.19. Letter from M.P. Shade to D.V. Eckman (DAO-DOE). March 28, 1991.

EG\&G Mound Applied Technologies. Charter for 'he Tritium Environmental and Safety Overview Committee. March 28, 1991.

EG\&G Mound Applied Technologies. EG\&G Mcund Tritium Workers' Newsletter. Volume 4, Issue 1. April 1991.

EG\&G Mound Applied Technologies. Response to Questions 1, 2, 4, 8, 9, 11, 12, and 13 of DOE Request for Information Concerning Tritium Facilities. Letter from Donald E. Michel to James A. Morley (with attachments). April 8, 1991.

EG\&G Mound Applied Technologies. Response to Questions 5, 6, 7, 10, 14, 15, 16, and 17 of DOE Request for Information Concerning Tritium Facilities. Letter from Donald E. Michel to James A. Morley (with attachments). April 9, 1991.

EG\&G Mound Applied Technologies. Tritium Training at Mound. Memorandum from J.L. Hehmeyer to R. Cooperstein. May 1, 1991.

EG\&G Mound Applied Technologies. EG\&G Mound ALARA Program. Technical Manual MD-10314.

EG\&G Mound Applied Technologies. Safety Analysis Report for T-Building. November 1983.

EG\&G Mound Applied Technologies. Safety Analysis Report for SW/R Building. June 1988, Revised June 1991. 
Reynolds Electrical \& Engineering Co., Inc. 1990 Triennial Review of EG\&G Mound Applied Technologies Internal Safety Review Program. Memorandum from D.L. Fraser to D.E. Michel (with report attached). January 15, 1991.

U.S. Department of Energy. Office of Environment, Safety and Health. Technical Safety Appraisal of the T-Building, Mound Plant. DOE/EH-0066. April 1988.

U.S. Department of Energy. Tiger Team Action Plan - Responses to Safety and Health Findings. September 10, 1990.

\section{Oak Ridge Nacional Laboratory Documents}

Martin Marietta Energy Systems, Inc. Report on Inventory Discrepancy in ORNL Tritium Sales Program by the Tritium Inventory Discrepancy Investigation Committee. July 20, 1989.

Martin Marietta Energy Systems, Inc. Safety Documentation Revisions to the Operational Safety Requirements for the Bldg. 3019 Complex, ORNL/CF-81/38, Change No. 1, dated March 28, 1991. Memorandum from R.K. Genung to M.W. Kohring (with attachments). April 12, 1991.

Oak Ridge National Laboratory. Union Carbide Corporation. Safety Analysis for Krypton and Tritium Facility, Bldg. 3033. ORNL/TM-8642. August 1983.

Oak Ridge National Laboratory. Martin Marietta Energy Systems, Inc. Transmittal of Final Unusual Occurrence Report ORNL-83-19-OP-83-3. Letter from K.W. Sommerfeld to J.A. Lenhard (with attachment). November 8, 1983.

Oak Ridge National Laboratory. Martin Marietta Energy Systems, Inc. Transmittal of Final Unusual Occurrence Report ORNL-83-20-OP-83-4. Letter from K.W. Sommerfeld to J.A. Lenhard (with attachment). November 10, 1983.

Oak Ridge National Laboratory. Martin Marietta Energy Systems, Inc. Final Operational Safety Requirements for the Radiochemical Processing Plant (RPP). ORNL/CF-81/38 (draft). August 24, 1984.

Oak Ridge National Laboratory. Martin Marietta Energy Systems, Inc. Report on Tritium Release in Bldg. 3026C on April 28, 1989. Letter from J.R. Hightower to Lester K. Price (with attachments). May 5, 1989.

Oak Ridge National Laboratory. Martin Marietta Energy Systems, Inc. Unusual Occurrence Report Relating to the Dropping of a Radioluminescent (RL) Light. May 15, 1989. 
Oak Ridge National Laboratory. Martin Marietta Energy Systems, Inc. Unusual

Occurrence Report Relating to an Incorrect Shipment of Tritium. October 24, 1989.

Oak Ridge National Laboratory. Chemical Technology Division. Management Plan for Revising and Resuming Tritium Operations at ORNL. October 25, 1989.

Oak Ridge National Laboratory. Martin Marietta Energy Systems, Inc.

Recommendation to Resume Tritium Shipments. Letter from Thomas H. Row to Richard L. Egli. February 14, 1990.

Oak Ridge National Laboratory. Martin Marietta Energy Systems, Inc. Final Unusual Occurrence Report Relating to Tritium Release in Bldg. 3026C on April 28, 1989. Letter from T.H. Row to James A. Reafsnyder (with attachment). May 18, 1990.

Oak Ridge National Laboratory. Martin Marietta Energy Systems, Inc. Writing, Reviewing and Controlling Procedures. Procedure RTS-002. August 2, 1990.

Oak Ridge National Laboratory. Martin Marietta Energy Systems, Inc. HOH Tritium Cylinder Transfer Preparation-Empty Cylinders. Procedure IP-638. September 18, 1990.

Oak Ridge National Laboratory. Martin Marietta Energy Systems, Inc. Unloading Tritium Shipping Containers. Procedure IP-639. September 18, 1990.

Oak Ridge National Laboratory. Martin Marietta Energy Systems, Inc. ORNL Isotopes Facilities Shutdown Program Plan. ORNL/TM-11689. October 1990.

Oak Ridge National Laboratory. Martin Marietta Energy Systems, Inc. Tritium Cylinder Disposal Preparation. Procedure IP-641. October 11, 1990.

Oak Ridge National Laboratory. Martin Marietta Energy Systems, Inc. Inerting Uranium Filled Tritium Storage Traps. Procedure IP-631. November 15, 1990.

Oak Ridge National Laboratory. Martin Marietta Energy Systems, Inc. Operational Safety Requirements for Bldg. 7025 (draft). ORNL/CF-82/56. December 7, 1990.

Oak Ridge National Laboratory. Martin Marietta Energy Systems, Inc. Operational Safety Requirements for the Chemical Separations Laboratory and the Segmenting Hot Cells Facility Bldgs. 3026-C and 3026-D (draft). February 13, 1991.

Oak Ridge National Laboratory. Martin Marietta Energy Systems, Inc. Disposal of 16L Tritium Cylinders. Procedure IP-642. February 15, 1991. 
Oak Ridge National Laboratory. Martin Marietta Energy Systems, Inc. Disposal of Tritium Shipping Containers. Internal Correspondence from R.K. Kibbe to B.D. Patton. April 22, 1991.

Oak Ridge National Laboratory. Martin Marietta Energy Systems, Inc. DOE Requested Information on ORNL Tritium Operations. Letter from R.K. Kibbe to D.R. Brown (with attachments). April 25, 1991.

Oak Ridge National Laboratory. Martin Marietta Energy Systems, Inc. Managenıent Plan, Oak Ridge National Laboratory Isotope Facilities Shutdown Program. L.G. Hill and R.K. Kibbe. (n.d.)

Oak Ridge National Laboratory. Martin Marietta Energy Systems, Inc. Stack Monitoring Station 7025. (n.d.)

U.S. Department of Energy. Office of Nuclear Energy. Review of Discrepancies in Shipper-Receiver Measurements for Tritium Shipments Under the Isotope Production and Distribution Program. September 28, 1989.

U.S. Department of Energy. Oak Ridge Operations Office. Tritium Light Tubes Transfer to EG\&G Mound. Letter from Doyle Brown to W.R. Wilkes. February 6, 1991.

U.S. Department of Energy. Oak Ridge Operations Office. Tritium Data. Memorandum from R.L. Egli to Oliver Lynch. April 2, 1991.

U.S. Department of Energy. Oak Ridge Operations Office. Response to Request for Additional Information from Task Group on Operation of the Department of Energy (DOE) Tritium Facilities. Memorandum from Doyle R. Brown to Oliver Lynch. April 24, 1991.

\section{Pantex Plant Documents}

Mason \& Hanger-Silas Mason Co., Inc. Final Safety Analysis Report for Bldg. 12-44. March 1981.

Mason \& Hanger-Silas Mason Co., Inc. Operational Safety Requirements, SNM Staging Facilities, Magazines 4-34, 4-35, 4-36, \& 4-38. April 11, 1988.

Mason \& Hanger-Silas Mason Co., Inc. Operational Safety Requirements for Pit Vault, Bldg. 12-26. April 11, 1988. 
Mason \& Hanger-Silas Mason Co., Inc. Operational Safety Requirements, Component Staging, Bldg. 12-58. April 11, 1988.

Mason \& Hanger-Silas Mason Co., Inc. Operational Safety Requirements, Bldg. 12-42 South Vault. June 10, 1988.

Mason \& Hanger-Silas Mason Co., Inc. Operational Safety Requirements, 12-44 Assembly Cell Complex, Supplement B, Cell 8 Conversion for Interim SNM Staging. January 1989.

Mason \& Hanger-Silas Mason Co., Inc. Lessons Learned - Tritium Incident. Letter from J.E. Hemphill to B.L. Gage (with attachment). August 30, 1989.

Mason \& Hanger-Silas Mason Co., Inc. Lessons Learned - Tritium Incident, May 17, 1989. Letter from J.E. Hemphill to B.L. Gage (with attachment). October 12, 1989.

Mason \& Hanger-Silas Masen Co., Inc. Results of DOE/AL Investigating Committee Report of the Pantex Tritium Release Incident of May 17, 1989. Letter from J.E. Hemphill to Bob L. Gage (with attachment). November 6, 1989.

Mason \& Hanger-Silas Mason Co., Inc. Final Unusual Occurrence Report No. MHAAO-89-8 on Tritium Release. Letter from J.E. Hemphill to B.L. Gage (with attachment). February 2, 1990.

Mason \& Hanger-Silas Mason Co., Inc. Safety Analysis Report (SAR) Inventory Update. Letter from J.E. Hemphill to B.L. Gage. March 30, 1990.

Mason \& Hanger-Silas Mason Co., Inc. Reservoir Risk Analysis. Letter from C.D. Alley to P.M. Ramey (DOE-AAO). April 24, 1990.

Mason \& Hanger-Silas Mason Co., Inc. Pantex Plant Site Environmental Report for Calendar Year 1989. May 1990.

Mangor \& Hanger-Silas Mason Co., Inc. Notification, Investigation and Reporting of Occurrences. Standard Index No. 3140, Issue No. 23. June 1, 1990.

Mason \& Hanger-Silas Mason Co., Inc. Advisory Committee on Nuclear Facility Safety (ACNFS) Report. Letter from J.E. Hemphill to Anthony G. Ladino (with attachments). June 20, 1990.

Mason \& Hanger-Silas Mason Co., Inc. W44 Readiness Review. Letter from C.D. Alley to P.M. Ramey (with attachments). July 2, 1990. 
Mason \& Hanger-Silas Mason Co., Inc. Implementation Plan for DOE 5000.3A, Occurrence Reporting and Processing of Operations Information. September 1, 1990.

Mason \& Hanger-Silas Mason Co., Inc. Revised Tritium Operations Review Committee Report Implementation Plan. Letter from C.D. Alley to P.M. Ramey (with attachment). September 21, 1990.

Mason \& Hanger-Silas Mason Co., Inc. Draft Calendar Year 1990 Air Emissions Annual Report. Letter from John G. Burr to A. G. Ladino (with attachments). May 10, 1991.

Mason \& Hanger-Silas Mason Co., Inc. Modification of Action Plan for Tritium Operations Review Committee. Letter from C.D. Alley to P.M. Ramey (with attachments). May 16, 1991.

Mason \& Hanger-Silas Mason Co., Inc. Radiation Worker Training Course. (n.d.)

Mason \& Hanger-Silas Mason Co., Inc. Safety Standard 7-5000, Issue HE. (n.d.)

Mason \& Hanger-Silas Mason Co., Inc. Safety Standard 7-5044. (n.d.)

U.S. Department of Energy. Office of Defense Programs. Pantex Tritium Operations Investigation. Memorandum from Troy E. Wade to Bruce Twining. May 19, 1989.

U.S. Department of Energy. Report of the Investigation of the Tritium Release Incident at the Pantex Plant on May 17, 1989. Prepared July 1989.

U.S. Department of Energy. Report of the Pantex Tritium Operations Review Committee. Prepared August 1989.

U.S. Department of Energy. Albuquerque Operations Office. Recommendations Resulting from the Investigation of the May 17, 1989, Pantex Tritium Release Incident. Memorandum from Bruce G. Twining to Distribution List. August 21, 1989.

U.S. Department of Energy. Albuquerque Operations Office. Review of Final Draft Report of the Pantex Tritium Operations Review Conimittee, August 1989. Memorandum from John J. Schinkle to R.O. Inlow. September 4, 1989.

U.S. Department of Energy. Airborne Effluent Containment Systems at Pantex. Memorandum from James D. Watkins to John F. Ahearne. October 20, 1989.

U.S. Department of Energy. Amarillo Area Office. Advisory Committee on Nuclear Facility Safety - Pantex Plant. Letter from P.M. Ramey to C.D. Alley (with attachment). January 10, 1990. 
U.S. Department of Energy. Amarillo Area Office. Implementation Plan for Report of the Tritium Operations Review Committee, August 1989. Memorandum from B.L. Gage to Harry Season (with attachment). January 18, 1990.

U.S. Department of Energy. Amarillo Ax a Office. Revised Implementation Plan for Report of the Tritium Operations Revie:v Committee, August 1989. Memorandum from B.L. Gage to Harry Season (with attachment). February 13, 1990.

U.S. Department of Energy. Albuquerque Operations Office. Protability Assessment and Risk Reduction Analysis - Pantex Tritium Operations. Memorandum from Harry T. Season to B.L. Gage (with attachments).February 27, 1990.

U.S. Department of Energy. Amarilln Area Office. Revised Action Plan, Pantex Tritium Operations Review Committee. Memorandum from Bob L. Gage to Harry T. Season (with attachment). March 20, 1990.

U.S. Department of Energy. Amarillo Area Office. Request for Approval of Action Plan for Pantex Tritium Operations Review Committee Report. Memorandum from W.L. Harrell to H.T. Season (with attachment). May 25, 1990.

U.S. Department of Energy. Amarillo Area Office. Albuquerque Operations Office Request for Status of Corrective Activities Associated with the Pantex Tritium Operations Review Committee Report Action Plan. Letter from A.G. Ladino to J.E. Hemphill. June 5, 1990.

U.S. Department of Energy. Amarillo Area Office. Transmittal of Revised Implementation Plan for Tritiurn Operations Review Committee Report. Memorandum from Anthony G. Ladino to K.A. Carlson. July 31, 1990.

U.S. Department of Energy. Amarillo Area Office. Letter from P.M. Ramey to William B. Hatheway (EPA). August 29, 1990.

U.S. Department of Energy. Amarillo Area Office. Tritium Operations Review Committee Implementation Plan. Letter from A. G. Ladino to J. E. Hemphill (with attachment). September 4, 1990.

U.S. Department of Energy. Amarillo Area Office. Action Plan for the Pantex Tritium Operations Review Committee Report. Memorandum from P.M. Ramey to Bruce G. Twining (with attachment). September 25, 1990.

U.S. Department of Energy. Amarillo Area Office. Letter from David L. Heim to Robert Harmessch'ager (EPA). November 30, 1990. 
U.S. Department of Energy. Albuquerque Operations Office. Quantitative Risk Assessment on Pantex Tritium Operations Review Committee Report. Memorandum from N.S. Dienes to P. Ramey. December 5, 1990.

U.S. Department of Energy. Albuquerque Operations Office. Quantitative Risk Assessment on Pantex Plant Tritium Operations Review Committee Report. Memorandum from A.G. Ladino to N.S. Dienes. January 8, 1991.

U.S. Department of Energy. Albuquerque Operations Office. Health Protection Division - Health Physics Review of the Radiation Safety Programs of the Pantex Plant, January 28 - February 1, 1991. Memorandum from Gene E. Runkle to P.M. Ramey (with attachment). March 13, 1991.

U.S. Department of Energy. Albuquerque Operations Office. Implementation Plan for the Pantex Tritium Operations Review Committee Report. Memorandum from N.S. Dienes to P.M. Ramey (with attachment). April 1, 1991.

U.S. Department of Energy. Amarillo Area Office. Response to Request for Information from Task Group on Operation of Department of Energy Tritium Facilities. Memorandum from A.G. Ladino to N.S. Dienes (with attachments). April 19, 1991.

U.S. Department of Energy. Amarillo Area Office. DOE-AAO Instruction, Conduct of Surveillance. AAO 5600.XX (draft). (n.d.)

U.S. Environmental Protection Agency. Use of Environmental Measurements to Demonstrate Compliance with Radionuclide NESHAP Subparts A and $\mathbf{H}$. Letter from Robert E. Hannesschlager to P.M. Ramey (with attachment). October 24, 1990.

U.S. General Accounting Office. Nuclear Health and Safety, More Attention to Health and Safety Needed at Pantex. GAO/RCED-91-103. April 1991.

\section{Pinellas Plant Documents}

General Electric Company, Neutron Devices. Unusual Occurrence Report Regarding Elevated Tritium Activity in Air During Pump Oil Change-Out on June 24, 1986. NDD 86-04. June 25, 1986.

General Electric Company, Neutron Devices. Mixed Contaminated Waste. Memorandum from Carl Carter to Fred Alberg. June 29,1989. 
General Electric Company, Neutron Devices. OSP Surveillance Report - Revised $11 / 3 / 89$, Date(s) of Surveillance: September 12-13, 1989. Memorandum from Robert L. Peterson to J.R. Kirby. October 13, 1989.

General Electric Company, Neutron Devices. Final Safety Analysis Report for the Tritium Recovery System (Revision 1). January 1990.

General Electric Company, Neutron Devices. Unusual Occurrence Report Regarding Unexpected Water Droplets in Dry $T_{2}$ Gas Vacuum System on January 6, 1989. NDD 89-02. November 2, 1990.

General Electric Company, Neutron Devices. Environment, Safety, and Aealth Standards 5.1 through 5.12 (dated from May 18, 1989 to January 7. i991). List dated January 9, 1991.

General Electric Company, Neutron Devices. Pinellas Plant Occurrence Reports ALOPI-GEND-PINELLAS-1990-0003, ALO-PI-GEND-PINELLAS-1990-0026, ALO-PIGEND-PINELLAS-1991-0020, and ALO-PI-GEND-PINELLAS-1991-0022 (computer reports). March 21, 1991.

General Electric Company, Neutron Devices. Response to Request for InformationTritium Operations Task Group. Letter from Robert L. Poole to David W. Nierman (with attachments). April 3, 1991.

General Electric Company, Neutron Devices. Tritium Tank Downloading. Procedure MEEI 1357, Revision 05. May 21, 1991.

General Electric Company, Neutron Devices. Area Operating Envelop, Area 108 (draft). May 24, 1991.

General Electric Company, Neutron Devices. Electrical Load Lists/Panelboard List for Emergency Generator No. 3. December 18, 1986.

U.S. Department of Energy. Pinellas Area Office. Review of the General Electric Company Neutron Devices Division (GENDD) Health Physics Program for the Pinellas Facility, March 6-10, 1989. Memorandum from H.F. Gregory, Jr. to J.S. Caven (with attachments). March 2, 1989.

U.S. Department of Energy. Pinellas Area Office. Health Physics Review of Pinellas Plant, February 14-17 and March 6-10, 1989. Memorandum from H.F. Gregory, Jr. to J.S. Caven (with attachments). April 13, 1989.

U.S. Department of Energy. Pinellas Area Office. QAS 3.0 Survey Report 73-90-0026. Memorandum from H.F. Gregory, Jr. to W.F. Ierna. May 17, 1990. 
U.S. Department of Energy. Pinellas Area Office. QAS 3.0 Survey Report 73-90-0034. Memorandum from H.F. Gregory, Jr. to W.F. Ierna. August 22, 1990.

U.S. Department of Energy. Pinellas Area Office. QAS 3.0 Survey Report 73-91-0006. Memorandum from H.F. Gregory, Jr. to W.F. Ierna. December 27, 1990.

U.S. Department of Energy. Facility Performance Assessment of Tritium Areas. Memorandum from John R. Kirby to N.S. Dienes (with attachment). February 22, 1991.

U.S. Department of Energy. Pinellas Area Office. Completion Certificates for Findings and Recommendations from a Previous Appraisal of the General Electric Neutron Devices Department, Pinellas Plant. Memorandum from Dawn L. Gillas to U.M. Harder (with attachment). March 14, 1991.

U.S. Department of Energy. Response to Request for Tritium Operations Information. Memorandum from John R. Kirby to N.S. Dienes (with attachments). April 4, 1991.

U.S. Department of Energy. Pinellas Area Office. PAO Expectations for Environment, Safety and Health (ES\&H). Memorandum from Gerald W. Johnson to

R.C. Abington. April 10, 1991.

U.S. Department of Energy. Pinellas Area Office. Nuclear Safety Rules, Regulations, and Orders - Price Anderson Act. Memorandum from Gerald W. Johnson to Bruce G. Twining (with attachments). April 15, 1991.

U.S. Department of Energy. Pinellas Area Office. Health Protection - Health Physics and Industrial Hygiene Appraisal Reports, General Electric Company, Neutron Devices Department, Pinellas Plant, February 11-15, 1991. Memorandum from Dawn L. Gillas to U.M. Harder (with attachment). May 3, 1991.

\section{Sandia National Laboratory - Livermore Documents}

Comac Systems Corp. Comac Delta. Description of Maintenance Management System. (n.d.)

Sandia National Laboratories Livermore. Leak in TRL Dryer System. Memorandum from D.W. Putz to W.V. Ormond. January 7, 1986.

Sandia National Laboratories Livermore. Glove Box \#1, High Pressure Station, Tritium Release, Friday, February 13, 1987. Memorandum from W.R. Wall to D.W. Putz. February 16, 1987. 
Sandia National Laboratories Livermore. Unusual Occurrence Report on February 13, 1987, Tritium Release. UOR No. 87-3. February 26, 1987.

Sandia National Laboratories Livermore. Technical Review Committee to Investigate August 18, 1987, Tritium Release. Memorandum from W. Bauer to R.C. Wayne. August 20, 1987.

Sandia National Laboratories Livermore. Background Information Regarding August 18, 1987, Tritium Release. Memorandum from S.H. Goods and M.W. Perra to W. Bauer. August 24, 1987.

Sandia National Laboratories Livermore. Report of the Technical Review Committee on the Tritium Research Laboratory Incident of August 18, 1987. September 1987.

Sandia National Laboratories Livermore. TRL Tritium Release on August 18, 1987. Memorandum from D.W. Putz to H. Hanser. September 10, 1987.

Sandia National Laboratories Livermore. Second Revision of the SNLI TSA Action Plan. Letter from D.W. Putz to J.J. Schinkle. October 15, 1987.

Sandia National Laboratories Livermore. Third Revision of the SNLL TSA Action Plan. Letter from D.W. Putz to J.J. Schinkle (with attachments). November 3, 1987.

Sandia National Laboratories Livermore. Unusual Occurrence Report on August 18, 1987, Tritium Release. UOR No. 87-8. January 14, 1988.

Sandia National Laboratories Livermore. Implementation of the Recommendations of the Report of the Technical Review Committee on the Tritium Research Laboratory Incident of August 18, 1987. Memorandum from D.W. Putz to Distribution. January 18, 1988.

Sandia National Laboratories Liverınore. Vacuum Effluent Recovery System: Background and Status. Memorandum from D.W. Putz to R.A. Baroody. November 4, 1988.

Sandia National Laboratories Livermore. October 6, 1988, TRL Stack Release. Memorandum from W.R. Wall to D.W. Putz. November 7, 1988.

Sandia National Laboratories Livermore. Bldg. 968, Chilled Water Leak, February 6, 1989. Memorandum from W.R. Wall to D.W. Putz. February 10, 1989.

Sandia National Laboratories Livermore. Explanation of February 6, 1989, Tritium Release. Letter from Paul Brewer to William Adams. February 16, 1989. 
Sandia National Laboratories Livermore. Unusual Occurrence Report on February 6, 1989, Tritium Release. UOR No. 89-2. February 21, 1989.

Sandia National Laboratories Livermore. Tritium Release, March 6, 1989, Memorandum from W.R. Wall to D.W. Putz. March 7, 1989.

Sandia National Laboratories Livermore. CDL Phase 1A Safety Review. Memorandum from R.J. Detry to Distribution. April 25, 1989.

Sandia National Laboratories Livermore. Tritium Research Laboratory Technical Safety Appraisal Follow-up Visit Action Plan, Bldg. 968. June 14, 1989.

Sandia National Laboratories Livermore. DOE Technical Safety Appraisal, Follow-up Close Out Meeting, June 8, 1989. Memorandum from W.R. Wall to Donald W. Putz. June 15, 1989.

Sandia National Laboratories Livermore. Preventative Maintenance Plan for Safety Related Programmatic Equipment at the Tritium Research Laboratory (TRL). Safe Operating Procedure No. 1339. November 1989.

Sandia National Laboratories Livermore. Quarterly Status Report, October-December, 1989, Technical Safety Appraisal. Memorandum from D.W. Putz to George Beller (with attachment). March 1, 1990.

Sandia National Laboratories Livermore. TRL Safety Issues. Memorandum from Toff Garcia to Don Putz. March 9, 1990.

Sandia National Laboratories Livermore. Suspension of TRL Operations. Memorandum from R.J. Detry to D.W. Putz. March 15, 1990.

Sandia National Laboratories Livermore. Implications of the T. Garcia Memo to You dated January 17, 1990. Memorandum from D.A. Wright to D.W. Putz. March 15, 1990.

Sandia National Laboratories Livermore. Building 968 Access During Suspension of Activities. Memorandum from D.W. Putz to R.J. Detry. March 16, 1990.

Sandia National Laboratories Livermore. Root Causes of TRL Safety Issues Raised in Garcia Memo. Memorandum from D.W. Putz to R.J. Detry. March 20, 1990.

Sandia National Laboratories Livermore. Action Plan for Implementing Safe Operating Improvements in the TRL. Memorandum from D.W. Putz to R.J. Detry. March 21, 1990. 
Sandia National Laboratories Livermore. Resumption of TRL Operations.

Memorandum from R.J. Detry to D.W. Putz. March 23, 1990.

Sandia National Laboratories Livermore. Health Physics Safe Practices: The Hazards of Handling Tritium. HP-SP-2. March 27, 1990.

Sandia National Laboratories Livermore. Site Environmental Report for 1989. D.D.

Brekke. SAND90-8016, UC-600. September 1990.

Sandia National Laboratcries Livermore. Occurrence Report SNLL-90-F1-001

Concerning Four Power Outages. October 12, 1990.

Sandia National Laboratories Livermore. SNL Corporate Requirements Management Process. November 3, 1990.

Sandia National Laboratories Livermore. DOE/SNL Interface. Letter from L.D. Berthalf and A.R. Chernoff to B.G. Twining. January 4, 1991.

Sandia National Laboratories Livermore. Methodologies for Probabilistic Risk Assessment of the Tritium Research Laboratory. SAND90-8556. March 1991.

Sandia National Laboratories Livermore. Use of Tritium Research Laboratory (TRL). Draft \#4 OI 64676-L-8480-1. March 11, 1991.

Sandia National Laboratories Livermore. Tritium Research Laboratory. Safe Operating Procedure No. 709. Revised March 21, 1991.

Sandia National Laboratories Livermore. Operational Safety Requirements. SOP Number 1250. Reissued, Minor Revisions on March 21, 1991.

Sandia National Laboratories Livermore. Safety Analysis Report for the Tritium Research Laboratory (draft). SAND89-8012. April 1991.

Sandia National Laboratories Livermore. Response to Request for Information from Task Group on Operation of Department of Energy (DOE) Tritium Facilities. Memorandum from W.R. Wall to W.R. Bolton (with attachments). April 4, 1991.

Sandia National Laboratories Livermore. Tritium Research Laboratory Data Package for Field Evaluations of Sandia National Labs. May 21-23, 1991.

Sandia National Laboratories Livermore. Tritium Research Facility Logs. Start date: November 30, 1988. 
Sandia National Laboratories Livermore. Tritium Research Facility Abnormal Condition Reports. (n.d.)

Sandia National Labcratories Livermore. Tritium Research Facility Diesel Maintenance Logs, TRF Emergency Diesel Generator. Start date: September 7, 1988.

Sandia National Laboratories Livermore. Technical Manual for Installed Emergency Diesel Generator. 1975.

Sandia National Laboratories Livermore. TRL Daily Monitoring/Lab Readiness Checks. Daily, a.m. and p.m.

Sandia National Laboratories Livermore. Maintenance History Activity for Emergency Lighting in TRF. (n.d.)

Sandia National Laboratories Livermore. Standard Operating Procedures. SOP Number 1306. (n.d.)

Sandia National Laboratories Livermore. DOE/SNL Appraisal System. Memorandum from L.D. Berthalf to B.G. Twining and A.R. Chernoff. January 30, 1991.

U.S. Department of Energy. Office of Environment, Safety and Health. Technical Safety Appraisal of the Tritium Research Laboratory, Sandia National Laboratories, Livermore, California. DOE/EH-0041. June 1987.

U.S. Department of Energy. DOE Management Agreement Between the San Francisco Operations Office and the Albuquerque Operations Office. Signed by B.G. Twining, AL and D.W. Pearman, SAN. Letter \#DE-GM04-90AL65012. March 16, 1990.

U.S. Department of Energy. Albuquerque Operations Office. Response to Request for Information from Task Group on Operation of Department of Energy Tritium Facilities. Memorandum from Stephen J. Guidice to O.D.T. Lynch, Jr. (with attachment). April 8, 1991.

\section{Savannah River Site Documents}

E. I. Dupont de Nemours and Company. Revised Tritium Burial Records. Letter from G.W. Earle and W.J. Jacober to A.S. Barab (Dupont). January 14, 1974.

E. I. Dupont de Nemours and Company. Accountability of Tritium for Solid Waste Burials. Letter from W.J. Jacober to W.P. Bebbington (Dupont). February 8, 1974. 
E. I. Dupont de Nemours and Company. Process Hazards Review Report - Periodic, 232-H Tritium Extraction Process. PHR 200-H-360, Revision 0. March 15, 1988.

E. I. Dupont de Nemours and Company. Process Hazards Review Report - Periodic, Cryogenic Distillation Process. PHR 200-H-424, Revision 0. December 2, 1988.

E. I. Dupont de Nemours and Company. Operational Review Program. DPSPM-200-9, Revision 1. March 25, 1991.

U.S. Department of Energy. Savannah River Operations Office. DOE-SR Format and Content Guide for Safety Analysis Reports. SROM-5480.5-1. February 1989.

U.S. Department of Energy. Tiger Team Report (draft). February 1991.

U.S. Department of Energy. List of 51 DOE Orders. Transmittal Slip from F.W. Caldwell to C.C. Mason. February 26, 1991.

U.S. Department of Energy. Safety Evaluation Report, Restart of K Reactor, Savannah River Site. DOE/DP-0084T. April 1991.

U.S. Department of Energy. Savannah River Operations Office. Response to Request for Information from Task Group on Operation of Department of Energy Tritium Facilities. Memorandum from R.L. Chandler to Oliver D.T. Lynch, Jr. (with attachments). April 8, 1991.

U.S. Department of Energy. Draft Tritium Focus Group Charter. May 29, 1991.

U.S. Department of Energy. Savannah River Operations Office. Response to Surveillance Report on Diesel (WB). Letter from S.C. Poppy to M.A. Schmitz. OPSTPD-91-1083. January 14, 1991.

Westinghouse Savannah River Company. Leak Detection Instrumentation. Memorandum from P.K. Smith to Distribution. RTR-2628. February 27, 1989.

Westinghouse Savannah River Company. Leakage Detection Sensitivity of BTM and STM. OPS-ROD-90010. Memorandum from J.W. Ray to Distribution. March 13, 1990.

Westinghouse Savannah River Company. Tritium in the Savannah River Site Environment. WSRC-RP-90-424-1. May 1990.

Westinghouse Savannah River Company. SRS Mixed Waste Characterization Catalog. May 31, 1990. 
Westinghouse Savannah River Company. Tritium Facilities Waste Characterization. Memorandum OPS-TTG-900105 from P.J. Rowan and J.K. Puckett to D.J. Green. June $1,1990$.

Westinghouse Savannah River Company. Proposal for Safety Analysis Reports and Continued Operation of Nuclear Facilities. SRL-NPS-900023. June 29, 1990.

Westinghouse Savannah River Company. Tritium Contaminated Materials Report. Memorandum from Kelly Crandall to Distribution. ESH-HPP-900026. September 28, 1990.

Westinghouse Savannah River Company. Disposing of Empty Nonreclaimable Reservoirs. Standard Operating Procedure TF-H-5062, Revision 0. Approval Date: November 14, 1990.

Westinghouse Savannah River Company. Tritium Generator Improved Reliability Plan of Actions and Milestones. Letter from G.L. Cava to T.D. Griffin. OPS-SEK-900302. December 19, 1990.

Westinghouse Savannah River Company. FY91 Solid Waste Forecast. M.E. Gordon. Technical Report WSRC-RP-90-733. January 1991.

Westinghouse Savannah River Company. Facility Safety Analysis Manual. January 15, 1991.

Westinghouse Savannah River Company. Ventilation System Data. DPSOL 105-1183BK, Revision 24. February 4, 1991.

Westinghouse Savannah River Company. Tritium Monitor Operability Check and Environmental Release Calculation. DPSOL 105-1878-K, Revision 17, PCN 02. February 8, 1991.

Westinghouse Savannah River Company. Issue Classification and Notification. TX-5-1391A, Revision 0. March 13, 1991.

Westinghouse Savannah River Company. Conduct of Maintenance: Piping Flange Assembly. Savannah River Plant Surveillance Report 91-SUR-02-0020. March 22, 1991.

Westinghouse Savannah River Company. Berthold Tritium Monitor Calculation of $\mathrm{D}_{2} \mathrm{O}$ Losses. DPSOL 105-1887-K, Revision 5, PCN 01. March 22, 1991. 
Westinghouse Savannah River Company. Operations Review Program. Tritium Technology, Tritium Facilities Technical Guidelines. DPSPM-200-9, Section 11, Revision 1. March 25, 1991.

Westinghouse Savannah River Company. Exposure Summary Report by HPAREA, HPDEPT and NAME Throngh Cycle 4. S-6030. April 1991.

Westinghouse Savannah River Company. Radiation Exposure Report for April 1991.

Westinghouse Savannah River Company. Lockout. Reactor Restart Division Procedure RDP 2.08, Revision 0. April 1, 1991.

Westinghouse Savannah River Company. Temporary Modification Control. Reactor Restart Division Procedure RDP 5.07, Revision 0. April 1, 1991.

Westinghouse Savannah River Company. Estimating Curie Content of Radioactive Waste, Radiation Survey Procedures. DPSOL 193-501. Effective Date: April 1, 1991.

Westinghouse Savannah River Company. Stack Tritium Monitor Operation. DPSOL 105-1886-K, Revision 15. April 3, 1991.

Westinghouse Savannah River Company. ALARA Tiger Team Minutes/Agenda. RDDSII-910187. April 18, 1991.

Westinghouse Savannah River Company. Draft Waste Acceptance Criteria. WSRC-TS-1. May 8, 1991.

Westinghouse Savannah River Company. Fire Protection Exemption Requests Replacement Tritium Facility. ESH-910120. Letter from R.R. Caldwell toN.C. Aquilina. May 16, 1991.

Westinghouse Savannah River Company. Tritium Materials Issues Task Team Meeting Minutes. Memorandum from D.T. Rankin to J.R. Knight and T.L. Capeletti (WSRC). SRL-Mí S-91-4003. May 20, 1991.

Westinghouse Savannah River Company. Disposal of Tritium-Exposed Metal Hydrides. A. Nobilc. Technical Report SRL-HTS-91-008. May 22, 1991.

Westinghouse Savannāh River Company. Charter for the Tritium Safety Review Committee. Memorandum from M.J. Green to J.T. Buckner. OPS-TPD-91-0326. May 28, 1991.

Westinghouse Savannah River Company. Replacement Tritium Facility. WSRC-IM-9058. (n.d.) 
Westinghouse Savannah River Company. Maintenance Work Packages GHJ07 and GWA77. (n.d.)

Westinghouse Savannah River Company. ALARA Review Checklist. (n.d.)

Westinghouse Savannah River Company. Safety Analysis Report for the Replacement Tritium Facility. January 1991.

Westinghouse Savannah River Company. Safety Analysis Report for K Reactor. July 1989.

Westinghouse Savannah River Company. Safety Analysis Report for the WSRC Tritium Facilities. September 1987.

Westinghouse Savannah River Company. Tritium Training. DPSPU-88-11-3. November 1988.

Westinghouse Savannah River Company. 5Q Radiologica! Controls Manual (draft). May 1991.

Westinghouse Savannah River Company. Issue Classification and Notification Special. Tritium Facilities Manual 6Q. TX-5-13-91A (draft). May 1991.

Westinghouse Savannah River Company. Safety Analysis Report for the Experimental Metal Hydride Manifold. HCTD-MTF (232H), DPSTSA-200-22. March 1985.

Westinghouse Savannah River Company. Diesel Operations. Letter from W.P. Mayson to M.A. Schmitz. OPS-TPD-90-1223. December 1990. 

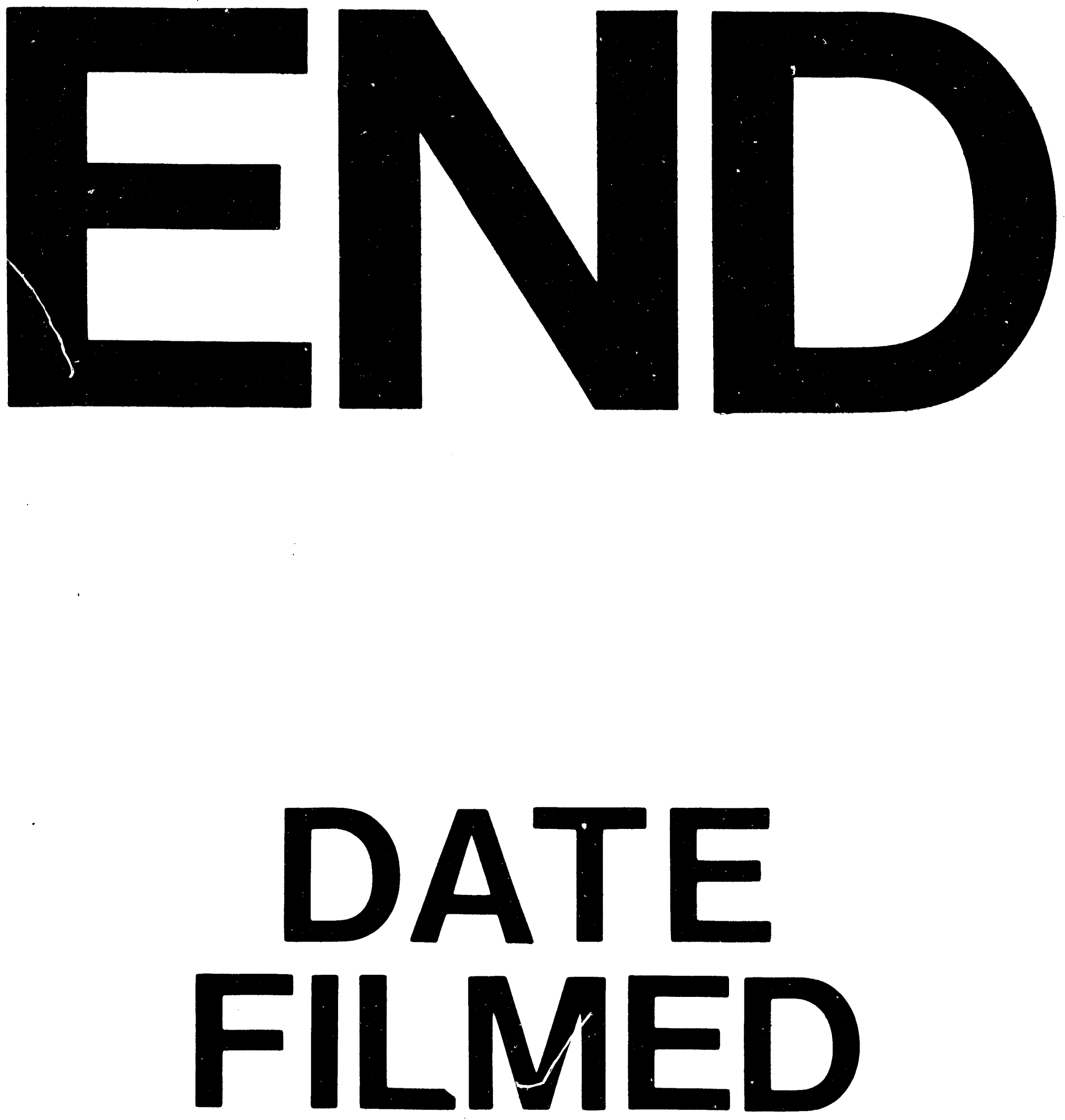

1

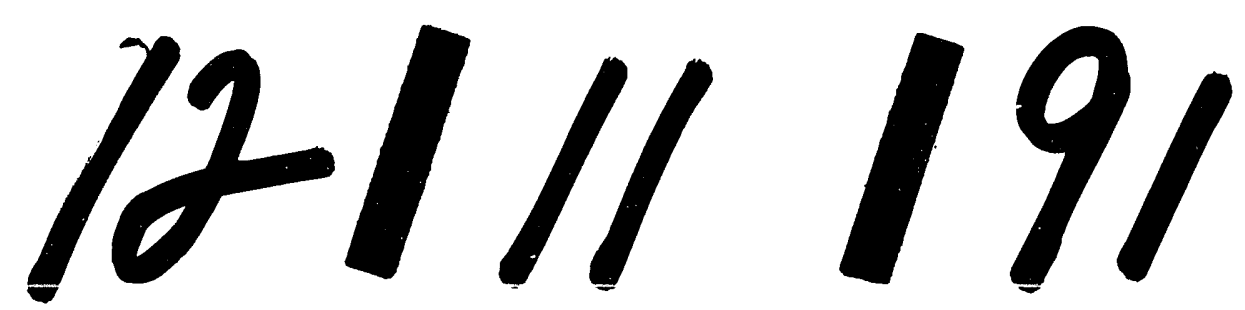


